\title{
Improving the health care response to gender-based violence: Project evaluation report
}

Meiwita P. Budiharsana

Population Council

Mai Quoc Tung

Follow this and additional works at: https://knowledgecommons.popcouncil.org/departments_sbsr-rh

Part of the Demography, Population, and Ecology Commons, Domestic and Intimate Partner Violence Commons, Family, Life Course, and Society Commons, International Public Health Commons, Maternal and Child Health Commons, and the Women's Health Commons How does access to this work benefit you? Let us know!

\section{Recommended Citation}

Budiharsana, Meiwita P. and Mai Quoc Tung. 2010. "Improving the health care response to gender-based violence: Project evaluation report." Hanoi: Population Council. 


\section{IMPROVING THE HEALTH CARE RESPONSE TO GENDER-BASED VIOLENCE}

Meiwita P. Budiharsana Mai Quoc Tung

\section{PROJECT EVALUATION REPORT}




\section{(2) Population Council}

The Population Council is an international, nonprofit, nongovernmental organization that conducts research worldwide to improve policies, programs, and products in three areas: HIV and AIDS; poverty, gender, and youth; and reproductive health.

Population Council - Viet Nam

No. 41 Le Hong Phong Street

Ba Dinh District

$\mathrm{Ha}$ Noi, Viet Nam

pchanoi@popcouncil.org

www.popcouncil.org

Any part of this publication may be photocopied without permission from the authors or publisher, provided that publication credit is given and that copies are distributed free. Any commercial reproduction requires prior written permission from the Population Council.

Suggested citation: Budiharsana, Meiwita P. and Mai Quoc Tung. Improving the Health Care Response to Gender-Based Violence - Phase II: Project Evaluation Report. Ha Noi, Viet Nam: Population Council, 2010.

Compass Printing.SJC

Illustrations in this book by "Unknown" were copied from a Vietnamese public source: www.binhduong.gov.vn 


\title{
(2) Population Council
}

Ha Noi Health Department

\section{Improving the Health Care Response to Gender-Based Violence - Phase II}

\section{Project evaluation report}

\author{
Meiwita P. Budiharsana \\ Mai Quoc Tung
}

Population Council Viet Nam

Ha Noi - 2010 


\section{TABLE OF CONTENTS}

ACKNOWLEDGEMENTS …… vii

GLOSSARY viii

EXECUTIVE SUMMARY _ ix

\section{Chapter 1 :}

INTRODUCTION

1.1. Background and purpose of the evaluation 3

1.2. Study Objectives 7

1.3. Research Methods 8

1.3.1. Selected Study Sites and Participating Organizations _............8

1.3.2. Methods of Data Collection ….........................................................9

\section{Chapter 2:}

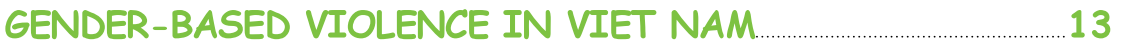

2.1. Background on gender-based violence (GBV) ….................

2.2. Viet Nam's global commitments to prevent and address GBV 19

2.2.1. Viet Nam's ratification of CEDAW …................................... 19

2.2.2. Stockholm Declaration and Agenda for Action …............... 19

\section{Chapter 3:}

FINDINGS

3.1. Qualitative study findings 23

3.1.1. Qualitative findings on awareness and perception towards GBV among GBV victims seeking help from the Women's Center for Counseling and Health Care of Duc Giang Hospital. 
3.1.2. Qualitative findings on change of awareness and perception towards GBV among hospital and $\mathrm{CHC}$ staff and community leaders, after enactment of the 2007 Law on Domestic Violence Prevention and Cotrol

3.2. Quantitative changes among hospital staff in integrating screening and treatment of GBV victims into general medical and reproductive health services.

3.2.1. General Characteristics of Hospital Staff $\quad 37$

3.2.2. Knowledge and Perceptions. _................. 40

3.2.3. Willingness to Integrate Detection of GBV in Hospital Services $\quad 48$

3.2.4. WCCH and Hospital Quarterly Reports _._. 55

\section{Chapter 4:}

CONCLUSIONS

4.1. Qualitative Findings 65

4.1.1. Among GBV victims _. 65

4.1.2. Among hospital staff and among community officers and members of civil society organizations (CSOs) in project intervention sites

4.2. Quantitative Changes

\section{Chapter 5:}

REFERENCES 77

ANNEXES 79 


\section{LIST OF TABLES}

Table 3.1. Respondents by hospital department 38

Table 3.2. Length of service (years) - $2009 \quad 39$

Table 3.3. Perceptions around common norms about GBV by gender, age group, marital status, and ever received GBV training - 2009

Table 3.4. Respondents' knowledge of general GBV norms, by type of violence.

Table 3.5. Perception of "very serious" health consequences of certain "violent acts" and its correlation with training, marital status, age, and gender.

Table 3.6. Relationships that lead to domestic violence

Table 3.7. Knowledge of legal regulations and GBV training in the last 2 years.

Table 3.8. Knowledge of violent behavior punishable according to regulations and law.

Table 3.9. Extent of interaction with GBV victims

by hospital department.

Table 3.10. Extent of dealing with physical, psychological, and sexual violence, 2005-2009.

Table 3.11. Increased proportions of hospital personnel detecting GBV victims by type of injury.

Table 3.12. Rationale for saying there were

"insufficient resources" for GBV victims.

Table 3.13. Types of support that hospital staff are willing to provide

Table 3.14. Types of standard protocol perceived as necessary, in relation to training.

Table 3.15. Recommendations to improve awareness of GBV

Table 3.16. Characteristics of Screened GBV victims

by occupation, age group, and educational level. 


\section{LIST OF FIGURES}

Figure 3.1. Respondents by age group.

Figure 3.2. Perception regarding trends in domestic violence during the last five years

Figure 3.3. Number of women visiting WCCH by year and reason for attendance 56

Figure 3.4. Mean number of women who presented to $\mathrm{WCCH}$ annually, before/after 2007

Figure 3.5. Place of origin of women attending $\mathrm{WCCH}$ for GBV by year

Figure 3.6. Women attending $\mathrm{WCCH}$ by reason for attendance. 59

Figure 3.7. Age of $\mathrm{WCCH}$ clients 59

Figure 3.8. Number of screened GBV victims receiving Counseling from WCCH, 2003-2009.

Figure 3.9. Average monthly screened GBV victim, before/ after GBV project implementation. 60

Figure 3.10. Reports of violence by type, March 2003 to Oct 2009

Figure 3.11. Number of detected GBV victims and number referred to WCCH by quater. 


\section{LIST OF ANNEXES}

Annex 1. Important Definitions used in Studies of GBV

Annex 2. Country Profile: geography, role of civil society organizations, and social development status..

Annex 3. List of health facilities that provide integrated health care and counseling/treatment for victims of domestic violence.

Annex 4. Questionnaire for Health Care Providers (HCPs) (Post-intervention assessment)

Annex 5. PCVN guideline for Focus Group Discussion

Annex 6. PCVN guideline for In-Depth Interviews.

Annex 7. Screening interview and monitor forms for gender-based violence victims (used in GBV-II project sites). 


\section{ACKNOWLEDGEMENTS}

Many people have been involved in the past Population Council GBV studies in Viet Nam which commenced in 1998 - we want to thank them all for they are the real pioneers who built the public's knowledge that violence against women is unacceptable. We will not be able to list all of them here. Nonetheless, we would like to acknowledge the support from the Ford Foundation and the Susan Thompson Buffett Foundation, as well as the cooperation of the following individuals from partner institutions:

Previous PCVN researchers and partners (2005):

Le Thi Phuong Mai

Le Ngoc Lan

Nguyen Thi Thom

Pham Le Tuan

Nguyen Van Anh (CSAGA)

\section{Representatives of Partner Institutions:}

Le Anh Tuan, Associate Professor, PhD - Director of Ha Noi Health Service Nguyen Thi Van Anh, MD, MSc - Deputy Director of Project Management Unit Pham Thi Kim Loan, MD, MSc - Secretary of the Project

Tran Bui Quang Duong, MD - Deputy Director, Duc Giang Hospital

Nguyen Ngoc Quyet, WCCH Head, Duc Giang Hospital

PCVN Field Research Coordinator and Team (2009)

Nguyen Thi Phuong Lan

Le Anh Vu

Nguyen Viet Linh

List of 2009 Survey Interviewers

Mai Quoc Tung, MD, PhD - Team Leader

Vu Hai Yen

Nguyen Thi Huong

Ngo Xuan Dai

Dao Huong Giang

Nguyen Tuyet Nga

Nguyen Tien Dung

Nguyen Thi Phuong Lan

Data analysis and document review: Peter Heywood (Honorary)

Editorial support: Martin Schell of American Services in Asia 


\section{GLOSSARY}

\begin{tabular}{|c|c|}
\hline BCC & Behavioral Change Communication \\
\hline CEDAW & $\begin{array}{l}\text { Convention on the Elimination of All Forms of Discrimination } \\
\text { against Women }\end{array}$ \\
\hline CHC & Commune Health Center \\
\hline CIHP & Consultation of Investment in Health Promotion \\
\hline CSAGA & $\begin{array}{l}\text { Center for Studies and Applied Science in Gender, Family, } \\
\text { Women and Adolescents }\end{array}$ \\
\hline CSOs & Civil Social Organizations \\
\hline DV & Domestic Violence \\
\hline $\mathbf{F F}$ & Ford Foundation \\
\hline GBV & Gender Based Violence \\
\hline GBV-I & Gender Based Violence Project - Phase I \\
\hline GBV-II & Gender Based Violence Project - Phase II \\
\hline GDI & Gender-related Development Index \\
\hline GEM & Gender-Empowerment Measure \\
\hline HCP & Health Care Provider \\
\hline HDI & Human Development Index \\
\hline HHD & Ha Noi Health Department \\
\hline IEC & Information, Education, and Communication \\
\hline MOH & Ministry of Health \\
\hline NGO & Non-Governmental Organization \\
\hline PCVN & Population Council Viet Nam \\
\hline TOT & Training of Trainer \\
\hline UNDP & United Nations Development Programme \\
\hline WCCH & Women's Center for Counseling and Health Care \\
\hline WHO & World Health Organization \\
\hline
\end{tabular}




\section{EXECUTIVE SUMMARY}

Consistent with previous studies, this study has provided evidence that Gender-based Violence (GBV) remains a problem in Viet $\mathrm{Nam}$ with indications that it may be on the increase. The classic pattern of physical and sexual violence is associated with low educational levels of women and their partners, men having more than one partner/ wife at the same time, and low household income, frequently a result of unemployment, drug taking and gambling. As might be expected given the traditional unequal power between men and women in Viet Nam, men consider it as a private family matter and certainly not something to be discussed with those outside the household and, perforce, women still see GBV as a problem that should be "tolerated". At the individual level, those women suffering from violence are subjected to repeated attacks which commonly start in the first year of marriage and many of which are severe.

Against this background there is broad support for the Law on Domestic Violence 2007 and, on the basis of interviews with young health staff, an increasing sensitivity to the problem of GBV. Nevertheless, women, especially those in rural areas have little, if any, knowledge of the Law and are in need of support from families, communities, professionals and the wider society.
In 2009 the Population Council Viet Nam (PCVN) in collaboration with the Ha Noi Health Department $(H H D)$ carried out an evaluation survey among the staff of Duc Giang hospital to assess the extent to which awareness and perceptions of GBV had changed since the project commenced in 2005. The survey also assessed the extent to which the response of the hospital and Women's Center for Counseling and Health Care to GBV had been strengthened, and made recommendations on changes to improve the situation. Two hundred and forty seven staff were surveyed in October 2009. The respondents were mostly female $(76.1 \%)$, under 30 years of age. Almost half were nurses; onesixth were doctors; most (70\%) said they had not received training on GBV. (Note: HHD provided additional information that $61.8 \%$ of staff had attended hospital briefing on GBV for professional staff; only $8.9 \%$ of newly recruited staff had no GBV training or briefing).

Staff showed a high level of awareness of GBV issues, regardless of gender, marital status, and prior GBV training. Younger staffs were more likely to recognize the problems of GBV and violent behavior against women. Overall, there is a wide understanding of the types and consequences of 
violence against women. Compared to 2005 , those surveyed in 2009 were more likely to perceive the severity and health consequences of GBV, agree that the incidence of GBV is increasing and that the relationship between husband and wife is the critical factor.

Although staff were generally supportive of the need to incorporate GBV screening in daily medical practice, implementation was less than ideal as there are obstacles such as lack of training, heavy workload, and the reluctance of most families to admit the problem. Important additional barriers are the lack of resources and facilities to support the actions needed for both immediate treatment and longer term solutions.

The new Law on Domestic Violence is seen by many health care providers as an important advance and those health care providers who had received training in the last 2 years were more likely to be aware of the legal requirements and to support inter-sector approaches, increased resources and women's empowerment. At the same time the Law is perceived as not strong enough to empower local officials to take the actions needed. A critical constraint is the low capacity of local institutions (courts, commune, and police) to deal with GBV issues; especially when they do not have practical guidelines on how to apply the Law at the local level.
Training of health care providers has been a central element of the project. However, for those who have been trained, the effects are limited to increased knowledge of the requirements of the new Law, the need for protocols and guidelines, the importance of increased resources and inter-sector approaches. Despite the limited extent of the training, there is a much increased awareness of the importance of GBV. This increased awareness appears to be due to the wider use of guidelines and protocols from previous training which, in themselves, have raised awareness of staff, whether or not they have been trained. At the same time, the new and younger health care providers seem to be more sensitive to the issues and have been more responsive to GBV issues. The need now is a new approach to train that addresses the critical issues expressed by health staff and responds to their explicit requests for updated guidelines and protocols that include operational clauses from the Law on Domestic Violence.

While the increased awareness of health care providers in the hospital has been an important step in the response to GBV, a critical complementary step was the establishment of the Women's Center for Counseling and Health Care (WCCH) where the total number of women presenting to WCCH has increased dramatically 
in the last 6 years from 108 in 2003 to more than 380 per quarter in 2009; about $33 \%$ of those are for GBV issues. The Quarterly Report is an important first step that now needs to be strengthened so that analyses using multiple variables are possible. The wide acceptance and recognition of the WCCH as a central institution in the response to GBV is attested not only by the increase in clients but also by the fact that $80 \%$ of women presenting are from non-project communes as well as the support from police and court personnel and the media. Important aspects of the WCCH are: its ability to build comprehensive network with other sectors, its effort to strengthen the capacity of law enforcement and justice officials, and its focus on raising public awareness about domestic violence and the right of women to live in a household free of violence. WCCH is an important resource for GBV training for sectors outside health.
Overall, this project has been very effective in raising awareness and willingness to integrate GBV screening in health services. The project has conducted its training program at a time when the community was also becoming increasingly aware, with the result that younger health practitioners are more sensitive to GBV issues. These two actions were complementary and reinforced one another. The result is health staffs are more willing to screen and help GBV victims. The time is ripe for a much greater and more coordinated effort to build on the advances already made. But, to map out where GBV is most prevalent, who is most vulnerable, and how can it be most effectively addressed, high quality population-based surveys of GBV should be a priority for Viet Nam. Despite impressions that GBV is on the increase, the lack of population-based data on GBV is an important constraint on the response to the problem. 




\subsection{BACKGROUND AND PURPOSE OF THE EVALUATION}

During the period from June 2002 to May 2004, the Ha Noi Health Service $(H H D)$, in collaboration with Population Council in Viet Nam (PCVN) and Centre for Applied Studies in Gender and Adolescence (CSAGA) conducted a pilot intervention project called Gender Based Violence Project - Phase I (GBV-I), funded by the Ford Foundation (FF). The project significantly increased GBV awareness among the communities and health providers and improved health care and social support to GBV victims. The effective intervention in Phase I led to a further intervention project or GBV Phase II, also conducted by the $H H D$ with Ford Foundation funding. The Phase II project ("Improving the Health Care Response to Gender-Based Violence - Phase I") was implemented from May 2006 through April 2007. In this phase, the project continued the community and hospital-based intervention to address gender-based violence (GBV) in the sites of Phase I as well as in a new district hospital and two communes.

Between mid-September and October 13, 2009, the Population Council Viet Nam (PCVN) planned and conducted quantitative and qualitative data collection for evaluating GBV-Phase II. The three-year project began in May 2006 and was initially scheduled to end in April 2009. Both project implementation and the technical assistance were supported by the Ford Foundation. Based on the HHD request and the Ford Foundation's approval, the project was extended through December 2009.

In Phase I of the project, PCVN in collaboration with $\mathrm{HHD}$ has developed a GBV form (green form) that health providers should complete, when they identify potential victims. This form was then sent to the WCCH but not to the planning unit of hospital. The hospital did not synthesize GBV information since records were not kept at the hospital. PCVN also assisted in the development of Training of Trainers (TOT) course materials, including Guidelines for health care providers (HCPs) working with victims of GBV. Training contents were enriched with new materials from the Domestic Violence and Incest Resource Centre (DVIRC), WHO Ten-country study, and other international training materials. It was agreed by PCVN, $H H D$, and FF that the evaluation at the end of GBV Phase I would be used as the final evaluation of that project and also served as the baseline for evaluation of GBV Phase II. The same questionnaire was used for both phases. 
In Phase II, PCVN assisted HHS in four main activities:

(1) Training of Trainers (TOT) and technical assistance during subsequent trainings conducted for health care providers (HCPs). This TOT was held between July 17 and July 22, 2006. 30 participants (trainers-to-be) were selected from a pool of experienced HCPs working in Duc Giang Hospital and Dong Anh Hospital, as well as key persons from HHS;

(2) Development of training curriculum for the HCPs training:

(3) Development of recommended monitoring indicators; and

(4) Development of integrated GBV and medical service record forms at Duc Giang hospital.

Participants were trained on gender sensitivity, types of domestic violence (DV) and sexual violence (SV), country and international context, how to support victim, and counseling skills. Relevant issues were also included, such as the 9 common beliefs held in Viet Nam about DV, facts, and factors that could lead to DV as well as the perception of DV and SA in health care settings, and the connection between health, RH, HIV/AIDS and GBV. Health staffs were taught effective intervention strategies and skills, including routine questioning of clients about DV and SA; providing sensitive, non-judgmental and nonpunitive support; psychological management, addressing patient safety and privacy; documenting abuse; and providing information about options and other resources.

During this training, the "Quick Screening (yellow) Form" and the model "Viet Nam" was explained and discussed. "Viet Nam" is the model developed for health workers to follow if women answer "yes" to any of the 3 questions on DV, child sexual abuse (CSA) and rape. These trainers-to-be were also provided with training skills and participatory methods and approaches such as brainstorming, group discussions, and role plays covering issues of $D V$, rape and child sexual abuse (CSA) to practice. Results of the final day evaluation indicated that the training course was useful and necessary, and met trainees' expectation. Most of them have found that seven steps working on GBV "Viet Nam" elements of the course were most useful. PostTOT training, PCVN recommended to $H H D$ a list of potential trainers for the subsequent/echo trainings conducted by HHD. 
In phase II, the green form was updated also. Based on these forms, PCVN developed the synthesis tables on GBV recorded in hospitals for quarterly reports to HHS. The synthesis tables include main indicators on GBV as follows:

(i) Number of GBV victims aged 15+ identified by:

- types of abuse (DV, child sexual abuse, and rape)

- age group (15-24; 2544 , and 45+)

- marital status

- departments under hospital

(ii) Percent of victims among total of female clients aged $15+$ screened

(iii) Percent of victims among total of female clients aged 15+

In September 2009, approaching the end of the project, PCVN conducted an overall project evaluation at Duc Giang Hospital in Long Bien district, and two Commune Health Centers (CHCs) in Gia Lam district. Both districts are within $\mathrm{Ha} \mathrm{Noi}$ and therefore these public health facilities are covered by $\mathrm{HHD}$ monitoring and reporting.

Staff, especially those in women's health departments suchas obstetrics and gynecology, maternal and child health, or antenatal care have a critical role to play in screening victims of GBV. Sometimes, the Eye (Ophthalmology), Surgery, and Ear, Nose, and Throat (ENT) departments receive clients with obvious signs of DV in parts of the face, or neck and shoulders. However, GBV victims typically prefer to remain silent rather than talk spontaneously about the violence in their lives. HCPs at all levels need appropriate training on techniques to use in discussing sensitive topics with clients on DV, especially intimate partner violence $(\mathbb{P V})$, and help to develop interpersonal skills that can enhance provider-client relationships, which is a component of the quality of care standard that the $\mathrm{MOH}$ recently stressed.

Previous results from Phase 1 were recognized as successful in raising the Ha Noi Health Service's awareness of the importance of providing health care and social supports for gender-based violence victims. This led to the approval necessary for establishing the Women's Center for Counseling and Health Care (WCCH) at Duc Giang Hospital (March 8, 2003), followed by a center at Dong Anh Hospital in December 2006. All women visiting any department of the hospital as patients are now screened as possible victims of GBV, including in-patients. After 16 months of piloting the operation, the CSAGA counselor handed over responsibility for the counseling services to the Duc Giang health staff (October 2004). 
As of April 2005, the Duc Giang WCCH had provided counseling for approximately 300 clients. The WCCH built a close working relationship with other departments through regular morning meetings. In addition, a WCCH Advisory Committee was established with hospital department heads as members to provide medical professional support. The committee serves as a bridge for integrating GBV treatment/counseling into all other medical services, encouraging all staff from diverse health specialties to participate in screening, recording, and supporting GBV victims. Currently, word of mouth has positioned the Duc Giang WCCH as a well-known center for providing treatment support and counseling for GBV victims. Many GBV victims bring other GBV victims in their area to this center as a "first resort" to seek not only health treatment but also para-legal advice regarding safety and rights to communal property.

The results of Phase I inspired the Ministry of Health $(\mathrm{MOH})$ to implement another project titled
"Improving quality of health care for gender-based violence victims at health centres in Viet Nam" (focusing on commune health centres), right after the promulgation of the Law on Domestic Violence Prevention in 2007/8. The $\mathrm{MOH}$ saw this as an opportunity to monitor GBV cases detected at $\mathrm{CHCs}$ and hospitals nationwide. The project implementer is the Medical Service Administration $\mathrm{MOH}$, in coordination with $\mathrm{HHD}$ and the Health Departments of Ho Chi Minh City and Da Nang, with pilot activities in four hospitals: Da Nang, Cam Le (in Da Nang City), Nguyen Tri Phuong, and Thu Duc (in HCM City). PCVN offered technical assistance, including a pre-assessment study at the four hospitals in May 2009, with support from the Ford Foundation. In the long run, if HCPs are able to screen, identify, and treat GBV victims early, the quality of women's health services will improve and the costly consequences of physical, psychological, and social deterioration will decrease in Viet Nam. 


\subsection{STUDY OBJECTIVES}

\section{The objectives of the Phase II evaluation are:}

1. To investigate the change of awareness and perception towards GBV and the new Law on Domestic Violence, using qualitative methods, among GBV victim, and the staff of Duc Giang public hospital in Long Bien District, community officers and members of different civil society organizations (CSOs) at the commune level, and staff from the two $\mathrm{CHCs}$ in Gia Lam District (project extended intervention sites);
2. To quantitatively evaluate the changes of perception and practice in integrating screening and treatment of GBV victims into general medical and reproductive health services among the staff of Duc Giang public hospital in $\mathrm{Ha}$ Noi (see the Important Definitions used in Studies of GBV in Annex 1);

3. To draw opinions and recommendations from hospital and CHC staff, and commune leaders about interventions to address GBV in the future. 


\subsection{RESEARCH METHODS}

\subsubsection{Selected Study Sites and Participating Organizations:}

\section{Duc Giang Hospital:}

Duc Giang Hospital is a public hospital located in Long Bien district within Ha Noi. The hospital offers four major medical specialties (surgery, internal medicine, obstetrics/ gynecology, and pediatrics) and an array of other specialties (ophthalmology, stomatology/dentistry, otolaryngology, anesthesia, medical imaging, and an intensive care unit). The number of staff has grown from 283 in 2006 to 369 in 2009 (Head of Nursing, Duc Giang Hospital). Training in GBV during these three years reached only $29.3 \%$ of the total staff (108 out of 369). Doctors, midwives, and assistant doctors constitute $25.5 \%$, nurses $54.2 \%$, pharmacists and assistant pharmacists 3.3\%, and other supporting roles (laboratory, infection control, accounting, equipment/supply, administrative, and personnel) $17.0 \%$ of total staff. A Focus Group Discussion (FGD) at Duc Giang Hospital was attended by the Deputy Director and the Heads of the following departments: Intensive Care and Resuscitation, Internal Medicine, Surgery, Obstetrics and Gynecology, General Clinic,
Ophthalmology, Otolaryngology and Dental, Nursing, and the Women's Center for Counseling and Health (WCCH). Of 10 respondents, 8 are doctors, one Assistant Doctor, and one nurse, and 6 of them are men. Age of the respondents ranged from 35 to 55 years. All had participated in GBV training previously.

The hospital was founded on 10 Oct 1963 (Ha Noi Liberation Day) with the name North Red River Hospital. The hospital started with 50 in-patient beds, providing mostly Internal Medicine, General Surgery, and Obstetrics/Gynecology services for Gia Lam and Dong Anh districts and neighboring provinces. In 1964, war broke out and the hospital changed its name to Gia Lam Hospital. In 2004, due to rapid urbanization, Gia Lam district was divided into two districts: Gia Lam and Long Bien. The Gia Lam Hospital was then upgraded from a district hospital to a city hospital and was renamed Duc Giang Hospital. Its inpatient care was expanded from 200 beds in 1964 to 230 in 2003 and then 350 beds in 2009. Since 2003, the hospital has averaged approximately 125,000 patient-visits per year. On March 6, 2003, Duc Giang Hospital opened a Women's Center for Counseling and Health 
Care with Nguyen Ngoc Quyet as its Head. He was trained as a counselor in 2002 during the training for trainers conducted as part of the Population Council's technical assistance under PCVN Program Officer Le Thi Phuong Mai. He took over the counseling for GBV victims that had been initiated by CSAGA counselors in 2003.

\section{Yen Thuong CHC:}

The Yen Thuong Commune Health Centre (CHC) in Gia Lam district has 7 staff, serves 16,400 commune residents, and averages 6,500 patient-visits per year. This $\mathrm{CHC}$ became involved in integrating GBV screening into its daily medical services in April 2006, after its staff received training in GBV case management and counseling. Based on its record in 2009 (up to October), approximately $7 \%$ of the commune's female population visited the $\mathrm{CHC}$, and about $2.6 \%$ were identified as GBV victims. The FGD at this $\mathrm{CHC}$ was attended by the Head of $\mathrm{CHC}$ (a doctor), Commune President, Commune Officer in Charge for Food Safety, Head of Commune Women's Union, Officer for Population Data (registrar of births, deaths, and marriages), $3 \mathrm{CHC}$ staff (assistant doctor, nurse, and midwife), and the President of the Commune Veterans Union. There were 6 women among the 10 FGD respondents. Ages ranged from 25 to 60 . Of the 10 participants in the FGD, 7 said that they had received GBV training.

\section{Yen Vien $\mathrm{CHC}$ :}

The Yen Vien $\mathrm{CHC}$, also located in Gia Lam district, has 6 staff, covers 12,700 commune residents, and averages 5,000 patientvisits per year. This $\mathrm{CHC}$ started integrating GBV screening into its daily medical services in April 2006. Based on its record in 2009 (up to October), approximately $8.6 \%$ of the commune's female population visited the $\mathrm{CHC}$, and about $2.4 \%$ were identified as GBV victims. The FGD arranged by this CHC was attended by the Head of $\mathrm{CHC}$ (an assistant doctor), Vice President of the Commune People's Committee, Head of the Commune Voice Station, Deputy Head of the Commune, Officer for Population Data (registration of births, deaths, and marriages), and $2 \mathrm{CHC}$ staff (both nurses). Four of the seven FGD respondents were women. Ages ranged between 32 and 49 years, and all seven respondents said they had received GBV training.

\subsubsection{Methods of Data Collection:}

Qualitative methods were utilized to explore the perceptions of women GBV victims about the Women's Center for Counseling and Health Care of Duc Giang, the willingness of hospital staff to integrate GBV screening and treatment into daily medical services, and the awareness of community officers and members of civil society organizations (CSOs) to support victims at the commune level. The impact of the new Law 
No 2/2007/QH12 on Domestic Violence Prevention and Control was also studied.

A quantitative survey was conducted by 8 interviewers using a structured questionnaire (as in Phase I) to measure evidence of changes in practice (willingness) to integrate screening and treatment of GBV victims into general medical and reproductive health services at Duc Giang public hospital. The data collection methods were:

\section{Qualitative method - In-Depth Interviews:}

To understand feelings, experiences, and solutions from the perspective of GBV victim, In-Depth Interviews were given to five women victims who had sought help at the $\mathrm{WCCH}$ during the two weeks prior to the interview date (October 13, 2009). Voluntary agreement to receive an in-depth interview was sought verbally. Each in-depth interview took an average of 45 minutes, led by a facilitator and a co-facilitator, who began by introducing the purpose of the interview and creating an atmosphere where the respondent could talk openly and honestly. An interview guide sheet consisting of five open-ended questions with probing follow-ups was used by the interviewers. Questions referred to the initial triggering of GBV, witnesses among family and commune members, types of community support, coping strategy, and familiarity with the new law. Nonverbal behavior was also observed during the in-depth interview. Each interview was closed by thanking the respondent. Data were transcribed and translated into English from both a tape recording and the facilitators' notes. Data then were extracted relating to themes that pertain to the GBV experiences of the victims.

\section{Qualitative method - Focus Group Discussions:}

A focus group discussion (FGD) was conducted on October 13, 2009 among 10 Duc Giang senior staff, in order to obtain qualitative information from them. The purpose was to evaluate the degree to which changes in willingness to integrate GBV screening and treatments into daily practice among trained and untrained Duc Giang Hospital staff were results of HHD' threeyear intervention. Two other FGDs were conducted with participation by $\mathrm{CHC}$ staff, district authorities, and community leaders (October 8 and 9, 2009) in the Yen Vien and Yen Thuong communes of Gia Lam district, respectively. The two FGDs at the commune level, with an average of ten respondents, focused more on the types of GBV, consequences, and community preparedness to support GBV victims in a rural (suburban) setting. Each respondent completed a fact sheet that recorded time, date, place, and demographic information. Each FGD took an average of 90 minutes, led by two co-facilitators utilizing a focus group script containing 10 openended questions that moved from general awareness to a specific 
example or issue. Complementing the two co-facilitators who kept the FGD conversation flowing, a note-taker took written notes on specific responses (recorded verbatim) from each respondent (who was assigned a number for later identification of the source of responses). The notes were then merged with the transcription of a tape recording (which was done with approval from the respondents). Agreement to participate and be tape recorded was sought verbally from each FGD respondent before the process started. The FGD began with an introductory greeting that included the background and purpose of the focus group, and it concluded with closing remarks to thank all respondents for their participation.

\section{Quantitative method - survey:}

As preparation, PCVN held an inhouse workshop during September 21-24, 2009 to review materials, including the pre- and postintervention questionnaires from the "Improving Health Care Response to Gender-Based Violence - Phase I" project. The workshop was followed by pre-testing of the 2009 Phase II survey questionnaire, and a two-day training of interviewers that resulted in the selection of 8 qualified interviewers. The Phase II survey interviews were then conducted between October 5 and 7 , with an additional day on October 13, 2009. To ensure that the information collected in Phase $\|$ is comparable to the Phase I information, most of the questions used in the Phase I questionnaire were retained for the Phase II survey. Only a few questions were modified and regrouped to facilitate the new evaluation process. The survey questionnaire contains four categories of questions: general socio-demographic characteristics of the health care providers (hospital staff) being surveyed; their perception of integrating GBV screening into daily practices; actual integrative practices; and recommendations for future policy to prevent and control GBV. All questions were pre-coded to facilitate data entry and management. All interviewers were fluent in Vietnamese and spoke a dialect similar to the survey group. PCVN conducted a two-day training workshop to train and select 8 qualified interviewers. Interviewers were also asked to follow a standard professional code of ethics and to pose questions with a neutral expression conveying objectivity.

The sample of 248 respondents was drawn from Duc Giang Hospital staff who were available on the dates of data collection, selected by the HHD and Duc Giang Hospital Director from the total of 369 employed. Individual rooms were requested for conducting the face-to-face interviews. However, due to limited space, some interviews were done without complete privacy. At the start of each interview, the interviewer asked the consent of the respondent verbally and informed her/him about the objective of the survey 
as well as the confidentiality of the answers. Each interview took 45 to 60 minutes.

After the interview, all the questionnaires were checked by a consultant to ensure accuracy and completeness. If there was information missing, the interviewer who conducted that interview was asked to re-interview via telephone or in person to complete the survey form. A database was designed using MS Access 2003 to facilitate data entry and management. An electronic data entry form was developed to minimize errors in data entry. Two PCVN interns who had previous data entry experience were assigned to input the data. A two-day workshop on data analysis (dummy tables) was conducted October 29-30, 2009 to discuss "cut-off points", labeling and recoding variables, univariate/bivariate tabulation, and possible regression models. Data analysis was done in November, using SPSS software version 17.0 and continued throughout the first week of December 2009. The quarterly reports from April 2007 to October 2009 were analyzed and presented in various graphs for more meaningful presentation. Draft report (in English) was then translated into Vietnamese and sent to Ha Noi Health Service for comments. A dissemination seminar was scheduled on the last week of January 2010. 


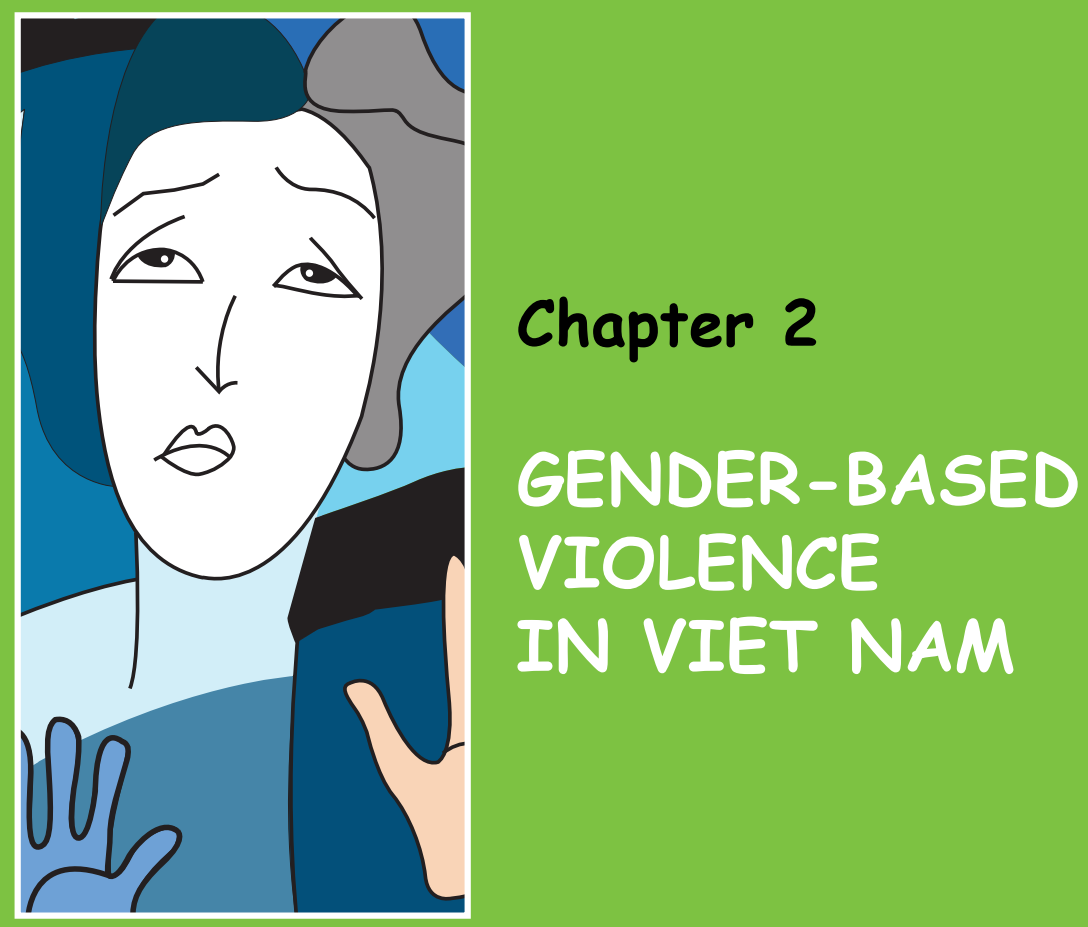





\subsection{BACKGROUND ON GENDER-BASED VIOLENCE (GBV)}

Viet Nam is a developing country in East Asia with a population of about 86.2 million people (end of 2008). The country is located in the Eastern part of the Indochina peninsula, bordering China to the north, Laos and Cambodia to the west, and facing the Eastern Sea (South China Sea) and the Pacific Ocean to the east and south (http://www.mofa.gov.vn/tt Viet Nam/geo/- 5 Nov 09) (For more details of country profile, see Annex 2).

The first study of domestic violence (DV) in Viet $\mathrm{Nam}$ was reported by the Population Council Viet Nam (PCVN) in 1998 in a qualitative report titled "Violence and its Consequences for Reproductive Health". Reported factors associated with DV include: alcohol, drug abuse, gambling, stress and/or frustration, mental illnesses, and preference for male children. The issue of forced sex in marriage was also raised in focus group discussions, which revealed that women saw it as a problem but "tolerable" while men did not consider it as an issue to be discussed seriously. This report was based on recorded interviews of women who used the services of the Ho Chi Minh City Counseling Centre and its anonymous "hotline" counseling (Le Thi Phuong
Mai, 1998; Le Thi Phuong Mai and Katharine Landfield, 1999). Other small-scale studies, mainly qualitative research on domestic violence (DV) or intimate partner violence (IPV) seemed to indicate that DV occurs in both urban and rural settings and at all social strata (Loi VM, et al., 1999).

In 2002, within the framework of the demographic surveillance in $\mathrm{Ba}$ Vi District (northern rural $\mathrm{Ha} \mathrm{Noi}$ ), 37 clusters were selected through a random cluster sampling technique from a cohort of approximately 50,000 individuals (69 clusters), to investigate the impact of DV or IPV on women's health (Nguyen Dang Vung, PO Ostergren and G. Krantz, 2008). A number of households were selected from each cluster, proportional to its total number of households. Married or partnered women ages 17 to 60 years were selected in this first populationbased study to investigate type, severity, and risk factors of DV (or IPV) against women. Instruments for data collection originated from a questionnaire developed in the World Health Organization's Multicountry Study on Women's Health and Life Experiences. A sample of 883 women aged 17 to 60, all claiming to be married women, were interviewed. Findings showed that the lifetime prevalence of 
physical violence (i.e., had ever been subjected to any form of physical violence in their lifetime) was 30.9 percent and the past-year prevalence (i.e., had been subjected to any form of physical violence in the preceding year) was 8.3 per cent. The lifetime prevalence for psychological violence was 27.9 percent. In most cases, the psychological violence was severe and persistent (repeated acts over time).

For lifetime and past-year occurrence of physical and sexual violence, three main associated factors were:

\section{(1) low educational levels of women and their partners/husbands, \\ (2) low household income, and \\ (3) man having more than one wife/partner.}

For psychological violence, the risk factors were:

(1) husband/partner has low professional status, and

(2) wife/woman has intermediate level of education.

Polygamy is still practiced in rural areas although it became illegal in 1960. This indicates that the Vietnamese patriarchal norm remains grounded in traditional society, although officially the country has new laws on Gender Equality and on Marriage and Family that abolish polygamy.
Women's lack of knowledge about these laws, especially in rural and poor areas, make polygamous relationships a common factor associated with domestic violence (Nguyen Dang Vung, et al., 2008).

Questions about DV were developed in reference to the Index of Spouse Abuse and the Conflict Tactics Scales which have established reliability and construct validity, supported by the Violence Against Women project and the Health System Research Programme (funded by Sida/SAREC, Sweden and the Department of Social Medicine at Gothenburg University). Approval came from the $\mathrm{Ha} \mathrm{Noi}$ Medical University, Ministry of Health, People's Committee of $\mathrm{Ha}$ Noi and $\mathrm{Ba}$ Vi district, and $\mathrm{Ba}$ Vi District Health Center (Nguyen Dang Vung, PO Ostergren, and G. Krantz, 2008). Violence occurrence was assessed by types (physical, psychological, and sexual), timing (lifetime and pastyear exposure), and frequency (number of incidents).

Physical violence was assessed in terms of 11 items: slapping, throwing things, pushing or shoving (all classified as moderate physical abuse); hitting, kicking, dragging, beating, choking, burning, and threatening with or using a weapon such as a knife or scissors (all classified as severe physical abuse). Sexual violence was assessed in terms of 3 items: having sexual intercourse against the respondent's will; partner using excessive physical force during sexual intercourse; and 
being forced to engage in sexually degrading acts.

Psychological violence was assessed in terms of 3 items: insults or degrading activities, belittlement or humiliation, and scaring the respondent (including threats of violence). Lifetime occurrence of any kind of violence was defined as experience of any act of violence up to the date of the interview, perpetrated by a current or former husband/ partner. Abuse taking place within the past year was defined as any act taking place within the past 12 months. For bi- and multi-variate analyses, the dependent variables were dichotomized into experience of violence as opposed to no experience of violence. For these analyses, those with only a single experience of violence over their lifetime were considered as nonexposed, in order to strengthen the criterion for violence exposure (Nguyen Dang Vung, PO Ostergren and G. Krantz, 2008).

Findings showed that married women in rural Viet Nam are heavily exposed to all forms of serious, repeated abuse from their husbands or male partners. DV or IPV not only affected women's health but also that of their children and other family members, thus constituting a serious violation of women's rights. There is an urgent need for effective support, counseling, and treatment of violence victims. This affirms that health care providers ( $\mathrm{HCPs}$ ) play an important role because widespread access to them as a health professional enables them to screen their patients for early detection of DV. However, HCPs at all levels need appropriate training in: how to address victimized women and their partners; how to deliver counseling; and how to pose sensitive questions to probe violence (Nguyen Dang Vung, PO Ostergren and G. Krantz, 2008).

In May 2006, the Consultation of Investment in Health Promotion $(\mathrm{ClHP})$, a local NGO, began a feasibility study to assess whether an integrated gender-based violence prevention model at the commune level can create community support for GBV prevention and control. Their 30-month "Integrated Model for Responding to Gender-Based Violence (GBV) in Clinic and Community Settings" to initiate a network in seven communities in Cua Lo town, Nghe An province, was funded by the Ford Foundation. Strategies focused on "behavioral change communication" (BCC) and commune and district level campaigns to mobilize community support for abused women at the end of the project ( $\mathrm{Vu}$ Song $\mathrm{Ha}$, TA Hoang and TT Quach, 2009). The ClHP network organized hundreds of BCC sessions for local men and women, and disseminated various information, education, and communication (IEC) materials, including true stories of domestic violence, through local newspapers, radio, and television. Reported outcomes include: an increasing percentage of women visiting district hospitals were screened for possible GBV; significant number 
of counseling sessions for abused women; and expanded word of mouth among women victims of domestic violence encouraged more abused women to seek support and consider options to change a relationship with an abusive partner. Consequently, local authorities began to take concrete actions such as sanctions against abusive men and fines for second or third offenders. Other sanctions were mandatory reeducation sessions about the Law on Domestic Violence Prevention and Control or community service in the commune.

As part of its Seventh Country Programme (2006-2010), the United Nations Population Fund (UNFPA) Viet Nam funded a pilot model for domestic violence prevention in 16 communes in Doan Hung district of Phu Tho province, and Binh Dai district of Ben Tre province. The pilot aims to: raise people's awareness of gender equality, most importantly, men's participation, women's empowerment, and the negative impacts of domestic violence; increase support for DV victims through reasonable distribution of health care, legal assistance, and social protection services; and strengthen cooperation among agencies from the national level to the grassroots. Activities include providing GBV screening and counseling at district hospitals, and examining referral to other services such as reconciliation teams, police, courts, and the Women's Union. Target groups are local authorities, police officers and the justice system, health care providers, women and men, and young people, as well as perpetrators and victims of violence. Target policy making bodies include the Ministry of Culture, Sport, and Tourism (MOCST), MOH, the National Assembly, the Viet Nam Communist Party, and the General Statistics Office (GSO). The project has also set up a steering committee at the provincial, district, and commune levels to integrate police, the People's Committee, and the justice sector, and train them to deal effectively with genderbased violence (Vietnam.unfpa. org/gender.htm.). 


\subsection{VIET NAM'S GLOBAL COMMITMENTS TO PREVENT AND ADDRESS GBV}

\subsubsection{Viet Nam's rati- fication of CEDAW}

The Convention on the Elimination of All Forms of Discrimination against Women (CEDAW), was adopted by the United Nations General Assembly on 18 December 1979, and became an international treaty on 3 September 1981.

Viet Nam was one of the first countries to ratify the Convention in 1979, but it has not signed the Optional Protocol to CEDAW. Since 1982, Viet Nam has been represented on the CEDAW, a body of 23 independent experts from around the world that monitors implementation of the Convention in over 185 countries. As a member, Viet Nam is obliged to report to the Committee on how the rights enumerated in the Convention are being implemented. At least once every four years, Viet Nam is expected to submit a national report to the Committee, indicating the measures that have been adopted to achieve the provisions of the Convention. Annually, Committee members discuss these reports with Government representatives and explore areas for further action by their country. The Committee also makes general recommendations to State organizations and other parties on matters concerning the elimination of discrimination against women.

\subsubsection{Stockholm Dec- laration and Agenda for Action}

Viet Nam was a signatory at the East Asia and the Pacific Regional Consultation for the Second World Congress against Commercial Sexual Exploitation of Children, which was held in Bangkok, October 16-18, 2001. This Regional Consultation meeting was attended by 252 representatives from countries that had adopted the Stockholm Declaration and Agenda for Action against the Commercial Sexual Exploitation of Children. The 1996 Declaration and Agenda for Action was declared at the First World Congress against Commercial Sexual Exploitation of Children held in Stockholm in 1996, signed by representatives from 119 countries (UNICEF, ESCAP, ECPAT International, et al. 2001).

In June 2004, the Government of Viet Nam approved the amended Law on Child Protection, Care, and Education (UNICEF EAPRO, July 2005; UNICEF, ESCAP, ECPAT International, et al. 2001). This 
amended Law ratified the Stockholm Declaration and Agenda for Action. It states that "protection, care, and education are the responsibility of every citizen, all families and all states; and that all children are integrated into the family and the community." For the period 20052010, the Government of Viet Nam has developed National Strategies on Child Protection, Integrated Early Childhood Development, and Child Participation, which include efforts to strengthen the capacity of families to realize and respect the rights of children, women, and the elderly. Adolescent needs for higher education, employment, and protection from drug abuse and sexual exploitation are equally a focus of policy development (UNICEF, ESCAP, ECPAT International, et al. 2001).

The Stockholm Declaration states that "poverty cannot be used as a justification for the commercial sexual exploitation of children". Child prostitution in Viet $\mathrm{Nam}$ is considered a crime. However, statistics on child sexual exploitation and trafficking in Viet Nam show that anywhere from $7 \%$ to $10.5 \%$ of the country's 200,000 prostitutes are children. These children are at risk for HIV/AIDS, pregnancy, and drug and alcohol abuse, as well as physical and psychological violence. From 1991 to 1992, about 22,000 Vietnamese women were bought and sold, both in and out of Viet Nam, some of them more than once. About $40 \%$ of the children and women who work as prostitutes in Cambodia are Vietnamese. In addition, Vietnamese girls are trafficked to Cambodia and Thailand for prostitution and also to China and Hong Kong as domestic workers (Viet Nam Country Progress Report, Nov. 2004).

Emerging awareness of commercial sexual exploitation of children tends to concentrate in large cities and provinces near Viet Nam's borders, including Ha Noi (Viet Nam Country Progress Report, Nov. 2004). 


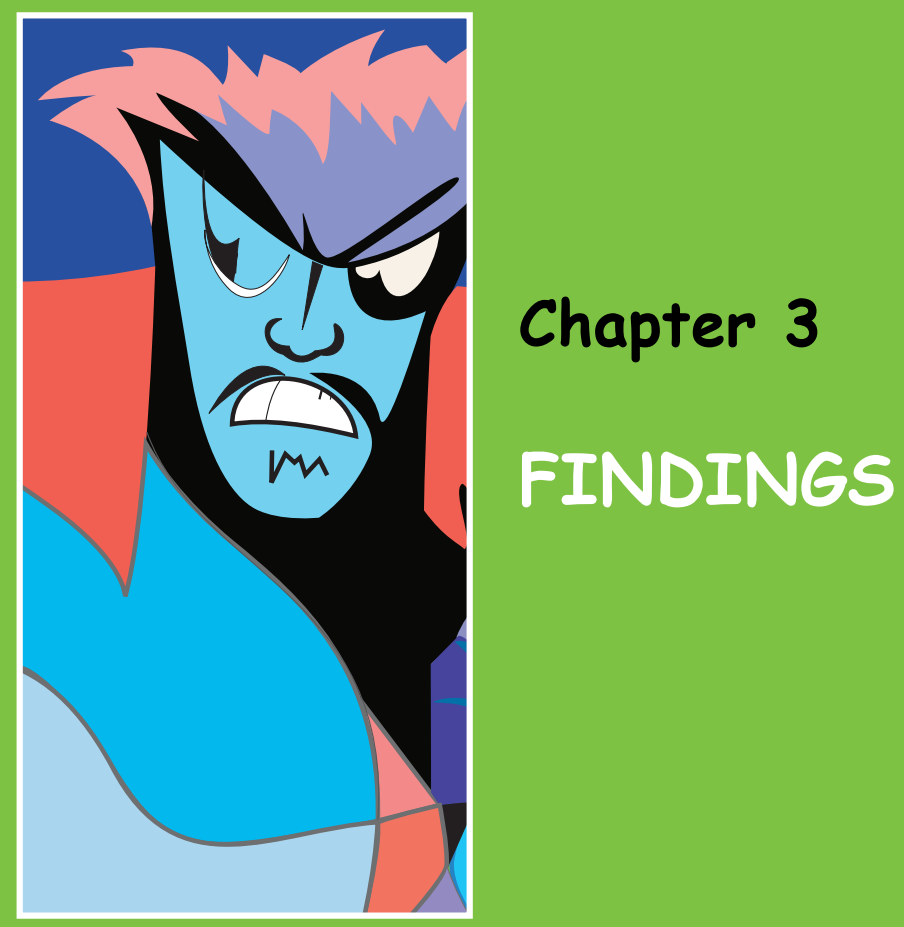





\subsection{QUALITATIVE STUDY FINDINGS}

\subsubsection{Qualitative find-} ings on awareness and perception towards GBV among GBV victims seeking help from the Women's Center for Counseling and Health Care of Duc Giang Hospital:

In spite of government intervention and promulgation of the new Law on Domestic Violence, findings indicate that there is a high risk of domestic violence (DV) for women and children who live with men who are reported to be linked to alcohol, drug abuse, gambling, mental distress, or mental illnesses, and traditional preference for male children.

The following are some typical samples of suffering by women served by WCCH counseling services at Duc Giang Hospital.

\section{Case 1}

"Violent behavior of my husband began during the first two months of our marriage and had continued for 14 years. First, only verbal violence. Then,... I could not remember when and what was the cause of the first hitting. Now,... it happens so often... that I no longer remember what initiates it. It was always physical violence, even during my pregnancy. He would punch my face, grab my shoulders, and hit my fingers with his hand and a broom. Look at these scars..."

When asked what brought her to the $\mathrm{WCCH}$, she said that she was hospitalized twice in the past due to her injuries. On the first occasion, she was beaten by her husband until she fell unconscious. They had a row after she questioned him about her missing motorbike. $\mathrm{He}$ had sold it without telling her. The neighbor called 113 (police) after seeing her fall and blood spattering from her nose. But her in-laws persuaded her not to file a case with the police because they said she should forgive him for his "first" violent act. So she did not report it officially and continued to live in fear for 14 years. The second time, she was asked not to leave the house, which meant to stop working and stay the whole day at home so that he could have sex with her anytime he wanted to. First she followed this "rule" and stayed for two weeks at home. But they kept fighting and finally she did not obey that rule anymore. She questioned him, "If I do not work, will you feed me?" His answer was, "... you are not 
a handicapped person, why do I have to feed you?" So she went to work that day, and when she returned home her husband beat her till she had to be brought to the hospital's emergency ward. The beating usually took place for about 20 minutes, but had been getting more severe lately. Beating could occur at any time of the day even in front of their daughters or in front of her mother-in-law. At the hospital she was thinking about reporting it to the police, but then her husband made an apology in front of their two daughters, so she decided not to report it. During this time, she heard about the WCCH and thus she made a decision to visit the WCCH for a consultation. However, her first visit to $\mathrm{WCCH}$ was fruitless because the counselor was not in that day. She came back to $\mathrm{WCCH}$ for the second time to seek consultation because in the last quarrel she was thrown out of the house and then forbidden to come back. She managed to take her 4-year-old daughter with her but the older daughter did not dare to go with her because she was afraid of her father. The older daughter is 13 years old and had been kept by the father inside the house with no one else. On the day of the interview, this woman had already been living outside the house with her younger daughter for two weeks.

Even so, when asked about the future, she said, "I am still willing to go back to live with the children but I also accept if he wants to divorce me." Her husband has threatened to divorce her many times in the past year. He drafted three divorce letters and forced her to sign one of them. She gave copies of this letter to the commune leaders and the Women's Union when they asked to see the signed divorce letter; then they sent a copy to the legal office and another copy to the police. But nothing happened. On the fifth day, the commune leader and another reconciliation member went to her husband to ask him to go to the education center but he told them, "I did not commit any crime, why should I go there?"

Experiencing all these failures, she went back to WCCH. From her perspective, the counseling services offered by the WCCH at Duc Giang Hospital have not only encouraged her but also taught her strategies to get protection and understand the legal basis for child custody. When asked about the Law on Domestic Violence Prevention and Control, she spontaneously replied, "No, I have not heard about it" (GBV victim, age 35 years, indepth interview, WCCH).

On the day of the interview, this woman had already been living outside the house with her younger daughter for two weeks.

\section{Case 2}

Similar to case 1: "Violent behavior of my husband began during the first year, when I was three months pregnant... I remember the cause of our quarrel was my suggestion 
that he should work to earn some money. Since then, at least once a month, he beats me when I ask for money to pay the children's tuition. He would hit me on my abdomen, legs, head, back... everywhere. Then force me to have sex, even in front of my daughter..."

When asked what brought her to the WCCH, she said that she was hospitalized four times in the past due to broken ribs or other injuries. Her husband beat her in front of their daughter (age 11 years), her mother, her brother, neighbors, and even the commune head, but none of them dared to help her. She herself never hit him back or said a word. Her only coping mechanism was crying. When asked about the Law on Domestic Violence Prevention and Control, she replied, "No, I have not heard about it."

From her understanding, the counseling service at the $\mathrm{WCCH}$ at Duc Giang Hospital provided not only knowledge about her rights to property but also about what procedures to go through to get a legal divorce because her husband of 21 years had never signed their marriage certificate. The local authorities in her commune refused to help her because they were afraid of her in-laws, despite knowing that her husband, unemployed, had many extramarital affairs and recently was in the process of marrying a girl that he planned to bring to their house to live with them (GBV victim, 42 years old, in-depth interview, WCCH).

\section{Case 3}

Another GBV victim was a peasant, married for 19 years, with two sons. She knew that her husband had a habit of gambling, even before she married him. The first beating occurred just one year after their marriage, when they got into a row because he sold her bike and used the money for gambling. Within the first 12 years of their marriage, she said, "He only beat me a little, twice a year." In 2001, he was jobless and sold almost all the household furniture, which forced her to find work outside the house. He became jealous and started to beat her more often and more severely, although not every day. He also liked to beat her in public, dragging her outside of their house. Sometime he visited her work-place and beat her in front of people. The beating was usually targeted at her chest, using a big pipe. But she said, "He never beat the boys and he did not have extramarital affairs". She reported the beatings to the Women's Union twice, and they came to the house to talk to her husband, but this was not effective because he would beat her again soon afterward.

She was not aware that a woman has the right not to be beaten by her husband, until she was referred by the Commune Health Center to the WCCH at Duc Giang in 2002. Here she was coached on how to manage him. Later she brought home two leaflets from the $\mathrm{WCCH}$ and deliberately left these leaflets at a place inside the house that her husband would see. 
Apparently he read it and since then stopped beating her, only shouting or verbally threatening her. She would not talk much when he was in such a bad mood. However, she was brave enough to participate in a local TV talkshow about banning GBV. Her husband did not watch it but a neighbor saw it and her motherin-law told their son, "Your mother is ridiculing your father in public." However, she clarified to her son, "I only tell other women that GBV is unacceptable and your father is not a thief. So don't worry about that" (GBV victim, age 39 years, in-depth interview, WCCH).

\section{Case 4}

Another in-depth interview respondent said, "We were actually in a good relationship. He would beat me only when he was engaged in drugs or love affairs. The violent behavior of my husband began during the first year, when I was two months pregnant." She got married at the age of 22 when her husband was 28. In 2002, he got addicted to drugs and gambling. The beatings then became more severe and frequent. All these years, she kept silent. However, in August 2006, he beat her, choked her neck, and threw her out of the house. This became public knowledge and she returned to live with her family. She made up her mind to get a divorce.
When asked about the Law on Domestic Violence Prevention and Control, she claimed that she only knew a little but that was enough to make up her mind about getting a divorce. Her concern was that she would not have enough money as a single parent to raise her only daughter. She did not want her daughter to have no father. When she consulted the Women's Union, they referred her to the WCCH (GBV victim, age 33 years, indepth interview, $\mathrm{WCCH}$ ).

\section{Case 5}

An elderly woman came to seek protection from the WCCH. She had been subjected to physical violence and psychological threats from her husband and their two sons, who wanted her to give up a 100 sq. meter plot of land that was under her name. "I got broken ribs after my husband beat me with a stick..." Her sons, instead of helping her, also assisted their father in beating her. The last beating broke her hip-bone and caused her to have difficulty walking. She has sought advice in many quarters but found the WCCH most reliable. The day of the interview was her fourth visit to get advice on protection. Her wish was to move out of her house and live in a home for the elderly home to feel safe, "I only want to live a few years more..." (GBV victim, age 67 years, in-depth interview, WCCH). 
3.1.2. Qualitative findings on change of awareness and perception towards GBV among hospital and CHC staff and community leaders. after enactment of the 2007 Law on Domestic Violence Prevention and Control

The qualitative findings relate staff's awareness and perception to four main themes:

- General awareness and willingness to integrate screening of GBV into daily services of a particular department/specialty (due to knowledge about forms of violence, causes, and consequences to women's and children's health);

- Obstacles to integrating GBV screening or identifying GBV victims in daily hospital services;

- Opinions about the effects of the 2007 Law on Domestic Violence Prevention and Control; and

- Acceptance of the role of the Women's Center for Counseling and Health (WCCH) in mobilizing social network support.

General awareness and willingness to integrate GBV screening, in relation to forms of violence, causes, and consequences.
Focus group discussions with hospital staff indicate general awareness that doctors and nurses are in prime positions to integrate domestic violence prevention and screening in daily health care practices. FGD respondents almost unanimously agreed when one of them said, "GBV creates family disturbances, unhappiness, and damage to women's health both physically and psychologically. Most of the time, it is the woman who suffers physical and psychological damage. Those who are in extreme fear beg to be admitted to an in-patient care unit because they do not want to go home. They do not feel safe and need a temporary place to live" (Male doctor, DG hospital).

Domestic violence (DV) is very upsetting for children, because they see one of their parents abusing or attacking the other. They often show signs of great distress, usually manifested as lower grades in school. "... Although their children may have strong potential to be good students... in a violent family environment, their grades will drop for sure. Younger children may show symptoms of psychological development disturbances, such as delay in talking or difficulty interacting with others" (Female doctor, Internal Medicine Dept., DG hospital).

Hospital staff who participated in this FGD were well aware that DV makes a family's life become a cycle of violence. Everyday life revolves around anticipating 
violence; coping with actual acts of violence; or recovering from the violence. The children in these homes are at high risk of being battered themselves by either the batterer or the victim. "... so, violent families do not create a good environment for raising children" (Male doctor, DG hospital).

"I have seen some strong, resilient children. Despite their parents' situation, they try to focus on their studies. Or, some of these children were sent to live at their grandparents' homes, still.. I can see that witnessing violence in their family put a strain on their development. These children are more likely to become "unhealthy" adults. Thus, the cycle continues from one generation to the next, because children who have witnessed violence are more likely to grow up to be either abusers or victims themselves" (Female doctor, Intensive Care and Resuscitation Dept., DG hospital).

Most of the FGD respondents agreed that GBV not only harms the entire family but also society as a whole. "... First, it will corrupt society's feeling of security; second, it will increase society's burden (resources needed to solve GBV problems); and third, it will also increase hospital costs in general. GBV also destroys our cultural tradition because it prevents women from contributing to society..." (Male doctor, WCCH, DG hospital).
"... GBV affects not only the victim, but society as well; because it generates psychological trauma among children as well as reproductive health problems for women victims... GBV undermines the quality of life, because the long-term effects of witnessing such violence will create a cycle of violence that spans generations, and ultimately affects our society. Both men and women who come from abusive homes may come to view the violence they have witnessed as normal, and carry it into their own relationships as adults. The cost to both victims and society is enormous" (Female doctor, Intensive Care and Resuscitation Dept., DG hospital).

Both FGDs at the commune level indicated that mobilization of community support to GBV victims can be powerful. It has already been successful in disseminating various information, education, and communication (IEC) materials to women who are living in silence. The heads of both $\mathrm{CHC}$ s claimed that they are very confident in approaching GBV victims and thus there was an increasing percentage of female clients visiting their $\mathrm{CHCs}$ being screened to detect possible GBV victims. They stated that they were still more comfortable advising reconciliation rather than divorce, but if the victim continued to be beaten, they referred her to the Commune Legal Officer (FGDs at Yen Vien and Yen Thuong CHCs, Gia Lam district). 
Obstacles to integrating GBV screening in daily work.

The first obstacle relates to the difficulty of detecting psychological violence. Although hospital staff are aware that they occupy key positions for violence prevention and treatment, and they have the knowledge about GBV definition (as both physical (including sexual) and psychological violence), their examples mostly described physical violence; and they acknowledged the problem of detecting other types of violence.

"...] when I saw a female patient with black eyes, I asked her quick questions to screen for domestic violence and if she said she had fallen or hit something by accident, I would probe further if I suspected that her injury was the result of a serious GBV condition. Then I would refer her to the WCCH counselor. At the other extreme, I also experienced an occasion where a female patient asked to purchase the medical record with my diagnosis in it so that she could submit it as an evidence to the court" (Male doctor, Ophthalmology Dept., DG hospital).

[example of sexual violence] "... when a man wants to have sexual activity that is 'strange' in our traditional context and his partner did not want to cooperate... he would beat and use physical force to accomplish his wish against her will. The patient came in with injured sexual organs..." (Male doctor, Ob-Gyn Dept., DG hospital).
"I had to treat a primary school teacher who found out that her husband was having an extramarital affair. When she questioned him, he beat her severely. Yet when she came to seek treatment for a bruise in her face, she said she had fallen. Later, during the examination, she broke into tears and began to tell the truth..." (Male doctor, Internal Medicine Dept., DG hospital).

Psychological impact of violence was brought up by a female nurse, who observed that "... some patients have been admitted to in-patient wards with mental breakdown symptoms such as chronic headaches, difficulty concentrating or thinking, and sleeplessness." When she had conversations with them, they would usually hide the cause, but later they disclosed their real stories. In one of these cases, the husband of the GBV victim was the 'boss' of a company. "He never hit her... he ignored her and spent his time outside the house every day; and he avoided the 'husband and wife' (sexual) relationship. She was suspicious and via investigation found out that her husband was having an affair. This caused high anxiety and sleep difficulties. We tried to counsel her but we failed... it was a very difficult case" (Female nurse, Nursing Dept., DG hospital).

A second example was presented by a female doctor: "I had a patient whose husband lied all the time about having an affair. She suffered from sleep difficulties and mental distress. She busied 
herself with doing business abroad to avoid her husband. But for the sake of the children, she returned. Her husband did not change, and finally they got a divorce. The wife was sleepless for months before coming to us" (Female doctor, Surgery Dept., DG hospital).

Despite having been trained about GBV, all hospital staff who participated in the FGD at Duc Giang Hospital admitted that victims with physical signs of violence are easier to recognize. Those who suffer from psychological violence tend to be more difficult to screen. "We need not only skill but also more time to approach them, to get them to open up their feelings. Usually, during treatment we can find out more about their feelings and their thoughts. Understanding the GBV patient's feelings is very important in making decisions about appropriate treatment... that will help us treat them successfully" (Male doctor, Ob-Gyn Dept., DG hospital).

According to the Head of WCCH, there are two types of GBV victims. First, those who openly acknowledge suffering from gender-based violence. Second, those who keep denying that they are suffering.

[...] "The second group is the more difficult to screen. Therefore, enhanced knowledge and specialized training are needed... we doctors in Duc Giang Hospital are among the very few people who are fortunate to have undergone
GBV training. We have acquired the skills to deal with GBV issues. Even so, we still see that some clients do not automatically follow our advice until they recognize the effectiveness of the suggested solution. Often, such cases need more case management time."

At Duc Giang Hospital, to sharpen skills for making a diagnosis related to GBV, doctors regularly share their diagnostic conclusions based on individual expertise and experience. Anticipating possible fraud is also included. "... we sometimes received a report that a woman had been raped, but our examination found no evidence of injury; we have to be careful..." (Male doctor, Ob-Gyn Dept., DG hospital).

Over the last three years, with increasing number of GBV cases, hospital staff gradually improved their skills to screen gender-based violence victims. They said, "... we can recognize the symptoms of $G B V$, even though the patient did not tell us, through our experience." For example, "one day an elderly woman was brought to our Emergency ward for resuscitation because she had a chronic respiratory problem. However, I then realized that her children were very violent toward her. They kept threatening her which made her condition worse. Through an investigation via a family member, we got further information that these children starved her, left her unattended, and whenever she cried for help they committed 
physical violence until people who saw it stopped them. They wished death would come soon to their mother so that they could inherit her property. Regrettably, the hospital staff has no legal power to protect the elderly woman. We called the security guard to protect the woman. But when we were processing her admission to in-patient care and contacting WCCH, the family members took the woman away. It's disappointing that we cannot detain her" (Female doctor, Intensive Care and Resuscitation Dept., DG hospital).

The second obstacle is the "common law" regarding the continuation of male domination. This is a tradition that persists in a way that supports the continuation of battering and violence against women by husbands and boyfriends in Viet Nam. Health care providers (especially doctors, nurses, and midwives) often hold the same prejudices as their society, thus considering domestic violence a "private or legal" matter. They are afraid of offending their patients by asking about domestic violence. Many hospital staff recognize GBV victims in daily interaction with their clients but they are not sure how to ask about battering and what resources would be available. This uncertainty has resulted in "underreporting" in the health facilitybased GBV data base.

The above example of "family members can take the victim away from the hospital by force" reflects a difficult issue in recording, protecting, and supporting GBV victims. Hospital staff do not have the legal power to retain the victim if the family members decide to take the GBV victim back home or to another place. Duc Giang Hospital has clear protocols for identifying and treating GBV victim, and then referring victims to the WCCH. Printed screening tools and protocols for intervention can be seen on almost all of the desks in out-patient departments. Universal screening for GBV victims using the yellow form has been implemented as part of the hospital's standardized patient intake form in the emergency as well as other departments, following protocols for physical examination (the green form) as the basis for diagnosis and treatment. However, the approval of family members is still needed for hospital admission, because family members are responsible for financial support to cover the hospital cost. Doctors do not have the legal power to retain a GBV victim in the hospital even after identifying her as a victim.

The Head of WCCH presented the fact that many doctors became frustrated by the cyclical nature of GBV - seeing a woman coming back again and again with repetitive and often more serious injuries, instead of escaping the battering environment. Others mentioned that many health professionals were pressured by time constraints within the healthcare delivery system. They feared asking about abuse because it might take more time to assess the danger and to design a safety plan. 
The third obstacle is cost. The majority of GBV victims seeking help at the WCCH of Duc Giang Hospital come from poor rural areas and "... about $40 \%$ of GBV victims could not afford to purchase prescribed drugs because they have no money" (Male doctor, WCCH, DG hospital). "Those who are covered by health insurance can get reimbursement, but those without health insurance usually run away and do not pay the hospital fee" (Male doctor, WCCH, DG hospital). Many of those without health insurance hide the truth and report their wounds as accidental. This contributes to the under-reporting of GBV cases. As the WCCH Head said, "to sustain this integration of GBV screening into hospital medical services, a new financing policy is needed. Not only to subsidize health care but also to get legal assistance, social protection, and other forms of network support that need inter-sector cooperation and coordination, including the police and court systems."

The fourth obstacle is providing a safe place to protect the GBV victim from her perpetrator. This remains an unsolved problem. "Right now Duc Giang has only one shelter located far away, for security reasons. And we do not have security guards to protect them from their husbands... When a GBV victim seeks our hospital's protection, we can only consider her as an in-patient so she does not have to go home. When they recover from their injuries but do not want to go home or are afraid to go home for safety reasons, they should be able to go to a temporary shelter. In Ha Noi, at this time, there is only one place like that, and it is on Thuy Khue Street. It is so far from here."

"... We used to contract with the police to protect the women victims but now that the project is reaching an end, we are running out of funds to continue paying the police." There are some community shelters built by those who support women victim, but feedback from women victims who stayed there indicate too many weaknesses" (Male doctor, WCCH, DG hospital).

Opinions about the 2007 Law on Domestic Violence Prevention and Control

According to participants in the FGD at Duc Giang Hospital, and also in the CHC level FGDs, the 2007 Law on Domestic Violence Prevention and Control does not have sufficient enforcement provisions to automatically refer every GBV victim or rape victim to the legal authorities (police or court). Of paramount importance is the education of the public. Many Vietnamese women living in rural districts have not heard about this Law. "[...] / think people's knowledge about the law on domestic violence is very low; people don't know what DV is, nor where to go to seek help when they need it. The information, 
education, and communication (IEC) efforts are not working well. Brochures about GBV have limited information; and frankly speaking, even those given to health care providers have very limited information. Very few people care or listen about this issue..." (Male doctor, DG hospital).

Nonetheless, the Head of WCCH at Duc Giang Hospital is optimistic that as more and more Vietnamese women learn about this Law and the legal system gives them a chance to use it to change their life, then people's attitudes towards domestic violence will gradually change. He said, "it was worse without the law, because domestic violence was often not considered a crime". According to patriarchal traditions in Vietnamese society, a husband has the right to "teach" his wife, even using physical violence. Therefore, violence between intimate partners is surrounded by silence in Viet Nam.

Although he admitted seeing difficulties in applying this Law, he added, "... recently we have done some good social marketing about the Law." A national television series "Breaking the Silence" produced by the Centre for Studies and Applied Sciences in Gender, Family, Women, and Adolescents (CSAGA) and the United Nations Office on Drugs and Crime (UNODC), talk shows, and other media campaigns have raised women's awareness. But the coverage remains mostly in urban areas. Many rural and poor women are still unaware of this Law. The broadcasting of information regarding this Law throughout a commune via a vehicle equipped with a loudspeaker is not effective at all. The loudspeaker volume cannot compete with other "noises" in the street. People do not pay attention and so they do not absorb the information communicated through this mechanism.

Another concern about implementing this new Law is the low capacity of local institutions. Institutions at the local level are rarely prepared to interfere in family cases of GBV. Viet Nam has for a long time established "reconciliation groups" headed by the President of the People's Committee at the commune level and, in some cases, the village level. However, no professional training is required to become a member of such a group. The traditional view that domestic violence is a family matter still prevails and thus the reconciliation group only pays attention when the physical violence is very severe. In addition, reconciliation becomes an ineffective intervention when the reconciliation group members themselves have very little knowledge about the Law and still believe that a woman should respond to her partner's violent behavior by maintaining silence. $\mathrm{He}$ gave an example in Phu Tho where a GBV victim said the President of her Commune People's Committee advised her: "talk less or he'll beat you more". 
The law is perceived as not strong enough to empower local authorities and non-health sectors, such as the police and justice system to deal with the perpetrator (husband or partner). This Law needs to be supplemented with Ministerial Decrees to create a strong collaboration of relevant agencies at the local level. In actual practice, there is inadequate concern among authorities and poor collaboration of relevant agencies to protect GBV victims. Consequently, this condition poses difficulties for the President of the Commune when reprimanding the perpetrator to stop violence.

Some violent husbands or partners openly show their disrespect of the law. The Head of WCCH shared his observation in Phu Tho where the deputy of the president of the commune called a couple to his office to advise them not to fight anymore. Right after they passed beyond the gate of the office, the husband beat the wife until she fell unconscious and had to be brought to the emergency ward of a hospital.

A similar story was presented by a participant in a $\mathrm{CHC}^{\prime} \mathrm{s}$ FGD in Gia Lam district. "... When we told the husband about the Law, he did not show any fear at all; in cases where drug addiction was involved, the husband even beat the wife right after a visit from the commune head or women's union representative, and we could not do much..." The husband challenged the local authorities by showing his attitude to the visitors: "what can you do; my wife is my property". The concerned commune head could not do much in that instance. He had to put other network support together before successfully bringing the husband to court or to an "education center". It took a very long time to get sanctions on the violent husband. "On average it takes about 10 months, during which time the wife must endure continuous beating and other forms of GBV. Therefore, women victims of GBV still feel that the Law is inadequate..." (Yen Thuong commune president, FGD in Gia Lam district).

The Head of the Women's Union and the Court staff agreed that the Law is weak because it has no specific punishment period that can make GBV incidents drop significantly:

"... Punishment is very important to position the Law as a strong legal protection for GBV victims. Punishment should be elaborated in more detail because this is also needed as the basis for the police and commune head to take action" (FGD in Yen Thuong commune, Gia Lam district).

The Head of WCCH, who is also the senior counselor at Duc Giang Hospital, noted two other relevant Laws: the Law on Marriage and Family, and the Law on Gender Equality.

The Law on Gender Equality applies the principles of gender equality to all aspects of social and family life, including monitoring measures for 
gender equality, and enumerating responsibilities of agencies, organizations, families, and individuals. It was approved by the Vietnamese National Assembly on Nov 29, 2006 (effective July l, 2007).

The Law on Marriage and Family aims to contribute to building, perfecting, and protecting progressive marriage and the family by formulating legal standards for the conduct of family members. It also aims to protect the legitimate rights and interests of family members; and to promote the ethical traditions of the Vietnamese family. This Law describes the responsibilities of citizens, the State, and society. It was approved by the Socialist Republic of Viet Nam's $X^{\text {th }}$ National Assembly during its $7^{\text {th }}$ session on June 9, 2000 (signed by the National Assembly Chairman - HE NONG DUC MANH), to replace the 1986 Law on Marriage and Family and then go into effect on January 1, 2001.

\section{The Commune Legal Officer} stated, "the clauses in the Law on Domestic Violence are too broad and too general, leaving the followup to ministries who must formulate specific rules and directions. And so far, they have not done that..." (FGD in Yen Thuong commune, Gia Lam district).

The GBV victims from urban areas have more knowledge about the new Laws and can present their appeal on that basis. But poor rural women victims are not familiar with the new Laws. Knowledge is still very limited, even among rural commune presidents or heads. It is understandable that at the commune level, members of the reconciliation group who are not aware of the Law are afraid to work with the perpetrator of violence in a family because that violence could suddenly be turned against the mediators. Legislation should be clearer on this matter. "During my visit, they usually promised to apply the Law, but they never did their responsibilities." He presented a case where a "husband and wife relationship existed for 21 years, yet the husband said that he never signed the marriage certificate, so the husband does not feel any obligation to support his "wife" but feels it is his right to beat her. The local authorities refused to help the victim. This shows two possibilities: the local officials do not know about the Law; or they do not respect the Law." (Male doctor, Head of WCCH, FGD at DG hospital).

\section{Women's Center for Counseling and Health (WCCH)}

In-depth interviews with five GBV victims who had sought support from the WCCH of Duc Giang Hospital revealed that, although they know that the first formal report of GBV including sexual violence should go to the police, they prefer to go to health care providers or directly to hospitals. When women victims of DV were asked why they did not formally report to the police first, they answered, "... I was attacked by police officers ..." (GBV victim, in-depth interview, Duc Giang W(CH). 
The Head of the WCCH said that he gradually built a comprehensive approach to prevent and reduce GBV. In this context, he needed to build the capacity of the law enforcement and justice sector officers, parallel to other project components that focus on raising public awareness about domestic violence and the right of women to live in a household free of violence. Although this is a painstakingly slow process, he did receive increased support from other health care facilities in the area, civil society organizations such as the Women's Union, legal assistance from police and court personnel, and eventually from the media. His work speaks for itself because the Duc Giang WCCH now has a strong role in strengthening cooperation among agencies, from the national level to the grassroots level. He turned data and specific cases from the $\mathrm{WCCH}$ database into public education materials that are delivered through talk-shows, films, trainings, seminars, and other methods to reinforce community support for GBV victims. More important, he worked to make reconciliation focus on making sure that the violence stops. GBV training is also needed to build the capacity of the law enforcement and justice sector, including the police force.

He admitted that, "I see that, in many areas, the local government tries not to perform their responsibilities. When / visited them, they would say they will deal with $G B V$ issues, but they never do ..." He described a case where a couple have lived together for 21 years and have two children but the husband refused to register and get a marriage certificate. Now that the wife wants to seek legal advice regarding DV and property rights, the people's committee told her, "... you are not a married couple so we cannot help resolve this matter." 


\subsection{QUANTITATIVE CHANGES AMONG HOSPITAL STAFF IN INTEGRAT- ING SCREENING AND TREATMENT OF GBV VICTIMS INTO GENERAL MEDICAL AND REPRODUCTIVE HEALTH SERVICES}

\subsubsection{General Charac- teristics of Hospital Staff}

Two hundred and forty eight hospital staff were interviewed. One record is incomplete. Thus, 247 complete questionnaires were processed and analyzed.

This survey had far more female (76.1\%) than male (23.9\%) respondents. The mean age of the respondents was 33.8 years $( \pm$ 9.7 years), with the youngest 20 years old and the oldest 57 years old (see Figure 3.1). The Duc Giang Hospital expanded its scope of work and number of staff between 2006 and 2009. As a result of this expansion the age composition of staff has changed significantly between GBV Phase I and GBV Phase II. Most of the new staff members are younger, with the sample showing that $50 \%$ of the respondents are in the youngest age group (30 years or less).'

Figure 3.1. Respondents by age group ( $N=247)$ - 2009

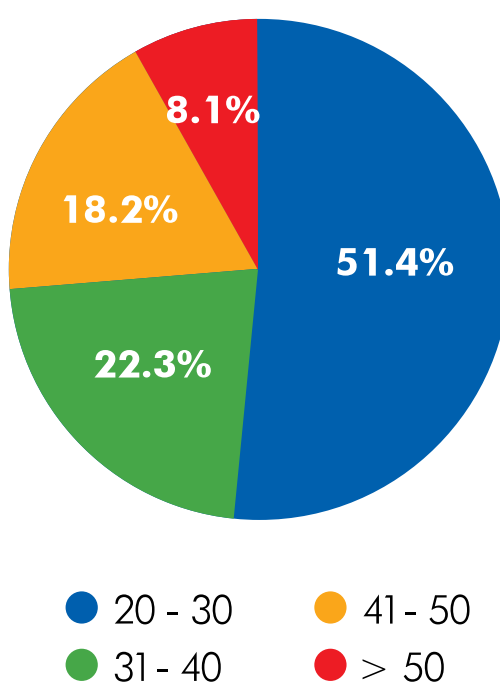

IIt would be interesting to compare the proportion of this age group with that in the GBV Phase I survey; however, the ages of hospital staff who participated in the GBV Phase I post-intervention survey were not reported. 
The recent hospital expansion and recruitment of new staff also changed the proportions of GBV trained $(29.3 \%)$ and untrained staff $(70.7 \%)^{2}$. In-house training could not keep pace with the expansion of staff. Regarding marital status, $29.9 \%$ of the staff are still single. In regard to occupation, approximately half of the survey respondents are nurses $(45.3 \%), 17.4 \%$ physicians, $3.6 \%$ assistant physicians, and $5.7 \%$ midwives. Support, technical, and other non-health staff count for $27.9 \%$ of the total.

Overall, survey respondents came from 22 out of 23 departments and offices (except the office of the Hospital's Board and Chairperson).

Analyzing these 22 departments in terms of frequency of screening suspected GBV victims led us to categorize three groups of departments - those in which there is less frequent interaction with GBV victim, those with frequent direct interaction, and those with frequent but indirect interaction ${ }^{3}$. Most respondents are from departments that have frequent direct interaction with GBV victims (55.5\%), followed by departments with less frequent interaction (24.3\%), and those with frequent but indirect interaction (20.2\%) (see Table 3.1)

\section{Table 3.1. Respondents by hospital department}

\begin{tabular}{l|c|c}
\multicolumn{1}{c|}{ Departments } & N & $\%$ \\
\hline Less frequent interaction & 60 & 24.3 \\
\hline Frequent direct interaction & 137 & 55.5 \\
\hline Frequent but indirect interaction & 50 & 20.2 \\
\hline Total & 247 & 100.0 \\
\hline
\end{tabular}

\footnotetext{
${ }^{2}$ In the survey, $29.3 \%$ of staff said they had attended GBV training. HHD provided additional information that $91.1 \%$ of staff had attended hospital briefing on GBV for professional staff. Only 8.9\% of newly recruited staff had no GBV training or briefing.

${ }^{3}$ Departments interacting less frequently with GBV victims: Pediatrics, Operating Room and Anesthesia, Pharmacy, Infection Control, and Equipment and Supply; Departments with frequent direct interaction and/or screened the most GBV victims: Obstetrics and Gynecology, Internal Medicine Clinic, Emergency \& Intensive Care, Traumatology, Internal Medicine II, Internal Medicine III (infectious diseases), General Surgery, Surgery Clinic, Ophthalmology, Otolaryngology, Somato-Dental-Facial, and Traditional Medicine; and Departments interacting frequently but not directly with GBV victims: Medical Imaging, Accounting, Administration and Personnel, and General Affairs Department.
} 
There is no correlation between daily work site in any of the above departments and age of staff.

Half of the respondents (50.6\%) are relatively new, having worked for Duc Giang Hospital for 5 years or less. The staff members having length of service in the 6-10 year range constitute $17.8 \%, 11-20$ years $13 \%, 21-30$ years $15 \%$, and those serving longer than 30 years constitute 3.6\% (see Table 3.2).
Comparison between their length of service at Duc Giang Hospital and their total experience in the health sector (including work before they joined Duc Giang) did not reveal any significant difference. This means most of the respondents joined Duc Giang Hospital near the beginning of their career as a health care provider (particularly true of the younger staff members).

Table 3.2. Length of service (years) - 2009

\begin{tabular}{c|c|c|c|c|}
\hline \multirow{2}{*}{$\begin{array}{c}\text { Length of service } \\
\text { (years) }\end{array}$} & \multicolumn{2}{|c|}{$\begin{array}{c}\text { At Duc Giang } \\
\text { hospital }\end{array}$} & \multicolumn{2}{c}{$\begin{array}{c}\text { In the } \\
\text { Healith Sector }\end{array}$} \\
\cline { 2 - 5 } & $\mathbf{N}$ & $\%$ & N & $\%$ \\
\hline 55 & 125 & 50.6 & 115 & 46.6 \\
\hline $6-10$ & 44 & 17.8 & 47 & 19.0 \\
\hline $11-15$ & 21 & 8.5 & 23 & 9.3 \\
\hline $16-20$ & 11 & 4.5 & 13 & 5.3 \\
\hline $21-25$ & 20 & 8.1 & 20 & 8.1 \\
\hline $26-30$ & 17 & 6.9 & 19 & 7.7 \\
\hline$\geq 31$ & 9 & 3.6 & 10 & 4.0 \\
\hline Total & 247 & 100.0 & 247 & 100.0 \\
\hline
\end{tabular}




\subsubsection{Knowledge and Perceptions}

The survey questionnaire addressed three separate issues: five questions assessed hospital staff perception of cultural norms and expectations that shape male violence against women; six questions related to whether the husband had the right to beat his wife; and four related to the wife's right to refuse sex (see attached questionnaire section).

The questions about cultural norms and expectations asked respondents whether they agreed/disagreed that common types of spousal behavior led to gender-based violence such as: husband showing off his position as the owner of the wife; wife must always listen and never disagree; wife must satisfy his sexual desire even when she has no desire; domestic violence is only a private matter inside the family; and external intervention is justified during a beating.

Perception of negative stereotypes that a husband has the right to beat his wife was measured through the mean scores of six possible causes: wife failed to fulfill domestic chores; wife is addicted to gambling or drugs; wife disagreed with husband's opinion; wife verbally insulted husband; wife is unable to satisfy husband's sexual need; and wife is suspected having an extramarital affair.

Opinions about a woman's right to refuse sex with her husband included when she has no desire, she is tired, or he is drunk.
Responses to all questions were "yes" and "no" (nominal). These were combined to form an index for each of the three sections. If the respondent disagreed with the first four questions and agreed with the fifth question (external intervention is proper during a beating) the score was 100. Conversely, if the respondent agreed/disagreed with all questions the score was zero. This approach was used to calculate the mean value of the total scores. The mean scores were then crosstabulated with "gender, age group, marital status, and whether training had been received".

The results for all three issues (cultural norms and expectations; husband's right to beat his wife; woman's right to refuse sex with her husband) are summarized in Table 3.3. Higher mean scores indicate that the hospital staff members are more aware of or sensitive to GBV or domestic violence (DV) issues. The only significant differences in the mean score were by age group for cultural norms and expectations: the mean significantly decreased with increasing age $(p=0.015$, univariate test). The score was highest within the $20-30$ year age group (86.4\%) then decreased to $65.4 \%$ among the group older than 50 years. This indicates that older hospital staff members have less sensitive perception about the listed types of violence, in particular non-physical or verbal violence types. 
There were no significant had received or not received GBV differences between males and training (see Table 3.3) on each of females, between married and the three issues.

single staff, or between those who

Table 3.3. Perceptions around common norms about GBV by gender, age group, marital status, and ever received GBV training - 2009

\begin{tabular}{|c|c|c|c|c|c|c|c|}
\hline \multirow{2}{*}{\begin{tabular}{|l} 
Category \\
Cender
\end{tabular}} & \multirow[t]{2}{*}{$\mathbf{N}$} & \multicolumn{2}{|c|}{$\begin{array}{l}\text { Common } \\
\text { perception of } \\
\text { GBV }\end{array}$} & \multicolumn{2}{|c|}{$\begin{array}{l}\text { Husband's } \\
\text { right to beat } \\
\text { the wife }\end{array}$} & \multicolumn{2}{|c|}{$\begin{array}{l}\text { Wife's right } \\
\text { to refuse } \\
\text { sex }\end{array}$} \\
\hline & & $\begin{array}{l}\text { Mean } \\
\text { (SE) }\end{array}$ & $\mathbf{P}$ & $\begin{array}{l}\text { Mean } \\
\text { (SE) }\end{array}$ & $\mathbf{P}$ & $\begin{array}{c}\text { Mean } \\
\text { (SE) }\end{array}$ & $\mathbf{P}$ \\
\hline Male & 59 & $78.8(2.7)$ & \multirow{2}{*}{0.295} & $93.7(3.4)$ & \multirow{2}{*}{0.197} & $98.5(2.0)$ & \multirow{2}{*}{0.231} \\
\hline Female & 188 & $82.3(1.4)$ & & $88.6(1.9)$ & & $95.6(1.1)$ & \\
\hline \multicolumn{8}{|c|}{ Age group (years) } \\
\hline $20-30$ & 127 & 86.4 (3.1) & \multirow{4}{*}{0.015} & $94.1(3.1)$ & \multirow{4}{*}{0.355} & $95.6(1.8)$ & \multirow{4}{*}{0.945} \\
\hline $31-40$ & 55 & $80.3(2.9)$ & & 88.7 (3.7) & & $96.7(2.1)$ & \\
\hline $41-50$ & 45 & $76.5(5.1)$ & & $84.2(5.2)$ & & $97.8(3.1)$ & \\
\hline$\geq 51$ & 20 & $65.4(8.5)$ & & $78.1(7.4)$ & & $96.3(4.4)$ & \\
\hline \multicolumn{8}{|l|}{ Marital status } \\
\hline Married and others & 64 & $78.8(2.7)$ & \multirow{2}{*}{0.166} & $84.5(3.5)$ & \multirow{2}{*}{0,076} & $98.5(2.1)$ & \multirow{2}{*}{0.224} \\
\hline Single & 183 & $82.5(1.5)$ & & $91.6(2.0)$ & & $95.6(1.2)$ & \\
\hline \multicolumn{8}{|l|}{ Training } \\
\hline Yes & 73 & $86.5(4.0)$ & \multirow{2}{*}{0.108} & $97.4(4.6)$ & \multirow{2}{*}{0,080} & $94.9(2.7)$ & \multirow{2}{*}{0.576} \\
\hline No & 174 & $79.5(2.0)$ & & $86.8(2.4)$ & & $96.9(1.4)$ & \\
\hline
\end{tabular}




\section{Knowledge of behaviors categorized by types of violence against women}

Knowledge of hospital personnel was assessed for the three categories of GBV: physical, psychological, and sexual violence. Then findings from this 2009 survey (GBV-II) are compared with findings from the 2005 survey (GBV-I) in Table 3.4 (knowledge of types of physical, psychological, and sexual violence) and Table 3.5 (knowledge of severity of physical, psychological, and sexual violence).
Regarding physical violence, all interviewed respondents recognized easily the three common types listed in the questionnaire. The previous survey in 2005 already reached $100 \%$ (maximum scores) on knowledge about physical violence and the same level was maintained in the 2009 survey.

Overall, GBV-II respondents' knowledge of types of psychological and sexual violence was not significantly different from that of GBV-I respondents. There was little effect of training, marital status or age. 
Perception of severity of health consequences of violence.

Table 3.5 shows a statistically significant increase between GBV-I and GBV-II in hospital personnel's perception about level of severity of the consequences of physical, psychological, and sexual violence. There is no significant influence or effect of prior GBV training, marital status, or gender. The only significant effect of training is on recognition that the act of "throwing a woman out of home" is a type of psychological violence.

Both Tables 3.4 and 3.5 indicate that age of hospital personnel is a very important variable. At the same time, GBV training appears to have little effect on the responses.
Table 3.5 presents the percentage of hosital personnel who thought the stated act of violence is a "very serious" category. Compared to the 2005 survey findings, the fraction of current hospital personnel (2009 survey) who thought that "assault and hurt a woman" should be categorized as "serious severity of physical violence," doubled from $31 \%$ (in 2005) to $67 \%$ (in 2009).

Remarkably, the largest percentage increases are seen in psychological and sexual violence categories, approximately $30 \%$ or higher among those answering all subquestions. This indicates a much higher sensitivity for recognizing the severity (danger) of health consequences of psychological and sexual violence. 
Table 3.5. Perception of "very serious" health consequences of certain "violent acts" and its correlation with training, marital status, age, and gender

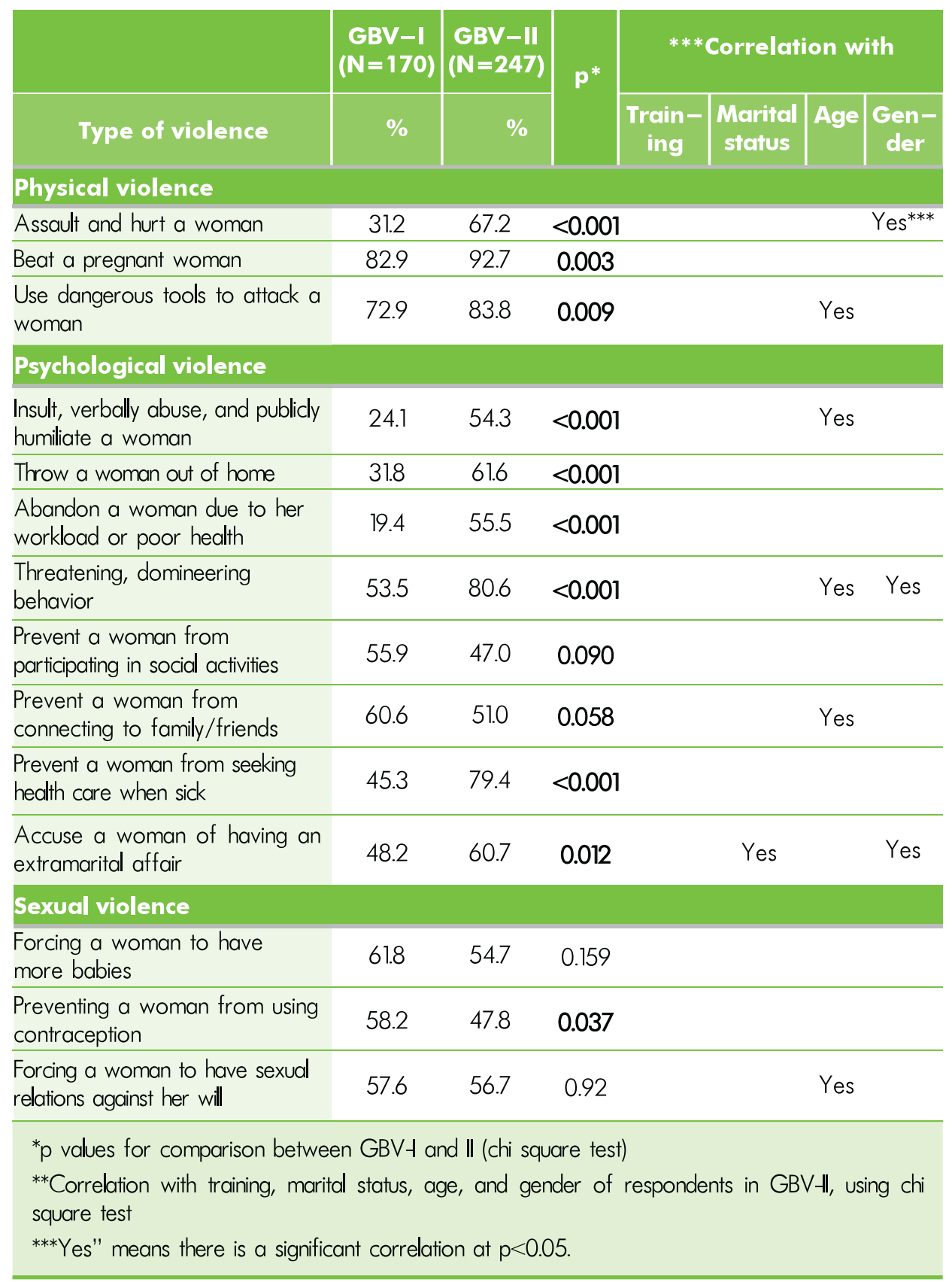


The perception of respondents about trends in domestic violence frequency during the last 5 years is summarized in Figure 3.2. Notwithstanding the 15\% (2005) and almost 20\% (2009) of hospital personnel who answered "cannot evaluate" the trend, there was a significant increase in the number of hospital personnel who said that more women are experiencing domestic violence today: $57.9 \%$ (in 2009) compared to $31.2 \%$ (in 2005). The percentage of hospital personnel who perceived that domestic violence has not increased remained about the same $11.7 \%$ in 2009 compared to $10.0 \%$ in 2005 ). In short, there is a significant higher incidence of violence against women, as perceived by current hospital personnel (2009) compared to in 2005.

Figure 3.2. Perception regarding trends in domestic violence during the last five years

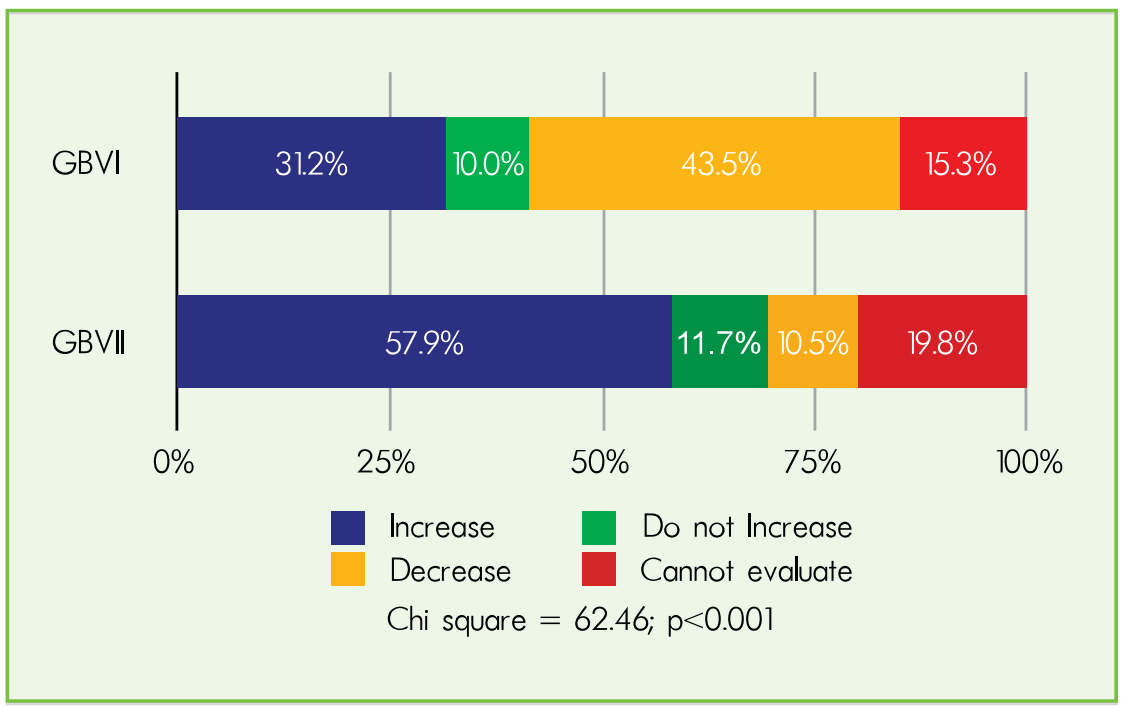

In terms of the type of relationships having the greatest risk of domestic violence, most of the hospital personnel $(88.7 \%)$ considered the wife and husband relationship to be the most vulnerable (see Table 3.6).

\section{Table 3.6. Relationships that lead to domestic violence}

\begin{tabular}{l|c|c}
\multicolumn{1}{c|}{ Relationship } & N & $\%$ \\
\hline Wife and husband & 219 & 88.7 \\
\hline Wife and husband's family & 21 & 8.5 \\
\hline Wife and other women/young girls in the family & 3 & 1.2 \\
\hline No answer/don't know & 4 & 1.6 \\
\hline Total & 247 & 100.0 \\
\hline
\end{tabular}


The Viet Nam Law on Domestic Violence of 2008/9 is much newer than the Viet Nam Law of Marriage and Family issued in 1960. Nonetheless, many cases of violence against women continued to occur because the perpetrators were not always given proper punishment/sanctions, especially where local authorities had no knowledge of these two laws. The
2009 survey showed a significant association between knowledge of laws and GBV training: $86.2 \%$ of hospital personnel who had received GBV training in the last two years said they knew about this law, compared to $53.4 \%$ of those who had not received GBV training (see table 3.7). This was the only significant impact of GBV training.

Table 3.7. Knowledge of legal regulations and GBV training in the last two years

\begin{tabular}{c|c|c|c}
\multirow{2}{*}{$\begin{array}{c}\text { Knowledge of } \\
\text { legel regulations }\end{array}$} & \multicolumn{2}{c|}{$\begin{array}{c}\text { Training in the } \\
\text { last 2 years }\end{array}$} & \multirow{2}{*}{ Total } \\
\cline { 2 - 4 } Yes & $86.2 \%$ & $53.4 \%$ & $61.1 \%$ \\
\hline No & $13.8 \%$ & $46.6 \%$ & $38.9 \%$ \\
\hline Total & $100.0 \%$ & $100.0 \%$ & $100.0 \%$ \\
\hline \multicolumn{4}{c}{$\mathrm{N}=247 ;$ chi square $=20.05 ; p<0.001$} \\
\end{tabular}

Table 3.8 compared hospital personnel's knowledge about which violent behaviors are "punishable" according to the new law (or the earlier marriage (aw), between those interviewed in 2009 GBV$\|$ and those interviewed in 2005 GBV-I. There is an increased knowledge about psychological violence as punishable behavior (36.9\% in 2005 compared to
$58.3 \%$ in 2009); but there is also a decreased percentage of personnel who mention sexual violence as punishable behavior under these laws $191.5 \%$ in 2005 to $76.8 \%$ in 2009). These differences are statistically significant, confirming that knowledge about laws related to GBV is significantly influenced by training. 
Table 3.8. Knowledge of violent behavior punishable according to regulations and law

\begin{tabular}{|c|c|c|c|c|}
\hline \multirow[t]{2}{*}{$\begin{array}{c}\text { Type } \\
\text { of violence }\end{array}$} & \multicolumn{2}{|c|}{$\begin{array}{l}\% \text { "Yes" } \\
\text { response }\end{array}$} & \multirow{2}{*}{$\begin{array}{l}p^{*} \text { value for } \\
\text { comparison } \\
\text { between } \\
\text { GBV-I and } \\
\text { GBV-II }\end{array}$} & \multirow{2}{*}{$\begin{array}{l}\text { Correlation } \\
\text { with training } \\
\text { in the last } \\
2 \text { years in } \\
\text { GBV-II }\end{array}$} \\
\hline & GBV-I & GBV-II & & \\
\hline Physical violence & 85.8 & 80.1 & 0.150 & No \\
\hline Psychological violence & 36.9 & 58.3 & $<0.001$ & Yes** \\
\hline Extramarital affair & 63.8 & 31.8 & $<0.001$ & Yes \\
\hline Sexual violence & 91.5 & 76.8 & $<0.001$ & No \\
\hline
\end{tabular}

\subsubsection{Willingness to Integrate Detection of GBV in Hospital} Services

Table 3.9 shows the extent of hospital personnel's interaction with GBV victims, as recorded in the 2009 survey. Viewing similar groupings of departments that screened the most suspected GBV victims (Table 3.1), one can see that $87.9 \%$ of all hospital personnel have ever met or interacted with a GBV victim (in 2009).

Table 3.9. Extent of interaction with GBV victims by hospital department

\begin{tabular}{|c|c|c|c|c|}
\hline \multirow[b]{2}{*}{$\begin{array}{l}\text { Ever seen } \\
\text { GBV victim }\end{array}$} & \multicolumn{3}{|c|}{ Department grouping } & \multirow[b]{2}{*}{ Total } \\
\hline & $\begin{array}{c}\text { Less } \\
\text { frequent } \\
\text { interaction }\end{array}$ & $\begin{array}{l}\text { Frequent } \\
\text { direct } \\
\text { interaction }\end{array}$ & $\begin{array}{l}\text { Frequent } \\
\text { but indirect } \\
\text { interaction }\end{array}$ & \\
\hline Yes & $78.3 \%$ & $92.0 \%$ & $88.0 \%$ & $87.9 \%$ \\
\hline No & $21.7 \%$ & $8.0 \%$ & $12.0 \%$ & $12.1 \%$ \\
\hline Total & $100.0 \%$ & $100.0 \%$ & $100.0 \%$ & $100.0 \%$ \\
\hline \multicolumn{5}{|c|}{$\mathrm{N}=247 ;$ chi square $=7.2 ; \mathrm{p}=0.02$} \\
\hline
\end{tabular}


Table 3.10 shows significant increase of personnel experience dealing with all types of violence. The largest changes in percentages are seen in the psychological and sexual violence categories. This trend confirms that there was a significant increase in the number of Duc Giang Hospital personnel who are willing to deal (and have dealt) with all three types of violence (physical, psychological, and sexual). Considering that only
29.6\% have received prior GBV training while $70.4 \%$ have not (see section 3.2.1), we conclude that training is not the effective factor that produces willingness to screen and provide care to GBV victims. Because most of new hospital personnel are young professionals, age seems to be the change factor here. Compared to the GBV-I survey in 2005, the GBV-\|l survey in 2009 shows statistically significant differences.

Table 3.10. Extent of dealing with physical, psychological, and sexual violence, 2005-2009

\begin{tabular}{|c|c|c|c|}
\hline Physical violence & $\begin{array}{c}\text { GBV-I } \\
(\%)\end{array}$ & $\begin{array}{c}\text { GBV-II } \\
(\%)\end{array}$ & $\mathbf{P}$ \\
\hline Assault and hurt a woman & 81.6 & 93.0 & 0.001 \\
\hline Beat a pregnant woman & 5.7 & 35.5 & $<0.001$ \\
\hline Use dangerous tools to attack a woman & 31.0 & 58.4 & $<0.001$ \\
\hline \multicolumn{4}{|l|}{ Psychological violence } \\
\hline $\begin{array}{l}\text { Insult, verbally abuse, and publicly humiliate } \\
\text { a woman }\end{array}$ & 42.4 & 74.8 & $<0.001$ \\
\hline Throw a woman out of home & 7.0 & 50.9 & $<0.001$ \\
\hline $\begin{array}{l}\text { Abandon a woman due to her workload } \\
\text { or poor health }\end{array}$ & 9.5 & 54.7 & $<0.001$ \\
\hline Threatening, domineering behavior & 10.1 & 46.7 & $<0.001$ \\
\hline $\begin{array}{l}\text { Prevent a woman from participating in } \\
\text { social activities }\end{array}$ & 5.7 & 48.1 & $<0.001$ \\
\hline $\begin{array}{l}\text { Prevent a woman from connecting to } \\
\text { family/friends }\end{array}$ & 3.2 & 49.5 & $<0.001$ \\
\hline $\begin{array}{l}\text { Prevent a woman from seeking health } \\
\text { services when sick }\end{array}$ & 5.7 & 39.9 & $<0.001$ \\
\hline $\begin{array}{l}\text { Accuse a woman of having an } \\
\text { extramarital affair }\end{array}$ & 20.3 & 53.7 & $<0.001$ \\
\hline \multicolumn{4}{|l|}{ Sexudl violence } \\
\hline Forcing a woman to have more babies & 10.1 & 51.9 & $<0.001$ \\
\hline $\begin{array}{l}\text { Preventing a woman from using } \\
\text { contraception }\end{array}$ & 7.0 & 41.6 & $<0.001$ \\
\hline $\begin{array}{l}\text { Forcing a woman to have sexual relations } \\
\text { against her will }\end{array}$ & 20.3 & 44.4 & $<0.001$ \\
\hline
\end{tabular}


Comparing the 2005 GBV- survey and the 2009 GBV-II survey, Table 3.11 shows that the proportion of the hospital staff who witnessed injuries caused by gender-based violence rose significantly for every type of injury. The most common physical injury seen by hospital personnel in the 2009 GBV-II survey was the same as the most common one in the 2005 GBV- survey: external wounds, including black-and-blue marks, scratched skin, and swollen areas $(91.1 \%$ in 2009 , up from $74.7 \%$ in 2005). Reports of more severe iniuries increased dramatically: wound in a dangerous area more than doubled in frequency (from 21.5\% to $46.5 \%)$; and broken leg or arm increased one-and-a-half fold (from $20.3 \%$ to $37.1 \%$ ).

The number of hospital personnel claiming to have seen a miscarriage caused by gender-based violence against a pregnant woman increased more than fourfold (from $5.1 \%$ to $22.5 \%$ ). The number of personnel detecting injuries of internal organs more than doubled (from $13.3 \%$ to $33.8 \%$ ).

Iniury to the genitals was seen by more hospital personnel in 2009, double the number who reported seeing such iniuries in the 2005 survey.

The number of hospital personnel claiming to have seen at least one GBV victim who suffered psychological damage also increased significantly, from 53.8\% in 2005 to $75.6 \%$ in 2009 .

Considering that there is a much smaller proportion of GBV-trained personnel $(29.6 \%)$ than untrained $(70.4 \%)$, this evidence of higher "sensitivity" in detecting GBV-caused physical wounds or psychological distress could be due to the large fraction of "younger" personnel (50\% of the 2009 survey respondents are 30 years old or less).

Table 3.11. Increased proportions of hospital personnel detecting GBV victims, by type of injury, between 2005 and 2009

\begin{tabular}{l|c|c|c}
\multicolumn{1}{c|}{$\begin{array}{c}\text { Type of injury/ } \\
\text { damage }\end{array}$} & $\begin{array}{c}\text { GBV-I } \\
(\%)\end{array}$ & $\begin{array}{c}\text { GBV-II } \\
(\%)\end{array}$ & P \\
\hline $\begin{array}{l}\text { External wound/injury (black and blue, scratches, } \\
\text { or swelling) }\end{array}$ & 74.7 & 91.1 & $<0.001$ \\
\hline Iniury in a dangerous area (head, chest, or abdomen) & 21.5 & 46.5 & $<0.001$ \\
\hline Broken leg or arm & 20.3 & 37.1 & $<0.001$ \\
\hline Miscarriage & 5.1 & 22.5 & $<0.001$ \\
\hline Wound/iniury of an internal organ & 13.3 & 33.8 & $<0.001$ \\
\hline Wound/iniury of genitals & 13.3 & 26.8 & 0.002 \\
\hline $\begin{array}{l}\text { Psychological form of "damage": stress, mental } \\
\text { disorder, fear/panic }\end{array}$ & 53.8 & 75.6 & $<0.001$ \\
\hline
\end{tabular}


In the GBV-II survey (2009), 97.9\% of the 247 respondents said they are aware of the need to collaborate with local authorities, maintaining the high level of the GBV-I survey $195.3 \%$ of 170 interviewed in 2005). When probed, $84.7 \%$ of the respondents in 2009 mentioned the name of a relevant agency that the hospital had collaborated with, compared to $85.3 \%$ being able to do so in 2005.

About two thirds (68.3\%) of the total respondents in the 2009 survey said they had seen instruction manuals for screening, examining, and treating GBV victims in the hospital, and $73.7 \%$ of them had used the instruction manuals.

Almost all (96.4\%) of the 2009 respondents described evidence of efforts to promote GBV protection and control). Nearly all of them used leaflets (98.7\%) and posters (95.4\%).

About two thirds (68.4\%) of the 247 hospital personnel interviewed in the 2009 survey felt that resources to help GBV victims were sufficient. However, among the 78 (31.6\%) who felt that there were insufficient resources, most $(73.1 \%$ or 57) identified insufficient budget as the biggest problem, compared to only $35.0 \%$ of the 2005 survey respondents who complained of insufficient resources (see Table 3.12). A large fraction of respondents who said that local authorities have indequate knowledge about GBV or health care providers lack of the skills to screen and counsel GBV victims. Specific knowledge about these forms of insufficient resources correlates significantly with "received GBV training in the last 2 years."

Table 3.12. Rationalle for saying there were "insufficient resources" for GBV victims

\begin{tabular}{|c|c|c|c|c|}
\hline Rationale & $\begin{array}{l}\mathrm{GBV}-\mathrm{I} \\
\mathbf{N}=60\end{array}$ & $\begin{array}{c}\text { GBV-II } \\
N=78\end{array}$ & $\begin{array}{l}\text { P (GBV-I } \\
\text { versus } \\
\text { GBV-II) }\end{array}$ & $\begin{array}{l}\text { Correlation } \\
\text { with GBV } \\
\text { training in } \\
\text { the last } 2 \\
\text { years }\end{array}$ \\
\hline $\begin{array}{l}\text { Inadequate knowledge of local } \\
\text { government/authorities at } \\
\text { different administrative levels }\end{array}$ & 46.7 & 43.6 & 0.733 & *Yes \\
\hline $\begin{array}{l}\text { Health care providers lack } \\
\text { skills to detect (screen) and } \\
\text { counsel GBV victims }\end{array}$ & 33.3 & 48.7 & 0.083 & Yes \\
\hline $\begin{array}{l}\text { Lack of collaboration among } \\
\text { agencies/sectors/departments }\end{array}$ & 50.0 & 46.2 & 0.732 & Yes \\
\hline $\begin{array}{l}\text { Too weak or too few } \\
\text { sanctions for perpetrators }\end{array}$ & 31.7 & 34.6 & 0.856 & Yes \\
\hline Insufficient budget & 35.0 & 73.1 & 0.552 & Yes \\
\hline Other reasons & 35.0 & 79.3 & $<0.001$ & No \\
\hline
\end{tabular}


Although more respondents in 2009 felt that resources to help GBV victims were sufficient, Table 3.13 indicates a lower willingness (84.5\%) to provide medical examination and treatment to GBV victim, compared to the $92.9 \%$ proportion in the 2005 GBV-I survey. There is a possibility that this decreased level of support can be attributed to the lack of a standard protocol for examining and treating GBV victim, which made new hospital staff (who have not received GBV training) hesitant to treat the physical injuries of GBV victims.
Table 3.13 indicates very high willingness to provide psychological support (98\%) in both the 2009 and 2005 surveys. Willingness to provide "any other support" tripled in 2009 (95.3\%, up from 30.6\% in 2005). "Other" support includes providing information about agencies or related authorities that can help GBV victim, or even giving money, food, or temporary shelter. This result suggests that the current staff of Duc Giang Hospital shows a higher willingness to support GBV victims in 2009, possibly related to the large proportion of younger personnel.

Table 3.13. Types of support that hospital staff are willing to provide

\begin{tabular}{|c|c|c|c|c|}
\hline $\begin{array}{l}\text { Type of } \\
\text { support }\end{array}$ & $\begin{array}{c}\text { GBV-I } \\
(N=170)\end{array}$ & $\begin{array}{c}\mathrm{CBV}-\mathrm{II} \\
(\mathrm{N}=247)\end{array}$ & $\begin{array}{c}\text { P (GBV-I } \\
\text { versus } \\
\text { GBV-II) }\end{array}$ & $\begin{array}{l}\text { Association with } \\
\text { training in the } \\
\text { last } 2 \text { years }\end{array}$ \\
\hline Medical treatment & 92.9 & 84.5 & 0.013 & *No \\
\hline Psychological support & 98.2 & 98.0 & 0.577 & No \\
\hline Other support & 30.6 & 95.3 & $<0.001$ & No \\
\hline \multicolumn{5}{|c|}{ *No: no correlation with recent GBV training } \\
\hline
\end{tabular}


Table 3.14 shows that hospital personnel interviewed in 2009 expressed the need to have a standard protocol on how to screen and treat GBV victims, as well as a protocol to collaborate with local authorities and detect psychological "damage" that could be attributed to GBV. These expressed needs for protocols correlate significantly with having received GBV training in the last 2 years.

No significant correlation was found between age or training and desire for a protocol about: counseling, provision of information about violence against women (VAW), legal advice relating to VAW, and "other" issues.

Table 3.14. Types of standard protocol perceived as necessary, in relation to training

\begin{tabular}{|c|c|c|c|c|c|}
\hline \multirow[b]{2}{*}{$\begin{array}{l}\text { Type of protocol } \\
\text { needed }\end{array}$} & \multirow{2}{*}{$\begin{array}{c}\text { CBV-I } \\
(2005) \\
N=154 \\
(\%)\end{array}$} & \multirow{2}{*}{$\begin{array}{c}\text { GBV-II } \\
(2009) \\
N=229 \\
(\%)\end{array}$} & \multirow{2}{*}{$\begin{array}{l}\text { P value } \\
\text { (GBV-I vs } \\
\text { GBV-II) }\end{array}$} & \multicolumn{2}{|c|}{ Correlation } \\
\hline & & & & $\begin{array}{l}\text { Age } \\
\text { group }\end{array}$ & $\begin{array}{c}\text { Training in } \\
\text { the last } 2 \\
\text { years }\end{array}$ \\
\hline Screening GBV victim & 30.5 & 31.9 & 0.823 & *No & *Yes \\
\hline Treating GBV victim & 38.3 & 31.9 & 0.228 & No & Yes \\
\hline $\begin{array}{l}\text { Collaboration with } \\
\text { authorities }\end{array}$ & 25.3 & 22.3 & 0.539 & No & Yes \\
\hline $\begin{array}{l}\text { Detecting consequences } \\
\text { of psychological violence }\end{array}$ & 28.6 & 17.9 & 0.017 & No & Yes \\
\hline Counseling GBV victim & 83.1 & 56.8 & $<0.001$ & No & No \\
\hline $\begin{array}{l}\text { Providing information on } \\
\text { violence against women }\end{array}$ & 35.1 & 34.5 & 0.913 & No & No \\
\hline $\begin{array}{l}\text { Legal advice relating to } \\
\text { violence against women }\end{array}$ & 59.1 & 42.1 & 0.001 & No & No \\
\hline Other & 13.6 & 63.3 & $<0.001$ & No & No \\
\hline \multicolumn{6}{|c|}{$\begin{array}{l}\text { *Yes: there is a significant correlation with training (2009 GBV-II) at } p<0.05 \text {, } \\
\qquad \text { *No: no correlation with GBV training }\end{array}$} \\
\hline
\end{tabular}


When respondents were asked about future recommendations, they gave the suggestions described in Table 3.15. The three strongest recommendations were: educate the community about gender equality principles (51.6\%); educate men about GBV issues (50.4\%); and subject perpetrators to stricter sanctions (50\%). The specific recommendations (other than educating men) are generally associated with having had GBV training in the last two years, including recommendations for inter-sector collaboration and women's empowerment.

Table 3.15. Recommendations to improve awareness of GBV

\begin{tabular}{|c|c|c|c|c|c|}
\hline \multirow[b]{2}{*}{ Recommendations } & \multirow[b]{2}{*}{$\begin{array}{c}C B V-1 \\
N=170 \\
(\%)\end{array}$} & \multirow[b]{2}{*}{$\begin{array}{c}\text { CBV-II } \\
N=247 \\
(\%)\end{array}$} & \multirow[b]{2}{*}{$\begin{array}{l}\text { P (GBV-I } \\
\text { versus } \\
\text { GBV-II) }\end{array}$} & \multicolumn{2}{|c|}{ Correlation } \\
\hline & & & & $\begin{array}{l}\text { Age } \\
\text { group }\end{array}$ & $\begin{array}{c}\text { Training in } \\
\text { the last } 2 \\
\text { years }\end{array}$ \\
\hline Inter-sector collaboration & 52.4 & 36.3 & 0.002 & *No & *Yes \\
\hline $\begin{array}{l}\text { Educate men about GBV } \\
\text { issues }\end{array}$ & 44.1 & 50.4 & 0.233 & No & No \\
\hline $\begin{array}{l}\text { Stricter sanctions for } \\
\text { perpetrators }\end{array}$ & 47.6 & 50.0 & 0.620 & No & Yes \\
\hline $\begin{array}{l}\text { Educate the community } \\
\text { about gender equality } \\
\text { principles }\end{array}$ & 66.5 & 51.6 & 0.002 & No & Yes \\
\hline $\begin{array}{l}\text { Support women's } \\
\text { roles and women's } \\
\text { empowerment }\end{array}$ & 58.2 & 41.1 & 0.001 & No & Yes \\
\hline Other & 33.5 & 85.6 & $<0.001$ & No & No \\
\hline
\end{tabular}




\subsubsection{WCCH and Hos- pital Quarterly Reports}

In 2003, Duc Giang Hospital opened a Women's Center for Counseling and Health Care (WCCH). At that time, PCVN's technical assistance focused on improving the counseling skills of the Head of WCCH and expanding the use of GBV screening (yellow) forms and physical examination (green) forms by training staff in other departments of the hospital. Beginning with Phase II, PCVN has recommended the use of "synthesis tables." These tables provide quantitative data for the quarterly reports submitted routinely to HHD. The synthesis tables categorize GBV victims aged $15+$ by: type of abuse (DV, child sexual abuse, and rape); age group (15-24, 2544, and 45+); and marital status. The synthesis tables are compiled by various departments.

The HHD approved the GBV screening form and the use of synthesis tables during the first quarter of 2007. It has been agreed that these quarterly reports should continue to apply evidencebased indicators of hospitals' willingness to integrate GBV screening into their services. The data track trends among the GBV victims who visit the hospital over the years, according to type and frequency of GBV, and indicate the percent of victims found among all female patients aged 15+. Using these regular quarterly reports, the HHD can monitor the level of improvement in integrating GBV into hospital services, as well as track case-management, planning, and budgeting improvements.

Data prior to April 2007 are somewhat unreliable, due to under-reporting of GBV cases (poor screening), especially in over-crowded departments such as ophthalmology, dentistry, and internal medicine, where the examination rooms tend to have multiple patients and thus lack the privacy that is essential for screening GBV victims. In April 2007, PCVN and HHD revised the synthesis tables and clarified guidelines on how to report GBV indicators correctly. As part of this evaluation, PCVN requested access to Duc Giang Quarterly Report data from April 2007 to October 2009 (evaluation survey collection time). The findings are described in this section of our report.

\section{WCCH Quarterly report (2003- 2009)}

Between March 2003 and October 2009, a total of 4,515 women clients presented to $\mathrm{WCCH}$. These women then made a total of 9,375 visits to the $\mathrm{WCCH}$, an average of roughly two visits per person.

\section{The activities of WCCH with the clients}

Figure 3.3 indicates that the number of women presenting to $\mathrm{WCCH}$ increased rapidly between 2004 and 2005 , then at a slower pace between 2005 and 2008. The increase became rapid again at the beginning of 2008 and was still robust when the survey 
ended in October 2009. There is with average of 384 per quarter in about 3 fold increase in GBV victims 2009.

Figure 3.3. Number of women visiting $\mathbf{W C C H}$, by year and reason for attendance

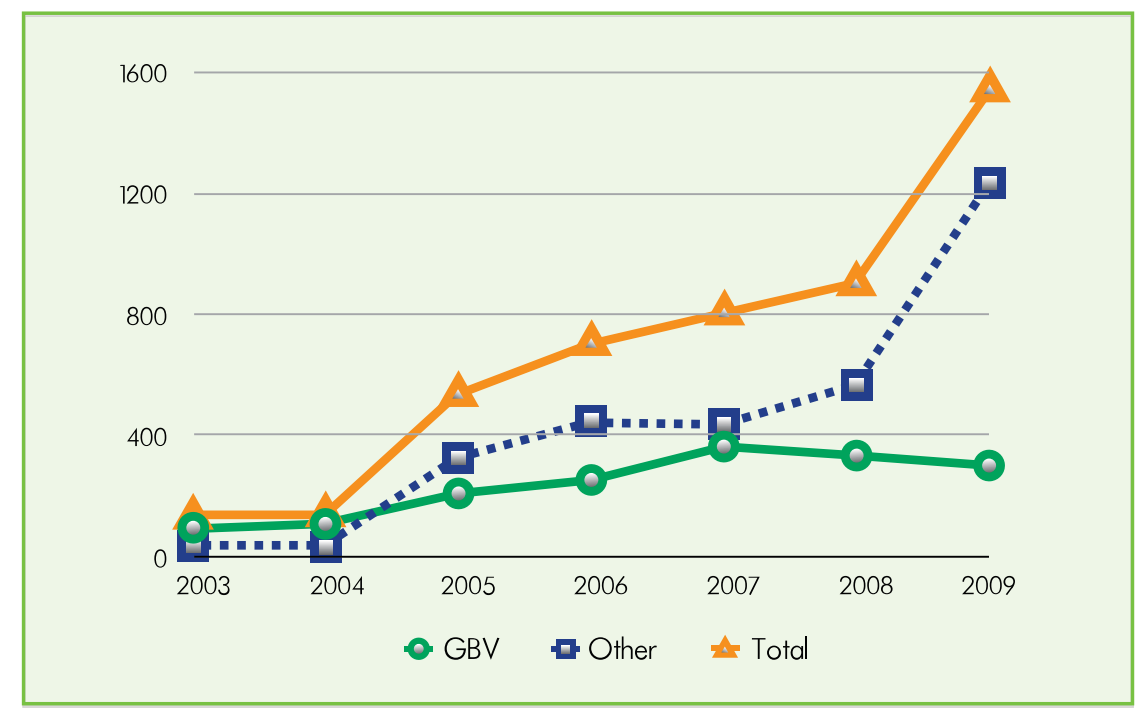

We made a comparison of women who visited $\mathrm{WCCH}$ before and after the 2007 implementation of the Hospital Quarterly Report for $H H D$. The mean number of women visiting per year was calculated for three full years $(2004,2005$, 2006) when quarterly reports were not officially mandated, and then compared to the first two years (2007 and 2008) that occurred after the quarterly report was officially mandated. Figure 3.4 shows that the mean annual number of women visiting to the $\mathrm{WCCH}$ almost doubled (84\% rise from 467 to 860 per year) after the Quarterly Report was mandated in 2007. 
Figure 3.4. Mean number of women who presented to WCCH annually, before/after 2007

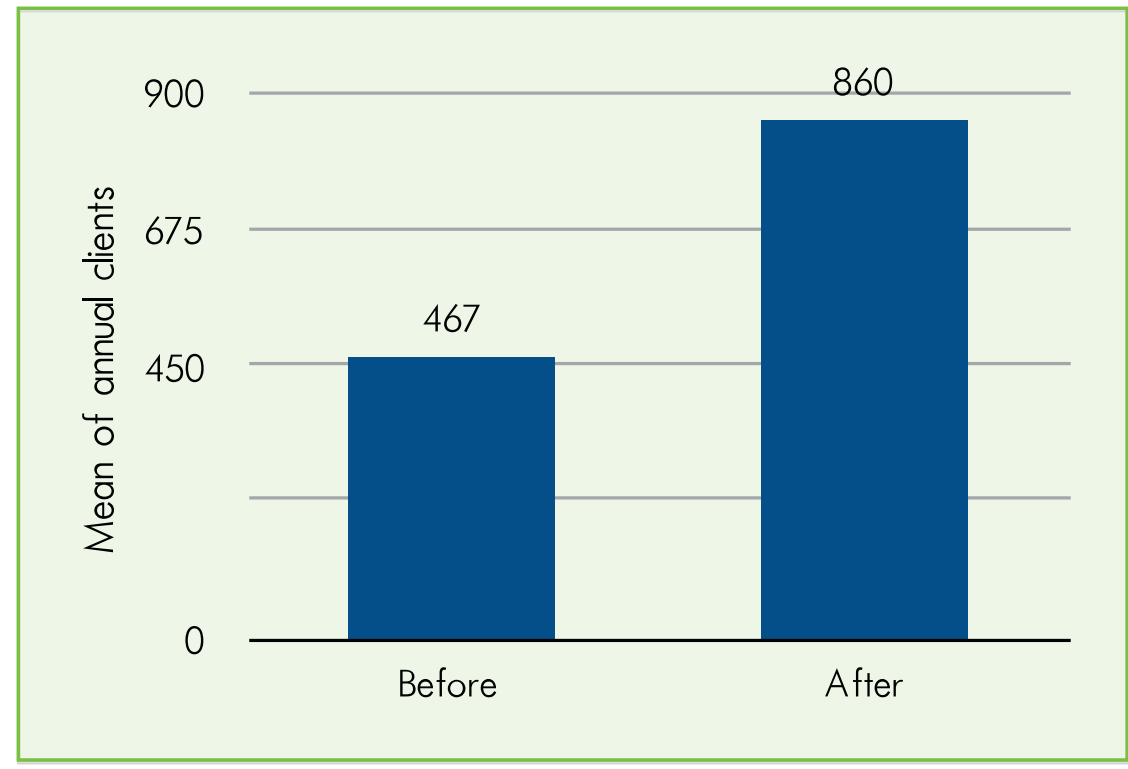

Figure 3.5 outlines the composition trained $\mathrm{CHC}$ s or other agents in the of women who presented to WCCH GBV project's intervention areas by place of origin. Approximately only accounted for about 6\%, and $80 \%$ of them were from nontends to decrease. Besides these project communes. In contrast, the percentage of women referred by two places, about $14 \%$ of women came from other provinces.

Figure 3.5. Place of origin of women attending WCCH for GBV by year

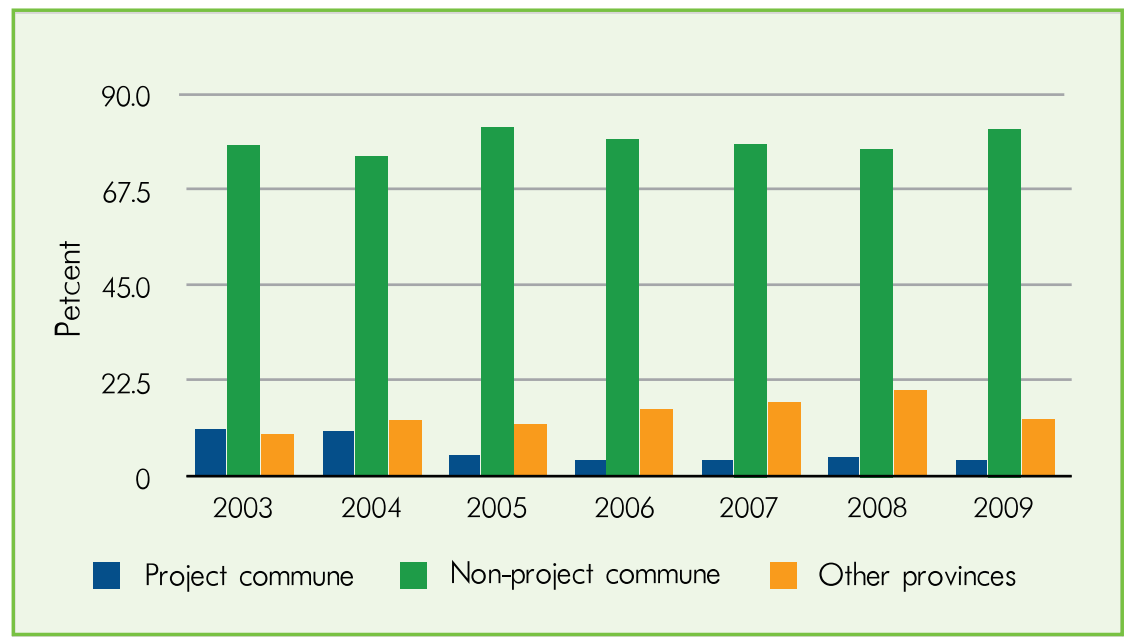




\section{We suggest three possible explanations for this}

counter-intuitive trend:

- $\mathrm{CHCs}$ that have trained personnel to screen GBV handled GBV victims by themselves. They felt capable to do so and did not refer women to $\mathrm{WCCH}$. Moreover, there are only 6 project communes out of a total 577 communes and districts in $\mathrm{Ha} \mathrm{Noi}$;

- Training and campaigning materials about GBV were disseminated more widely than expected, reaching other neighbourhood communes and increasing their awareness about types of GBV and where to seek help;

- WCCH has been widely covered by the mass media, with its Head sharing his experiences with the public through television and radio talk shows. As a result, the project intervention coverage reached other communes and even other provinces. 
The Quarterly Report data show that the two most common reasons for seeking help from the hospital are: domestic violence (33\%) and sexual and reproductive health consultation (32\%). Other reasons (as stated in Law on DV Prevention and Control (2007) such as causing damage to property) accounted for $25 \%$, and "worry about HIV/ AIDS" 6\%. A small fraction (1\%) "reported being raped" and about $2 \%$ indicated "other type of violence." The increase in total number of women was mostly due to a large increase in number of women attending for "other" which is sexual and reproductive health consultation reasons - more than 30 fold increase since 2003 and the number in 2009 double that seen in 2007 (see Figure 3.6).

\section{Figure 3.6. Women attending WCCH by reason for attendance}

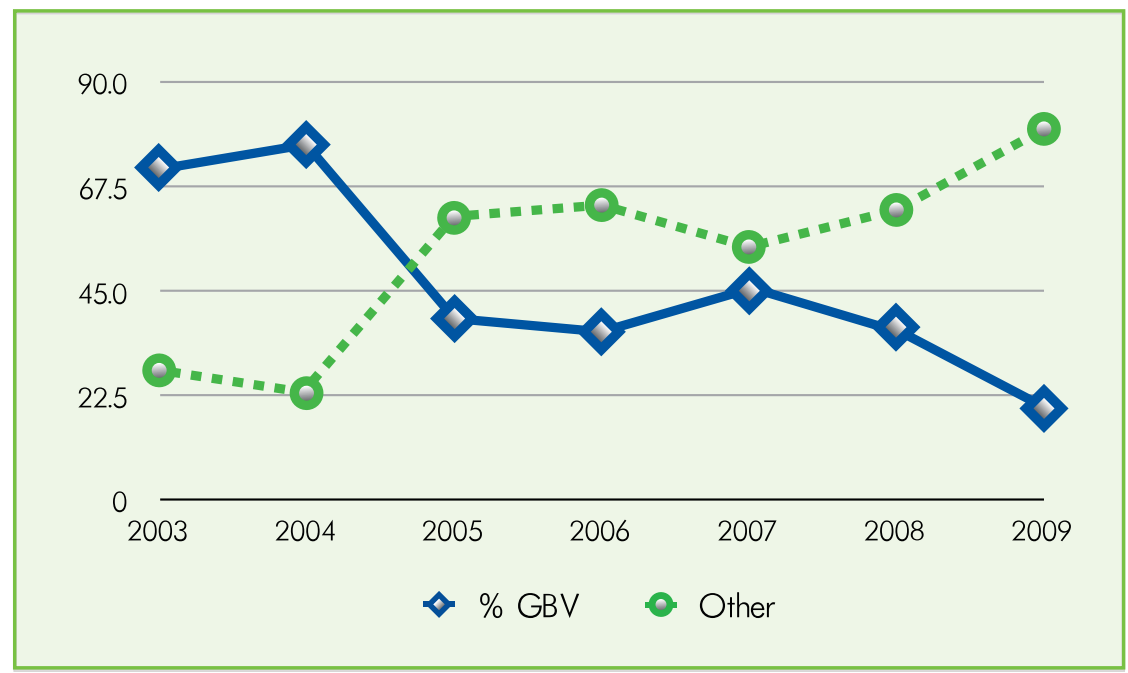

Figure 3.7 shows that most women screened are in the age range 2029 years (39\%), followed by $30-$ 39 (25\%), and then 40-49 (23\%). Although secondary data from the Quarterly Reports did not allow us to cross-tabulate the reasons for seeking WCCH consultation with age, these percentages suggest that the younger women ( $<29$ years old) is the larger age group who visited the hospital for consultation about sexual and reproductive health.
Figure 3.7. Age of WCCH clients

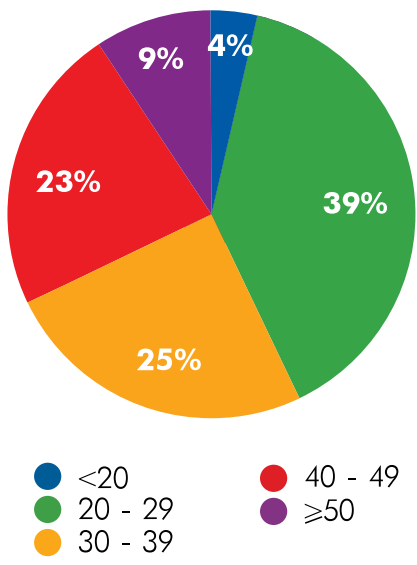




\section{The activities of WCCH with GBV clients}

Figure 3.8 shows that the annual total screened GBV victims presenting to $\mathrm{WCCH}$ increased rapidly from 2003 to 2007, but then decreased through the end of the study period.

Figure 3.8. Number of screened $\mathrm{GBV}$ victims receiving counselling from WCCH, 2003-2009

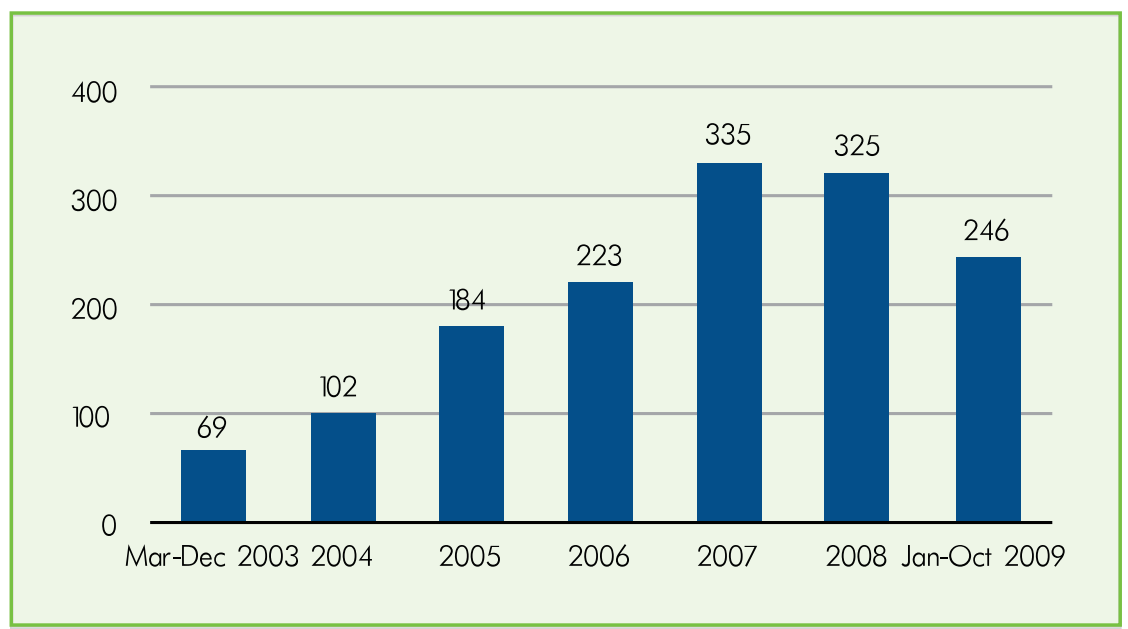

However, making the submission of a Quarterly Report mandatory exerted a significant effect on detection of victims.
Figure 3.9 shows that the average monthly number of screened GBV victims virtually doubled from 14 to 27 after the official introduction of the Quarterly Report in 2007.

Figure 3.9. Average monthly screened GBV victims, before/after GBV project implementation

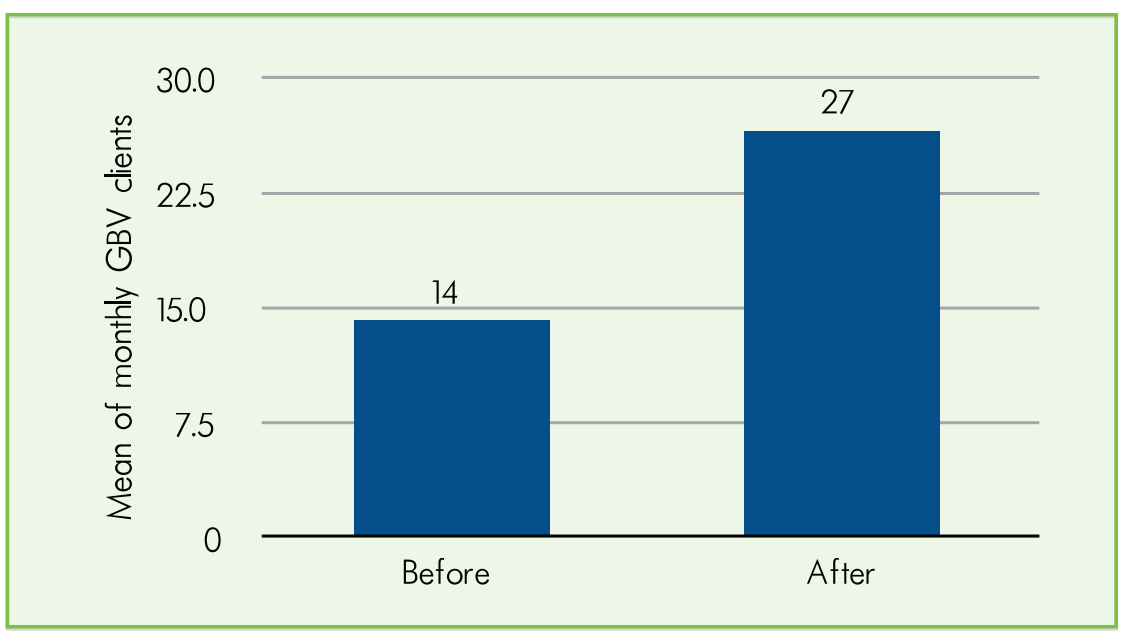


Table 3.16 shows that most of women (78.5\%) who visited WCCH worked as farmers or employees in the public or private sector. A significant number (18.5\%) were entrepreneurs, and only a few of the women reported being housewives (3.0\%) who did not work outside their house. Women aged 30-39 experienced the highest rates of GBV, followed by women aged $40-49$ years. The youngest age group 20-29 years accounted for $23.5 \%$ of victim, possibly because this group may not be assertive enough to seek help from the health sector. Over $77 \%$ of the victims had either primary or secondary school education, and an additional $21 \%$ had tertiary education.

Table 3.16. Characteristics of Screened GBV Victims, by occupation, age group, and educational level

\begin{tabular}{lcc}
\hline Occupation & (n) & $\%$ \\
\hline Farmer & 418 & 28.2 \\
\hline Employee & 746 & 50.3 \\
\hline Small business owner & 275 & 18.5 \\
\hline Housewife & 44 & 3.0 \\
\hline Student & 1 & 0.1 \\
\hline Total & 1484 & 100.00 \\
Age group (years) & 1 & \\
$<20$ & 349 & 0.1 \\
\hline $20-29$ & 516 & 23.5 \\
\hline $30-39$ & 473 & 34.8 \\
\hline $40-49$ & 145 & 31.9 \\
\hline$>=50$ & 1484 & 100.0 \\
\hline Total & & \\
Educational level & 18 & 1.2 \\
\hline No formal education & 577 & 38.9 \\
\hline Primary or junior high school & 577 & 38.9 \\
\hline Senior high school & 312 & 21.0 \\
\hline College/University & 1484 & 100 \\
\hline Total & & \\
\hline
\end{tabular}


The Quarterly Report data from March 2007 to March 2009 documented physical violence as the most frequent (46.2\%) type reported, followed by psychosocial violence $(43.8 \%)$, economic and other $(6.1 \%)$ and sexual violence (3.9\%) (see Figure 3.10)

Figure 3.10. Reports of violence $(\mathrm{N}=2,722)$ by type, March 2003 to Oct 2009

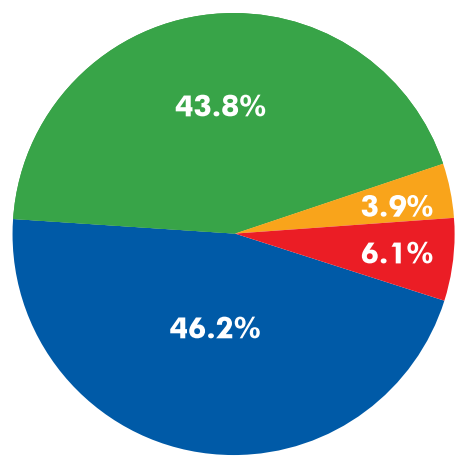

- Physical violence

- Psychosocial violence

- Sexual violence

- Economic and others
Hospital Quarterly report (2007-2009)

Between March 2007 and March 2009, Duc Giang Hospital screened 67,970 women visitors. A majority $(81.3 \%)$ of those screened were married women. During 8 quarters, only $104(0.15 \%$ of total women visitors) were judged to be GBV victims. The number of detected victims and victims referred to WCCH by quarter is presented in Figure 3.11. Both the number of detected victims and the number of victims referred to $\mathrm{WCCH}$ tend to decrease. Of these 104 victim, 76.0\% experienced domestic violence; $19.2 \%$ suffered from sexual violence (including three cases of sexual assault); and $4.8 \%$ experienced other types of GBV. About $61.5 \%$ of these GBV victims were referred to the $\mathrm{WCCH}$.

Figure 3.11. Number of detected GBV victims and number referred to WCCH by quarter (Q)

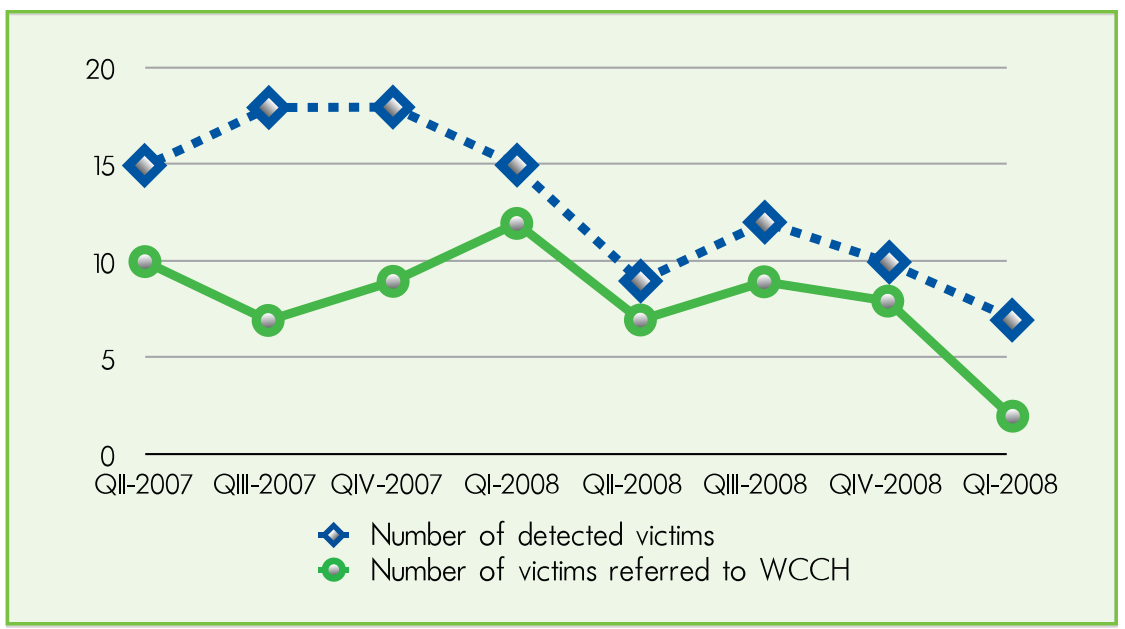




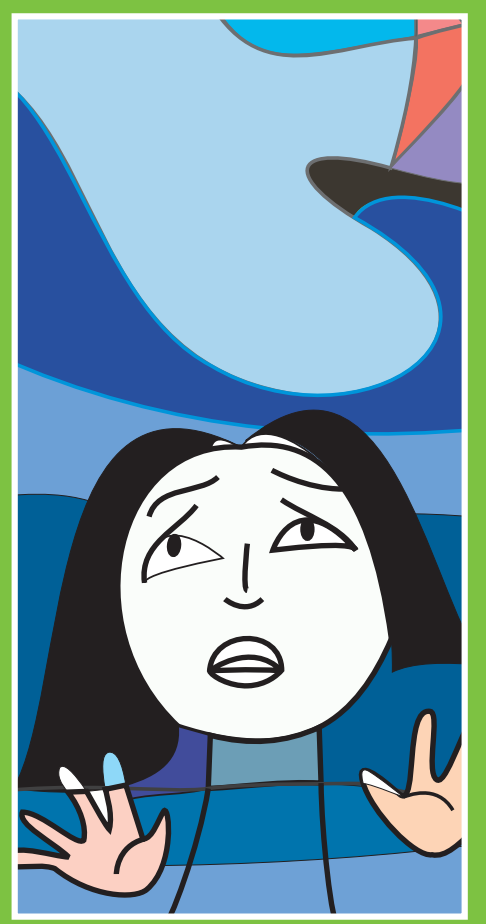

Chapter 4

CONCLUSIONS 



\subsection{QUALITATIVE FINDINGS}

\subsubsection{Among GBV vic- tims}

The Women's Center for Counseling and Health (WCCH) has obviously had a positive impact on GBV victims who sought help from Duc Giang Hospital

Although women still see GBV as a problem that should be "tolerated" and men or family members still consider it a private family matter, the counseling received from $\mathrm{WCCH}$ can change GBV victims' awareness of their rights to protection, treatment, and other legal rights. In a couple of visits alone, a GBV victim could be turned into a GBV survivor. Women stated that WCCH provided not only counseling but also knowledge about strategies to protect themselves and understanding about their legal rights, including how to approach the law enforcement and justice sector officials.

Other than this remarkable change, the fate of a GBV victim remains grim. Women, especially from rural areas, have no knowledge about the new (2007) Law on Domestic Violence. Most incidents of physical violence were severe; women suffered from repeated violent acts that typically began during the first years of marriage. The pattern of physical and sexual violence is associated with three main factors: low educational levels of women and their partners/ husbands; men having more than one wife/partner concurrently; and low household income due to husband/partner having low occupational status together with taking drugs and/or gambling.

\subsubsection{Among hospital staff and among commu- nity officers and members of civil society organiza- tions (CSOs) in project intervention sites}

Overall, there is an increase of awareness in relation to forms of violence, causes, and consequences, and this led to greater willingness to integrate GBV screening in hospital procedures

There is wide understanding amongst hospital and commune level staff of the types and consequences of gender-based violence, in particular the severity of domestic violence suffered by women and children. This has built a basis for greater willingness to integrate GBV screening into daily medical practice. Staff at hospital and commune level recognized that gender-based violence (GBV) includes all types: physical, sexual, mental, and social. 
In line with increased awareness, staff at hospital and commune level have greater demand for a practical guideline/protocol to help with implementation of the Law on Domestic Violence into daily medical practice, and to develop a network with local authorities such as the police and justice system.

Increased awareness and greater willingness to treat GBV victims are in conflict with awareness of existing obstacles to integrate GBV screening in daily medical practices.

Hospital and commune health center staff as well as key community leaders such as the Women's Union, People's Committee, and Court staff at commune level expressed the need for protocols that focus on legal requirements. Training materials for health staff should focus on how to identify the symptoms of violence apart from physical violence. Protocol with clear referral paths will attract hospital staff with high workload.

Many hospital staff with awareness and willingness to treat GBV victims are still unclear about how to proceed, especially when families are reluctant to admit the problem; they felt there was not enough legal ground and resources. The approval of family members is still needed as family members are responsible for financial support to cover the hospital cost, and doctors do not have the legal power to retain a GBV victim in in-patient care.

Cost and provision of a safe place to protect the GBV victim from the perpetrator are the other main obstacles for the hospital staff.

Opinions about the 2007 Law on Domestic Violence Prevention and Control.

The new Law on Domestic Violence Prevention and Control (2007) is seen by health care providers as an important advance. However, the Law is perceived as not strong enough to empower local authorities and non-health sectors, such as the police and justice system to deal with the perpetrator (husband or partner). Because many local institutions, such as the police force and court personnel, have a low understanding about the Law, many commune authorities still rely on the existing "reconciliation groups" headed by the Commune People's Committee; but these groups also have limited professional training about GBV, and group members tend to advise GBV victims to maintain silence. A more practical guideline/protocol on the new Law for use by local groups is needed.

Educating the public is of paramount importance as many Vietnamese women living in rural districts have not heard about the new Law on Domestic Violence Prevention and Control (2007). 
Acceptance of the role of the Women's Center for Counseling and Health (WCCH).

Respondents recognized that the WCCH at Duc Giang hospital has gained wide acceptance by GBV victim, police and court personnel, and from the media as an important resource. Nowadays, many GBV victims prefer to initially present to WCCH rather than to the police, court or community reconciliation group.

There is no doubt that WCCH has gradually built a comprehensive approach to GBV by networking and developing the capacity of the law enforcement and justice sector officers, in parallel with other project components that focus on raising public awareness about domestic violence and the right of women to live in a household free of violence.

The existence of WCCH has strengthened Duc Giang hospital's role in anti-violence against women, from the national to the grassroots levels. The WCCH database could provide public education materials to be delivered through talk-shows, films, trainings, seminars, and other methods to reinforce community support for GBV victims. 


\subsection{QUANTITATIVE CHANGES}

The Duc Giang Hospital expanded its scope of work and number of staff between 2006 and 2009. This expansion and recruitment of new staff have resulted in a small proportion of GBV trained staff (29.6\%). In-house training could not keep pace with the expansion of staff.

However, since most of the new staff members are young, with the sample showing that $50 \%$ of the respondents are 30 years or less, Duc Giang Hospital personnel show a high level of awareness of GBV issues, regardless of gender, age, marital status, and prior GBV training.

An increasing proportion of staff members recognize violent behavior against women. Considering that only $29.6 \%$ of the total sample had received GBV training, this change is not directly influenced by prior training. More evident is that the age of staff is an important variable in shaping their perceptions around gender-based violence issues. The younger the personnel, the more sensitive they are in recognizing violent behavior against women.

However, training has some effect on respondents' knowledge of types of psychological and sexual violence. Regarding physical violence, all interviewed respondents recognized easily the three common types listed in the questionnaire. The previous survey in 2005 already reached $100 \%$ (maximum score) on knowledge about physical violence and the same level was maintained in the 2009 survey.

Compared to the 2005 survey findings, hospital personnel are now (2009) more informed about differentiating the severity of health consequences between "very serious" and "serious", with fewer responses in the "not serious" or "do not know" categories. The fraction of current hospital personnel who thought that certain violent acts such as "hit, choke, slap, push, and kick a woman" should be categorized as "serious severity of physical violence" doubled from $31 \%$ (in 2005) to $67 \%$ (in 2009).

Remarkably, the largest percentage increases are seen in psychological and sexual violence categories, approximately $30 \%$ or higher among those answering all subquestions. This indicates a much higher sensitivity for recognizing the serious health consequences of psychological and sexual violence.

There was a significant increase in the number of hospital staff who said that more women are experiencing domestic violence today: $57.9 \%$ 
(in 2009) compared to $31.2 \%$ (in 2005). And more hospital staff in 2009 had ever met or interacted with GBV victims than in 2005.

Training shows a significant association with specific knowledge about the new Law: $86.2 \%$ of hospital personnel who had received GBV training in the last two years said they know about types of violence mentioned in this law, compared to $53.4 \%$ of those who stated that they "had not" received GBV training (see Table 3.7).

Between those interviewed in 2009 GBV-\|l and those interviewed in 2005 GBV-I, there is an increase in knowledge about psychological violence as punishable behavior (36.9\% in 2005 compared to $58.3 \%$ in 2009); but there is also a decreased percentage of personnel who mention sexual violence as punishable behavior under these laws $(91.5 \%$ in 2005 to $76.8 \%$ in 2009). These differences confirm that knowledge about laws related to GBV is significantly influenced by training.

Only $29.6 \%$ of survey respondents indicated having attended official GBV "training" organized by HHD; however, hospital records show that 91.1\% have been given professional briefings about GBV as a regular in-house event (see section 3.2.1). It is difficult to conclude whether training has directly affected the willingness of staff to screen and provide care to GBV victims. However, we can conclude that the products of the previous training, such as the yellow and green forms and protocols that mandate all departments to use them, have indirect effects that, combined with the decrease in staff age, are the change factor here. Compared to the GBV-I survey in 2005, the GBV-II survey in 2009 shows a statistically significant increase in the number of Duc Giang Hospital personnel who are willing to deal (and have dealt) with all three types of violence (physical, psychological, and sexual). About two thirds $(68.3 \%)$ of the total respondents in the 2009 survey said they had seen instructions for screening, examining, and treating GBV victims in the hospital, and $73.7 \%$ of them had used the instructions. Almost all (96.4\%) of the 2009 respondents described evidence of efforts to promote GBV protection and control. The overwhelming majority of them used leaflets $(98.7 \%)$ and posters (95.4\%).

Furthermore, compared to the 2005 GBV-I survey, the 2009 GBV-II survey found that the proportion of the hospital staff who witnessed injuries caused by gender-based violence rose significantly for all types of injury. Reports of more severe injuries increased dramatically: wounds in a dangerous area more than doubled in frequency (from 21.5\% to $46.5 \%)$; and broken leg or arm increased one-and-a-half fold (from $20.3 \%$ to $37.1 \%$ ). The number of hospital personnel claiming to have seen a miscarriage caused by gender-based violence against 
a pregnant woman increased more than fourfold (from $5.1 \%$ to $22.5 \%$ ). The number of personnel detecting injuries of internal organs more than doubled (from $13.3 \%$ to $33.8 \%$ ). Injury to the genitals was seen by more hospital personnel in 2009, double the proportion who reported seeing such injuries in the 2005 survey. The proportion of hospital personnel claiming to have seen at least one GBV victim who suffered psychological damage also increased significantly, from 53.8\% in 2005 to $75.6 \%$ in 2009 .

Again, considering that there is a much smaller proportion of GBVtrained personnel (29.6\%) than untrained $(70.4 \%)$, this evidence of higher sensitivity in detecting GBV-caused physical wounds or psychological distress could be due to the large fraction of young personnel $150 \%$ of the 2009 survey respondents are 30 years old or less).

Training seems to correlate significantly with acquiring specific knowledge such as the need for more resources, and the GBVtrained staff have higher awareness that insufficient budget is an important problem (see Table 3.12). The GBV-trained staff also were able to point out that local authorities have inadequate knowledge about GBV, and health care providers lack the skills to screen and counsel GBV victims. Specific knowledge about these forms of insufficient resources correlates significantly with "received GBV training in the last 2 years."
Overall, there is a very high willingness to provide psychological support (98\%) in both the 2009 and 2005 surveys. Willingness to provide "any other support" tripled (95.3\%, up from $30.6 \%$ in 2005 ). "Other" supports includes providing information about agencies or related authorities that can help GBV victim, or even giving money, food, or temporary shelter (see Table 3.13). This result suggests that the current staff of Duc Giang Hospital show a higher willingness to support GBV victims in 2009, possibly related to the large proportion of younger personnels.

Higher awareness among hospital personnel interviewed in 2009 led to greater need expressed to have an updated standard protocol on how to screen and treat GBV victim, as well as a protocol to collaborate with local authorities and detect psychological "damage" that could be attributed to GBV. These expressed needs for protocols also correlate significantly with having received GBV training in the last 2 years.

Consistent with the findings from the qualitative study, the WCCH plays an important role in promoting GBV awareness and providing support to GBV victims. This is confirmed by the rapid increase in the number of woman seeking consultation at the WCCH from 2003 to 2008 - the number increased by more than 100 cases each year.

In a comparison between the years before and after the implementation 
of the project in 2007, the number of clients presenting to $\mathrm{WCCH}$ almost doubled. It is interesting to note that $80 \%$ of women attending WCCH were from non-project areas, and only 6\% from areas covered by the project. Domestic violence $(33 \%)$ and concerns of sexual and reproductive health (32\%) are two main reasons for women to visit $\mathrm{WCCH}$.

The Quarterly Reports on GBV screening at Duc Giang were available from March 2007 to March 2009. During this period, 67,970 women visitors were screened for GBV. A majority $(81.3 \%)$ of those screened were married women. Overall, more than $90 \%$ of GBV attendances at $\mathrm{WCCH}$ are for reasons of "domestic violence"; $80 \%$ of women attending WCCH for GBV are from non-project communes. Only $104(0.15 \%$ of total women visitors) women screened at Duc Giang readily admitted that they were GBV victims and the number detected each year tended to decrease. This is a sharp contrast with the overall increase in the number of GBV victims presenting to $\mathrm{WCCH}$. 



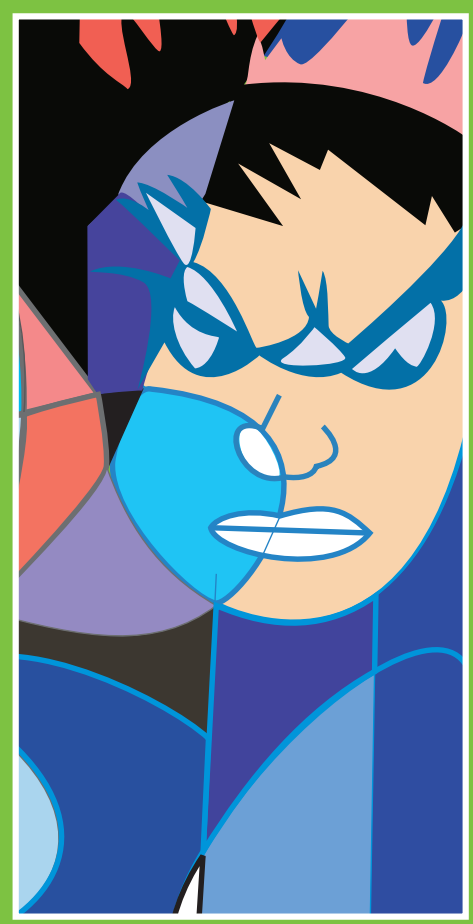

Chapter 5

RECOMMENDATIONS 

The background to these recommendations is the remarkable increase in demand for services on GBV and counseling on sexual and reproductive health in recent years presented in Chapter 3. The main institution for providing these services is the Women's Center for Counseling and Health (WCCH) at Duc Giang hospital, which requires a significant increase in resources if it is to meet the increased demand. Implementing the recommendations below will allow the increased level and quality of services to be provided.

(1) Strengthen $\mathrm{WCCH}$ with particular attention to hospital policies and resources to provide more trained staff, administrative resources and increased training capacity to train other sectors (police, court, community leaders others).

(2) Introduce the WCCH counseling model to other health facilities throughout the country.

(3) Issue regulation to reinforce Article 14 that states the responsibility of related department and authorities for implementing Circular No. 16/2009/TT-BYT.

(4) Training content to integrate GBV prevention and management into daily medical and reproductive health services should be updated to ensure that all staff are aware of the new Law on Domestic Violence (DV)
Prevention and Control No 02/2007/QH12 (effective on July 1, 2008) especially Article 37 on Responsibilities of the Ministry of Health, in addition to previous Law on Gender Equality (2006) and Law on Marriage and Family (2000). This training materials should emphasize $\mathrm{MOH}$ Circular no $16 / 2009$, to meet the rights of domestic violence victims to receive health care and psychological and legal counseling services, and to meet the needs expressed by hospital and commune health staff to have guideline/ protocol that relates to $\mathrm{MOH}$ Circular No 16/2009/TT-BYT:

- Article 2: screening, discovering, ensuring confidentiality

- Article 4: examination and treatment

- Article 5: advice on strategies to prevent, care... and counseling, etc.

- Article 6: safety house (shelters), creating network with police, commune people's committee, GBV victim, HCPs, etc.

- Article 7: mobilization of different sources of funding to cover victims' hospital cost, including health insurance, total or partial exemption by the hospital.

(5) Training should add a session on evidence-based funding or budget proposal based on their statistics of GBV screening and treatment to $\mathrm{MOH}$ Department of Planning and Finance and 
peoples' committee, and to DV coordinator (Family Department) in the Ministry of Culture, Sports and Tourism.

(6) Strengthen monitoring through Quarterly Reports by maintaining a data-base that includes details to allow tabulations by multiple variables (age, education, occupation, residence, type of circumstances when first violence occurred, and other); in adjustment with the $\mathrm{MOH}$ Circular No 16/2009/TT-BYT Article $9 \& 10$ re: provision of GBV statistics, in an integrated health facility report (every six months and annually).

(7) Strengthen the capacity of commune officials, local civil society organizations (including local advocates from commune reconciliation committee) and local commune health staff, with emphasis on specific knowledge, skills and attitudes required to implement the new Law on DV.

(8) Strengthen the capacity of local police and justice (court) officials, with emphasis on rural areas, to handle GBV cases appropriately in accordance with the new Law, using a variety of cost-effective communication approaches.

(9) Carry out periodic populationbased GBV surveys to provide greater understanding of the causes of GBV and estimate the magnitude of GBV problems in the community.

(10) Analyze why cases other than GBV are presenting to WCCH in increased numbers and identify the most effective ways in which the demand for these services can be met. 


\section{REFERENCES}

Asian Development Bank (2005). Viet Nam Gender Situation Analysis. Ha Noi, Asian Development Bank.

Heise, L., J. Pitanguy, et al. (1994). "Violence against Women: The Hidden Health Burden." World Bank Discussion Papers.

Heise, L., M. Ellsberg, et al. (1999). "Ending violence against women." Popul Rep L 27(4).

Jonzon, R., N. D. Vung, et al. (2007). "Violence against women in intimate relationships: explanations and suggestions for interventions as perceived by healthcare workers, local leaders, and trusted community members in a northern district of Viet Nam." Scand J Public Health 35(6): 640-647.

Krantz, G. and D. V. Nguyen (2009). "The role of controlling behaviour in intimate partner violence and its health effects: a population based study from rural Viet Nam." BMC Public Health 9: 143.

Loi, V., VT. Huy, et al. (1999). Gender-based violence: the case of Viet Nam. Ha Noi, World Bank.

Mai, L. T. P. (1998). Violence and its Consequences for Reproductive Health, the Viet Nam case. South \& East Asia Regional Working Papers. Ha Noi, PCVN. 12.

Mai, L. T. P. and K. Landfield (1999). Report on an Intervention Project: Developing Counseling Materials on Domestic Violence for the Ho Chi Minh City Hotline. An internal document. Ha Noi, Population Council Viet Nam.

Nguyen, D. V., P. O. Ostergren, et al. (2008). "Intimate partner violence against women in rural Viet Nam--different socio-demographic factors are associated with different forms of violence: need for new intervention guidelines?" BMC Public Health 8: 55.

Saltzman, L., JL. Fanslow, et al. (1999 (2002 - 2 $2^{\text {nd }}$ Printing with revisions). Intimate Partner Violence Surveillance: Uniform definitions and recommended data elements, Version 1.0. Atlanta (GA), National Center for Injury Prevention and Control, Centers for Disease Control and Prevention, USA.

Saltzman, L. E., Y. T. Green, et al. (2000). "Violence against women as a public health issue: comments from the CDC." Am J Prev Med 19(4): 325-329.

UNDP. (2009, October 20, 2009). "The Human Development Index - going beyond income and Viet Nam HDI Rank - 116. Country Factsheet." Human Development Report Viet Nam 2009, from http://hdrstats.undp.org/en/countries/data_sheets/cty_ds_VNM.html.

UNFPA, Viet Nam (2007). Gender - Based Violence Programming Review. Ha Noi, UNFPA. 
UNICEF, ESCAP, et al. (2001). Report of the East Asia and the Pacific Regional Consultation fro the Second World Congress Against Commercial Sexual Exploitation of Children. Bangkok.

UNICEF EAPRO (2005). Report of the Seventh East Asia and Pacific Ministerial Consultation on Children: Siem Reap, Angkor, Cambodia. Bangkok, UNICEF EAPRO.

Viet Nam Country Progress Report (2004). Draft Report for the Conference on monitoring Viet Nam's Realization of Yokohama Commitment's Objectives and Plan of Action against Commercial Sexual Exploitation of Children. Post-Yokohama Mid-Term Review of the East Asia and the Pacific Regional Commitment and Action Plan against Commercial Sexual Exploitation of Children. CSEC. Bangkok.

Domestic Violence Law means nothing without strong actions. Viet Nam News. Ha Noi, January 15.

General geographical information of Viet Nam. Viet Nam Ministry of Foreign Affairs. (2009, Nov 5, 2009). from http://www.mofa.gov.vn/tt_Viet Nam/geo/.

Vu Song Ha, TA Hoang, et al. (2009). "Domestic Violence in Viet Nam: Situations and Challenges." Health Alert Asia Pacific Newsletter(15).

Vung, N. D., P. O. Ostergren, et al. (2009). "Intimate partner violence against women, health effects and health care seeking in rural Viet Nam." Eur J Public Health 19(2): 178-182.

"Circular No: 16/2009/TT-BYT, guidance on the admission and provision of health care and reporting on patient who are victims of domestic violence at the health facilities", Ministry of Health, 2009, last accessed on Jan 7, 2010 on http://www.moh. gov.vn/homebyt/vn/portal/InfoDetail.jsp?area $=58 \&$ cat $=1544 \& / D=8757$.

"Decree No. 08/2009/ND-CP, detail regulations and guidance on implementing of some articles in the Law on domestic violence prevention and control", 2009, last accessed on Jan 12, 2010 on http://www.chinhphu.vn/portal/page? pageid=33,638900\& dad $=$ portal\&_schema $=$ PORTAL\&docid $=83305$.

Law on Domestic Violence Prevention and Control, 2007, last accessed on Jan 5, 2010 on http://vbappl2.moigov.vn/law/vi/2001_to_2010/2007/200711/20071121000 5_en.

Law on Gender Equality, 2006, last accessed on Oct 14, 2009 on http://vbqppl.moj. gov.vn/law/en/2001_to_2010/2006/200611/200611290009_en.

The Marriage and Family Law, 2000, last accessed on 26 Nov 2009 on http:// vbqppll.moj.gov.vn/law/vi/1991_to_2000/2000/200006/200006090007_en.

UN's Declaration on the Elimination of Violence against Women, 1993, last accessed in Dec 2009 on http://www.unhchr.ch/huridocda/huridoca.nsf/(symbol)/ares.48.104.en. 


\section{ANNEXES}

\section{ANNEX 1. IMPORTANT DEFINITIONS USED IN STUDIES OF GBV}

Researchers have used some terms related to gender-based violence in different ways and, conversely, have used different terms to describe the same acts. To minimize these inconsistencies, this section on Definitions aims to be usable for a wide audience, including policy-makers, researchers, public health practitioners, victim advocates, service providers, and media professionals.

In 2007, the government of Viet Nam issued a Law on Domestic Violence Prevention and Control, which declares that "any intentional action by a family member to cause damage or potentially cause damage in terms of physical, spiritual, and economic damages to another family member" should be categorized as domestic violence and that the Law provides a legal framework for intervening to stop or prevent such an act of violence. For example, explicit criminalization of marital rape gives an important signal regarding the unacceptability of sexual coercion within the family (for more details, see Essential Training Materials - GBV-related Laws as of December 2009).

During the same year, the development of a National Standard Guideline on Reproductive Health also incorporated domestic violence (DV) as a women's health issue. The 2007 Law's definition of DV has been disseminated to the public through nongovernmental organizations (NGOs) as well as the Domestic Violence Prevention Network (Vu Song Ha, et al., 2009).

The United Nations definition of gender-based violence includes "any act that results in, or is likely to result in physical, sexual or psychological harm or suffering to women, including threats of such acts, coercion or arbitrary deprivations of liberty, whether occurring in public or private life" (UN Declaration on the Elimination of Violence Against Women, adopted by the UN General Assembly's 85 th plenary meeting, 20 December 1993)

The WHO 1948 definition of Health is: "... a state of complete physical, mental and social well-being and not merely the absence of disease or infirmity."

Heise et al. (1999) pointed out that, "... gender based" violence evolves in part from women's subordinate status in society. Therefore, any beliefs, 
norms, and social institutions that legitimize a lower status foster violence against women. The same acts that would be punished if directed at an employee, a neighbor, or an acquaintance often go unchallenged when men direct them at women, especially within the family. Gender-based violence can occur at any point in a woman's life. From battering of the mother during pregnancy (with effects on birth outcome), to gender-selective abortion, to female infanticide, to differential access to food and medical care, female circumcision or female genital mutilation, sexual abuse, child prostitution, and child marriage. During adolescence, violence ranges from dating violence to economically coerced sex ("sugar daddies"), sexual abuse in the workplace, rape, sexual harassment, forced prostitution, and trafficking. Within the reproductive age group, additional types of gender-based violence range from abuse of women by intimate partners to marital rape, forced pregnancy, dowry abuse, and psychological abuse, abuse of the disabled and even murder. Abuse of the elderly mostly affects women and widows (Heise et al., 1994).

Intimate Partners Violence (IPV), as specified in the Centers for Disease Control (CDC) and Prevention 2002 Uniform Definitions, refers to victim/ perpetrator relationships among current or former intimate partners (Saltzman et al., 1999-2002).

Victim is a person who is the target of violence or abuse (ibid).

Perpetrator is a person who inflicts the violence or abuse, or causes the violence or abuse to be inflicted, on the victim (ibid).

Intimate Partners include (ibid):

- Current spouses (including common-law spouses),

- Current non-marital partners,

- Dating partners, including first date (heterosexual or same-sex),

- Boyfriends/girlfriends (heterosexual or same-sex),

- Former marital partners,

- Divorced spouses,

- Former common-law spouses,

- Separated spouses,

- Former non-marital partners,

- Former dates (heterosexual or same-sex),

- Former boyfriends/girlfriends (heterosexual or same-sex). 
The term "intimate partners violence" describes physical, sexual, or psychological harm by a current or former partner. This type of violence can occur among heterosexual or same-sex couples and does not require sexual intimacy (Saltzman et al., 1999-2002).

"Sexual exploitation of children and adolescents" refers to the "commercial sexual exploitation of children" defined in the 1996 Stockholm Declaration and Agenda for Action (as "sexual abuse by the adult and remuneration in cash or kind to the child or a third person or persons"). This includes child prostitution, child pornography, and the trafficking of children for sexual exploitation (cited from www.kinderrechte.gv.at/home/upload/downloads/ internationales/agenda_for_action_stockholm-1996.pdf).

Violence is divided into four categories (Saltzman et al., 1999-2002):

- Physical Violence

- Sexual Violence

- Threat of Physical or Sexual Violence

- Psychological/Emotional Abuse (including coercive tactics) when there has also been prior physical or sexual violence, or prior threat of physical or sexual violence.

Physical Violence is the intentional use of physical force with the potential to cause death, disability, injury, or harm. Physical violence includes, but is not limited to: scratching, pushing, shoving, throwing, grabbing, biting, choking, shaking, poking, hair pulling, slapping, punching, hitting, burning, use of a deadly weapon (gun, knife, or other object), use of restraints, or overpowering with one's body size or strength.

Physical violence includes coercing other people to commit any of the above acts. (Saltzman et al., 1999-2002).

Sexual Violence is divided into three categories (Saltzman et al., 1999-2002):

- Use of physical force to compel a person to engage in a sexual act against his or her will, whether or not the act is completed.

- An attempted or completed sex act involving a person who is unable to understand the nature or condition of the act or unable to decline participation by communicating unwillingness to engage in the sexual act (e.g., because of illness, disability, the influence of alcohol or other drugs, or being silenced due to intimidation or pressure).

- Abusive sexual contact. 
Threat of Physical or Sexual Violence is the use of words, gestures, or weapons to communicate the intent to cause death, disability, injury, or harm. Also the use of words, gestures, or weapons to communicate the intent to compel a person to engage in sex acts or endures abusive sexual contact when the person is either unwilling or unable to consent. Examples: "I'll kill you"; "I'll beat you up if you don't have sex with me"; showing a weapon; firing a gun into the air; making hand gestures; reaching toward a person's breasts or genitalia (Saltzman et al., 1999-2002).

Psychological Violence or Emotional Abuse is trauma to the victim caused by acts, threats of acts, or coercive tactics, such as those on the following list (which is not exhaustive). Other behaviors may be considered emotionally abusive if they are perceived as such by the victim. Thus, operational definitions related to psychological violence will need to incorporate victim perception, because it is only considered violence when there has also been prior physical or sexual violence, or prior threat of physical or sexual violence (by this criterion, the number of women experiencing acts, threats of acts, or coercive tactics that constitute psychological/emotional abuse may be greater than the number of women experiencing psychological/ emotional abuse that can also be considered psychological/emotional violence) (Saltzman et al., 1999-2002).

Types of psychological violence can include, among other possibilities:

- Humiliating the victim,

- Controlling what the victim can and cannot do,

- Withholding information from the victim,

- Getting annoyed if the victim disagrees,

- Deliberately doing something to make the victim feel diminished (e.g., less smart, less attractive),

- Deliberately doing something that makes the victim feel embarrassed,

- Taking advantage of or using money that belongs to the victim,

- Disregarding what the victim expressly wants,

- Isolating the victim from friends or family (e.g., prohibiting access to transportation or telephone),

- Inducing the victim to engage in illegal activities,

- Using the victim's children to control the victim's behavior (e.g., threatening loss of custody), 
- Smashing objects or destroying property to cause fear or loss

- Denying the victim access to money or other basic resources

- Disclosing information that would tarnish the victim's reputation

Pattern of Violence is the way that violence is distributed over time in terms of frequency, severity, or type (physical violence, sexual violence, and threat of physical or sexual violence, psychological/emotional abuse).

The Consequences of Violence can be detected in any of the following ways (Saltzman et al, 1999-2002):

- Physical Injury - Any physical damage occurring to the body resulting from exposure to thermal, mechanical, electrical, or chemical energy interacting with the body in amounts or rates that exceed the threshold of physiological tolerance, or from the absence of such essentials as oxygen or heat.

- Disability - Impairment resulting in some restriction or lack of ability to perform an action or activity in the manner or within the range considered normal.

- Psychological Consequences - Consequences involving the mental health or emotional well-being of the victim.

- Medical Health Care - Treatment by a physician or other health care professional related to the physical health of the victim.

- Mental Health Care - Includes individual or group care by a psychiatrist, psychologist, or counselor. 
ANNEX 2. COUNTRY PROFILE: GEOGRAPHY, ROLE OF CIVIL SOCIETY ORGANIZATIONS, AND VIET NAM SOCIAL DEVELOPMENT STATUS

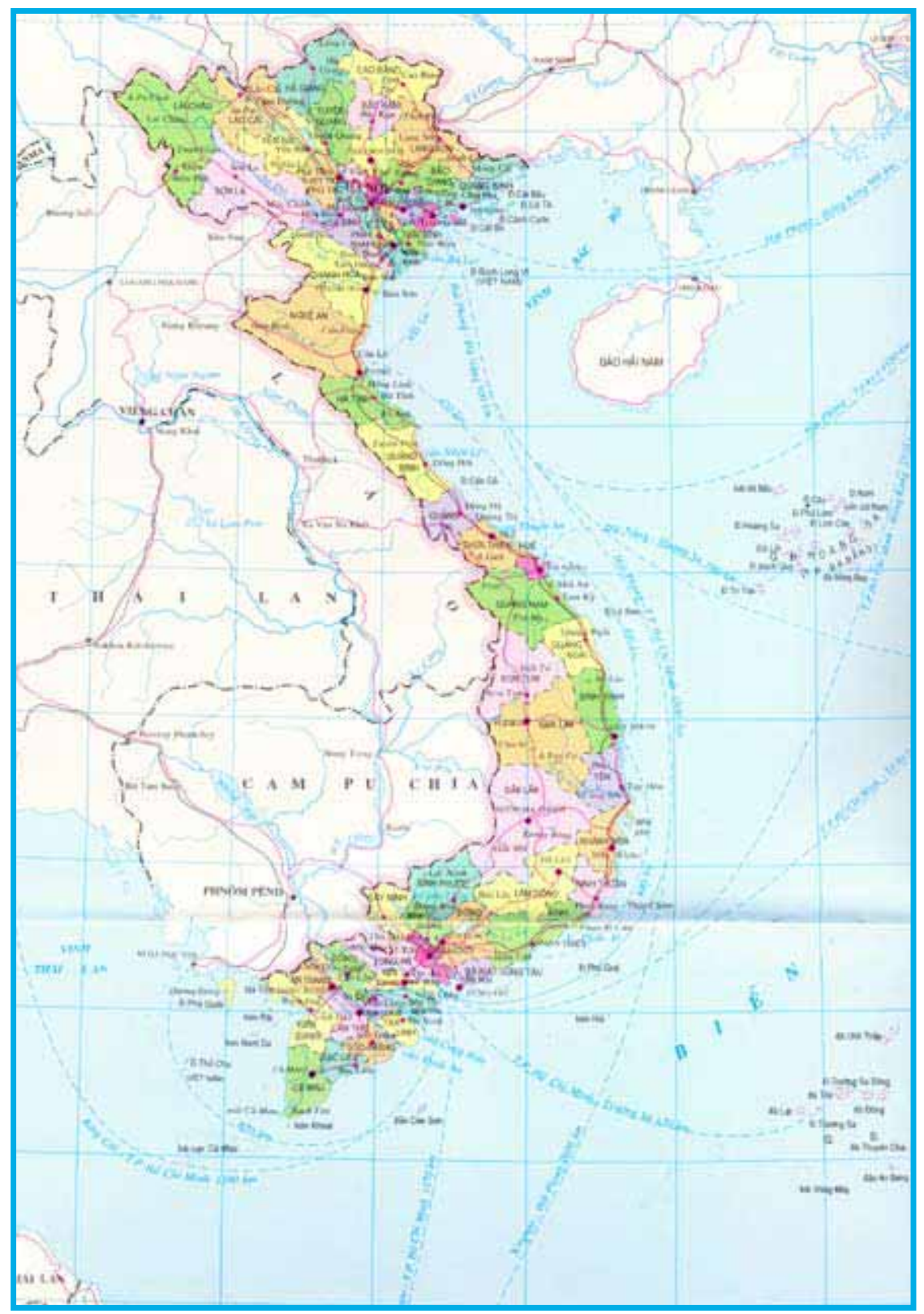

Area: $331,150 \mathrm{~km}^{2}$

Population: 86,2 million people (as of 2008) 
Geography: Area: $331.150 \mathrm{~km}^{2}$

An estimated 86.2 million Vietnamese (end of 2008) live in the S-shaped strip of land located in the Eastern part of the Indochina peninsula, bordering China to the north, Laos and Cambodia to the west, and facing the Eastern Sea (South China Sea) and the Pacific Ocean to the east and south_(http://www.mofa.gov.vn/tt_Viet Nam/geo/- 5 Nov 09).

A typical feature of Vietnamese culture is village life. Traditional Vietnamese village culture has a strong spirit of unity that reflects the result of different wars to gain national independence.

The role of civil society organizations (CSOs): entering the $2^{\text {st }}$ century, the government of Viet Nam regularly consults people's organizations on issues such as solutions for domestic violence. Mass organizations like the Fatherland Front, Farmers' Union, and the Communist Youth Union are important. However, women only constitute $20 \%$ of their membership, and the proportion of women in leadership positions is very small $(A D B$ Viet Nam Gender Situation Analysis, November 2005: 58). The Viet Nam Women's Union (VWU), a CSO under the Fatherland Front, has a president and officers who are also key members of the Communist Party.

The VWU was established in 1930 to support the women's emancipation movement and mobilize women to fight for an independent Viet Nam. Although the VWU is very active in promoting policies and projects to benefit women, its political influence is limited. Government Decision No. 19/2003/ND-CP instructs all levels of government to facilitate the VWU's participation in State management. In reality, the VWU tends only to be consulted on women-specific issues (such as quotas for women in elected organizations) and traditional areas of women's interest, such as education and health.

In 1993, the government appointed the National Committee for the Advancement of Women (NCFAW) as the agency responsible for overseeing gender equality initiatives implemented in all 63 provinces of $V$ iet Nam. Many trainings and monitoring missions have been conducted but gathering information to evaluate progress is still a significant challenge for NCFAW itself. In 2003, the Gender Advisor Network was set up to help NCFAW improve the coordination among CFAWs. This Network consists of gender trainers, experts, and focal points in national ministries/ agencies which meet quarterly at the NCFAW office to share information in gender mainstreaming training and advocacy. 
The Viet Nam Women's Union (VWU) also works to implement many gender and economic development projects to improve women's lives. The VWU operates at four levels: national, provincial, district, and commune to ensure that the organization has considerable outreach at the grassroots level. Programs such as literacy classes or savings and credit schemes are directed towards poor, rural, and remote areas where women have disadvantaged situations as a consequence of war or economic difficulty. By June 2007, VWU had over 13.6 million members (around 47.8 percent of women in the labor force) aged 15 and over (http://hoilhpn.org.vn/ newsdetail.asp?Catld $=66 \&$ Newsld $=819 \& /$ ang $=E N$, last accessed on Oct $25,2009)$. Yet VWU does not represent ethnic minority women who cannot speak Vietnamese (ADB, 2005: 62).

Social Development Status: The 2009 Human Development Index (HDI) for Viet Nam, which refers to the 2007 progress of human development in Viet Nam, highlights very large gaps in well-being and life expectancy. The HDI for Viet Nam is 0.725 , which ranks the country at 116 out of 182 countries that provided data (UNDP Human Development Reports, 2009). Currently, Viet Nam belongs to the Medium Human Development category, meaning $\mathrm{HDl}$ in the 0.500-0.799 range.

Quite remarkably, Viet Nam's HDI rose by $1.16 \%$ annually from 0.561 in 1985 to 0.725 in 2007. The HDI for Viet Nam measures three dimensions of human development:

a/ Living a long and healthy life (measured by life expectancy at birth, which was 74.3 years in 2007),

b/ Educational attainment (measured by $90.3 \%$ adult literacy, defined as age 15 and above, from 1999 to 2007), and

c/ A decent standard of living (measured by purchasing power parity (PPP) equivalent to a GDP per capita of US $\$ 2,600$ ). 
The Human Poverty Index (HPI-l) that measures the level of deprivation of people who live below certain thresholds in each of the HDI dimensions indicated that $21.5 \%$ of the population is still living below $\$ 1.25$ a day (PPP), which is the government's poverty line. Looking beyond simple income deprivation, the $\mathrm{HPl}-1$ value for Viet Nam is $12.4 \%$, ranking $55^{\text {th }}$ among 135 countries for which the index has been calculated (UNDP Human Development Reports, 2009). The probability of not surviving to age 40 for the cohort reaching that age between 2005 and 2010 is 5.8\%, the fraction of the population not using an improved water source in 2006 was $8 \%$, and $25 \%$ of children under 5 were underweight between 2000 and 2006 (UNDP Human Development Reports, 2009).

Viet Nam's GDI (Gender-related Development Index) value, which is derived by adjusting the $\mathrm{HDI}$ measures to account for inequalities between men and women, ranks 94 among 182 countries in 2007, with a value of 0.723 . The life expectancy at birth for females and males were 76.1 years and 72.3 years, respectively, while the adult literacy rates for the period 1999-2007 were $86.9 \%$ for women and $93.9 \%$ for men. Comparing the GDI of 0.723 to the HDI of 0.725 , Viet Nam's GDI/HDI ratio is $99.7 \%$. Of the 155 countries that have both $\mathrm{HDI}$ and $\mathrm{GDI}$ values calculated, only 30 show a better ratio than Viet Nam's. The public expenditure on health per capita in 2006 was $\$ 86$ (PPP), accounting for $6.8 \%$ of total government expenditures.

In Viet Nam, women have had the right to vote and stand for national election since 1946. The GEM (Gender-Empowerment Measure) of Viet Nam in 2007 was 0.554, (calculated as a composite index measuring three dimensions of female empowerment: economic participation and decision-making, political participation, and decision-making and power over economic resources) which ranks 62 among 182 countries. During 1999-2007, female legislators, senior officials, and managers accounted for $22 \%$ of all people in those positions. The ratio of estimated female to male earned income was 0.69 during 1996-2007. Women make up 25.7\% of National Assembly deputies, which is the highest in Southeast Asia (Viet Nam News, Nov. 28, 2009), but they account for only $4 \%$ of cabinet ministerial positions (UNDP Human Development Reports, 2009). 


\section{ANNEX 3. LIST OF HEALTH FACILITIES THAT PROVIDE INTEGRATED HEALTH CARE AND COUNSELING/TREATMENT FOR VICTIMS OF DOMESTIC VIOLENCE (DV)}

Hospitals providing integrated health care and counseling for GBV victims.

1. Duc Giang hospital

Address: Truong Lam Street, Long Bien District - Ha Noi

Tel: (04) 38774001

2. Dong Anh hospital

Address: Dong Anh Town, Dong Anh District, Ha Noi

Tel: (04) 38835340

3. Cua Lo General hospital

Address: Cua Lo Town, Nghe An province

Tel: (038) 3955477

4. Doan Hung General hospital

Address: Doan Hung Town, Doan Hung District, Phu Tho province

5. Binh Dai General hospital

Add: Ward 1, Binh Dai Town, Binh Dai District, Ben Tre province Tel: (075) 3851953

Other counseling and supporting centers for victims of DV:

1. Gia Lam Women's Center for Counseling and Health Care.

Address: Duc Giang General Hospital, Truong Lam Street, Long Bien District - Ha Noi

Tel: (04) 38776625 or 0913522500

2. Dong Anh Women's Center for Counseling and Health Care Address: Dong Anh general hospital, Dong Anh Town, Dong Anh District, Ha Noi.

Tel: (04) 39654355 or 0912461448 
3. Cua Lo Women's Center for Counseling and Health Care, Cua Lo General Hospital

Address: Cua Lo Town, Nghe An Province

Tel: (038) 3955912

4. Doan Hung Office for Counseling, Preventing and Controlling Domestic Violence

Address: Doan Hung General Hospital, Doan Hung Town, Doan Hung District, Phu Tho Province.

5. Binh Dai counseling office for health care and gender equality

Address: Binh Dai General Hospital, Ward 1, Binh Dai Town, Binh Dai District, Ben Tre province

Tel: (075) 3742588

\section{Note:}

The above Counseling Centers/Offices are located within local hospital's areas and over the years have built a network with other sectors that are relevant to support, treat and counsel domestic violence victims. These centers/offices open daily between 7.30 am until 4.30 pm; receiving referrals from $\mathrm{CHCs}$, hospitals or other agencies as well as women in the community who need counseling and treatment both physically and emotionally. These centers also provide hotline (phone) counseling service.

\section{Government agencies for operating and managing GBV support:}

1. Medical Services Administration - Ministry of Health - 138A Giang Vo Street, Ha Noi

Tel: (04) 62732280

Fax: (04) $62732289 / 62732094$

The administration provides instruction on operating, managing and implementing information on activities to prevent and control GBV and DV.

2. Ha Noi Health Service - 4 Son Tay street, Ha Noi

Tel: (04) 38437021

Service provided: referral of GBV victims to a suitable supporting agency. 


\section{Non-health care counseling addresses:}

1. Psychology-Emotional Counseling 1080:

Service: counseling victims of gender-based violence.

Hotline: (04) 38011084.

Provided information to increase knowledge on GBV.

2. Safety House, addresses:

- Center for Women and Development: 20 Thuy Khue, Tay Ho, Ha Noi Tel: (04) 37280280

- Office of supporting and developing consultation, 2nd floor, B Building Tel: (04) 37281035

- Consultation Office, $4^{\text {th }}$ floor, B Building Tel: (04) 3728 0936, and

- Hotline: 0946833 380/0946 833 382/0946 833384.

Safety House is the place to provide free support for trafficked children and women and victims of DV including safe accommodation, health care, psychological and emotional counseling, legal advising and legal procedures supporting, vocational training, guidance and other support. 


\section{ANNEX 4. QUESTIONNAIRE FOR HEALTH CARE PROVIDERS (HCPS) (POST-INTERVENTION AS- SESSMENT)}

Population

Council
Ford

Foundation
Ha Noi Health

Service

\footnotetext{
PROJECT: IMPROVING THE HEALTH CARE

IN RESPONSE TO GENDER-BASED VIOLENCE

POST-INTERVENTION ASSESSMENT
}

QUESTIONNAIRE FOR HEALTH CARE PROVIDERS

(Project final assessment in Duc Giang hosiptal)

ID

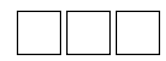

Population Council

41 Le Hong Phong - Ha Noi

Tel: (04) 37345821

Fax: (04) 37345827 
Say to the interviewee: Hello. My name is... I am a representative of the Population Council - an organization which specializes in doing research on population and public reproductive health. We are collaborating with the $\mathrm{Ha} \mathrm{Noi}$ Health Service to conduct postintervention assessment for the project "Improving Health Care in Response to Gender-based Violence (gender violence)" at Duc Giang General Hospital.
We are interested in your experience of providing healthcare services to the victims of gender violence. I would like to ask you some questions pertaining to this issue. We ensure that the information provided by you will be confidential and your name will not be recorded. You don't have to answer the questions that you don't want to and you can stop at any time.

\section{A. IDENTIFICATION}

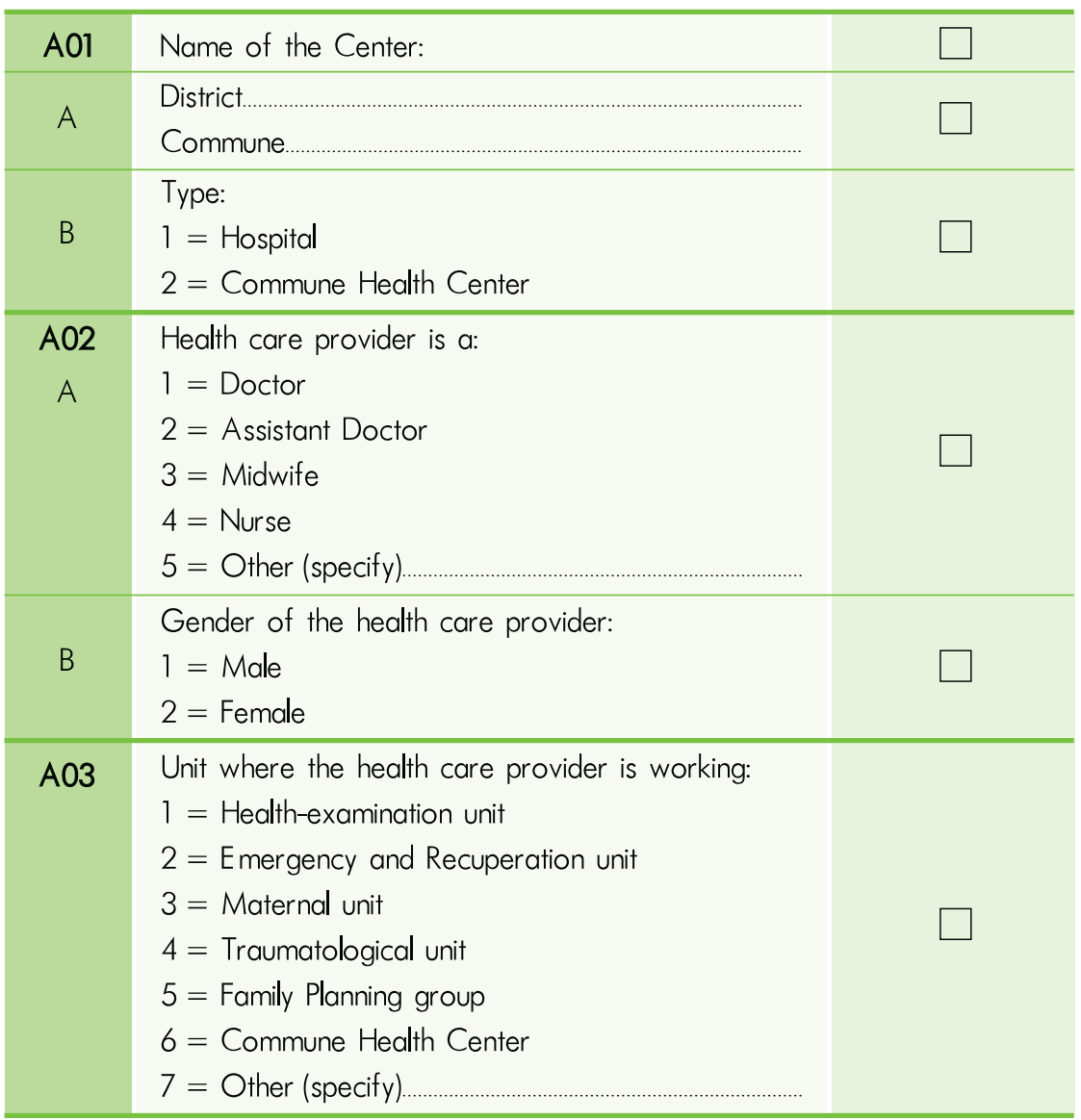




\begin{tabular}{|c|c|c|}
\hline A04 & $\begin{array}{l}\text { Number of years of service at this center? } \\
\text { ((to round up) } \ldots \ldots \text { (year) } \\
\text { (Less than } 12 \text { months }=1 \text { year) }\end{array}$ & $\square \square$ \\
\hline A05 & $\begin{array}{l}\text { Number of years working in the health sector } \\
\text { (to round up) } \ldots \ldots \text { (years) } \\
\text { (Less than } 12 \text { months }=1 \text { year) }\end{array}$ & $\square \square$ \\
\hline A06 & Age: $\quad \ldots \ldots \ldots$ & $\square \square$ \\
\hline A07 & $\begin{array}{l}\text { Marital status } \\
\begin{array}{l}1=\text { Single } \\
2=\text { Married } \\
3=\text { Separated } \\
4=\text { Divorced } \\
5=\text { Widowed }\end{array}\end{array}$ & \\
\hline A08 & $\begin{array}{l}\text { How many children do you have (alive)? } \\
\text { children }\end{array}$ & $\square \square$ \\
\hline A09 & $\begin{array}{l}\text { Religion } \\
1=\text { None } \\
2=\text { Buddhism } \\
3=\text { Christian } \\
4=\text { Other (specify).... }\end{array}$ & $\square$ \\
\hline A10 & $\begin{array}{l}\text { Ethnicity } \\
1=\text { Kinh } \\
2=\text { Other (specify) ......... }\end{array}$ & $\square$ \\
\hline & $\begin{array}{l}\text { Name of interviewer } \ldots \ldots \ldots \ldots \ldots \ldots \ldots \ldots . . . . \\
\text { Date }\end{array}$ & $\square$ \\
\hline
\end{tabular}




\section{B. PERCEPTION/KNOWLEDGE OF VIOLENCE AGAINST WOMEN}

\begin{tabular}{|c|c|c|c|c|c|c|}
\hline \multirow{2}{*}{ No. } & \multirow{2}{*}{$\begin{array}{l}\text { Question } \\
\text { People may have different } \\
\text { views of the behaviors between } \\
\text { spouses in family. Do you agree } \\
\text { or disagree with the following } \\
\text { ideas? (read from a - e) }\end{array}$} & \multicolumn{5}{|c|}{ Code } \\
\hline & & Agree & $\begin{array}{l}\text { Dis- } \\
\text { agree }\end{array}$ & $\begin{array}{l}\text { It de- } \\
\text { pends }\end{array}$ & $\begin{array}{l}\text { Do not } \\
\text { know/ } \\
\text { Do not } \\
\text { answer }\end{array}$ & \\
\hline a) & $\begin{array}{l}\text { The husband should demonstrate } \\
\text { to his spouse that he is the } \\
\text { owner of the family }\end{array}$ & 1 & 2 & 3 & 4 & $\square$ \\
\hline b) & $\begin{array}{l}\text { A good wife should listen to her } \\
\text { spouse though she disagrees } \\
\text { with his opinions or behaviors }\end{array}$ & 1 & 2 & 3 & 4 & $\square$ \\
\hline c) & $\begin{array}{l}\text { The woman is responsible for } \\
\text { satisfying her husband's sexual } \\
\text { demand even when she doesn't } \\
\text { want to }\end{array}$ & 1 & 2 & 3 & 4 & $\square$ \\
\hline d) & $\begin{array}{l}\text { Family/domestic conflicts should } \\
\text { be solved domestically (it's } \\
\text { better not to wash one's dirty } \\
\text { linen in public) }\end{array}$ & 1 & 2 & 3 & 4 & $\square$ \\
\hline e) & $\begin{array}{l}\text { There should be external } \\
\text { interventions if the man always } \\
\text { beat his wife }\end{array}$ & 1 & 2 & 3 & 4 & $\square$ \\
\hline B02 & $\begin{array}{l}\text { In your opinion, does a man } \\
\text { has the right to beat his wife if } \\
\text { she: (read from } a-f \text { ) }\end{array}$ & Yes & No & It de & apends & \\
\hline a) & $\begin{array}{l}\text { Does not fulfill the domestic } \\
\text { duties as expected by } \\
\text { her husband (i.e. laziness, } \\
\text { wastefulness, not taking care of } \\
\text { the children, etc.) }\end{array}$ & 1 & 2 & & 3 & $\square$ \\
\hline b) & Is addicted to gambling and drugs & 1 & 2 & & 3 & $\square$ \\
\hline c) & Contradicting her husband's opinions & 1 & 2 & & 3 & $\square$ \\
\hline d) & Insults and abuses her spouse & 1 & 2 & & 3 & $\square$ \\
\hline e) & $\begin{array}{l}\text { Does not satisfy her husband's } \\
\text { sexual demand }\end{array}$ & 1 & 2 & & 3 & $\square$ \\
\hline f) & Has extra-marital relations & 1 & 2 & & 3 & $\square$ \\
\hline g) & Others (specify) & 1 & 2 & & 3 & $\square$ \\
\hline B03 & $\begin{array}{l}\text { In your opinion, a woman has } \\
\text { the right to refuse to have } \\
\text { sex with her spouse when: (read } \\
\text { from a - d) }\end{array}$ & Yes & No & $\begin{array}{l}\text { Do no } \\
\text { Do not }\end{array}$ & $\begin{array}{l}t \text { know/ } \\
\text { t answer }\end{array}$ & \\
\hline a) & $\begin{array}{l}\text { She does not want to (without } \\
\text { specific reasons) }\end{array}$ & 1 & 2 & & 3 & $\square$ \\
\hline b) & She is tired & 1 & 2 & & 3 & $\square$ \\
\hline
\end{tabular}




\begin{tabular}{|c|c|c|c|c|c|}
\hline No. & Question & & & Code & \\
\hline c) & Her husband is drunk & 1 & 2 & 3 & $\square$ \\
\hline d) & Her husband treats her violently & 1 & 2 & 3 & $\square$ \\
\hline e) & Others (specify).... & 1 & 2 & 3 & $\square$ \\
\hline B04 & $\begin{array}{l}\text { In your opinion, which of the } \\
\text { following behaviors should } \\
\text { be treated or considered as } \\
\text { domestic violence against } \\
\text { women: (read from a-o) }\end{array}$ & Yes & No & $\begin{array}{l}\text { Do not know/ } \\
\text { Do not answer }\end{array}$ & \\
\hline a) & $\begin{array}{l}\text { Assaulting and hurting women (i.e. } \\
\text { smacking, cuffing, or punching) }\end{array}$ & 1 & 2 & 3 & $\square$ \\
\hline b) & $\begin{array}{l}\text { Beating women when they are } \\
\text { pregnant }\end{array}$ & 1 & 2 & 3 & $\square$ \\
\hline c) & $\begin{array}{l}\text { Using sticks, canes or dangerous } \\
\text { tools (such as knife) to attack } \\
\text { women }\end{array}$ & 1 & 2 & 3 & $\square$ \\
\hline d) & $\begin{array}{l}\text { Insulting, abusing, humiliating } \\
\text { women and making them feel } \\
\text { ashamed }\end{array}$ & 1 & 2 & 3 & $\square$ \\
\hline e) & Driving women out of home & 1 & 2 & 3 & $\square$ \\
\hline f) & $\begin{array}{l}\text { Abandoning/ not taking care of } \\
\text { women's work and health }\end{array}$ & 1 & 2 & 3 & $\square$ \\
\hline g) & $\begin{array}{l}\text { Threatening, controlling (using knife, } \\
\text { arms, economic tools or children } \\
\text { as the tools to control women, or } \\
\text { threatening to divorce) }\end{array}$ & 1 & 2 & 3 & $\square$ \\
\hline h) & $\begin{array}{l}\text { Preventing women from } \\
\text { participating in social activities/ } \\
\text { working/studying }\end{array}$ & 1 & 2 & 3 & $\square$ \\
\hline i) & $\begin{array}{l}\text { Preventing women from contacting } \\
\text { with their families/friends }\end{array}$ & 1 & 2 & 3 & $\square$ \\
\hline i) & $\begin{array}{l}\text { Preventing women from seeking } \\
\text { health care or taking medicines } \\
\text { when they are sick }\end{array}$ & 1 & 2 & 3 & $\square$ \\
\hline k) & $\begin{array}{l}\text { Forcing women to have more } \\
\text { babies/pregnancies }\end{array}$ & 1 & 2 & 3 & $\square$ \\
\hline 1) & $\begin{array}{l}\text { Preventing women from using } \\
\text { contraceptives }\end{array}$ & 1 & 2 & 3 & $\square$ \\
\hline m) & $\begin{array}{l}\text { Forcing to have a sexual } \\
\text { intercourse when his wife } \\
\text { doesn't want to }\end{array}$ & 1 & 2 & 3 & $\square$ \\
\hline n) & Having extra-marital relationships & 1 & 2 & 3 & $\square$ \\
\hline o) & Others (specify) & 1 & 2 & 3 & $\square$ \\
\hline
\end{tabular}




\begin{tabular}{|c|c|c|c|c|c|c|}
\hline No. & Question & & & Code & & \\
\hline B05 & $\begin{array}{l}\text { With regard to the violent behaviors } \\
\text { against women mentioned above, } \\
\text { how do you judge the severity } \\
\text { of each type? (Only ask if the } \\
\text { answers for BO } 4=1 \text { ) }\end{array}$ & $\begin{array}{l}\text { Very } \\
\text { severe }\end{array}$ & Severe & $\begin{array}{l}\text { Not } \\
\text { Servere }\end{array}$ & $\begin{array}{c}\text { Irrele- } \\
\text { vant }\end{array}$ & \\
\hline a) & $\begin{array}{l}\text { Assaulting and hurting women (i.e. } \\
\text { smacking, cuffing, or punching) }\end{array}$ & 1 & 2 & 3 & 4 & $\square$ \\
\hline b) & $\begin{array}{l}\text { Beating women when they are } \\
\text { pregnant }\end{array}$ & 1 & 2 & 3 & 4 & $\square$ \\
\hline c) & $\begin{array}{l}\text { Using sticks, canes or dangerous } \\
\text { tools (such as knife) to attack } \\
\text { women }\end{array}$ & 1 & 2 & 3 & 4 & $\square$ \\
\hline d) & $\begin{array}{l}\text { Insulting, abusing, humiliating women } \\
\text { and making them feel ashamed }\end{array}$ & 1 & 2 & 3 & 4 & $\square$ \\
\hline e) & Driving women out of home & 1 & 2 & 3 & 4 & $\square$ \\
\hline f) & $\begin{array}{l}\text { Abandoning/ not taking care of } \\
\text { women's work and health }\end{array}$ & 1 & 2 & 3 & 4 & $\square$ \\
\hline g) & $\begin{array}{l}\text { Threatening, controlling (using knife, } \\
\text { arms, economic tools or children } \\
\text { as the tools to control women, or } \\
\text { threatening to divorce) }\end{array}$ & 1 & 2 & 3 & 4 & $\square$ \\
\hline h) & $\begin{array}{l}\text { Preventing women from } \\
\text { participating in social activities/ } \\
\text { working/studying }\end{array}$ & 1 & 2 & 3 & 4 & $\square$ \\
\hline i) & $\begin{array}{l}\text { Preventing women from contacting } \\
\text { with their families/friends }\end{array}$ & 1 & 2 & 3 & 4 & $\square$ \\
\hline i) & $\begin{array}{l}\text { Preventing women from seeking } \\
\text { health care or taking medicines } \\
\text { when they are sick }\end{array}$ & 1 & 2 & 3 & 4 & $\square$ \\
\hline k) & $\begin{array}{l}\text { Forcing women to have more } \\
\text { babies/pregnancies }\end{array}$ & 1 & 2 & 3 & 4 & $\square$ \\
\hline l) & $\begin{array}{l}\text { Preventing women from using } \\
\text { contraceptives }\end{array}$ & 1 & 2 & 3 & 4 & $\square$ \\
\hline m) & $\begin{array}{l}\text { Forcing to have sexual intercourse } \\
\text { when his wife doesn't want to }\end{array}$ & 1 & 2 & 3 & 4 & $\square$ \\
\hline n) & Having extra-marital relationships & 1 & 2 & 3 & 4 & $\square$ \\
\hline o) & Others (specify) & 1 & 2 & 3 & 4 & $\square$ \\
\hline B06 & $\begin{array}{l}\text { In your opinion, are these } \\
\text { following behaviors of violence } \\
\text { against women common/ } \\
\text { frequent in your locality? } \\
\text { (Only ask if the answers for } \\
\text { B04 = l; read from a - o) }\end{array}$ & Yes & No & $\begin{array}{l}\text { Do not } \\
\text { know/ } \\
\text { Do not } \\
\text { answer }\end{array}$ & $\begin{array}{l}\text { Irrele- } \\
\text { vant }\end{array}$ & \\
\hline a) & $\begin{array}{l}\text { Assaulting and hurting women (i.e. } \\
\text { smacking, cuffing, or punching) }\end{array}$ & 1 & 2 & 3 & 4 & $\square$ \\
\hline b) & $\begin{array}{l}\text { Beating women when they are } \\
\text { pregnant }\end{array}$ & 1 & 2 & 3 & 4 & $\square$ \\
\hline
\end{tabular}




\begin{tabular}{|c|c|c|c|c|c|c|}
\hline No. & Question & \multicolumn{5}{|c|}{ Code } \\
\hline c) & $\begin{array}{l}\text { Using sticks, canes or dangerous } \\
\text { tools (such as knife) to attack } \\
\text { women }\end{array}$ & 1 & 2 & 3 & 4 & $\square$ \\
\hline d) & $\begin{array}{l}\text { Insulting, abusing, humiliating } \\
\text { women and making them feel } \\
\text { ashamed }\end{array}$ & 1 & 2 & 3 & 4 & $\square$ \\
\hline e) & Driving women out of home & 1 & 2 & 3 & 4 & $\square$ \\
\hline f) & $\begin{array}{l}\text { Abandoning/ not taking care of } \\
\text { women's work and health }\end{array}$ & 1 & 2 & 3 & 4 & $\square$ \\
\hline g) & $\begin{array}{l}\text { Threatening, controlling (using knife, } \\
\text { arms, economic tools or children } \\
\text { as the tools to control women, or } \\
\text { threatening to divorce) }\end{array}$ & 1 & 2 & 3 & 4 & $\square$ \\
\hline h) & $\begin{array}{l}\text { Preventing women from } \\
\text { participating in social activities/ } \\
\text { working/studying }\end{array}$ & 1 & 2 & 3 & 4 & $\square$ \\
\hline i) & $\begin{array}{l}\text { Preventing women from contacting } \\
\text { with their families/friends }\end{array}$ & 1 & 2 & 3 & 4 & $\square$ \\
\hline i) & $\begin{array}{l}\text { Preventing women from seeking } \\
\text { health care or taking medicines } \\
\text { when they are sick }\end{array}$ & 1 & 2 & 3 & 4 & $\square$ \\
\hline k) & $\begin{array}{l}\text { Forcing women to have more } \\
\text { babies/pregnancies }\end{array}$ & 1 & 2 & 3 & 4 & $\square$ \\
\hline I) & $\begin{array}{l}\text { Preventing women from using } \\
\text { contraceptives }\end{array}$ & 1 & 2 & 3 & 4 & $\square$ \\
\hline m) & $\begin{array}{l}\text { Forcing to have sexual } \\
\text { intercourse when his wife } \\
\text { doesn't want to }\end{array}$ & 1 & 2 & 3 & 4 & $\square$ \\
\hline n) & Having extra-marital relationships & 1 & 2 & 3 & 4 & $\square$ \\
\hline o) & Others (specify).... & 1 & 2 & 3 & 4 & $\square$ \\
\hline B07 & $\begin{array}{l}\text { In your opinion, has the } \\
\text { violence against women in your } \\
\text { locality escalated compared to } 5 \\
\text { years ago? } \\
1=\text { Yes } \\
2 \text { = Remain unchanged } \\
3 \text { = Decreased } \\
4=\text { Cannot assess }\end{array}$ & & & & & $\square$ \\
\hline B08 & $\begin{array}{l}\text { In your opinion, how common } \\
\text { is the situation of violence } \\
\text { against women in your locality } \\
\text { between: } \\
1=\text { Wife and husband } \\
2=\text { Wife and her spouse's family } \\
3=\text { Family members and } \\
\quad \text { women/young girls } \\
4=\text { Do not know, do not answer }\end{array}$ & & & & & $\square$ \\
\hline
\end{tabular}




\begin{tabular}{|c|c|c|c|c|c|}
\hline No. & Question & \multicolumn{4}{|c|}{ Code } \\
\hline B09 & $\begin{array}{l}\text { According to your assessment, } \\
\text { what are the causes leading to the } \\
\text { violence against women? (Do not } \\
\text { read ask "any other reasons?" }\end{array}$ & \multicolumn{2}{|c|}{ Mentioned } & $\begin{array}{l}\text { Not } \\
\text { mentioned }\end{array}$ & \\
\hline a) & $\begin{array}{l}\text { The influence of the male } \\
\text { chauvinism ideology }\end{array}$ & \multicolumn{2}{|c|}{1} & 2 & $\square$ \\
\hline b) & Economic difficulties & \multicolumn{2}{|c|}{1} & 2 & $\square$ \\
\hline c) & $\begin{array}{l}\text { Conflicts between the wife and } \\
\text { the husband }\end{array}$ & \multicolumn{2}{|c|}{1} & 2 & $\square$ \\
\hline d) & $\begin{array}{l}\text { Conflicts between the wife } \\
\text { and members of her spouse's } \\
\text { family }\end{array}$ & \multicolumn{2}{|c|}{1} & 2 & $\square$ \\
\hline e) & $\begin{array}{l}\text { Gambling, drinking, and drugs } \\
\text { addiction }\end{array}$ & \multicolumn{2}{|c|}{1} & 2 & $\square$ \\
\hline f) & Disagreement in educating children & \multicolumn{2}{|c|}{1} & 2 & $\square$ \\
\hline g) & $\begin{array}{l}\text { The wife/husband has extra } \\
\text { marital relationships }\end{array}$ & \multicolumn{2}{|c|}{1} & 2 & $\square$ \\
\hline h) & $\begin{array}{l}\text { Sexual issues between wife and } \\
\text { husband }\end{array}$ & \multicolumn{2}{|c|}{1} & 2 & $\square$ \\
\hline i) & Other reasons (specify) & \multicolumn{2}{|c|}{1} & 2 & $\square$ \\
\hline $\mathrm{B} 10$ & $\begin{array}{l}\text { In your opinion, what are the } \\
\text { consequences of domestic violence } \\
\text { against women? (Do not read) }\end{array}$ & \multicolumn{2}{|c|}{ Mentioned } & $\begin{array}{l}\text { Not } \\
\text { mentioned }\end{array}$ & \\
\hline a) & $\begin{array}{l}\text { Impact on the women's health } \\
\text { (physical/life) }\end{array}$ & \multicolumn{2}{|c|}{1} & 2 & $\square$ \\
\hline b) & $\begin{array}{l}\text { Impact on the women's mental } \\
\text { health }\end{array}$ & \multicolumn{2}{|c|}{1} & 2 & $\square$ \\
\hline c) & $\begin{array}{l}\text { Impact on the women's } \\
\text { reproductive health }\end{array}$ & \multicolumn{2}{|c|}{1} & 2 & $\square$ \\
\hline d) & $\begin{array}{l}\text { Impact on the development of } \\
\text { children }\end{array}$ & \multicolumn{2}{|c|}{1} & 2 & $\square$ \\
\hline e) & $\begin{array}{l}\text { Impact on family's happiness/ } \\
\text { family gets broken-up }\end{array}$ & \multicolumn{2}{|c|}{1} & 2 & $\square$ \\
\hline f) & Impact on family economy & \multicolumn{2}{|c|}{1} & 2 & $\square$ \\
\hline g) & Other (specify) & \multicolumn{2}{|c|}{1} & 2 & $\square$ \\
\hline $\mathrm{B} 11$ & $\begin{array}{l}\text { In your opinion, can these } \\
\text { following types of forced } \\
\text { sexual behaviors be considered } \\
\text { violence against women? }\end{array}$ & Yes & No & $\begin{array}{l}\text { Do not know/ } \\
\text { Do not answer }\end{array}$ & \\
\hline a) & Rape, sexual assault & 1 & 2 & 3 & $\square$ \\
\hline b) & $\begin{array}{l}\text { Rape, sexual assault of } \\
\text { children or any types of sexual } \\
\text { intercourse with children }\end{array}$ & 1 & 2 & 3 & $\square$ \\
\hline c) & Other (specify) & 1 & 2 & 3 & $\square$ \\
\hline
\end{tabular}




\begin{tabular}{|c|c|c|c|c|c|c|}
\hline No. & Question & \multicolumn{5}{|c|}{ Code } \\
\hline B12 & $\begin{array}{l}\text { How do you assess the } \\
\text { severity of the aforementioned } \\
\text { behaviors? (Ask only if the } \\
\text { answers for B11 = 1) }\end{array}$ & $\begin{array}{l}\text { Very } \\
\text { severe }\end{array}$ & Severe & $\begin{array}{c}\text { Not } \\
\text { Servere }\end{array}$ & $\begin{array}{c}\text { Irrele- } \\
\text { vant }\end{array}$ & \\
\hline a) & Rape, sexual assault & 1 & 2 & 3 & 4 & $\square$ \\
\hline b) & $\begin{array}{l}\text { Rape, sexual assault against } \\
\text { children or any types of sexual } \\
\text { intercourse with children }\end{array}$ & 1 & 2 & 3 & 4 & $\square$ \\
\hline c) & Other (specify) & 1 & 2 & 3 & 4 & $\square$ \\
\hline B13 & $\begin{array}{l}\text { Do you think that the following } \\
\text { types of forced sexual } \\
\text { behaviors are common/ popular } \\
\text { in your locality? }\end{array}$ & Yes & No & \multicolumn{2}{|c|}{$\begin{array}{l}\text { Do not know/ } \\
\text { Do not answer }\end{array}$} & \\
\hline a) & Rape, sexual assault & 1 & 2 & \multicolumn{2}{|c|}{3} & $\square$ \\
\hline b) & $\begin{array}{l}\text { Rape, sexual assault of } \\
\text { children or any types of sexual } \\
\text { intercourse with children }\end{array}$ & 1 & 2 & \multicolumn{2}{|c|}{3} & $\square$ \\
\hline c) & Other (specify) ......... & 1 & 2 & \multicolumn{2}{|c|}{3} & $\square$ \\
\hline B14 & $\begin{array}{l}\text { In your opinion, has rape/ } \\
\text { sexual assault against women } \\
\text { and young girls escalated } \\
\text { compared to } 5 \text { years ago? } \\
1=\text { Yes } \\
2=\text { Unchanged } \\
3=\text { Decreased } \\
4=\text { Cannot assess }\end{array}$ & & & & & $\square$ \\
\hline B15 & $\begin{array}{l}\text { In your opinion, what are } \\
\text { the causes leading to sexual } \\
\text { violence (rape, sexual } \\
\text { harassment...)? (Do not read; } \\
\text { ask "any other reasons?") }\end{array}$ & \multicolumn{2}{|c|}{ Mentioned } & \multicolumn{2}{|c|}{$\begin{array}{c}\text { Not } \\
\text { mentioned }\end{array}$} & \\
\hline a) & Influence of sex movies & \multicolumn{2}{|c|}{1} & \multicolumn{2}{|c|}{2} & $\square$ \\
\hline b) & Influence of alcohol, drugs & \multicolumn{2}{|c|}{1} & \multicolumn{2}{|c|}{2} & $\square$ \\
\hline c) & $\begin{array}{l}\text { Traditional ethical values have } \\
\text { been changed }\end{array}$ & \multicolumn{2}{|c|}{1} & \multicolumn{2}{|c|}{2} & $\square$ \\
\hline d) & Other (specify) & \multicolumn{2}{|l|}{1} & \multicolumn{2}{|c|}{2} & $\square$ \\
\hline B16 & $\begin{array}{l}\text { In your opinion, what are the } \\
\text { consequences of rape and } \\
\text { sexual assault against women } \\
\text { and young girls? (Do not read) }\end{array}$ & \multicolumn{2}{|c|}{ Mentioned } & \multicolumn{2}{|c|}{$\begin{array}{l}\text { Not } \\
\text { mentioned }\end{array}$} & \\
\hline a) & $\begin{array}{l}\text { Impact on the women's health } \\
\text { (physical/life) }\end{array}$ & \multicolumn{2}{|c|}{1} & \multicolumn{2}{|c|}{2} & $\square$ \\
\hline
\end{tabular}




\begin{tabular}{|c|c|c|c|c|}
\hline No. & Question & \multicolumn{3}{|c|}{ Code } \\
\hline b) & $\begin{array}{l}\text { Impact on the women's mental } \\
\text { health and psychology }\end{array}$ & 1 & 2 & $\square$ \\
\hline c) & $\begin{array}{l}\text { Impact on the women's } \\
\text { reproductive health }\end{array}$ & 1 & 2 & $\square$ \\
\hline d) & $\begin{array}{l}\text { Impact on the long-term } \\
\text { development }\end{array}$ & 1 & 2 & $\square$ \\
\hline e) & Other (specify)..... & 1 & 2 & $\square$ \\
\hline $\mathrm{Bl7}$ & $\begin{array}{l}\text { Do you know any legal } \\
\text { regulations on the penalties for } \\
\text { violent behaviors against women } \\
\text { (domestic violence, rape/sexual } \\
\text { assault)? } \\
1=\text { Yes } \\
2=\text { No ---> Move to CO1 }\end{array}$ & & & $\square$ \\
\hline B18 & $\begin{array}{l}\text { If Yes, what are they? } \\
\text { (Do not read, ask "any other } \\
\text { reasons?") }\end{array}$ & Mentioned & $\begin{array}{l}\text { Not } \\
\text { mentioned }\end{array}$ & \\
\hline a) & $\begin{array}{l}\text { Physical violence (murder, injure, } \\
\text { or damage others' health, } \\
\text { prosecute others) }\end{array}$ & 1 & 2 & $\square$ \\
\hline b) & $\begin{array}{l}\text { Psychological violence (force } \\
\text { to suicide, threaten to murder, } \\
\text { insult others, slander, etc.) }\end{array}$ & 1 & 2 & $\square$ \\
\hline c) & $\begin{array}{l}\text { Violation of monogamy marital } \\
\text { relationship }\end{array}$ & 1 & 2 & $\square$ \\
\hline d) & $\begin{array}{l}\text { Rape, sexual assault, and any } \\
\text { types of sexual assault and } \\
\text { sexual intercourse with children }\end{array}$ & 1 & 2 & $\square$ \\
\hline e) & Other (specify) & 1 & 2 & $\square$ \\
\hline B19 & $\begin{array}{l}\text { Have you known/heard about the } \\
\text { law on domestic violence prevention } \\
\text { and control that has been recently } \\
\text { issued by the Government? } \\
1=\text { Yes } \\
2=\text { No ---> Move to C01 }\end{array}$ & & & $\square$ \\
\hline B20 & $\begin{array}{l}\text { Do you know any legal } \\
\text { regulations on how to provide } \\
\text { health services to the victims of } \\
\text { gender violence at healthcare } \\
\text { centers? (The interviewer asks } \\
\text { details about the regulations if the } \\
\text { health care provider says Yes) } \\
1=\text { Yes } \\
2=\text { No }\end{array}$ & & & $\square$ \\
\hline
\end{tabular}




\section{EXPERIENCE OF WORKING WITH THE PATIENTS WHO ARE VICTIMS OF GENDER VIOLENCE}

\begin{tabular}{|c|c|c|c|c|c|}
\hline No. & Question & \multicolumn{4}{|c|}{ Code } \\
\hline $\begin{array}{l}5.1 \\
\mathrm{C} 01\end{array}$ & $\begin{array}{l}\text { Since working at this center, } \\
\text { have you ever met, known, or } \\
\text { heard about any female patients } \\
\text { who are victims of violence } \\
\text { (domestic violence, sexual } \\
\text { assault) as mentioned above? } \\
1=\text { Yes } \\
2=\text { No ---> Move to C06 }\end{array}$ & & & & $\square$ \\
\hline $\mathrm{CO} 2$ & $\begin{array}{l}\text { Have you ever met any female } \\
\text { patients who are victims of } \\
\text { violence (domestic violence, } \\
\text { sexual assault) as mentioned } \\
\text { above at your unit? } \\
1=\text { Yes } \\
2=\text { No (a,b, c of } C 03=3 \text { ) }\end{array}$ & & & & $\square$ \\
\hline $\mathrm{CO3}$ & $\begin{array}{l}\text { How do you know that they are } \\
\text { the victims of violence? (Do not } \\
\text { read; ask "any other reasons?") }\end{array}$ & Mentioned & $\begin{array}{l}\text { Not } \\
\text { mentioned }\end{array}$ & $\begin{array}{c}\text { Not } \\
\text { applicable }\end{array}$ & \\
\hline a) & Look at the wound/injury & 1 & 2 & 3 & $\square$ \\
\hline b) & Ask the patients directly & 1 & 2 & 3 & $\square$ \\
\hline c) & The patients tell & 1 & 2 & 3 & $\square$ \\
\hline d) & The patents' relatives tell & 1 & 2 & 3 & $\square$ \\
\hline e) & Other health care providers tell & 1 & 2 & 3 & $\square$ \\
\hline f) & Others (specify).... & 1 & 2 & 3 & $\square$ \\
\hline $\begin{array}{l}5.2 \\
\mathrm{CO}\end{array}$ & $\begin{array}{l}\text { For those who were victims } \\
\text { of violence, which types of } \\
\text { violence have they experienced? } \\
\text { (Read from } \mathbf{a}-\text { o) }\end{array}$ & Yes & & No & \\
\hline a) & $\begin{array}{l}\text { Assaulting and hurting women (i.e. } \\
\text { smacking, cuffing, or punching) }\end{array}$ & 1 & & 2 & $\square$ \\
\hline b) & $\begin{array}{l}\text { Beating women when they are } \\
\text { pregnant }\end{array}$ & 1 & & 2 & $\square$ \\
\hline c) & $\begin{array}{l}\text { Using sticks, canes or dangerous } \\
\text { tools (such as knife) to attack } \\
\text { women }\end{array}$ & 1 & & 2 & $\square$ \\
\hline d) & $\begin{array}{l}\text { Insulting, abusing, humiliating } \\
\text { women and making them feel } \\
\text { ashamed }\end{array}$ & 1 & & 2 & $\square$ \\
\hline e) & Driving women out of home & 1 & & 2 & $\square$ \\
\hline f) & $\begin{array}{l}\text { Abandoning, not taking care of } \\
\text { women's work and health }\end{array}$ & 1 & & 2 & $\square$ \\
\hline
\end{tabular}




\begin{tabular}{|c|c|c|c|c|}
\hline No. & Question & \multicolumn{3}{|c|}{ Code } \\
\hline g) & $\begin{array}{l}\text { Threatening, controlling (using } \\
\text { knife, arms, economic tools } \\
\text { or children as the tools to } \\
\text { control women or threatening } \\
\text { to divorce) }\end{array}$ & 1 & 2 & $\square$ \\
\hline h) & $\begin{array}{l}\text { Preventing women from } \\
\text { participating in social activities/ } \\
\text { working/studying }\end{array}$ & 1 & 2 & $\square$ \\
\hline i) & $\begin{array}{l}\text { Preventing women from } \\
\text { contacting with their families/ } \\
\text { friends }\end{array}$ & 1 & 2 & $\square$ \\
\hline i) & $\begin{array}{l}\text { Preventing women from seeking } \\
\text { health care or taking medicines } \\
\text { when they are sick }\end{array}$ & 1 & 2 & $\square$ \\
\hline k) & $\begin{array}{l}\text { Forcing women to have more } \\
\text { babies }\end{array}$ & 1 & 2 & $\square$ \\
\hline l) & $\begin{array}{l}\text { Preventing women from using } \\
\text { contraceptives }\end{array}$ & 1 & 2 & $\square$ \\
\hline m) & $\begin{array}{l}\text { Forcing to have sexual intercourse } \\
\text { when his wife doesn't want to }\end{array}$ & 1 & 2 & $\square$ \\
\hline n) & Having extra-marital relationships & 1 & 2 & $\square$ \\
\hline o) & Assaulting sexually/raping & 1 & 2 & $\square$ \\
\hline p) & Other (specify) & 1 & 2 & $\square$ \\
\hline $\mathrm{CO5}$ & $\begin{array}{l}\text { Types of wounds/pains that you } \\
\text { often find on the patients who } \\
\text { are victims of violence include: }\end{array}$ & Mentioned & $\begin{array}{c}\text { Not } \\
\text { Mentioned }\end{array}$ & \\
\hline a) & $\begin{array}{l}\text { Exterior wound/injury (black and } \\
\text { blue, chapped skin, swollen) }\end{array}$ & 1 & 2 & $\square$ \\
\hline b) & Broken legs/arms & 1 & 2 & $\square$ \\
\hline c) & $\begin{array}{l}\text { Iniury in dangerous areas (head, } \\
\text { chest, and stomach) }\end{array}$ & 1 & 2 & $\square$ \\
\hline d) & Miscarriage & 1 & 2 & $\square$ \\
\hline e) & Wound/injury in genital organs & 1 & 2 & $\square$ \\
\hline f) & Wound/injury in internal organs & 1 & 2 & $\square$ \\
\hline g) & $\begin{array}{l}\text { Mental injuries (stress, metal } \\
\text { disorder, panic, etc.) }\end{array}$ & 1 & 2 & $\square$ \\
\hline h) & Other (specify) & 1 & 2 & $\square$ \\
\hline $\mathrm{CO6}$ & $\begin{array}{l}\text { Do you examine the patients } \\
\text { directly? } \\
1=\text { Yes } \\
2=\text { No ---> Move to } \mathrm{C} 12\end{array}$ & & & $\square$ \\
\hline
\end{tabular}




\begin{tabular}{|c|c|c|c|c|c|c|}
\hline No. & Question & \multicolumn{5}{|c|}{ Code } \\
\hline $\mathrm{CO}$ & $\begin{array}{l}\text { When examining the patients, do } \\
\text { you ask them directly in order to } \\
\text { identify whether they are physically } \\
\text { violated or morally threatened by } \\
\text { their family members? } \\
1=\text { Yes } \\
2 \text { = No ---> Move to C9 }\end{array}$ & & & & & $\square$ \\
\hline $\mathrm{C08}$ & $\begin{array}{l}\text { If Yes, in which cases do you ask } \\
\text { and do you do this frequently? }\end{array}$ & $\begin{array}{l}\text { Fre- } \\
\text { quently }\end{array}$ & $\begin{array}{l}\text { Some- } \\
\text { times }\end{array}$ & Never & $\begin{array}{c}\text { Not } \\
\text { Applicable }\end{array}$ & \\
\hline a) & In the first check-up/emergency & 1 & 2 & 3 & 4 & $\square$ \\
\hline b) & In regular check-ups & 1 & 2 & 3 & 4 & $\square$ \\
\hline c) & Examine injured patients & 1 & 2 & 3 & 4 & $\square$ \\
\hline d) & In the first prenatal check-up & 1 & 2 & 3 & 4 & $\square$ \\
\hline e) & In regular prenatal check-ups & 1 & 2 & 3 & 4 & $\bar{\square}$ \\
\hline f) & Other (specify)..... & 1 & 2 & 3 & 4 & $\square$ \\
\hline C09 & $\begin{array}{l}\text { There are difficulties in asking } \\
\text { female patients about violence } \\
\text { against women. In your opinion, } \\
\text { for what reasons that you } \\
\text { hesitate to ask about this issue? } \\
\text { (Do not read, let the interviewee } \\
\text { answer and then ask "any other } \\
\text { reasons?") }\end{array}$ & Mentic & ioned & & $\begin{array}{l}\text { Not } \\
\text { ntioned }\end{array}$ & \\
\hline a) & Time insufficiency & 1 & 1 & & 2 & $\square$ \\
\hline b) & Feel uncomfortable to ask & 1 & 1 & & 2 & $\square$ \\
\hline c) & Think that I can not help them & 1 & 1 & & 2 & $\square$ \\
\hline d) & Consider it patients' privacy & 1 & 1 & & 2 & $\square$ \\
\hline e) & Afraid that patients are shy & 1 & 1 & & 2 & $\square$ \\
\hline f) & $\begin{array}{l}\text { Consider treatment the most } \\
\text { important objective }\end{array}$ & 1 & 1 & & 2 & $\square$ \\
\hline g) & $\begin{array}{l}\text { Have not been trained on the } \\
\text { ways to ask to identify that the } \\
\text { injuries are caused by violence }\end{array}$ & 1 & 1 & & 2 & $\square$ \\
\hline h) & $\begin{array}{l}\text { Patients refuse to talk about } \\
\text { their history }\end{array}$ & 1 & 1 & & 2 & $\square$ \\
\hline i) & Patients are addicted to alcohol & 1 & 1 & & 2 & $\square$ \\
\hline i) & $\begin{array}{l}\text { Patients refuse to answer when } \\
\text { they are asked }\end{array}$ & 1 & 1 & & 2 & $\square$ \\
\hline k) & $\begin{array}{l}\text { Patients are accompanied by } \\
\text { their relatives }\end{array}$ & 1 & 1 & & 2 & $\square$ \\
\hline l) & $\begin{array}{l}\text { There is no medial regulation } \\
\text { on this }\end{array}$ & 1 & 1 & & 2 & $\square$ \\
\hline m) & $\begin{array}{l}\text { Insufficient resources to support } \\
\text { patients }\end{array}$ & 1 & 1 & & 2 & $\square$ \\
\hline n) & Other (specify) & 1 & 1 & & 2 & $\square$ \\
\hline
\end{tabular}




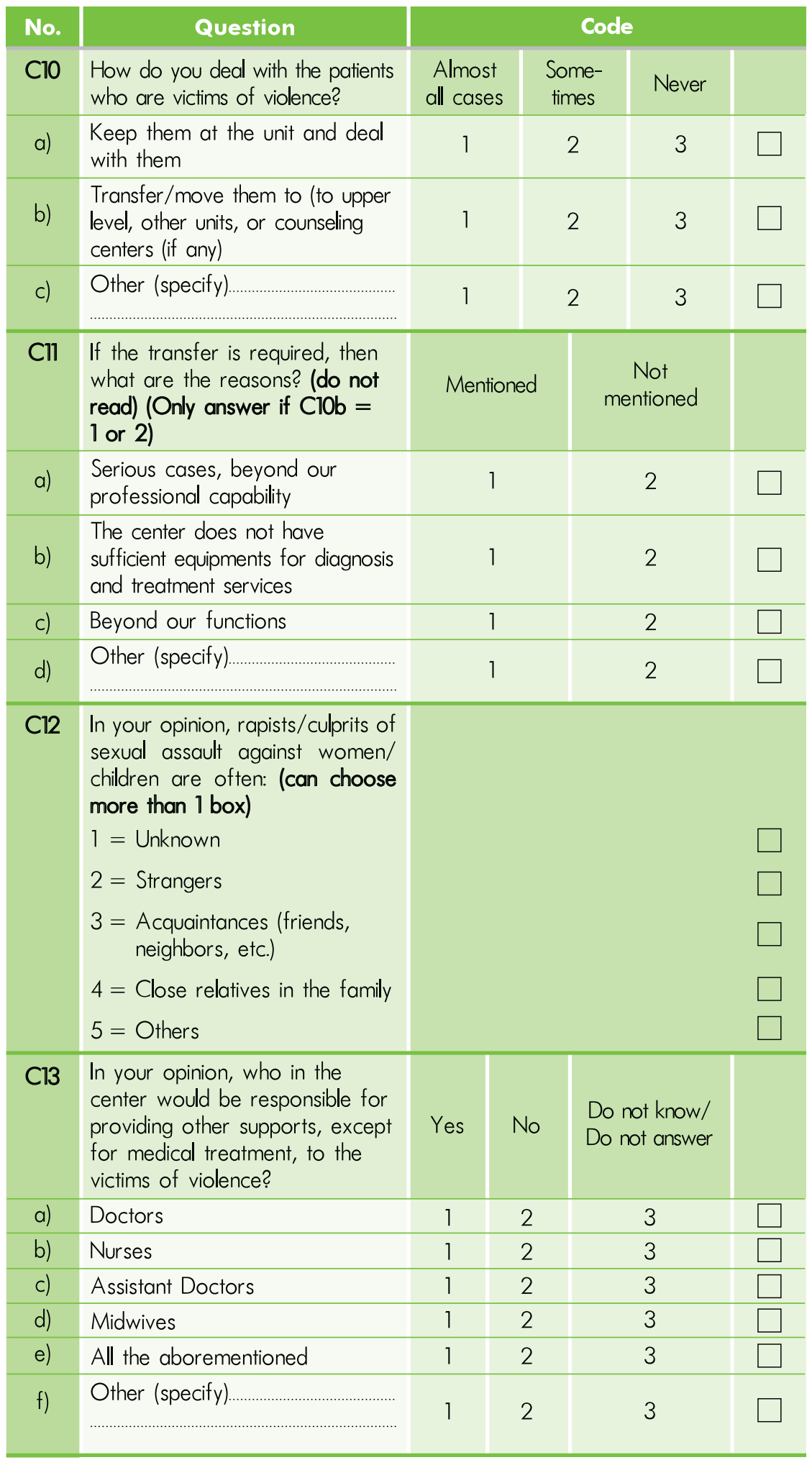




\begin{tabular}{|c|c|c|c|c|c|}
\hline \multirow{2}{*}{$\begin{array}{l}\text { No. } \\
\text { C.14 }\end{array}$} & \multirow{2}{*}{$\begin{array}{l}\text { Question } \\
\text { When you know or suspect that } \\
\text { a female patient is the victim of } \\
\text { violence, what do you often do } \\
\text { in addition to medical check-up } \\
\text { and treatment services? (Do not } \\
\text { read, ask "any thing else?") }\end{array}$} & \multicolumn{4}{|c|}{ Code } \\
\hline & & Mentioned & $\begin{array}{c}\text { Not } \\
\text { mentioned }\end{array}$ & $\begin{array}{c}\text { Not } \\
\text { applicable }\end{array}$ & \\
\hline a) & Emotional support & 1 & 2 & 3 & $\square$ \\
\hline b) & $\begin{array}{l}\text { Instruct the patient how to } \\
\text { protect herself and her children }\end{array}$ & 1 & 2 & 3 & $\square$ \\
\hline c) & $\begin{array}{l}\text { Provide the patient with } \\
\text { information about the places } \\
\text { from which she can get supports } \\
\text { (government authorities, legal } \\
\text { agencies, police offices) }\end{array}$ & 1 & 2 & 3 & $\square$ \\
\hline d) & $\begin{array}{l}\text { Direct the patient to counseling } \\
\text { services }\end{array}$ & 1 & 2 & 3 & $\square$ \\
\hline e) & $\begin{array}{l}\text { Arrange the temporary } \\
\text { residence for the patient if she } \\
\text { doesn't want to come back home }\end{array}$ & 1 & 2 & 3 & $\square$ \\
\hline f) & $\begin{array}{l}\text { Continue to support the } \\
\text { patient after she leaves the } \\
\text { hospital upon her request }\end{array}$ & 1 & 2 & 3 & $\square$ \\
\hline g) & Other (specify) & 1 & 2 & 3 & $\square$ \\
\hline C.15 & $\begin{array}{l}\text { When you know that a female } \\
\text { patient is the victim of a sexual } \\
\text { assault, what do you do in } \\
\text { addition to medical check-up and } \\
\text { treatment service? (Do not read, } \\
\text { let the interviewee answer and } \\
\text { then ask "any thing else?") }\end{array}$ & Mentioned & $\begin{array}{c}\text { Not } \\
\text { mentioned }\end{array}$ & $\begin{array}{c}\text { Not } \\
\text { applicable }\end{array}$ & \\
\hline a) & Spiritual encouragement & 1 & 2 & 3 & $\square$ \\
\hline b) & $\begin{array}{l}\text { Instruct the patient how to protect } \\
\text { herself and her children }\end{array}$ & 1 & 2 & 3 & $\square$ \\
\hline c) & $\begin{array}{l}\text { Provide the patient with } \\
\text { information about the places } \\
\text { from which she can get supports } \\
\text { (government authorities, legal } \\
\text { agencies, police offices) }\end{array}$ & 1 & 2 & 3 & $\square$ \\
\hline d) & $\begin{array}{l}\text { Direct the patient to counseling } \\
\text { centers }\end{array}$ & 1 & 2 & 3 & $\square$ \\
\hline e) & $\begin{array}{l}\text { Continue to support the patient } \\
\text { after she leaves the hospital } \\
\text { upon her request }\end{array}$ & 1 & 2 & 3 & $\square$ \\
\hline f) & Other (specify) & 1 & 2 & 3 & $\square$ \\
\hline
\end{tabular}




\begin{tabular}{|c|c|c|c|c|c|}
\hline No. & Question & \multicolumn{4}{|c|}{ Code } \\
\hline $\begin{array}{l}\mathrm{Cl6} \\
\mathrm{A}\end{array}$ & $\begin{array}{l}\text { After transferring/directing the } \\
\text { patient to Counseling center, do } \\
\text { you have any information about } \\
\text { this patient? } \\
\begin{array}{l}1=\text { Yes } \\
2=\text { No }\end{array}\end{array}$ & & & & $\square$ \\
\hline $\begin{array}{c}\mathrm{Cl} 6 \\
\mathrm{~B}\end{array}$ & $\begin{array}{l}\text { Do you continue to provide } \\
\text { supports to the patients after } \\
\text { they are transferred/directed to } \\
\text { Counseling centers? } \\
1=\text { Yes } \\
2=\text { No ----> move to Cl7A }\end{array}$ & & & & $\square$ \\
\hline $\begin{array}{l}\mathrm{Cl6} \\
\mathrm{C}\end{array}$ & $\begin{array}{l}\text { If Yes, what kinds of supports } \\
\text { do you provide? }\end{array}$ & & & & \\
\hline $\begin{array}{c}\mathrm{Cl} 7 \\
\mathrm{~A}\end{array}$ & $\begin{array}{l}\text { Do you take note of information } \\
\text { about the violence situation of } \\
\text { the patients in a separate form? } \\
1=\text { Yes } \\
2=\text { No ----> move to C18 }\end{array}$ & & & & $\square$ \\
\hline $\begin{array}{c}\mathrm{C} 17 \\
\mathrm{~B}\end{array}$ & $\begin{array}{l}\text { If Yes, are those forms kept at } \\
\text { your unit or transferred to the } \\
\text { Counseling centers? } \\
1=\text { Kept at the unit } \\
2=\text { Transferred }\end{array}$ & & & & $\square$ \\
\hline $\mathrm{C} 18$ & $\begin{array}{l}\text { How many victims of violence } \\
\text { have you provided health services } \\
\text { to over the last two years? } \\
\text { If not remember, write code } 99\end{array}$ & & & & $\square \square$ \\
\hline $\mathrm{C} 19$ & $\begin{array}{l}\text { Do you know any centers that } \\
\text { provide supports to the victims } \\
\text { of violence (domestic violence, } \\
\text { sexual assault)? } \\
1=\text { Yes } \\
2=\text { No ----> Move to C21 }\end{array}$ & & & & $\square$ \\
\hline $\mathrm{C} 20$ & $\begin{array}{l}\text { If Yes, which agencies and } \\
\text { organizations? (Do not read, } \\
\text { let the interviewee answer and } \\
\text { then ask "any other agencies/ } \\
\text { organizations?") }\end{array}$ & Yes & No & $\begin{array}{l}\text { Do not know/ } \\
\text { Do not answer }\end{array}$ & \\
\hline a) & Police offices & 1 & 2 & 3 & $\square$ \\
\hline b) & Judicial offices/Courts & 1 & 2 & 3 & $\square$ \\
\hline c) & Government authorities & 1 & 2 & 3 & $\square$ \\
\hline
\end{tabular}




\begin{tabular}{|c|c|c|c|c|c|}
\hline No. & Question & \multicolumn{4}{|c|}{ Code } \\
\hline d) & Women's union & 1 & 2 & 3 & $\square$ \\
\hline e) & Youth's union & 1 & 2 & 3 & $\square$ \\
\hline f) & Mediation groups & 1 & 2 & 3 & $\square$ \\
\hline g) & Counseling centers & 1 & 2 & 3 & $\square$ \\
\hline h) & Other (specify) & 1 & 2 & 3 & $\square$ \\
\hline $\mathrm{C} 21$ & $\begin{array}{l}\text { Have your center collaborated } \\
\text { with the local authorities to } \\
\text { provide supports to the victims } \\
\text { of violence? } \\
1=\text { Yes } \\
2=\text { No ---> Move to C23 }\end{array}$ & & & & $\square$ \\
\hline $\mathrm{C} 22$ & $\begin{array}{l}\text { If "Yes", with which bureaus/ } \\
\text { agencies? (Do not read; ask } \\
\text { "any other bureaus/ agencies?") }\end{array}$ & Yes & No & $\begin{array}{l}\text { Do not know/ } \\
\text { Do not answer }\end{array}$ & \\
\hline a) & Police offices & 1 & 2 & 3 & $\square$ \\
\hline b) & Judicial offices/Courts & 1 & 2 & 3 & $\square$ \\
\hline c) & Government authorities & 1 & 2 & 3 & $\square$ \\
\hline d) & Women's union & 1 & 2 & 3 & $\square$ \\
\hline e) & Youth's union & 1 & 2 & 3 & $\square$ \\
\hline f) & Mediation groups & 1 & 2 & 3 & $\square$ \\
\hline g) & Counseling centers & 1 & 2 & 3 & $\square$ \\
\hline h) & Other (specify) & 1 & 2 & 3 & $\square$ \\
\hline $\mathrm{C} 23$ & $\begin{array}{l}\text { Does the hospital/healthcare } \\
\text { center have any specific } \\
\text { regulations or instructions on } \\
\text { providing check-up/treatment } \\
\text { services to the victims of violence? } \\
1=\text { Yes } \\
2=\text { No } \\
3=\text { Do not know/ do not answer }\end{array}$ & & & & $\square$ \\
\hline $\mathrm{C} 24$ & $\begin{array}{l}\text { Does the hospital/healthcare } \\
\text { center have the list of agencies/ } \\
\text { organizations to which you can } \\
\text { introduce/direct the victims to } \\
\text { approach for supports? } \\
1=\text { Yes } \\
2=\text { No } \\
3=\text { Do not know/ do not answer }\end{array}$ & & & & $\square$ \\
\hline
\end{tabular}




\begin{tabular}{|c|c|c|c|c|}
\hline No. & Question & \multicolumn{3}{|c|}{ Code } \\
\hline $\mathrm{C} 25$ & $\begin{array}{l}\text { Do you know any materials that } \\
\text { provide instructions to health care } \\
\text { providers about how to work } \\
\text { with the victims of violence? } \\
1=\text { Yes } \\
2=\text { No ---> Move to C } 30\end{array}$ & & & $\square$ \\
\hline $\mathrm{C} 26$ & $\begin{array}{l}\text { Do you use those materials? } \\
1=\text { Yes } \\
2=\text { No }-->\text { Move to C } 30\end{array}$ & & & $\square$ \\
\hline $\mathrm{C} 27$ & $\begin{array}{l}\text { How do you think about those } \\
\text { materials } \\
1=\text { Very useful } \\
2=\text { Useful } \\
3=\text { Average } \\
4=\text { Unuseful } \\
5=\text { Do not know/ do not answer }\end{array}$ & & & $\square$ \\
\hline $\begin{array}{c}\mathrm{C} 28 \\
\mathrm{~A}\end{array}$ & $\begin{array}{l}\text { Have you met any difficulty in } \\
\text { using those materials? } \\
1=\text { Yes } \\
2=\text { No ---> Move to C29A }\end{array}$ & & & $\square$ \\
\hline $\begin{array}{c}\mathrm{C} 28 \\
\mathrm{~B}\end{array}$ & What are the difficulties? & & & \\
\hline $\begin{array}{c}\mathrm{C} 29 \\
\mathrm{~A}\end{array}$ & $\begin{array}{l}\text { Do you have any suggestions for } \\
\text { these materials? } \\
\begin{array}{l}1=\text { Yes } \\
2=\text { No ---> Move to C } 30\end{array}\end{array}$ & & & ] \\
\hline $\begin{array}{l}\text { C.29 } \\
\text { B }\end{array}$ & Suggestions & & & \\
\hline С 30 & $\begin{array}{l}\text { Has your hospital/healthcare } \\
\text { center conducted any education } \\
\text { and communication activities on } \\
\text { the topic of violence against } \\
\text { women? } \\
\begin{array}{l}1=\text { Yes } \\
2=\text { No } \\
3=\text { Do not know/ Move to D01 } \\
\text { do not answer }\end{array} \text {. }\end{array}$ & & & $\square$ \\
\hline C31 & If Yes, they are: & Yes & No & \\
\hline a) & Leaflets, handbooks & 1 & 2 & $\square$ \\
\hline b) & Pano, posters & 1 & 2 & $\square$ \\
\hline c) & Other (specify) & 1 & 2 & $\square$ \\
\hline
\end{tabular}




\section{RECOMMENDATIONS FOR IMPROVING CAPACITY TO SUPPORT THE VICTIMS OF VIOLENCE}

\begin{tabular}{|c|c|c|c|c|c|}
\hline No. & Question & \multicolumn{4}{|c|}{ Code } \\
\hline D01 & $\begin{array}{l}\text { Do you think that there are } \\
\text { sufficient resources/conditions } \\
\text { from the community to support } \\
\text { the victims of violence? } \\
1=\text { Yes ---> Move to D03 } \\
2=\text { No }\end{array}$ & & & & $\square$ \\
\hline D02 & $\begin{array}{l}\text { If No then Why? (Do not read; } \\
\text { ask "anything else?") }\end{array}$ & \multicolumn{2}{|c|}{ Mentioned } & $\begin{array}{l}\text { Not } \\
\text { mentioned }\end{array}$ & \\
\hline a) & $\begin{array}{l}\text { Insufficient and inadequate } \\
\text { perception/ knowledge of } \\
\text { the government authorities at } \\
\text { different levels }\end{array}$ & \multicolumn{2}{|c|}{1} & 2 & $\square$ \\
\hline b) & $\begin{array}{l}\text { Health care providers lack } \\
\text { of skills on approaching and } \\
\text { consulting the victims }\end{array}$ & \multicolumn{2}{|c|}{1} & 2 & $\square$ \\
\hline c) & $\begin{array}{l}\text { Lack of collaboration among } \\
\text { agencies/departments }\end{array}$ & \multicolumn{2}{|c|}{1} & 2 & $\square$ \\
\hline d) & $\begin{array}{l}\text { Inappropriate and insufficient } \\
\text { sanctions on criminals }\end{array}$ & \multicolumn{2}{|c|}{1} & 2 & $\square$ \\
\hline e) & Insufficient budget & \multicolumn{2}{|c|}{1} & 2 & $\square$ \\
\hline f) & Other (specify)..... & \multicolumn{2}{|c|}{1} & 2 & $\square$ \\
\hline D03 & $\begin{array}{l}\text { Do you think that you can help } \\
\text { the victims of violence with the } \\
\text { following? }\end{array}$ & Yes & No & $\begin{array}{l}\text { Do not know/ } \\
\text { Do not answer }\end{array}$ & \\
\hline a) & Medical knowledge & 1 & 2 & 3 & $\square$ \\
\hline b) & Psychological/counseling support & 1 & 2 & 3 & $\square$ \\
\hline c) & Other (specify) & 1 & 2 & 3 & $\square$ \\
\hline D04 & $\begin{array}{l}\text { Do you think that in addition to } \\
\text { professional responsibilities, health } \\
\text { care providers should take the } \\
\text { responsibilities for providing victims } \\
\text { of violence with other supports } \\
\text { (Psychological, social, etc.)? } \\
1=\text { Yes } \\
2=\text { No }\end{array}$ & & & & \\
\hline $\begin{array}{c}\text { D05 } \\
\text { A }\end{array}$ & $\begin{array}{l}\text { Have you participated in nay } \\
\text { training courses/workshops } \\
\text { (official or unofficial) with topics } \\
\text { related to violence against } \\
\text { women over the last two year? } \\
1=\text { Yes } \\
2=\text { Not yet }\end{array}$ & & & & $\square$ \\
\hline
\end{tabular}




\begin{tabular}{|c|c|c|c|c|c|}
\hline No. & Question & \multicolumn{4}{|c|}{ Code } \\
\hline $\begin{array}{c}\text { D05 } \\
\text { B }\end{array}$ & How many times? & & & & $\square$ \\
\hline D06 & $\begin{array}{l}\text { Would you like to participate in } \\
\text { any training on this topic? } \\
1=\text { Yes } \\
2=\text { No }--->\text { Move to D08 }\end{array}$ & & & & $\square$ \\
\hline D07 & $\begin{array}{l}\text { Which areas would you like to } \\
\text { be trained on? (Do not read; } \\
\text { ask "anything else?") }\end{array}$ & Yes & No & $\begin{array}{l}\text { Do not know/ } \\
\text { Do not answer }\end{array}$ & \\
\hline a) & $\begin{array}{l}\text { How to identify a female patient } \\
\text { as the victim of violence? }\end{array}$ & 1 & 2 & 3 & $\square$ \\
\hline b) & $\begin{array}{l}\text { Methods of intervention } \\
\text { (examination of patients' } \\
\text { security, information provision, } \\
\text { empowerment, etc.) }\end{array}$ & 1 & 2 & 3 & $\square$ \\
\hline c) & $\begin{array}{l}\text { Selection of agencies/mass } \\
\text { organizations that can provide } \\
\text { supports to the victims of violence }\end{array}$ & 1 & 2 & 3 & $\square$ \\
\hline d) & $\begin{array}{l}\text { Health, mental, and psychological } \\
\text { consequences }\end{array}$ & 1 & 2 & 3 & $\square$ \\
\hline e) & $\begin{array}{l}\text { Skills on consulting the victims of } \\
\text { violence }\end{array}$ & 1 & 2 & 3 & $\square$ \\
\hline f) & $\begin{array}{l}\text { General information on violence } \\
\text { against women (domestic and } \\
\text { overseas) }\end{array}$ & 1 & 2 & 3 & $\square$ \\
\hline g) & $\begin{array}{l}\text { Legal issues relating to violence } \\
\text { against women }\end{array}$ & 1 & 2 & 3 & $\square$ \\
\hline h) & $\begin{array}{l}\text { quan dến ngược đãi phụ nữ } \\
\text { Other (specify) }\end{array}$ & 1 & 2 & 3 & $\square$ \\
\hline D08 & $\begin{array}{l}\text { Do you think that it is necessary } \\
\text { to have specific medical } \\
\text { regulations on supporting the } \\
\text { female victims of violence? } \\
1=\text { Yes } \\
2=\text { No }\end{array}$ & & & & \\
\hline D09 & $\begin{array}{l}\text { In your opinion, which measures } \\
\text { might help to improve the } \\
\text { situation of violence against } \\
\text { women? (Do not read; ask } \\
\text { "anything else?") }\end{array}$ & & ned & $\begin{array}{l}\text { Not } \\
\text { mentioned }\end{array}$ & \\
\hline a) & $\begin{array}{l}\text { There should be collaboration } \\
\text { among agencies/mass } \\
\text { organizations (women's union, } \\
\text { youth's union, etc.) }\end{array}$ & & & 2 & $\square$ \\
\hline
\end{tabular}




\begin{tabular}{|c|c|c|c|c|}
\hline No. & Question & \multicolumn{3}{|c|}{ Codé } \\
\hline b) & Educate men on this issue & 1 & 2 & $\square$ \\
\hline c) & Strict sanctions on criminals & 1 & 2 & $\square$ \\
\hline d) & $\begin{array}{l}\text { Educate the community on } \\
\text { gender equality }\end{array}$ & 1 & 2 & $\square$ \\
\hline e) & $\begin{array}{l}\text { Help the women acknowledge } \\
\text { about their roles and } \\
\text { empowerment }\end{array}$ & 1 & 2 & $\square$ \\
\hline f) & Other (specify).... & 1 & 2 & $\square$ \\
\hline
\end{tabular}

SAY THANK YOU AND END THE INTERVIEW 


\title{
ANNEX 5. PCVN GUIDELINE FOR FOCUS GROUP DISCUSSION
}

\author{
PCVN GUIDELINE TO CONDUCT \\ Focus Group Discussions (dev. October 2, 2009)
}

The purpose of this focus group discussions (FGD) is to obtain qualitative information relevant for evaluating the degree to which changes in knowledge, attitudes and practice/actions are the result of the three year community and hospital-based intervention to address gender-based violence (GBV) implemented by Hanoi Health Service (HHS). It is expected that FGD answer questions that the development cannot resolve and can lead to new ideas. FGD is not for reaching a consensus!

What are the differences between Focus Groups and Surveys?

\begin{tabular}{ll}
\multicolumn{1}{c|}{ Focus Groups } & \multicolumn{1}{c}{ Surveys } \\
\hline $\begin{array}{l}\text { Provide depth over breadth } \\
\begin{array}{l}\text { Use small samples and the findings } \\
\text { cannot be generalized }\end{array}\end{array}$ & $\begin{array}{l}\text { Require large samples and are more } \\
\text { readily generalized }\end{array}$ \\
\hline $\begin{array}{l}\text { Enable the agency to ask a variety of } \\
\text { questions and explore the answers as } \\
\text { they arise }\end{array}$ & $\begin{array}{l}\text { Are standardized but do not allow } \\
\text { the exploration of answers in } \\
\text { depth }\end{array}$ \\
\hline $\begin{array}{l}\text { Generate rich, complex ideas and are } \\
\text { difficult to analyze }\end{array}$ & $\begin{array}{l}\text { Can be relatively simple to analyze } \\
\text { but yield less rich data }\end{array}$ \\
\hline
\end{tabular}

\section{FOCUS GROUP FACILITATION/PREPARATION STEPS}

\section{Focus Group Facilitation}

FGD needs a facilitator and a co-facilitator:

1. Role of facilitator: leads the discussion, keeps the conversation flowing and takes a few notes to remember comments that s/he may want to use later.

2. Role of co-facilitator: takes comprehensive notes, operates the tape recorder, handles the environmental conditions and logistics, and responds to unexpected interruptions and keeps track of time. 
3. Total Participants per FGD: six to twelve participants. Fewer than six participants tends to limit the conversation, because there is not enough diversity. A group larger than twelve gets to be unwieldy and voices get lost. However, be prepare for no-shows.

4. Basic information of participants (Form FGD \#1); Assign a number to a participant and ask her/him to fill in the basic info: gender, age, occupation, position, number of years of service, marital status, number of children, and whether she/he has ever participated in any training course or workshop on Gender-Based Violence.

\section{Facilitation Guide:}

There are two approaches to facilitate FGD:

1) The first is being a "blank slate" - approaching the focus group with an open mind and as few preconceptions as possible about what participants are likely to say or not say;

2) The other essential approach is to prepare a FGD script beforehand (in bullet points or single-questions) and stick to it.

Length of Time: 1-2 hour time frame, including for opening and closing remarks.

Be cautious not to exceed two hours.

Time to spend on each question: not more than 10-12 minutes.

This means an effective FGD can only have time for 7 - 10 questions.

Once you have a list of questions, look at your purpose statement again. Keep questions that are really important and that qualify for your purpose. Eliminate as many questions as possible.

Note: all FGD questions should be open-ended and move from the general to the specific, and close with the following question: "Do you have any suggestions about what they should do?

Be aware of potential biases as a facilitator. Differences in race/ethnicity, class/SES and education levels between the moderator and participants can bring unforeseen biases to how a facilitator runs a focus group.

\section{The Physical Environment}

- Choose or set up a physical space for the focus group that is going to feel welcoming and comfortable to the participants. It should be neutral, private, free from distractions and easily accessible. 
- Facilitators should arrive before the participants

- Arrange participants so that participants can view one another. U-shaped or a circle seating is best; and ASSIGNED NUMBER (or NAME TAGS)

- Tell participants where the bathrooms are.

- Provide refreshments and place them away from the circle to avoid distractions.

\section{Materials Needed and Preparation Steps}

1. Note pad and pen for taking notes.

2. List of participants with name tags/assigned number; ask participants to fill in Basic Information Form (Form FGD-1)

3. Focus group script with 7-10 single questions

4. Clock or watch to write the Starting Time and the Finishing Time

5. Tape record the discussion and transcribe it (check the tape recorder before and immediately after each session if it did not work, do an immediate debrief).

6. Be ready for unexpected problems, such as bad weather, fewer participants than expected, poor meeting space, field coordinator did not make adequate preparations, participants bring other adults, other uninvited people show up, or the group doesn't want to talk.

\section{Opening: Introduce facilitator and co - facilitator}

1. Greet and tell participants "They're the experts" - convey to them that you value their opinions, that they are the experts! The focus group facilitator and other staff have come to learn from them. This empowers participants, and helps eliminate any barriers that may arise as a result of differences between participants and FGD facilitators; participants must feel good about the session;

2. Explain the means to record the session. Make sure you record the session!

3. Carry out the focus group as per the plan and script.

4. The facilitator should have some room for spontaneity, i.e., asking spontaneous questions that arise from the discussion, probing deeper into a topic. 
5. Make sure every participant is heard; draw out quieter group members;

6. Get full answers (not just "yes" or "no"). Use Probes When You Need More Information. When participants are not providing enough information, try the following probes:
a. Would you explain further?
b. Would you give me an example of what you mean?
c. Would you say more?
d. Tell us more.
e. Is there anything else?
f. Please describe what you mean.
g. I don't understand.
h. Does anyone see it differently?
i. Has anyone had a different experience?

7. Ask only one question at a time - Don't ask more than one question at a time, even if the questions go together. Participants usually cannot remember several questions at one time, and asking multiple questions makes it hard for them to know where to start.

8. Frequently repeat key phrases from the question - Participants tend to lose focus on the question after 2-3 other participants have responded to it. Repeating key phrases from the question at strategic times, or asking participants to link their response to key terms in the question will help participants stay focused.

9. Monitor time closely; don't exceed time limits.

10. Keep the discussion on track; try to answer all or most of the questions.

11. Avoid "leading" participants with any reaction to their comments, facilitator should be warm but value-neutral. Ways to be value-neutral are: information seeking- "Tell me more about that...", clarifying"Can you explain what you mean?" and acknowledging "I hear what you are saying...".

12. Be Comfortable with Silence. It is also important that moderators be comfortable with silence and "pregnant pauses." Some participants may participate more if they have more time to consider the question before they speak.

13. The closing section wraps up the focus group. This includes thanking the participants, giving them an opportunity and avenue for further input, telling them how the data will be used, and explaining when the larger process will be completed. 


\section{After the Focus Group: Clarify any scratching on your written notes, ensure pages are numbered, fill out any notes that don't make senses, etc.}

Interpret and Report the Results: there are 3 steps to create a report on your FGD:

1. Summarize each meeting. The facilitator should review the session with another person to capture fresh impressions.

IMPORTANT: transcribe field notes soon after the session is over and write a summary of the focus group. The quick turnaround time on the transcription helps avoid memory lapses. It's easiest for the facilitator or recorder to remember what was meant by a particular acronym or shorthand immediately following the session than it is a month later.

2. Analyze the summaries. Start by reading all the focus group summaries in one sitting. Look for trends (comments that seem to appear repeatedly in the data) and surprises (unexpected comments that are worth noting). Keep in mind that context and tone are just as important as the reiteration of particular words. If a comment (or a number of comments) seemed to be phrased negatively, elicited emotional responses, or triggered many other comments, that would be worth noting in the analysis.

3. Write the report. The final report can take many different shapes, but it should include all information about the background and purpose of the focus group, details of the sessions, results, and conclusions.

\section{REFERENCES:}

Judith Sharken Simon, How To Conduct A Focus Group

http://www.tgci.com/publications/99fall/conductfocusgp.html (primary)

Carter McNamara, Basics of Conducting Focus Groups

http://www.mapnp.org/library/evaluatn/focusgrp.htmEanchor911239

The Small Schools Project, Conducting Focus Groups

http://www.smallschoolsproject.org/tools/files/focusgroups.PDF 


\section{FOCUS GROUP DISCUSSIONS (FGD) SCRIPT}

\section{Participants: Duc Giang Hospital Health Managers}

Time to spend on each question: not more than 10-12 minutes.

Total: 7 - 10 questions in a maximum of 2 hour time frame, including for opening and closing remarks

Date: October ......., 2009 Time: ......... -

Total participants:...... (see list of names/positions attached)

Part A: introduction, purpose of interview, and seeking voluntary participation

Introduction. This is a three year project implemented by the $\mathrm{Ha}$ Noi Health Department (HHD) or Ha Noi Health Service (HHD) starting in May 2006, with funding from the Ford Foundation (Grant Đ10600655) and in collaboration with the Center for Studies and Applied Sciences in Gender, Family, Women and Adolescents (CSAGA). This project was supposed to end on April 2009, but HHD requested a no-cost extension to the Ford Foundation and was approved up to December 2009. Ford Foundation allocated a sub-award for threeyears technical assistance from the Population Council Viet Nam (PCVN) to $\mathrm{HHD}$ during the implementation of the project. Although not explicitly stated, the objectives of this project are: (1) to apply tools for monitoring and evaluation of community and hospital-based intervention to address gender-based violence (GBV) in the study sites; and (2) to integrate GBV related measures into the hospital health statistics reporting system of the HHD. The ultimate goal is improvement of quality of care for gender-based violence victims at health facilities in Ha Noi.

The purpose of FGD is to contribute qualitative information for an evaluation of the three year community and hospital-based intervention to address gender-based violence (GBV) implemented by HHD.

Voluntary participation: All participants are asked to voluntarily participate in this discussion as PCVN sees them as the experts! The focus group facilitator and other staff have come to learn from them.

Part B: geographic/biographic information of participants = see Basic Information Form FGD-1 


\section{Part C: (FGD) SCRIPT}

Cl: General awareness and knowledge: what is GBV or Domestic Violence (DV) or Intimate Partners Violence (IPV)? (any of the following forms: physical: hitting, kicking, beating; psychological: intimidation, constant humiliation and belittling; sexual violence: forced sexual intercourse, and other forms of sexual coercion; controlling behavior: isolating women from family and friends, restricting their movements or access to information, services and resources, verbal abuse)

C2: Provide examples of GBV in the community where you live (note down whether they mention who are the victims of DV or rape. How that was identified. How common it was in the past 2 years? Compared to the past 5-10 years?

C3: What do you think is the impact of GBV on woman's health, her family and her children?

Get full answers (not just "yes" or "no"). Use Probes When You Need More Information. When participants are not providing enough information, try the following probes:
a. Would you explain further?
b. Would you give me an example of what you mean?
c. Would you say more? d. Tell us more.
e. Is there anything else? $f$. Please describe what you mean.
g. I don't understand.
h. Does anyone see it differently?

\section{i. Has anyone had a different experience?}

C4: What do you know about the legal protection or law on Violence Against Women (VAW)? Please give your opinion as well as that of your community or professional groups (is it difficult to apply the law?)

C5: Experience in working with DV victims: in your current job, were you able to identify and help GBV victims? Did you help all DV victims go to the reconciliation, local authorities, legal offices, health facility to seek support? If not why? Which cases were prioritized? Where was the very first place that women and girl-child go for help?

C6: What difficulties do you encounter in working with the husband or wife? How did you overcome these difficulties? Is there a standard procedure in your work-site for dealing with GBV victims? Is the consultation with victims required? Is it difficult to reach reconciliation with the husband? How did you overcome it? 
C7: Is it true that "every woman being raped came to the legal authority, police or health facility to seek support?" In Duc Giang hospital or the hospital you work with, are there standard procedures for dealing with Rape victims? Does this include counseling?

C8: Recommendation/solutions for GBV: what do you recommend for prevention of and solving GBV problems? Explain how we can see progress in that recommendation

C9: According to you, which community organizations or which community leaders can play the key role in this issue? For example, health, women's union, local authority, legal office, police, youth union, peasants union? Does your current organization participate in GBV prevention or support for victims? What should government do?

Q10: How much of your knowledge about GBV and the above comments came from the training or advice received from Duc Giang staff that have been trained by HHD; compared to general information from TV or newspapers or others? 


\title{
ANNEX 6. PCVN GUIDELINE FOR IN-DEPTH INTERVIEWS
}

\author{
PCVN GUIDELINE TO CONDUCT \\ In-depth Interviews (dev. October 4, 2009)
}

The purpose of this In-depth Interview guide is to obtain qualitative information as a complement to quantitative assessment of the degree to which changes in knowledge, attitudes and practice/actions are the result of the three year community and hospital-based intervention to address gender-based violence (GBV) implemented by Ha Noi Health Service (HHD). In-depth interviews as well as Focus Group Discussions are useful if used together with a quantitative method in a complementary manner - to bring about in-depth understanding of the topics of inquiry

\section{In-depth Interviews Preparation Steps}

An in-depth, qualitative interview is an open-ended research technique with an objective to understand the nature of the area/topics being investigated (including program processes and outcomes) from the perspective of the target audience or key stakeholder. The goal is to explore in depth the respondent's point of view, feelings and perspectives, and not to measure the size and shape of it. The key to this technique lies in its flexible approach, so there is no such thing as the 'standard' in -depth interview. But there are generally agreed rules about the application of the in-depth interview.

Length of Time: Experience indicates that an in-depth interview should last 45 - 60 minutes, and is conducted with one individual respondent at a time. There are also variations such as: mini-depth interviews, extended depth interviews (can last to two and a half hours), observational depth interviews, and others.

\section{Facilitation Guide:}

- The process is similar to a guided conversation;

- Interviewer uses flexible, dynamic, open-ended questions worded in such a way that respondents cannot simply answer yes or no, but must get beneath superficial responses

- A list of pre-planned questions to ask can be used but must also allow questions to flow naturally, based on information provided by the respondent. Interviewer should not insist upon asking specific questions in a specific order! 
- The flow of the conversation dictates the questions asked and those omitted, as well as the order of the questions. There should be smooth transitions from one topic to the next.

- The primary role of the interviewer is to be an attentive listener who shapes the conversations in a familiar and comfortable form of social engagement;

- The interviewer may explore a few general topics to help uncover the respondent's views, but otherwise respects how the respondent frames and structures the responses, the perspective, and what the respondent wants, not as the researcher views it!

- The interviewer should try to interpret what is heard as well as seek clarity and a deeper understanding from the respondent throughout the interview.

- Both parties behave as though they are of equal status all through the period of the in-depth interview- whether or not this is actually so.

\section{Materials Needed and Preparation Steps}

1) Determine who to talk to - how heterogeneous are the respondents chosen for in-depth interviews?

2) Determine who should be the interviewer (level of skill to establish a rapport with the individual throughout the session, able to notice and react to nonverbal clues, flexible, open minded, willing to release power and control, and able to project the feeling that although the views of the respondent are paramount, the interviewer is reciprocating or sharing the experience)

3) Must create an atmosphere where the respondent can talk openly and honestly and in which any projective techniques can be properly introduced to uncover the innermost thoughts and feelings of the respondent;

4) Record responses - typically with audiotape and written notes (fieldnotes)

5) Record observations - observe and record non-verbal behaviors on the field notes as they occur. Communication research indicates that only $7 \%$ of what we say is conveyed through the actual words we use; $38 \%$ by tone and inflection; and $55 \%$ by non-verbal cues.

6) Record reflections - interviewer's views and feelings immediately after the interview 
7) Determine what level of analysis is desired and what level of accuracy is required - this needs a systematic recording and documenting of responses coupled with intense probing for deeper meaning and understanding of the responses.

\section{Seven stages of conducting an in-depth interview}

Thematizing, designing, interviewing, transcribing, analyzing, verifying, and reporting

1) Thematizing - This is the first stage of the process whereby the interviewer clarifies the purpose of the interview, i.e., "we are using this interview to complement other methods of evaluating the HHD GBV intervention program."

2) Designing an interview guide - An interview guide is a list of questions and probing follow-ups that guide the interviewer through the interview. The interviewer should anticipate possible changes in direction during the interview, but the interview guide will: help to stay on track; insure that important issues/topics are addressed; provide a framework and sequence for the questions; and help maintain some consistency across interviews with different respondents. The interviewer guide consists of 3 basic parts: fact sheet, actual questions, and postinterview cover sheet.

a. The face sheet - record (1) factual information such as time, date, and place of the interview; (2) demographic information about the interviewee; and (3) any special conditions or circumstances that may affect the interview;

b. The actual interview questions - record the actual questions, probing questions or statements, anticipated follow-up questions and an additional column alongside the questions for observations made during questioning;

c. The post-interview comment sheet is a place to write notes after the interview that details your feelings, interpretations, and other comments.

3) Interviewing - The actual interview consists of three main parts:

a. The first part: approx. 15 minutes - involves introducing the interviewer and the study. Establish a good rapport with the respondent. Put the respondent at ease. Then ask permission of the respondent before turning on the audiotape recorder. Inform the respondent that audiotape is needed for later reference and increased accuracy. Begin by "breaking the ice" with a general 
question and gradually move on to more specific ones. This makes the respondent feel at ease to express her/his current state of mind towards the topics of inquiry. Interviewer's main responsibility is to listen and observe while guiding the respondent through a conversation until all of the important issues on the interview guide are explored. Strategies:

al. Active listening - listen and re-phrase what was said to insure complete understanding of what the respondent mean.

a2. Patience - do not rush the respondent

a3. Flexibility - be open to slight deviations from the topic - this requires re-ordering the questions or coming up with new questions (and then carefully return the respondent to the topic at hand)

a4. Interviewer can use the projective techniques: instead of questioning the respondent directly, the interviewer asked the respondent to respond indirectly, either talking about other people, these other people's feelings, attitudes and opinions, or an ambiguous situation in which the respondent has to use the ego defense mechanism of projection. In projecting to a third party or an object/a situation, the respondent projects her/his covert feelings to the third party or object, and once these are in the open they may be discussed directly in the second part;

b. The second part: approx. 15-20 minutes - maintain a tone of friendly chat while trying to remain close to the guideline of the topics of enquiry, encourage the interviewee to proceed in expressing how her/his opinion lead to her/his attitude and decision about the issue of discussion (while the interviewer notes down the train of thought and the emotional responses shown by the interviewee) '

c. The third part: approx.15-25 minutes - involves the respondent in a full discussion of what has been said, while also intelligently asking questions intended to check the truth of statements made by the respondent and how these match expectations (the objectives of the study), and how in practice this differs from what is originally intended, as to what really affects the related process, decision and actions.

d. Closing - thank the respondent on behalf of the institutions that organize the interviews. 
4) Transcribing - This is a pre-analysis stage. Transcribing involves creating a written text of the interviews. This step involves bringing together all of information-gathering approaches into one written form - include each question and response (verbatim) from the respondent (respondent's notes, typically by highlighted text) using recorded answers in the audiotape and the interviewer's field notes and the post interview comment sheet (observations, feelings and reflections). Study and review these transcriptions, then denote the important information related to the study.

5) Analysis - In principle, there are no 'right' ways to analyze qualitative in-depth data; however, when comparisons are to be made across different respondents, a more formal and structured content analysis should be done in order to achieve comparable data. Analysis can be conducted from listening directly to the raw data (the tape recorder) or from a transcription of the interview combined with the interviewer's note on the emotional responses of the interviewee. Content analysis is to study the important information and look for themes, commonalities, and patterns to try to make sense of the information.

6) Verifying - This involves checking the credibility and validity of the information gathered. A method called triangulation is used as a means of checks and balances (An article on triangulation is available at http://edis.ifas.ufl.edu). Basically, one type of triangulation would be to use multiple perspectives to interpret a single set of information. For example, for GBV, we would interview the hospital staff who attended the GBV training, the GBV victim, and the GBV data collector (counselor)-if applicable. If each one says basically the same thing, then the weight of evidence would be that the information is credible and valid.

7) Reporting - The final step of the process is to share what you have learned from the in-depth interviews with other internal and external stakeholders through the form of a formal written report.

\section{Strength and weaknesses of in-depth interviews}

Strength: In-depth interviews are appropriate to obtain:

1) Detailed behavioral or attitudinal information or a particular decision process. For example, how does an individual choose to exercise a particular policy; what influences are brought to bear upon the final decision making; what exactly she or he is looking for? 
2) The insight in revealing sensitive feelings and emotions or unexplored issues, i.e., what an individual feels about certain sensitive issues such as highly intimate personal matters.

\section{Weakness/disadvantages:}

1) In-depth interviews are time consuming and costly (travel and costs between interviews)

2) In-depth interviews arguably have the greatest problems with validity - that is, this technique cannot provide answer to: "Would other researchers reach similar conclusions if they apply the same method in their research analysis?"

A combination of qualitative and quantitative methods of analysis often yields richer insights and provides creative triangulation solutions to a broad set of problems. This is because the loosely linked issues that emerged in the course of a study require both quantitative and qualitative analysis to dissect their constituent form to help understand their nature more. Qualitative information can help sharpen the researcher's insights about findings, the focus of further research and which results need to be emphasized - this complements the strength of quantitative analysis, which can help to measure magnitudes and trade-offs between different policy options.

\section{REFERENCES}

Guion, Lisa. Conducting an In-depth Interview. A second of a four-part series of the Family Youth and Community Sciences Department, Florida Cooperative Extension Service, Institute of

Food and Agricultural Sciences, University of Florida. Original publication date October 15, 2001. Revised January 2006. Visit the EDIS Web Site at http://edis.ifas.ufl.edu.

Musah, Stoik. A Critical Analysis of In-depth Qualitative Interview in Organisational Research Studies. Leicester, UK: May 2007

Willis, Kate. "In-depth Interviews" in The International Handbook of Market Research Techniques (Chapter 16). London, UK: Kogan Page Ltd. 2004 (reprinted). 


\section{IN-DEPTH INTERVIEW GUIDE}

\section{Respondents: Duc Giang Hospital Leaders and its Network Members}

Time: 60 minutes

Total: 5 open-ended questions

Number and Name of Respondent:

\section{Prepare Attachments:}

(1) The face sheet: to record (1) factual information such as time, date, and place of the interview; (2) demographic information about the interviewee; and (3) any special conditions or circumstances that may affect the interview;

(2) The actual interview questions - record the actual questions, probing questions or statements, anticipated follow-up questions and an additional column alongside the questions for observations made during questioning;

(3) The post-interview comment sheet - to write notes after the interview that details your feelings, interpretations, and other comments.

Part A: introduction, purpose of interview, and seeking voluntary participation

Introduction. This is a three year project implemented by the Ha Noi Health Department (HHD) or Ha Noi Health Service (HHD) starting in May 2006, with funding from the Ford Foundation (Grant Đ1060-0655) and in collaboration with the Center for Studies and Applied Sciences in Gender, Family, Women and Adolescents (CSAGA). This project was supposed to end on April 2009, but HHD requested a no-cost extension to the Ford Foundation and was approved up to December 2009. Ford Foundation allocated a subaward for a three-year technical assistance from the Population Council Viet Nam (PCVN) to HHD during the implementation of the project. Although not explicitly stated, the objectives of this project are: (1) to apply tools for monitoring and evaluation of community and hospital-based intervention to address gender-based violence (GBV) in the study sites; and (2) to integrate GBV related measures into the hospital health statistics reporting system of the HHD. The ultimate goal is improvement of quality of care for genderbased violence victims at health facilities in Ha Noi.

The purpose of this In-depth Interview is to contribute qualitative information for an evaluation of a three year community and hospital-based intervention to address gender-based violence (GBV), implemented by HHD. 
Voluntary participation: Each respondent is asked to voluntarly participate in this In-depth Interview as PCVN values her/him as a resource person!

Thank the respondent after completing the In-depth Interview.

\section{List of pre-planned questions for In-depth Interview \\ - October 4, 2009}

This is a list of questions and probing follow-ups to guide the interviewer

\section{Describe/define the problem}

What is Gender-Based Violence (GBV), how many types in the community, what are the observable impacts? Mostly who are the victims in the family, and why?

What is problematic in protecting GBV victims?

\section{Assemble the evidence}

What information on GBV has been collected in the past two years? Violence Against Women (VAW), Sexual Assaults (SA), Rape of women and girls and children? Has this information been presented to anyone? To whom? Legal authorities: who? What difficulties encountered in assembling and presenting this information? Why? Before or after the issuance of the Law on Anti-VAW?

\section{Construct the alternatives/solutions for GBV}

3.1 Does your work have anything to do with GBV? What is your experience (difficulties) in working with victims (domestic violence $(\mathrm{DV})$, sexual assaults (SA) and rape)? And when dealing with the perpetrators (i.e., husbands, intimate partners, others)? Assuming that the situation remains as it is, how can your work contribute to the effort to reduce GBV?

3.2 What did you observe on patterns of when, where and to whom did the GBV victims seek help or support? What were the barriers that they faced?

3.3 What are the basic intervention strategies for preventing and reducing GBV(specify which type of GBV) in your community? How these interventions are being financed? In your opinion, have these programs been successful in preventing/reducing GBV? Why? Why not?

3.4 What government activities, policy or law issuances have the potential for preventing and reducing GBV (DV, SA, and Rape)? Please explain which Ministries should implement the regulation, which one should play the key-role in promoting and implementing the new Law on VAW (2008)? 


\section{Select the most applicable/feasible solutions}

4.1 Remind interviewee that in the past three years HHD has been implementing a strategy to: (1) apply tools for monitoring and evaluation of community and hospital-based intervention to address genderbased violence (GBV) in the study sites; and (2) integrate GBV related measures into the hospital health statistics reporting system of the $H H D$. Based on your experience with this hospital-based intervention, what do you recommend to be done in the future?

4.2 For your organization (if not a hospital): what do you recommend to be done in the future?

\section{Project outcomes}

What do you think need to be done to improve the quality of care for GBV at health facilities in Ha Noi? How should we measure the effects of this activity (intervention)? 


\section{ANNEX 7. SCREENING INTERVIEW AND MONITOR FORMS FOR GENDER-BASED VIOLENCE VICTIMS (USED IN GBV-II PROJECT SITES)}

MINISTSRY OF HEALTH

NAME OF HEALTH FACLITY

\section{SCREENING INTERVIEW FORM FOR GENDER-BASED VIOLENCE VICTIMS \\ (Applicable to patients who are females above 15 year old)}

1. Examination Department/Ward

2. Date of examination: . . . . . . . . .

3. Reasons for examination:

4. Age:

5. Marital status: Married/Previously married

Introduction: We have a project on gender-based violence prevention and we ask all of our female patients about the issue so that necessary support can be provided appropriately.

\begin{tabular}{l|l|l|l|}
\multicolumn{1}{|c|}{ Previously } & Yes & Suspected & No \\
\hline $\begin{array}{l}\text { Domestic violence: "Have you ever been } \\
\text { beaten, cursed or forced to have unwilling } \\
\text { sexual intercourse by spouse/partners/ } \\
\text { relatives?" }\end{array}$ & $\square$ \\
\hline $\begin{array}{l}\text { Child sexual abuse: "Sometimes, women } \\
\text { at an early age, had been sexually abused } \\
\text { (intangible nature sexually), did that happen } \\
\text { to you?" }\end{array}$ & $\square$ \\
\hline $\begin{array}{l}\text { Rape: "Have an acquaintance or a stranger } \\
\text { ever forced you to have unwilling sexual }\end{array}$ & $\square$ \\
intercourse?"
\end{tabular}

If the answer is "Yes" or "Suspected" to any question above, Gender Based Violence information need to be recorded in the green form.

Health Care Provider

(Signature \& name) 
MINISTRY OF HEALTH

NAME OF HEALTH FACILITY

FORM TO MONITOR GENDER-BASED VIOLENCE VICTIMS

I. PATIENTPERSONAL INFORMATION: Date . Month .... Year

Full name Age Sex

Address

Phone (if any)

In case of need, please contact (name, address, phone number)

Occupation

Education

Marital status

Years of marriage:

Number of children

Boys.

Girls

Been sent to health facility or go by herself (in detail):

\section{SCREENING VERIFICATION}

Domestic violence $\square \quad$ Rape $\square$

Child sexual abuse $\square \quad$ Other types of violence $\square$

\section{EXAMINATION AND TREATMENT}

1. Patient history (disease history, sexual history, prior complications, and history of gender based violence). 
2. Physical examinations: (existing wounds: type of violence, date and time, draw the evidence of injuries on the schematic body such as bruises, scars etc.)

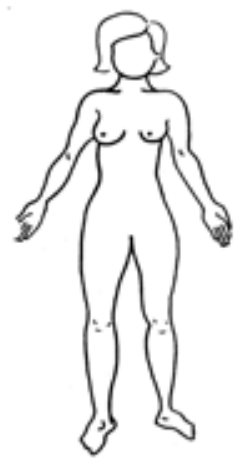

Schematic body (front)

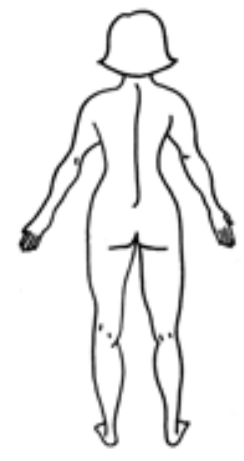

Schematic body (Back)

\section{The Procedures:}

Take away prescription (date/month/year)

Hospitalized (time, date/month/year)

Referred to other hospital (date/month/year)

Referred to Women Center for Counseling and Health care (date/month/ year)

Health condition at discharge

4. Evaluation of safety: $\quad$ Safe $\square \quad$ Unsafe $\square$

IV. REFERRAL TO SUPPORTED SERVICES

\section{Doctor}

(Signature and name) 


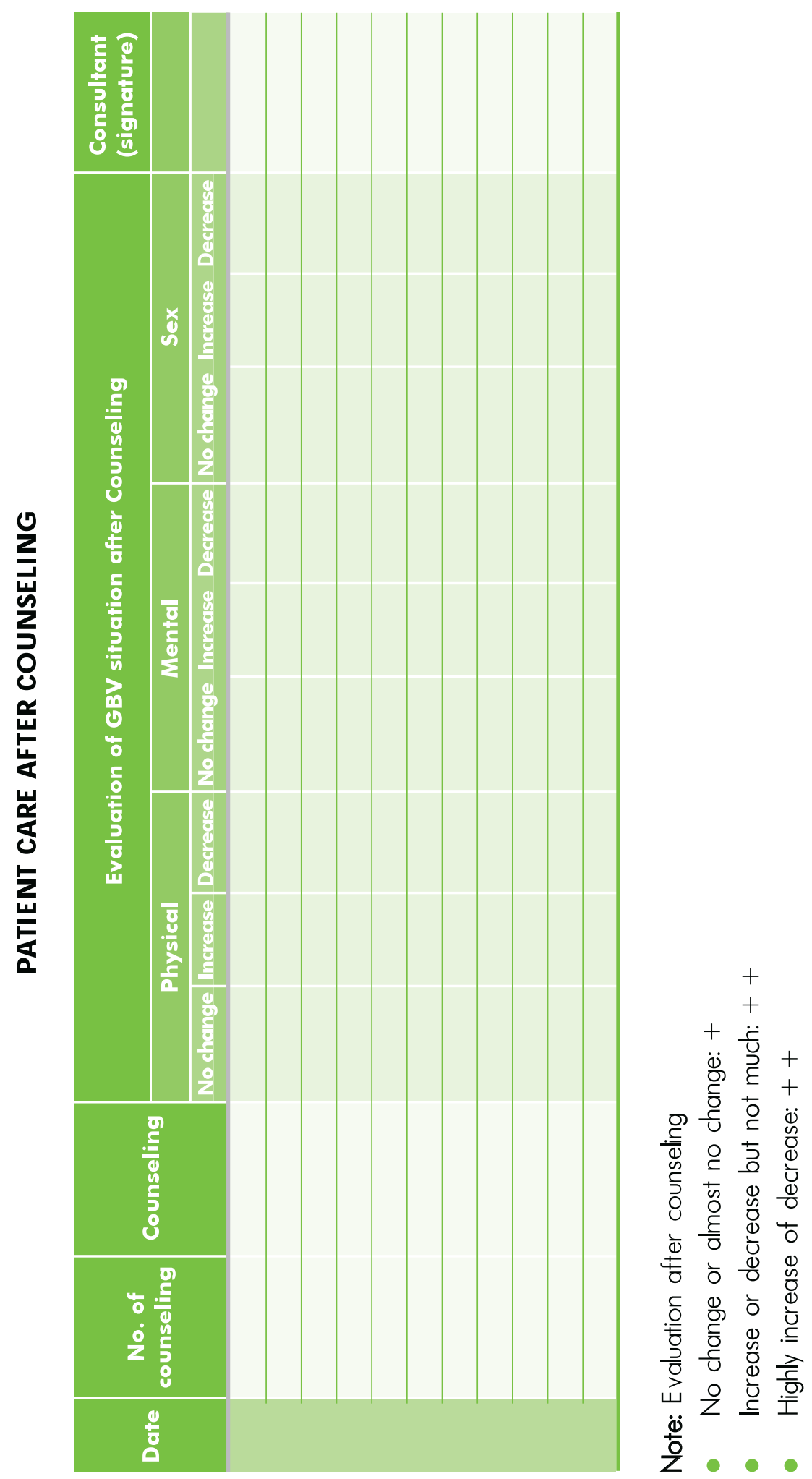




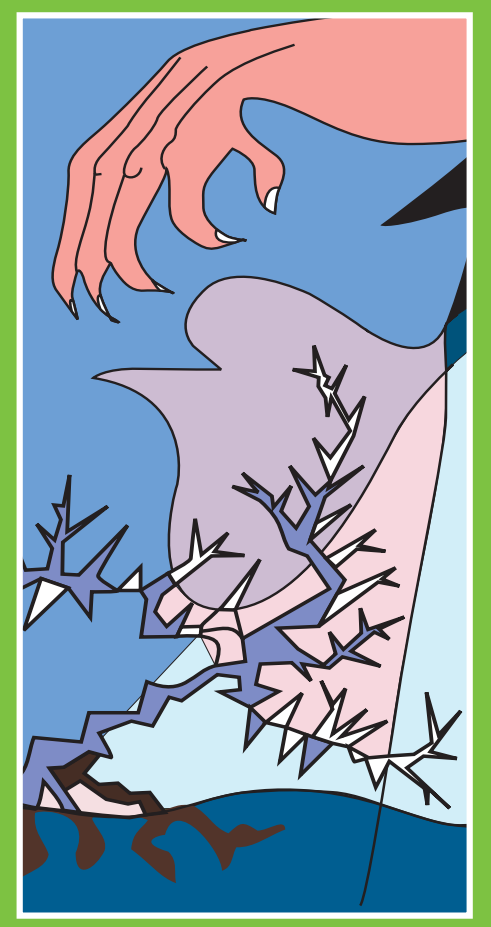

Essential Training Materials GBV-RELATED LAWS AS OF DECEMBER 2009 


\section{List of Essential Training Materials GBV-RELATED LAWS AS OF DECEMBER 2009}

1. Law on domestic violence prevention and control, passed 21/11/2007 by Viet Nam National Assembly

2. Decree No. $08 / 2009 / N D-C P$ detailing and guiding the implementation of a number of articles of the law on domestic violence prevention and control.

3. Circular No: $16 / 2009 /$ TT - BYT guidance on the admission and provision of health care and reporting on patient who are victims of domestic violence at health facilities.

4. Law on gender equality, passed $29 / 11 / 2006$

by Viet Nam National Assembly

5. Law on marriage and family, passed 9/6/2000

by Viet Nam National Assembly 
1. LAW ON DOMESTIC VIOLENCE PREVENTION AND CONTROL, PASSED ON 21/11/2007 BY VIET NAM NATIONAL ASSEMBLY

THE NATIONAL ASSEMBLY

Ref No: 02/2007/QH12
SOCIALIST REPUBLIC OF VIET NAM

Independence - Freedom - Happiness

Ha Noi, Day 21 month 11 year 2009

\section{LAW ON DOMESTIC VIOLENCE PREVENTION AND CONTROL}

(No. 02/2007/QH12)

Pursuant to the 1992 Constitution of the Socialist Republic of Viet Nam, which was amended and supplemented under Resolution No. 51/2001/ QH10;

The National Assembly promulgates the Law on Domestic Violence Prevention and Control.

\section{Chapter I}

\section{GENERAL PROVISIONS}

\section{Article 1. Governing scope}

1. This Law provides for domestic violence prevention, protection of and support for domestic violence victims; responsibilities of individuals, families, agencies and organizations in domestic violence prevention and control; and handling of violations concerning domestic violence prevention and control.

2. Domestic violence means an intentional act by a family member which causes or potentially causes physical, psycological and financial damage to other members of a family.

\section{Article 2. Acts of domestic violence}

1. Acts of domestic violence include:

a/ Persecuting, maltreating, beating or other intentional acts that harm another family members health or life;

b/ Reviling or other intentional acts that offend another family member's honor or dignity; 
c/ Isolating, driving away or frequently imposing psychological pressures that cause serious consequences;

d/ Obstructing the exercise of rights and fulfillment of responsibilities concerning family relationships between grandparents and grandchildren; parents and children; wives and husbands; and among siblings;

e/ Forcing sex;

f/ Forcing early marriage; forcing marriage or divorce, or obstructing voluntary and progressive marriage;

g/ Appropriating, destroying, breaking or other intentional acts that damage private property of other family members or common property of family members;

h/ Forcing family members to overwork or make financial contributions beyond their capacity; controlling family members' incomes in order to create financial dependence;

i) Committing illegal acts to force family members to leave their abode.

2. Acts of domestic violence specified in Clause 1 of this Article also apply to family members of divorced or cohabiting couples.

\section{Article 3. Domestic violence prevention and control principles}

1. To combine and implement comprehensive measures for domestic violence prevention and control, considering prevention essential, and attaching importance to family communication and education, counseling and conciliation in conformity with Vietnamese cultural traditions and good customs and habits.

2. Acts of domestic violence must be promptly detected, stopped and handled in accordance with law.

3. Domestic violence victims must be promptly protected and assisted in a manner suitable to their conditions and the country's socio-economic conditions; to prioritize protection of lawful rights and interests of children, the aged people with disabilities, and women.

4. To bring into play the role and responsibilities of individuals, families, communities, agencies and organizations in domestic violence prevention and control. 


\section{Article 4. Obligations of people committing acts of domestic violence}

1. To respect the lawful interference of the community; to immediately stop acts of domestic violence.

2. To observe decisions of competent agencies and organizations.

3. To promptly take their victims to hospital for first aid and medical treatment; to take care of domestic violence victim, unless refused by victims.

4. To pay compensation to domestic violence victims on request and according to the law.

\section{Article 5. Rights and responsibilities of domestic violence victims}

1. Domestic violence victims have the following rights:

a/ To request competent agencies, organizations or individuals to protect their health, life, dignity and other lawful rights and interests;

b/ To request competent agencies or individuals to apply measures on stoppage, protection and ban from contact under this Law;

c/ To receive healthcare, and psychological and legal counseling services;

d/ To be given temporary shelter, to have their temporary shelter and other information kept secret according to this Law;

e/ Other rights according to law.

2. Domestic violence victims are obliged to supply information on domestic violence to competent agencies, organizations and individuals at their request.

\section{Article 6. State policies on domestic violence prevention and control}

1. The State annually allocates funds for domestic violence prevention and control.

2. To encourage agencies, organizations and individuals to participate in and finance domestic violence prevention and control activities; to develop models of domestic violence prevention and support domestic violence victims.

3. To encourage research into and literature and art creation about domestic violence prevention and control; 
4. To organize and support training of domestic violence prevention and control workers.

5. People who directly engage in domestic violence prevention and control and gain achievements are entitled to commendation. If suffering health damage, life or property loss, they are entitled to prescribed policies.

\section{Article 7. International cooperation in domestic violence prevention and control}

1. The State encourages international cooperation in domestic violence prevention and control on the principles of equality, respect for sovereignty and compliance with Vietnamese and international laws.

2. International cooperation contents include:

a/ Formulating and implementing domestic violence prevention and control programs, projects and activities.

b/ Joining international organizations; concluding, acceding to and implementing treaties and agreements on domestic violence prevention and control;

c/ Exchanging domestic violence prevention and control information and experience.

\section{Article 8. Prohibited acts}

1. Acts of domestic violence specified in Article 2 of this Law.

2. Forcing, inciting, instigating and assisting other people to commit acts of domestic violence.

3. Using and disseminating information, images and sound in order to incite domestic violence.

4. Revenging or threatening to revenge people assisting domestic violence victims or people detecting, reporting and stopping acts of domestic violence.

5. Hindering the detection, reporting and handling of acts of domestic violence.

6. Taking advantage of domestic violence prevention and control activities for self-seeking purposes or commitment of illegal acts.

7. Tolerating, covering up, failing to handle acts of domestic violence or handling them in contravention with the law. 


\section{Chapter II \\ DOMESTIC VIOLENCE PREVENTION}

\section{Section 1. INFORMATION AND COMMUNICATION ON DOMESTIC VIOLENCE PREVENTION AND CONTROL}

Article 9. Purposes and requirements for information and communication on domestic violence prevention and control

1. Information and communication on domestic violence prevention and control aim to change awareness about, and acts of, domestic violence, contributing to gradually eliminating domestic violence and raising awareness about good traditions of Vietnamese people and families.

2. Information and communication on domestic violence prevention and control must satisfy the following requirements:

a/ Being accurate, clear, simple and practical;

b/ Being suitable to each group of people, education level, age, gender, traditions, culture, national identity and religion;

c/ Not affecting gender equity, honor, dignity and prestige of domestic violence victims and other family members.

Article 10. Contents of information and communication on domestic violence prevention and control

1. Laws and policies on domestic violence prevention and control, gender equity, rights and obligations of family members.

2. Fine traditions of Vietnamese people and families.

3. Harmful effects of domestic violence.

4. Measures on, models of, and experience in, domestic violence prevention and control.

5. Knowledge on marriage and family; code of conduct in and build cultured families.

6. Other contents concerning domestic violence prevention and control.

Article 11. Forms of information and communication on domestic violence prevention and control

1. Face-to-face. 
2. Through the mass media.

3. Integrating into training and learning programs of training institutions within the national education system.

4. Through literature and art activities, community activities and other forms of mass cultural activities.

\section{Section 2. CONCILIATION OF CONFLICTS AND DISPUTES BETWEEN FAMILY MEMBERS}

Article 12. Principles on conciliation of conflicts and disputes between family members

1. Being prompt, proactive and patient.

2. Conforming with the Party's guidelines and policies and the State's laws and policies, social ethics and Vietnamese fine customs and habits.

3. Respecting involved parties' voluntary conciliation.

4. Being objective, just, rational and reasonable.

5. Keeping involved parties' private information secret.

6. Respecting lawful rights and interests of others; not harming the State's interests and public interests.

7. Not conciliating conflicts and disputes between family members specified in Articles 14 and 15 of this Law in the following cases:

a/ They are involved in criminal cases, unless victims request not to handle under the Penal Code;

b/ They are involved in illegal acts subject to administrative sanction.

Article 13. Conflict and dispute conciliation by families or family lines

A family shall promptly detect and conciliate conflicts and disputes between its members.

When a family fails to conciliate or at request of family members, the head or a prestigious person of the family line may conduct conciliation or invite a prestigious person in the community to conduct conciliation. 
Article 14. Conflict and dispute conciliation by agencies and organizations

Agencies or organizations may conciliate conflicts and disputes between their employees and family members of these employees at the request of their family members; when necessary, they may coordinate with local agencies or organizations in conducting conciliation.

Article 15. Conflict and dispute conciliation by grassroots conciliation organizations

1. Grassroots conciliation organizations may conciliate conflicts and disputes between family members according to the law on grassroots conciliation.

2. People's Committees of communes, wards or townships (below referred to as commune-level People's Committees) may coordinate with Viet Nam Fatherland Front Committees of the same level and their member organizations in guiding, assisting, and facilitating grassroots organizations to conciliate conflicts and disputes between family members.

\section{Section 3. COUNSELING, COMMENT AND CRITICISM CONCERNING DOMESTIC VIOLENCE PREVENTION BY COMMUNITIES}

\section{Article 16. Family counseling at grassroots level}

1. The State facilities and encourages organizations and individuals to provide family counseling at grassroots level to community members for domestic violence prevention.

2. Grassroots-level family counseling covers the following activities:

a/ Providing information, knowledge and laws on marriage, family and domestic violence prevention and control;

b/ Guiding the code of conduct in families; skills of handling conflicts or disputes between family members.

3. The following target groups shall be provided with grassroots-level family counseling:

a/ Persons committing acts of domestic violence;

b/ Domestic violence victims;

c/ Alcohol and drug addicts, and gamblers;

d/ To-be-married persons. 
4. Commune-level People's Committees shall take the prime responsibility for, and coordinate with Viet Nam Fatherland Front Committees of the same level in, guiding and facilitating activities of grassroots-level family counseling.

\section{Article 17. Comment and criticism by communities}

1. Communities shall comment on and criticize acts of domestic violencecommitting people aged 16 or older who have been conciliated by a grassroots conciliation group but continue committing acts of domestic violence.

2. Heads of hamlets or villages, heads of street population groups or heads of equivalent units (below collectively referred to as community heads) shall decide and organize comment and criticism by communities. People giving comment and criticism include representatives of families, neighboring families and other persons invited by community heads.

3. Commune-level People's Committees shall assist and facilitate community heads in commenting on and criticizing persons committing acts of domestic violence.

\section{Chapter III}

\section{PROTECTION OF AND SUPPORT FOR DOMESTIC VIOLENCE VICTIMS}

\section{Section 1. MEASURES TO PROTECT AND SUPPORT DOMESTIC VIOLENCE VICTIMS}

\section{Article 18. Detecting and reporting domestic violence}

1. Persons who detect domestic violence shall promptly report it to the nearest police office or the commune-level, another family member's Committee or community head of the locality when it occurs, except for the cases prescribed in Clause 3, Article 23 and Clause 4, Article 29 of this Law.

2. Police offices, commune-level People's Committees or community heads who detect or are reported on domestic violence shall promptly deal with it or propose to and request competent agencies or persons to deal with it; keep secret the identity of persons detecting and/or reporting domestic violence and, when necessary, apply measures to protect these persons. 


\section{Article 19. Stoppage and protection measures}

1. Stoppage and protection measures to be promptly taken to protect domestic violence victim, stop acts of domestic violence and reduce their consequences include:

a/ To force prompt termination of acts of domestic violence;

b/ To give first aid to domestic violence victims;

c/ Stoppage measures under the laws on handling of administrative violations or criminal procedures applied to those committing acts of domestic violence;

d/ To ban persons committing acts of domestic violence from approaching their victims and using telephones or other communication devices to commit acts of domestic violence to their victims (below referred to as ban-from-contact measure).

2. Persons present at the place where domestic violence occurs shall, depending on the nature and severity of acts of domestic violence and their capacity, take measures specified at Points $a$ and b, Clause 1 of this Article.

3. The competence of and conditions for applying, changing and canceling measures specified at Point c, Clause 1 of this Article comply with the law on handling of administrative violations or criminal procedures.

4. Measures specified at Point $d$, Clause 1 of this Article shall be applied in accordance with Articles 20 and 21 of this Law.

\section{Article 20. Ban from contact under decisions of presidents of commune-level People's Committees}

1. The president of the commune-level, another family member's Committee of the locality where domestic violence occurs shall decide to apply the measure to ban from contact for not more than three days when all the following conditions are met:

a/ To receive a written request from domestic violence victim, their guardians or representatives-at-law or competent agencies or organizations; when a competent agency or organization makes such request, it must obtain the consent of domestic violence victims.

b/ Acts of domestic violence cause damage or threaten to cause damage to the health or threaten the life of domestic violence victims;

c/ Persons committing acts of domestic violence and domestic violence victims have different places of residence at the time of banning from contact. 
2. Presidents of commune-level People's Committees shall consider and decide to apply the ban-from-contact measure within 12 hours from the time of receiving a written request; when they do not issue such decision, they shall send a notice to request makers, clearly stating the reason.

A ban-from-contact decision takes effect after its signing and shall be sent to persons committing acts of domestic violence, domestic violence victim, and heads of the communities where domestic violence victims reside.

3. Presidents of commune-level People's Committees who have issued a ban-from-contact decision may cancel this decision when domestic violence victims make a written request or when this measure is considered no longer necessary.

4. When a family has a funeral- or marriage-related affair, or in other special cases in which the person committing acts of domestic violence and the victim have to contact each other, the person committing acts of domestic violence shall report it to the head of the community where the domestic violence victim resides.

5. Persons committing acts of domestic violence who violate the banfrom-contact decision may be taken into administrative custody or be administratively sanctioned.

6. The Government shall specify the application and termination of the ban-from-contact measure and handling of acts of domestic violence-committing persons who violate ban-from-contact decisions prescribed in this Article.

\section{Article 21. Ban from contact under courts' decisions}

1. The court which handles or settles a civil case between a domestic violence victim and the person committing acts of domestic violence may decide to apply the ban-from-contact measure for not more than four months when all the following conditions are met:

a/ The domestic violence victim, his/her guardian or representativeat-law or a competent agency or organization makes a written request; when this request is made by a competent agency or organization, this agency or organization must obtain the consent of the domestic violence victim.

b/ Acts of domestic violence cause damage or threaten to cause damage to the health or threaten the life of the domestic violence victim; 
c/ The person committing acts of domestic violence and the victim have different places of residence during the time of banning from contact.

2. A ban-from-contact decision takes effect after its signing and shall be sent to the person committing acts of domestic violence, domestic violence victim, the president of the commune-level Another family member's Committee, the head of the community where the domestic violence victim resides and the People's Procuracy of the same level.

3. The People's Court which has issued a ban-from-contact decision may annul that decision when the domestic violence victim makes a written request or when finding this measure no longer necessary.

4. When the family has a funeral- or marriage-related affair, or in other special cases in which the person committing acts of domestic violence and the victim have to contact each other, the person committing acts of domestic violence shall report it to the head of the community where domestic violence victim resides.

5. The competence and order of, and procedures for applying, changing or canceling the ban-from-contact measure prescribed in this Article comply with the civil procedure law concerning temporary urgent measures.

\section{Article 22. Supervising implementation of ban-from-contact decisions}

1. When receiving a ban-from-contact decision of presidents of commune-level People's Committees or competent courts, community heads shall coordinate with concerned grassroots organizations in designating a person to supervise the implementation of this decision.

2. The person designated to the supervision has the following tasks:

a/ To supervise the compliance of the decision to ban from contact between the person committing acts of domestic violence and the victim; when detecting that the person committing acts of domestic violence contacts the victim, to request this person to strictly comply with the ban-from-contact decision;

b/ When the person committing acts of domestic violence intentionally attempts to contact the victim, to report it to the community head for taking measures to force that person to terminate his/her act. 
3. In case the person committing acts of domestic violence is allowed to contact the victim under Clause 4, Article 20 and Clause 4, Article 21 of this Law, other family members shall supervise to ensure that domestic violence does not occur.

\section{Article 23. Taking care of domestic violence victims in healthcare establishments}

1. When receiving medical examination and treatment at healthcare establishments, domestic violence victims may be certified for their medical examination and treatment at request.

2. Expenses for medical examination and treatment of domestic violence victims shall be paid by the health insurance fund for persons covered by health insurance.

3. When performing their tasks, health workers shall keep secret information on domestic violence victims; when detecting that acts of domestic violence show signs of crime, they shall promptly report them to heads of healthcare establishments for report to the nearest police office.

\section{Article 24. Counseling for domestic violence victims}

1. A domestic violence victim may receive healthcare, domestic code of conduct, legal and psychological counseling to deal with domestic violence.

2. Healthcare establishments, social security establishment, domestic violence victim support establishments, domestic violence prevention and control counseling establishments, individuals and organizations specified in Articles 27, 28, 29 and 30 of this Law shall, within the scope of their functions and tasks, provide appropriate counseling for domestic violence victims.

\section{Article 25. Urgent support for essential needs}

Commune-level People's Committees shall take the prime responsibility for, and coordinate with Viet Nam Fatherland Front Committees of the same level and their member organizations and other local social organizations and domestic violence victim support establishments in, providing urgent support for essential needs of domestic violence victims when necessary. 


\section{Section 2. DOMESTIC VIOLENCE VICTIM ASSISTANCE ESTABLISHMENTS}

\section{Article 26. Domestic violence victim assistance establishments}

1. A domestic violence victim assistance establishment is a place to provide care, counseling, temporary shelter and other necessary support for domestic violence victims.

2. Domestic violence victim assistance establishments include:

a/ Healthcare establishments;

b/ Social security establishments;

c/ Domestic violence victim support establishments;

d/ Domestic violence prevention and control counseling establishments;

e/ Reliable community addresses.

3. The Government shall detail and guide activities of domestic violence victim assistance establishments.

\section{Article 27. Healthcare establishments}

1. Healthcare establishments shall provide healthcare services under Article 23 of this Law and healthcare counseling services.

2. Apart from complying with Clause 1 of this Article, state healthcare establishments shall, depending on their capacity and realities, arrange temporary shelter for domestic violence victims for not more than one day at the victims' request.

\section{Article 28. Social security establishments}

Social security establishments shall provide care, psychological counseling, temporary shelter and other necessary supports for domestic violence victims.

Article 29. Domestic violence victim support establishments and domestic violence prevention and control counseling establishments

1. The State encourages and creates conditions for organizations and individuals to set up domestic violence victim support establishments and domestic violence prevention and control counseling establishments; finances a number of these establishments under programs and plans on domestic violence prevention and control; the Government shall prescribe support funds and beneficiaries. 
2. According to their operation regulations or functions and tasks, domestic violence victim support establishments and domestic violence prevention and control counseling establishments may provide counseling services on law, psychology, healthcare, temporary shelters and other necessary conditions for domestic violence victims.

3. Domestic violence victim support establishments and domestic violence prevention and control counseling establishments must meet the following conditions:

a/ Having facilities and professional staff suitable to domestic violence victim assistance activities;

b/ Having financial sources to cover expenses for domestic violence victim assistance activities.

4. Counselors must possess moral qualities and professional qualifications as prescribed by law. In the course of providing counseling for domestic violence victim, counselors shall keep secret information on domestic violence victims; when detecting that acts of domestic violence show signs of crime, they shall report them to heads of their establishments for report to the nearest police office.

\section{Article 30. Reliable community addresses}

1. Reliable community addresses are individuals and organizations that have prestige and conditions and voluntarily assist domestic violence victims in communities.

2. Individuals and organizations shall notify commune-level People's Committees of localities where they register to be reliable addresses and the location of the reliable addresses.

3. Depending on their actual conditions and abilities, reliable community addresses may receive domestic violence victim, provide support, counseling and temporary shelter for victims and notify competent agencies thereof.

4. Commune-level People's Committees shall make and announce a list of reliable community addresses; guide and train in domestic violence prevention and control and protection of reliable community addresses when necessary.

5. Viet Nam Fatherland Front Committees of communes, wards and townships and their member organizations shall coordinate with People's Committees of the same level in propagating information on, mobilizing and setting up reliable community addresses. 


\section{Chapter IV \\ RESPONSIBILITIES OF INDIVIDUALS, FAMILIES, AGENCIES \\ AND ORGANIZATIONS IN DOMESTIC VIOLENCE \\ PREVENTION AND CONTROL}

\section{Article 31. Responsibilities of individuals}

1. To comply with the laws on domestic violence prevention and control, marriage and family, gender equity, prevention and control of drugs, prostitution and other social evils.

2. To promptly stop acts of domestic violence and notify competent agencies, organizations or individuals thereof.

\section{Article 32. Responsibilities of families}

1. To educate and remind family members to comply with the laws on domestic violence prevention and control, marriage and family, gender equity, prevention and control of drugs, prostitution and other social evils.

2. To conciliate conflicts and disputes between family members; to advise persons committing acts of domestic violence to stop their acts; to take care of domestic violence victims.

3. To coordinate with agencies, organizations and communities in preventing and controlling domestic violence.

4. To take other domestic violence prevention and control measures according to this Law.

\section{Article 33. Responsibilities of the Vietnam Fatherland Front and member organizations}

1. To disseminate, educate, encourage members and citizens to comply with, the laws on domestic violence prevention and control, marriage and family, gender equity, prevention and control of drugs, prostitution and other social evils.

2. To propose to concerned state agencies necessary measures to enforce the laws on domestic violence prevention and control, marriage and family, gender equity, prevention and control of drugs, prostitution and other social evils; to participate in domestic violence prevention and control, care for, support and protection of domestic violence victims.

3. To participate in supervising the implementation of the law on domestic violence prevention and control. 


\section{Article 34. Responsibilities of the Vietnam Women's Union}

1. To perform responsibilities prescribed in Article 33 of this Law.

2. To organize domestic violence prevention and control counseling establishments and domestic violence victim assistance establishments.

3. To organize vocational training, credit and savings activities to support domestic violence victims.

4. To coordinate with concerned agencies and organizations in protecting and assisting domestic violence victims.

\section{Article 35. Domestic violence prevention and control state management agencies}

1. The Government shall perform the unified state management of domestic violence prevention and control.

2. The Ministry of Culture, Sports and Tourism shall take responsibility before the Government for performing the state management of domestic violence prevention and control.

3. Ministries, ministerial-level agencies shall, within the scope of their tasks and powers, coordinate with the Ministry of Culture, Sports and Tourism in performing the state management of domestic violence prevention and control.

4. People's Committees of all levels shall, within the scope of their tasks and powers, perform the state management of domestic violence prevention and control in localities;

5. Annual socio-economic reports of commune-level People's Committees to another family member's Councils of the same level must include the situation and results of domestic violence prevention and control in localities.

\section{Article 36. Responsibilities of the Ministry of Culture, Sports and Tourism}

1. To elaborate and submit to competent agencies for promulgation or promulgate according to competence, legal documents, programs and plans on domestic violence prevention and control.

2. To take the prime responsibility for, and coordinate with ministries, ministerial-level agencies, government-attached agencies and provincial/ municipal People's Committees in, implementing legal documents, programs and plans on domestic violence prevention and control. 
3. To guide family counseling activities at grassroots level, formation and closure of domestic violence prevention and control counseling establishments, domestic violence victim assistance establishments.

4. To assume the prime responsibility for, and coordinate with concerned agencies and organizations in, promulgating and implementing regulations on training of domestic violence prevention and control workers.

5. To inspect and examine the implementation of the law on domestic violence prevention and control.

6. To carry out international cooperation in domestic violence prevention and control.

7. To assume the prime responsibility for, and guide the review and analysis of the situation of domestic violence prevention and control; to direct the reporting of and statistical work on domestic violence prevention and control; to sum up experience in and expand models of domestic violence prevention and control.

8. To assume the prime responsibility for, and coordinate with concerned agencies in, editing and supplying information on domestic violence prevention and control.

\section{Article 37. Responsibilities of the Ministry of Health}

1. To promulgate and implement a regulation on receipt of and healthcare for patients who are domestic violence victims in healthcare establishments.

2. To guide healthcare establishments in making statistics and reports on patients who are domestic violence victims.

3. To promulgate guidelines for detoxification of alcohol addicts.

Article 38. Responsibilities of the Ministry of Labor, War Invalids and Social Affairs

1. To direct the integration of domestic violence prevention and control contents into programs on hunger eradication and poverty reduction, vocational training and employment.

2. To guide the assistance of domestic violence victims in social security establishments. 
Article 39. Responsibilities of the Ministry of Education and Training, schools and other educational institutions within the national education system

1. The Ministry of Education and Training shall direct the integration of domestic violence prevention and control knowledge into education and training programs in response to the requirements of each discipline and educational level.

2. Schools and other educational institutions within the national education system shall carry out education programs that integrate domestic violence prevention and control knowledge.

\section{Article 40. Responsibilities of the Ministry of Information and} Communication and mass media agencies

1. The Ministry of Information and Communication shall direct mass media agencies in reporting on and disseminating the law and policies on domestic violence prevention and control.

2. Mass media agencies shall provide prompt and accurate information on the law and policies on domestic violence prevention and control.

Article 41. Responsibilities of police offices, courts and procuracies

Police offices, courts and procuracies shall, within the scope of their tasks and powers, take the prime responsibility for, and coordinate with concerned agencies and organizations in, protecting the lawful rights and interests of domestic violence victims; proactively prevent and promptly detect, stop and handle violations of the law on domestic violence prevention and control; coordinate with and create conditions for domestic violence prevention and control state management agencies in making statistics on domestic violence prevention and control. 


\section{Chapter V \\ HANDLING VIOLATIONS CONCERNING DOMESTIC VIOLENCE PREVENTION AND CONTROL AND COMPLAINTS AND DENUNCIATIONS}

\section{Article 42. Handling violators of domestic violence prevention and control}

1. Those who commit acts of violation of the law on domestic violence prevention and control shall, depending on the nature and severity of their violations, be administratively sanctioned, disciplined or examined for penal liability; if causing damage, they shall pay compensation according to law.

2. Cadres, public employees and servants and persons of another family member's armed forces who commit acts of domestic violence and are administratively sanctioned under Clause 1 of this Article shall have their acts notified to heads of their agencies, organizations or units.

3. The Government shall specify administrative violations in domestic violence prevention and control, sanctioning forms and remedy measures applicable to violators of the law on domestic violence prevention and control.

Article 43. Application of educational measures in communes, wards and townships and confinement to educational establishments and reform schools

1. People who still commit acts of domestic violence within six months from the date of receiving comment and criticism by their communities which are not serious enough to be examined for penal liability are subject to educational measures at communes, wards or townships.

2. People committing acts of domestic violence who have been educated at communes, wards or townships but recommit acts of domestic violence which are not serious enough to be examined for penal liability may be confined to educational establishments; people aged under 18 may be confined to reform schools.

3. The competence, time limit and order of and procedures for applying educational measures in communes, wards and townships or confining to educational establishments and reform schools comply with the law on handling of administrative violations. 
Article 44. Complaints and denunciations and settlement of complaints and denunciations

Complaints and denunciations concerning violations of the law on domestic violence prevention and control and their settlement comply with the law on complaints and denunciations.

\section{Chapter VI \\ IMPLEMENTATION PROVISIONS}

Article 45. Implementation effect

This Law takes effect on July 1, 2008.

Article 46. Implementation guidance

The Government shall detail and guide the implementation of this Law.

This Law was passed on November 21, 2007, by the Xllth National Assembly of the Socialist Republic of Viet Nam at its 2nd session

THE NATIONAL ASSEMBLY PRE SIDENT

(Signed)

Nguyen Phu Trong 


\section{DECREE NO. 08/2009/ND-CP DETAILING AND GUIDING THE IMPLEMENTATION OF A NUMBER OF ARTICLES OF THE LAW ON DOMESTIC VIOLENCE PREVENTION AND CONTROL}

THE GOVERNMENT

No. 08/2009/ND-CP
SOCIALIST REPUBLIC OF VIET NAM

Independence - Freedom - Happiness

Ha Noi, February 4, 2009

\section{DECREE}

\section{DETAILING AND GUIDING THE IMPLEMENTATION OF A NUMBER OF ARTICLES OF THE LAW ON DOMESTIC VIOLENCE PREVENTION AND CONTROL}

\section{THE GOVERNMENT}

Pursuant to the December 25, 2001 Law on Organization of the Government;

Pursuant to the November 21, 2007 Law on Domestic Violence Prevention and Control;

At the proposal of the Minister of Culture, Sports and Tourism,

\section{DECREES:}

\section{Chapter I}

\section{GENERAL PROVISIONS}

\section{Article 1. Scope of regulation and subjects of application}

1. This Decree details and guides the implementation of a number of articles of the Law on Domestic Violence Prevention and Control regarding state policies on domestic violence prevention and control; community counseling, comments and criticism on the prevention of domestic violence; measure of contact forbidding under decisions of presidents of commune/ward/ township People's Committees (below collectively referred to as commune-level People's Committees); and domestic violence victim support facilities.

2. This Decree applies to domestic agencies, organizations, families and individuals and foreign organizations and individuals operating in Viet Nam (below referred to as organizations and individuals). 


\section{Article 2. Domestic violence prevention and control programs}

and plans

1. The Ministry of Culture. Spoils and Tourism shall assume the prime responsibility for, and coordinate with concerned ministries, ministeriallevel agencies and government-attached agencies in, formulating a national plan of action on domestic violence prevention and control, to be submitted to the Prime Minister for approval.

2. Annually, based on the national plan of action on domestic violence prevention and control approved by the Prime Minister, the Ministry of Culture, Sports and Tourism shall formulate national domestic violence prevention and control plans; based on the national plan of action on domestic violence prevention and control approved by the Prime Minister and the domestic violence prevention and control plans adopted by the Ministry of Culture, Sports and Tourism. People's Committees at all levels shall make local anti-domestic violence plans and organize the implementation of those plans.

3. A domestic violence prevention and control program or plan has the following major contents:

a/ Assessing the real situation of domestic violence and domestic violence prevention and control work;

b/ Identifying its overall objective and specific targets;

c/ Identifying solutions and tasks to achieve the domestic violence prevention and control objective and targets, based on the national or local socio-economic conditions;

d/ Assigning responsibilities to agencies, organizations and individuals involved in domestic violence prevention and control;

d/ Making statistics on domestic violence prevention and control;

e/ Making cost estimates for domestic violence prevention and control work.

4. Before December 15 every year. People's Committees at all levels shall review and assess the situation and results of implementation of domestic violence prevention and control plans in localities and report thereon to higher-level People's Committees; People' Committees of provinces or centrally run cities (below referred to as provincial-level People's Committees) shall send reports on results of implementation of domestic violence prevention and control plans to the Ministry of Culture, Sports and Tourism.

The Ministry of Culture. Sports and Tourism shall review, assess and report to the Prime Minister on the implementation of the national action plan on domestic violence prevention and control. 


\section{Chapter II \\ STATE POLICIES ON DOMESTIC VIOLENCE PREVENTION AND CONTROL}

\section{Article 3. Funding sources for domestic violence prevention and control}

1. Funding sources for domestic violence prevention and control include the state budget and financial supports of domestic and foreign organizations and individuals.

2. The allocation of state budget funds for domestic violence prevention and control is provided for as follows:

a/ Annually, the State shall earmark state budget funds for domestic violence prevention and control work in accordance with the state budget law;

b/ Funds for domestic violence prevention and control activities of ministries, ministerial-level agencies, government-attached agencies and central bodies of socio-political organizations shall be included in their annual budget expenditure estimates;

c/ Funds for domestic violence prevention and control in localities shall be assured by local budgets and included in their annual budge expenditure estimates.

\section{Article 4. Encouragement of anti-domestic violence activities}

1. Domestic violence victim support facilities, counseling centers for domestic violence prevention and control or other non-public facilities for domestic violence prevention and support of domestic violence victim, which are set up and qualified to operate under competent state agencies' regulations, are eligible for socialization encouragement policies like socialized establishments in education, vocational training, healthcare, culture, sports and environmental protection according to current laws.

2. The State encourages and provides financial assistance for the research, composition, publication and dissemination of valuable and quality literary and artistic works against domestic violence.

Article 5. Policies towards people directly involved in domestic violence prevention and control

1. People who are directly involved and record achievements in domestic violence prevention and control will be commended or rewarded under the emulation and commendation law. 
2. People with brave actions to save humans or salvage the State's and people's property while directly preventing acts of domestic violence will, if losing their lives, be considered for recognition as martyrs or. if suffering injuries which reduce their working capacity by $21 \%$ or more, be considered for enjoying policies like war invalids in accordance with law.

3. People who are directly involved in domestic violence prevention and control and suffer property damage will be paid with damages by provincial-level People's Committees in localities where domestic violence occurs, if the violators are unable to pay such damages. Compensations shall be paid from provincial-level People's Committee budgets for domestic violence prevention and control in localities.

4. The Ministry of Culture, Sports and Tourism shall guide in detail the implementation of this Article.

\section{Chapter III}

\section{COMMUNITY COUNSELING, COMMENTS AND CRITICISM ON DOMESTIC VIOLENCE PREVENTION}

\section{Article 6. Grassroots counseling on family issues}

1. Commune-level People's Committees shall identify and make lists of persons for grassroots counseling on family issues according to Clause 3, Article 16 of the Law on Domestic Violence Prevention and Control.

2. Based on local plans on domestic violence prevention and control and lists of persons defined in Clause I of this Article, communelevel People's Committees shall assume the prime responsibility for, and coordinate with Viet Nam Fatherland Front and its member organizations and communities in. organizing grassroots counseling on family issues.

3. Grassroots counseling on family issues shall be conducted in the following forms:
a/ In person;
b/ Through the mass media;
c/ In other forms.

4. Commune-level civil servants in charge of judicial affairs shall coordinate with those in charge of socio-cultural affairs in providing 
and disseminating documents, information and knowledge on domestic violence prevention and control to couples before they are given marriage certificates; and provide contents of grassroots counseling on family issues to the mass media.

5. Commune-level civil servants in charge of socio-cultural affairs, civil servants in charge of judicial affairs, officials of the Viet Nam Fatherland Front, Viet Nam Women's Union, Ho Chi Minh Communist Youth Union, Viet Nam Peasants' Association, War Veterans' Association and Elderly Association; members of grassroots reconciliation teams and commune-level health workers who have been trained in counseling may conduct in-person counseling on family issues at the grassroots.

6. The Ministry of Culture. Sports and Tourism shall assume the prime responsibility for, and coordinate with the Ministry of Justice in, compiling documents on domestic violence prevention and control; and formulate training programs and organize the training of grassroots counselors on family issues related to domestic violence prevention and control.

\section{Article 7. Community comments and criticism}

1. Community comments and criticism apply to persons who commit acts of domestic violence identified in Clause 1, Article 17 of the Law on Domestic Violence Prevention and Control, if the interval between two acts of domestic violence is 12 months or less.

2. The competence to decide on and organize the gathering of community comments and criticism and persons involved in giving comments and criticism is provided for in Clause 2, Article 17 of the Law on Domestic Violence Prevention and Control. Comments and criticism on persons with domestic violence acts shall be gathered through separate meetings at appropriate time so that all related persons can attend.

3. After gathering community comments and criticism on persons with domestic violence acts, heads of communities shall make meeting minutes and send them to commune-tevel civil servants in charge of judicial affairs and civil servants in charge of socio-cultural affairs for archive and serving as a basis for the application of measures to handle violations, in case the violators repeatedly commit domestic violence acts.

4. If a person with domestic violence acts is deliberately absent from a meeting to gather comments and criticism on him/her, that meeting will still proceed. In this case, the meeting minutes will be sent to such person and individuals defined in Clause 3 of this Article. 


\section{Chapter IV \\ CONTACT FORBIDDING UNDER DECISIONS OF COMMUNE- LEVEL PEOPLE'S COMMITTEE PRESIDENTS}

\section{Article 8. Contact forbidding}

Forbidding contact with a domestic violence victim means prohibiting a person with domestic-violence acts from committing the following acts:

1. Approaching the victim within a distance of less than $30 \mathrm{~m}$, unless there is a partition between the person with domestic violence acts and the victim such as a wall, fence or other partitions which ensure safety for the victim.

2. Using telephones, facsimiles, emails or other means of communication to commit violent acts against the victim.

Article 9. Conditions for commune-level People's Committee presidents to issue decisions on contact forbidding

1. The president of a commune-level People's Committee of the locality where domestic violence occurs shall decide to forbid the violator to contact the victim within 3 days when all the following conditions are met:

a/ There is a petition of the domestic violence victim, his/her guardian or lawful representative or a competent agency or organization. In case a competent agency or organization makes such petition, consent of the domestic violence victim is required;

b/ There have been domestic violence acts which cause harms or threaten to cause harms to the health or life of the domestic violence victim

c/ The person with domestic violence acts and the domestic violence victim reside in different places in the duration of contact forbidding

2. Competent agency or organization defined at Point a. Clause 1 of this Article is the culture, sports and tourism agency; the labor, war invalids and social affairs agency; the police; the agency in which the domestic violence victim works or the socio-political organization, social organization of which the victim is a member.

3. A domestic violence act prescribed at Point b, Clause 1 of this Article is identified on one $o^{\prime}$ the following grounds:

a/ Written certification issued by a medical examination and treatment 
establishment regarding the examination and treatment of injuries caused by domestic violence;

b/ Evidence(s) on the victim's body which is (are) visible to naked eyes or the domestic violence victim shows obvious signs of mental disorder.

c/ Evidence on a threat of causing harms to the health or life of the domestic violence victim.

4. Different places defined at Point c. Clause 1 of this Article include houses of relatives, friends reliable addresses or other places where a domestic violence victim voluntarily moves to.

5. When the contact forbidding measure applies, priority must be given to protection of lawful rights and interests of children, women, the elderly and people with disabilities.

6. Special cases in which people with domestic violence acts may contact domestic violence victims after reporting to the heads of communities where the victims reside, include:

a/ There are funerals or weddings in their families;

b/ People suffering from accidents or serious diseases in their families;

c/ Their family property is seriously damaged due to a natural disaster, fire or epidemic;

d/ Other cases in which a contact is necessary according to fine local traditions or customs.

\section{Article 10. Contents of contact forbidding decisions}

1. A contact forbidding decision must clearly indicate:

a/ Date of issue, full name and position of the issuer;

b/ Full name and address of the person subject to the measure of contact forbidding;

c/ Grounds for application of the measure of contact forbidding;

d/ Reasons for application of the measure of contact forbidding;

d/ Duration of application of the measure of contact forbidding;

e/ Person assigned to supervise the enforcement of the measure of contact forbidding.

2. A contact forbidding decision must be signed by the decision issuer and stamped. 
Article 11. Removal of the measure of contact forbidding under decisions of commune-level People's Committee presidents

1. The measure of contact forbidding shall be removed in the following cases:

a/ Upon written request of the domestic violence victim;

b/ The measure is no longer necessary; c/ Information serving as grounds for the issue of the decision is discovered to be untruthful.

2. The president of a commune-level People's Committee who has issued a decision to apply the measure of contact forbidding is competent to issue a decision to remove it.

3. A decision to remove the measure of contact forbidding takes effect immediately after its signing and shall be sent to the person with domestic violence acts, the domestic violence victim and the head of the population community where the domestic violence victim resides.

\section{Article 12. Handling of violations of a contact forbidding decision}

1. A person with domestic violence acts who breaches a contact forbidding decision may be put into custody according to administrative procedures in the following cases:

a/ Upon written request of the domestic violence victim;

b/ $\mathrm{He} /$ she has been warned of by a competent agency, organization or individual but still commits the violation intentionally.

2. The competence, order and procedures for putting people into custody according to administrative procedures comply with the law on handling of administrative violations.

3. Persons with domestic violence acts who breach contact forbidding decisions shall be administratively sanctioned in accordance with law.

\section{Chapter V}

\section{DOMESTIC VIOLENCE VICTIM SUPPORT FACILITIES}

\section{Article 13. Activities in support of domestic violence victims}

1. Activities in support of domestic violence victims are humanitarian and non-profit activities aimed at helping the victim, including:

a/ Providing health and medical care;

b/ Providing legal and psychological counseling; 
c/ Providing shelters in case the victims have nowhere to reside, in order to avoid subsequent violent acts of the persons who have committed domestic violence acts;

d/ Supporting some essential needs of the victims in case they can neither afford those needs nor get support from their relatives or friends. Support for essential needs means supplying meals, drinking water or lending clothes, blankets and mosquito nets and other essential utensils.

2. People's Committees at all levels shall create conditions for the operation of domestic violence victim support facilities

3. Commune-level People's Committees shall organize the protection of domestic violence victim support facilities when necessary.

Article 14. Conditions for setting up domestic violence victim support facilities and counseling centers for domestic violence prevention and control

1. Conditions for setting up a domestic violence victim support facility:

a/ Having fixed workplaces and funding sources to ensure operation of the facility;

b/ The head of the facility must have full civil act capacity and not be currently serving a court criminal judgment or ruling, a decision on the application of educational measures at commune, ward or township or a decision on sending him/ her to a medical or educational establishment under the law on handling of administrative violations;

c/ Having counselors and workers at the facility who meet the criteria specified in Article 15 of this Decree.

2. Conditions for establishment of a domestic violence victim support facility:

a/ Conditions specified in Clause 1 of this Article;

b/ The establishment has a minimum area of 30 square meters, with rooms arranged as shelters for domestic violence victim, which must satisfy hygienic and environmental requirements.

Article 15. Criteria for counselors and workers at domestic violence victim support facilities and counseling centers for domestic violence prevention and control

1. A counselor must fully meet the following criteria: 
a/ Having full civil act capacity and good moral qualities;

b/ Having suitable knowledge and experience in counseling and support of victims;

c/ Having professional certificates of care and counseling on domestic violence prevention and control.

2. Workers at domestic violence victim support facilities and counseling centers for domestic violence prevention and control must be trained in domestic violence prevention and control.

3. The Ministry of Culture, Sports and Tourism shall specify criteria for counselors; the grant of counselor cards and professional certificates of care and counseling on domestic violence prevention and control, and training in domestic-violence prevention and control.

Article 16. Procedures for registration of operation of domestic violence victim support facilities and counseling centers for domestic-violence prevention and control

1. Domestic violence victim support facilities and counseling centers for domestic violence prevention and control may operate only after being granted operation registration certificates.

2. A dossier for operation registration comprises:

a/ An application for operation registration by the domestic violence victim support facility or counseling center for domestic violence prevention and control;

b/ A draft working regulation of the domestic violence victim support facility or counseling center for domestic violence prevention and control;

c/ Papers, documents proving the satisfaction of conditions for the establishment of a domestic violence victim support facility and counseling center for domestic violence prevention and control as specified in Article 14 of this Decree;

d/ Written certification by the commune-level People's Committee regarding the location of headquarters of the domestic violence victim support facility or counseling center for domestic violence prevention and control.

3. Within 30 days after receiving a complete dossier for operation registration from a domestic violence victim support facility or counseling center for domestic violence prevention and control as prescribed in Clause 2 of this Article, the competent state agency shall issue an operation registration certificate; in case of refusal, it must give reasons in writing. 
4. A domestic violence victim support facility or counseling center for domestic violence prevention and control shall operate strictly according to the contents of its operation registration certificate. In case of a change in its name, address of its headquarters, its head or operation contents, the organization or individual that has set up that facility or center must fill in procedures for renewal of the operation registration certificate.

5. The Ministry of Culture, Sports and Tourism shall guide in detail procedures for registration of operation of domestic violence victim support facilities and counseling centers for domestic violence prevention and control.

Article 17. Competence to grant operation registration certificates to domestic violence victim support facilities and counseling centers for domestic violence prevention and control

1. The provincial-level People's Committee shall grant operation registration certificate to a domestic violence victim support facility or counseling center for domestic violence prevention and control in the following cases:

a/ The facility or center is headquartered in a province or centrally run city and set up by a ministry, ministerial-level agency, government-attached agency or central body of a socio-political organization;

b/ The facility or center is located in a province or centrally run city and set up by a foreign organization or individual;

c/ The facility or center is set up by the provinciallevel People's Committee.

2. People's Committees of districts, towns or provincial cities shall grant operation registration certificates to domestic violence victim support facilities and counseling centers for domestic violence prevention and control which are set up by domestic organizations or individuals and fall into cases other than those specified in Clause 1 of this Article.

Article 18. Suspension, revocation of operation registration certificates of domestic violence victim support facilities and counseling centers for domestic violence prevention and control

1. A domestic violence victim support facility or counseling center for domestic violence prevention and control that, in its operation course, no longer satisfies the conditions specified in Article 14 of this Decree shall be suspended until it satisfies the operation conditions. 
2. A domestic violence victim support facility or counseling center for domestic violence prevention and control shall have its operation registration certificate revoked in the following cases:

a/ The certificate is granted ultra vires or in contravention of law;

b/ The facility or center fails to commence operation within 12 months after being granted the certificate;

c/ The facility or center changes its purpose of operation;

d/ The facility or center is dissolved.

3. The agency which has granted the operation registration certificate to a domestic violence victim support facility or counseling center for domestic violence prevention and control is competent to issue a decision to suspend or revoke the operation registration certificate of that facility or center.

Article 19. Financial support for domestic violence victim support facilities and counseling centers for domestic violence prevention and control

1. A domestic violence victim support facility or counseling center for domestic violence prevention and control may receive the State's financial support in the following cases:

a/ It is set up in a locality with many domestic violence victims as identified by the provincial-level People's Committee;

b/ It is set up in a deep-lying or remote area, area meeting with socio-economic difficulties or exceptional difficulties.

2. Financial support for facilities and centers specified in Clause 1 of this Article shall comply with domestic violence prevention and control plans made by People's Committees at all levels; the support shall be included in their annual budget estimates for domestic violence prevention and control.

2. Financial support for facilities and centers specified in Clause 1 of this Article shall be defined based on the scale and efficiency of operation of the facilities and centers and the number of annual support beneficiaries.

3. The Ministry of Finance shall assume the prime responsibility for, and reach agreement with the Ministry of Culture. Sports and Tourism in, specifying cases eligible for financial support and levels of support according to Clauses 2 and 3 of this Article. 


\section{Chapter VI \\ IMPLEMENTATION PROVISIONS}

Article 20. Application of law to domestic violence victim support facilities and counseling centers for domestic violence prevention and control which were set up before the effective date of this Decree

1. Domestic violence victim support facilities and counseling centers for domestic violence prevention and control which were set up before the effective date of this Decree but fully meet the conditions specified in Article 14 of this Decree may continue operation.

2. Within 6 months after this Decree takes effect, a facility or center defined in Clause 1 of this Article shall file an application to a competent agency defined in Article 17 of this Decree in order to be granted an operation registration certificate. If the facility or center fails to file such an application within the above time limit, it may not continue its operation.

3. Domestic violence victim support facilities and counseling centers for domestic violence prevention and control which were set up before the effective date of this Decree shall fill in operation registration procedures under Article 16 of this Decree in order to be granted operation registration certificates.

\section{Article 21. Effect}

This Decree takes effect 45 days from the date of its signing.

\section{Article 22. Implementation responsibility}

1. The Ministry of Culture, Sports and Tourism shall assume the prime responsibility for, and coordinate with concerned ministries and branches in, guiding the implementation of this Decree.

2. Ministers, heads of ministerialtevel agencies, heads of governmentattached agencies, presidents of provinciallevel People's Committees and concerned organizations and individuals shall implement this Decree.

\section{ON BEHALF OF THE GOVERNMENT PRIME MINISTER}

Nguyen Tan Dung 
3. CIRCULAR NO: 16/2009/TT - BYT GUIDANCE ON THE ADMISSION AND PROVISION OF HEALTH CARE AND REPORTING ON PATIENT WHO ARE VICTIMS OF DOMESTIC VIOLENCE AT HEALTH FACILITIES

MINISTRY OF HEALTH

No: $16 / 2009 /$ TT - BYT
SOCIALIST REPUBLIC OF VIET NAM Independence - Freedom - Happiness

$\mathrm{Ha}$ Noi, September 22, 2009

\section{CIRCULAR \\ GUIDANCE ON THE ADMISSION AND PROVISION OF HEALTH CARE AND REPORTING ON PATIENT WHO ARE VICTIMS OF DOMESTIC VIOLENCE AT HEALTH FACILITIES}

Pursuant to the Law on Domestic Violence Prevention and Control dated November 21,2007;

Pursuant to Decree No. 08/2009/N)-CP dated February 4, 2009 of the Government providing detailed regulations on the enforcement of certain articles of the Law on Domestic Violence Prevention and Control;

Pursuant to Decree No. 188/2007/ND-CP dated December 27,2007 of the Government stipulating the functions, responsibilities and organizational structure of the Ministry of Health;

The Ministry of Health hereby issues the following guidance on the admission, provision of health care and reporting patients who are victims of domestic violence at public and private health facilities as follows:

\section{Chapter I}

\section{ADMISSION OF PATIENTS WHO ARE DOMESTIC}

\section{VIOLENCE VICTIMS}

Article 1 Admission:

Patients who are domestic violence victims shall be admitted for first aid, medical consultation and treatment at medical facilities in accordance with regulations of the laws on disease examination and treatment. 


\section{Article 2. Screening to Identify Domestic Violence Victims}

\section{Screening:}

a. When examining patients and conducting routine medical history investigation, physicians should ask them about domestic violence issues relating to their health status in order to detect victims of domestic violence.

b. In case patients with accidents and injuries; patients who are females above 15 years old and those who have signs of domestic violence, physician and health workers should have measures to screen on domestic violence.

2. Screening principles

a. Ensure privacy and confidentiality;

b. Careful and comprehensive consultation not to miss any physical and mental and sexual problems including psychological trauma due to domestic violence

c. Treat patients with empathy, respect; be sharing, friendly, encouraging and non judgmental;

d. Ensure patients' safety at health settings.

3. Physicians shall watch and ask patients for signs and symptoms of physical, psychological and sexual maltreatment; reviewing the causal relationship between the injuries and related domestic violence behaviors. Patients should be encouraged to tell the truth even when they tend to hide away the fact that they are domestic violence victims.

4. Interview of patients shall be conducted without the presence of their family members to ensure the privacy, objectiveness and safety when providing information. In the case a patient is accompanied by his/her family members when s/he comes to the health facility for consultation and treatment, physicians should tactfully separate him/her from the escorts to ensure the validity of screening results. If it is the case in which the patient cannot answer the physicians' questions by themselves, interview will be put off later until they get well again.

5. Filling in domestic violence screening form and recording information on domestic violence victims:

a. Physicians and health workers fill the results in the domestic violence victim screening form which is Annex 1 of this Circular.

b. In the case the patient reveals or confirms that $s /$ he is a victim of domestic violence, physicians and health workers shall enter 
related information in the information recording form which is Annex 2 of this Circular;

c. Domestic violence screening form and information form shall be kept separately from the patient's medical records but coded in the patient record for monitoring the patient's condition and reporting and collecting statistical data on domestic violence.

6. Physicians will provide patients with counseling in accordance with regulations provided in Part II. Section II of this Circular which includes instruction, explanation for the patient about the right to be protected when suffering from domestic violence so that the patient will be cooperative during the course of screening.

\section{Article 3. Detection of Domestic Violence behaviors with criminal signs.}

1. Health care staff shall have the responsibility to notify the heads of health facilities immediately if domestic violence acts with criminal signs are detected during admission and provision of health care for patients.

2. The heads of health facilities shall have the responsibility to keep the police authority of the commune/precinct! township where the institution is located or the nearest police station by telephone, or in writing or via a messenger informed of the domestic violence acts with criminal signs and require the police to apply measures to ensure safety for the victims of domestic violence.

\section{Chapter II}

\section{HEALTH CARE FOR DOMESTIC VIOLENCE VICTIMS}

\section{Article 4. Provision of medical consultation and treatment for domestic violence victims}

1. Patients who are domestic violence victims shall be given health consultation and treatment in accordance with common regulations on providing health care for all patients seeking medical care at health facilities.

2. Requirements applied when conducting medical check up for domestic violence victims:

a. Physicians should ask patients in full about their history of domestic violence. 
b. The patients shall be given comprehensive medical check-up to avoid missing any physical, psychological and sexual injuries related to domestic violence.

c. The patient's health condition shall be assessed on the signs of physical, psychological and sexual injuries and other related signs. Detectable symptoms and signs of maltreatment should be paid special attention to, so as suitable treatment methods could be administered.

d. Results of medical check up shall be recorded, ensuring that no information is missing

3. Therapeutic requirements for domestic violence victims:

a. Ensure that all physical and mental injuries of the patients are treated properly

b. If the patient has been forced into sex, she should be given proper consultation, professional advice and contraceptives as soon as possible. In the case of a female patient, it is advisable that she is treated by a female physician. If the victim has unwanted pregnancy, she should be advised to visit appropriate health facilities where she can get advice on safe abortion services.

\section{Article 5. Health care counseling}

1. Content of counseling:

a. Providing patients with information about domestic violence, raising their awareness of domestic violence;

b. Giving patients advice on health care and rehabilitation as well as disease prevention information;

c. Providing psychological counseling to patients;

d. Referring patients to facilities that provide support for victims of domestic violence, or to related agencies, such as police, local authorities, or social organizations and unions for further support.

e. Informing patients of the legitimate rights and benefits stipulated for domestic violence victims that health facilities can ensure, such as provision of temporary refuge; application of remission of health care expenses (if any); health insurance benefits, or granting certificate of examination and treatment for victims of domestic violence.

2. Methods of counseling:

a. Physicians and health worker provide direct counseling for the patients; 
b. Providing booklets, leaflets, pictures or showing video-clips about domestic violence and the domestic violence prevention and control; providing patients with information on their legitimate rights and benefits, as well as other supporting information.

c. Physicians shall provide patients with alternatives and let them make their own choice in a friendly and non judgmental manner.

\section{Article 6. Arrangement of temporary refuge for domestic violence victims}

1. Public health care providers shall, depending on their actual capacity and conditions, provide a temporary domicile for patients who are domestic violence victims for no longer than one day at the request of the victims; private health facilities are encouraged to provide domestic violence victims with temporary domicile.

2. Victims shall be treated as in-patients and provided with bed, blankets and clothes;

3. If a domestic violence victim is not accompanied by family members and cannot handle eating themselves, health facilities are, depending on their actual capacity and conditions, to provide them with meals.

4. It is the responsibility of health facilities to inform and cooperate with the police and Commune People's Committee of the commune where the institution is located to ensure safety for both health staff and domestic violence victims during the time they are treated at the facilities; inform and collaborate with communal people's committee to assist in providing them with basic necessities if necessary and in accordance with regulations of laws on domestic violence prevention and control.

5. In the case when the time regulated for domestic violence victims to be given temporary domicile is over, but they still need to be sheltered, health facilities shall, depending on their actual capacity and conditions, the following options can be considered

a) Continuance of providing temporary refuge at health settings,

b) Sending a written request to the Commune People's Committee to arrange for them to be admitted and sheltered by appropriate domestic violence victim supporting centers, according to laws on domestic violence prevention and control.

c) Contact, suggesting that domestic violent support centers to take over and arrange the refuge for them accordingly. 
Article 7. Expenses of medical consultation and treatment provided for people who are domestic violence victims

1. Expenses of medical consultation and treatment incurred by health facilities for domestic violence victims who are health insurance card holders shall be reimbursed by the health insurance funds in line with laws on health insurance.

2. Expenses of medical consultation and treatment provided by health facilities for domestic violence victims who are not health insurance card holders shall be paid by the victims themselves. It is recommended that health facilities should consider remission of health care expenses for domestic violence victims who are in constrained circumstances and cannot afford the bill.

3. Health facilities may agree to accept funding from individuals and organizations as prescribed by laws to support victims of domestic violence at site.

\section{Article 8. Certification of medical consultation and treatment} provided for patients who are domestic violence victims

1 At their written request, domestic violence victims shall be granted with a certificate of medical consultation and treatment by health facilities;

2. It is the responsibility of the health facilities that have taken in and provided domestic violence victims with medical care to grant the victims with certificates of medical consultation and treatment, using the form which is Annex 3 of this Circular;

\section{Chapter III}

\section{STATISTICAL DATA COLLECTION AND REPORTING ON CASES OF DOMESTIC VIOLENCE AT HEALTH SETTINGS}

\section{Article 9. General regulations on statistics and reporting:}

1. Issued together with this Circular are templates and forms for data collection and reporting on cases of domestic violence which will be applied for all health facilities nationwide.

2. Publication and storage of such statistic data on victims of domestic violence must be done in conformity with the current laws.

3. Reporting formats: 
a) regular semi annual and annual reporting regimen

b) ad hoc reporting at the request of competent state authorities.

4. Reporting system:

a) National: Ministry of Health (Medical Services Administration).

b) At province and equivalent levels: Health Service, other sectoral health authorities

c) At district: district hospitals or district health centers functioning to provide health care services.

d) Health facilities nationwide.

\section{Article 10. Assignments for reporting and statistics:}

1. Medical Services Administration is responsible for:

a) Developing and directing the whole database and reporting system which is built for cases of victims of domestic violence;

b) Organizing for monitoring, supervision and evaluation of results of implementation of the domestic violence database and reporting system on a national scale.

c) Collecting and processing and summing up statistical data, reports on cases of domestic violence from health facilities nationwide.

2. Provincial Health Services are responsible for the:

a) Collection and processing and management of statistical data, reports on cases of domestic violence at local levels;

b) Provision of operation, organization for evaluation and classification of statistical data and reporting on cases of domestic violence at district levels of provinces.

3. Other ministry's health sectors are responsible for collecting statistical data and reports on cases of domestic violence at relevant levels.

4. District hospitals are responsible for collecting, processing and management of the whole statistical data and reporting system which is built for to domestic violence at district levels.

5. Commune health stations are responsible for primary records and statistics of cases of patients as victims of domestic violence at station.

6. Health facilities nationwide are responsible for preparing statistics and reporting on cases of domestic violence at site. 


\section{Chapter IV \\ IMPLEMENTATION}

Article 11. Responsibilities of heads of health facilities.

1. Organize the admission and provision of health care for patients who are domestic violence victims as stipulated by this Circular.

2. Arrange temporary domicile for domestic violence victims as stipulated by this Circular;

3. Arrange the exhibition and provision of leaflets/booklets on domestic violence and information on available services at the institutions to assist domestic violence victims and provide them with medical care and treatment;

4. Develop detailed guidelines on procedures for taking in and providing health care for and appropriate behavior towards domestic violence victims based on the guidance given in this Circular, to be applied at the institutions;

5. Training for onside physicians and health workers of the institution in professional knowledge and skills in taking in, providing health care and counseling for domestic violence victims.

6. Establish and maintain relationship with authorized state agencies in the area as well as domestic violence victim supporting centers in order to timely coordinate in assisting and protecting the victims;

7. Documenting of each case of domestic violence; provide statistical reports on cases of domestic violence victims at the facilities according to regulations;

\section{Article 12. Rights and responsibilities of physicians and health workers}

1. Physicians and health workers shall be protected by laws when providing medial care for and support to domestic violence victims at health facilities.

2. Physicians and health workers shall have the responsibility to:

a. Strictly comply with regulations in this Circular in taking in, providing medical consultation, treatment and giving advice on health care for patients who are domestic violence victims;

b. Keep all personal information about patients who are domestic violence victims confidential; 
c. Adopt appropriate manner when providing care for patients who are domestic violence victims; be friendly, empathetic, encouraging and non judgmental.

d. Attend relevant training workshops on domestic violence.

e. Monitor and assess the immediate safety of domestic violence victims and their children when conducting the screening examination.

\section{Article 13. Funding for domestic violence prevention and control}

Annually, based on the programs and plans for domestic violence prevention and control prepared by higher levels of authority agencies, health facilities are supposed to prepare budget estimates needed for activities of domestic violence prevention and control in accordance with current regulations

\section{Article 14. Responsibilities for organization of implementation}

1. Medical Service Administration presides and works in collaboration with the Department of Mother and Child Health to direct and check health faculties on admission and provision of health care services for the patients who are victims of domestic violence at site, working in collaboration with the Department of Planning and Finance to provide health facilities with instructions on how to make statistical reports on patients who are domestic violence victims.

2. Health services of provinces, centrally run cities, related ministries and industries are responsible for providing guidance to health facilities of various levels to properly implement provisions of this Circular

\section{Chapter V \\ ENFORCEMENT}

Article 15. This Circular shall come into effect 45 days from the date it is signed for promulgation.

Article 16. Heads of related agencies, organizations and units shall have the responsibility to arrange the dissemination, communication and implementation of this Circular. Problems arising during implementation should be reported to the Ministry of Health for timely revision and amendments accordingly.

MINISTER OF HEALTH

Nguyen Quoc Trieu 
(Attachment 1 of Circular No 16/2009/TT-BYT, date September 22, 2009 by Minister of Health)

NAME OF HEALTH FACILITIES

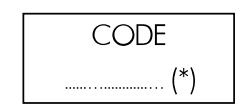

\section{SCREENING INTERVIEW FORM FOR DOMESTIC VIOLENCE VICTIMS}

(Applicable to all patients coming in health facilities with accidents and injuries; patients who are females above 15 year old and those who have signs of being a victim of domestic violence)

I. GENERAL INFORMATION

1. Full name Age Male/Female

2. Examination Department/Ward:

3. Date of examination:

4. Reasons for examination:

5. Marital status: Married/Previously married Single $\square$

\section{SCREENING VERIFICATION}

1. General statement: We ask all of our patients about domestic violence issues so that necessary support can be provided appropriately.

2. Domestic violence question: "Have you ever been beaten, cursed or forced to have unwilling sexual intercourse (by spouse/partners/ relatives)?" $\quad$ Yes $\square \quad$ No $\square$

(In case of "yes" or answer is suspected by the health worker, information associated to domestic violence is to be noted as apperared in Annex 2)

\section{Health Care Provider}

(Signature and name)

$\left(^{\star}\right)$ This code is included in the patient's record to be used for statistical and reporting purposes if needed 
(Attachment 2 of Circular No 16/2009/TT-BYT, date September 22, 2009 by Minister of Health)

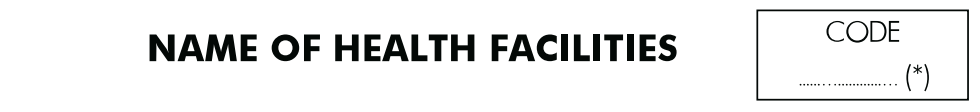

INFORMATION NOTE FORM FOR DOMESTIC VIOLENCE VICTIIMS

(For taking notes of case of domestic violence confessed or confirmed by the patient)

I. PATIENT PERSONAL INFORMATION:

1. Full name Age Male/Female

2. Address

3. Phone (if any)

4. In case of emergency, please contact (name, address, phone number).

5. Occupation

6. Education

7. Marital status.

\begin{tabular}{|c|c|c|c|c|}
\hline Married & $\square$ & Divorced & $\square$ & Widowed \\
\hline Single & $\square$ & Separated & $\square$ & As husband and wife \\
\hline
\end{tabular}

Years of marriage:

Number of children Boys Girls.

Name of alleged perpetrator:

Relationship with patient: Husband

Family members

8. Frequency of suffering:
Often

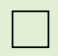
First time
On and off
Other (Specify)

$\left.{ }^{*}\right)$ This code is included into the patient's record to be used for statistical and reporting purposes if needed 


\section{TYPE OF VIOLENCE:}

1. Maltreatment, ill treatment, beating, causing injuries, threats to life

2. Insulting or other behaviors intended to offend the honor and dignit

3. Getting isolated, driving away, or putting on psychological pressure, resulting in severe outcomes

4. Rape, sexual abuse, forced sexual intercourse, forcible early marriage, forcible marriage and forcible divorce

5. Force family members work out of their might, irrational financial contribution; control of family's member's income, resulting in state of financial dependence

\section{EXAMINATION AND TREATMENT:}

1. Statements given by patient/patent's family members: (disease history, sexual history (abuse, forced relation, sexually transmitted diseases etc.), prior complications, and history of being victim of violence)

2. Physical examinations: (existing wounds: type of violence, when it happened; taking notes of injuries such as bruises, scars etc.)

3. Treatment methods employed (treatment/prescription):

Primary

Take away prescription

4. Evaluation of safety: (is the patient under any threats ?). Question that can be asked: Do you feel safe to go home now ?

Primary health care counseling

Safety planning

5. Admission:

Yes

No

6. Treatment: From to

7. Health condition at discharge (injuries status? Recovered ?) 


\section{REFERRAL TO RELATED SERVICES:}

1. Hospital referral: Yes $\square \quad$ No $\square$

2. Referral to supported services (as requested by the patient):

Yes $\square \quad$ No $\square$

Date.

Doctor

(Signature and name) 


\section{(Attachment 3 of Circular No 16/2009/TT-BYT, date September 22, 2009 by Minister of Health)}

Name of the holding agency:

Name of health facilities:

Ref No: . . GXN-
SOCIALIST REPUBLIC OF VIET NAM

Independence - Freedom - Happiness

Date

\section{CONFIRMATION CERTIFICATE}

\section{Subject: Examination and treatment for patients who are victims of domestic violence}

I. GENERAL INFORMATION:

1. Mr/Ms:..................... Date of birth Male/Female

2. ID number, date and place of issuance

3. Address:

4. Occupation, workplace:

II. EXAMINNATION AND TREATMENT:

1. Reasons for hospitalization/admission: Treating diseases caused by domestic violence as stated by the patient

2. Time of examination and treatment:

From: o'clock. on. to o'clock on.

- Inpatient

- Outpatient

3. Statement of the patient/relatives: Disease history, sexual history (abuse, forced relation, sexually transmitted diseases etc.).

4. Diagnosis:

5. Measures (therapies/prescription):

6. Health status at discharge (injuries status ? Recovered?) 
III. REFERALS TO RELATED SERVICES: (if any)

1. Hospital referral:

2. Referral to supported services:

HEALTH OF THE FACILITY

(Sing, name in full, seal) 


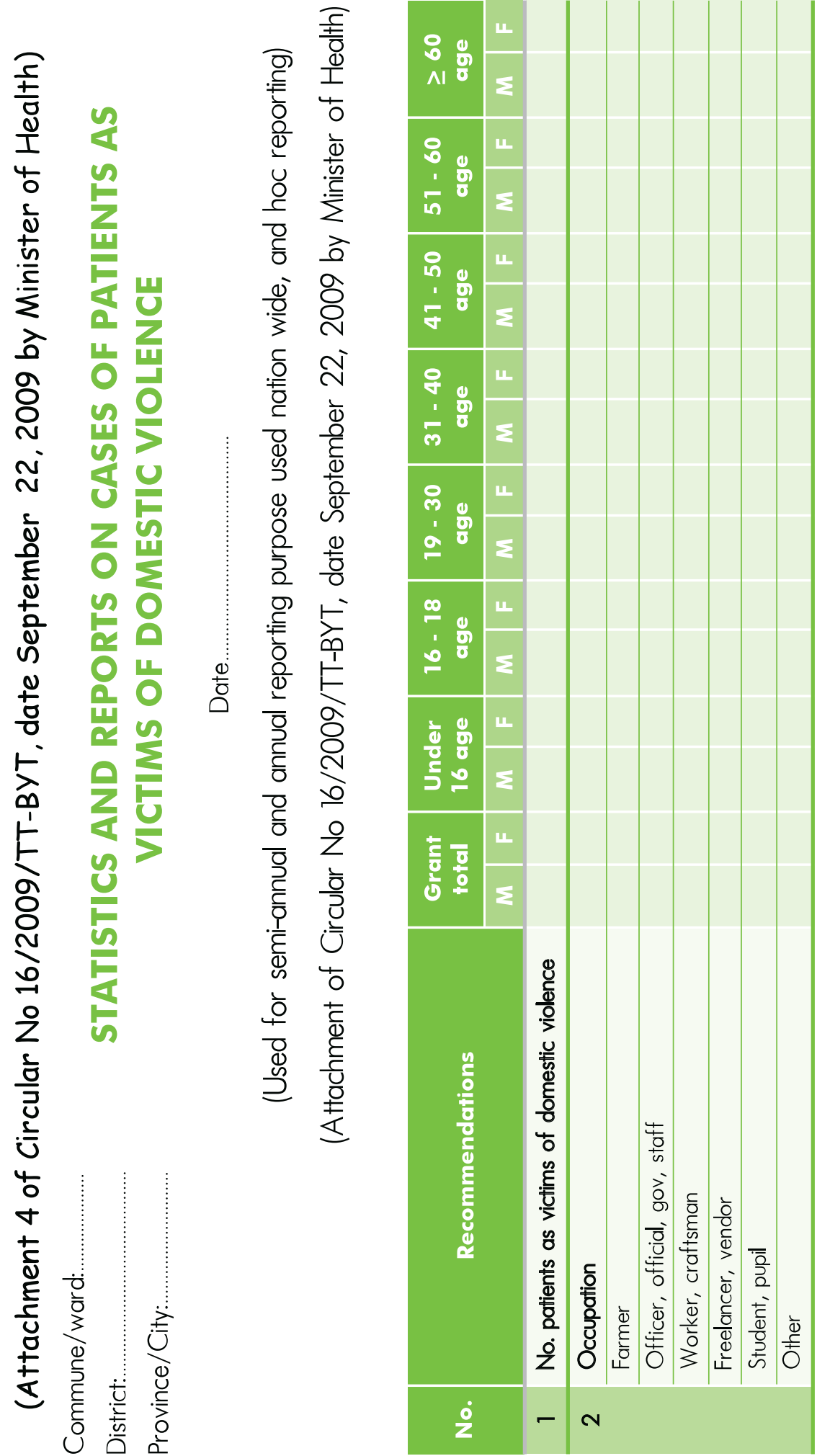




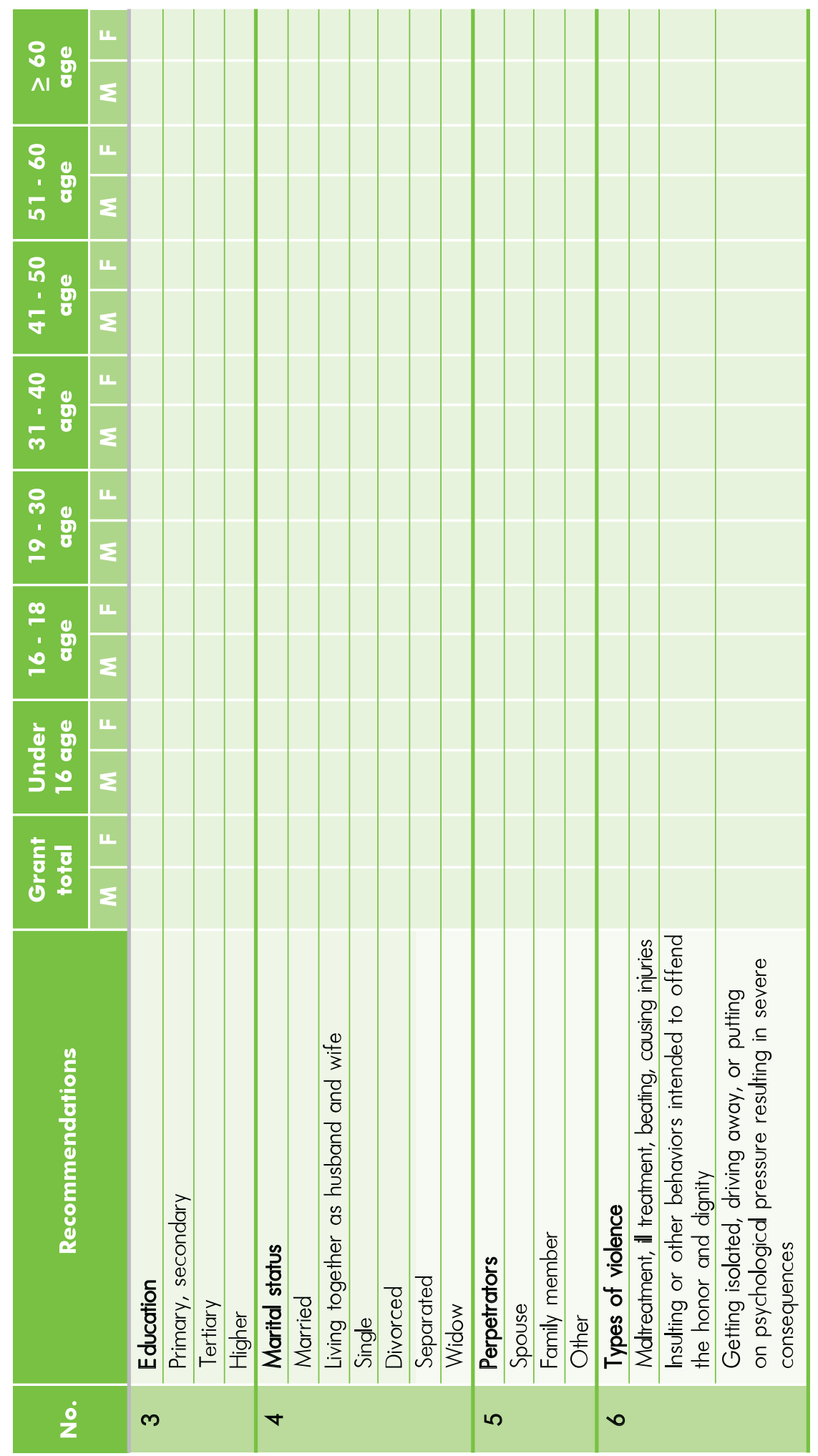




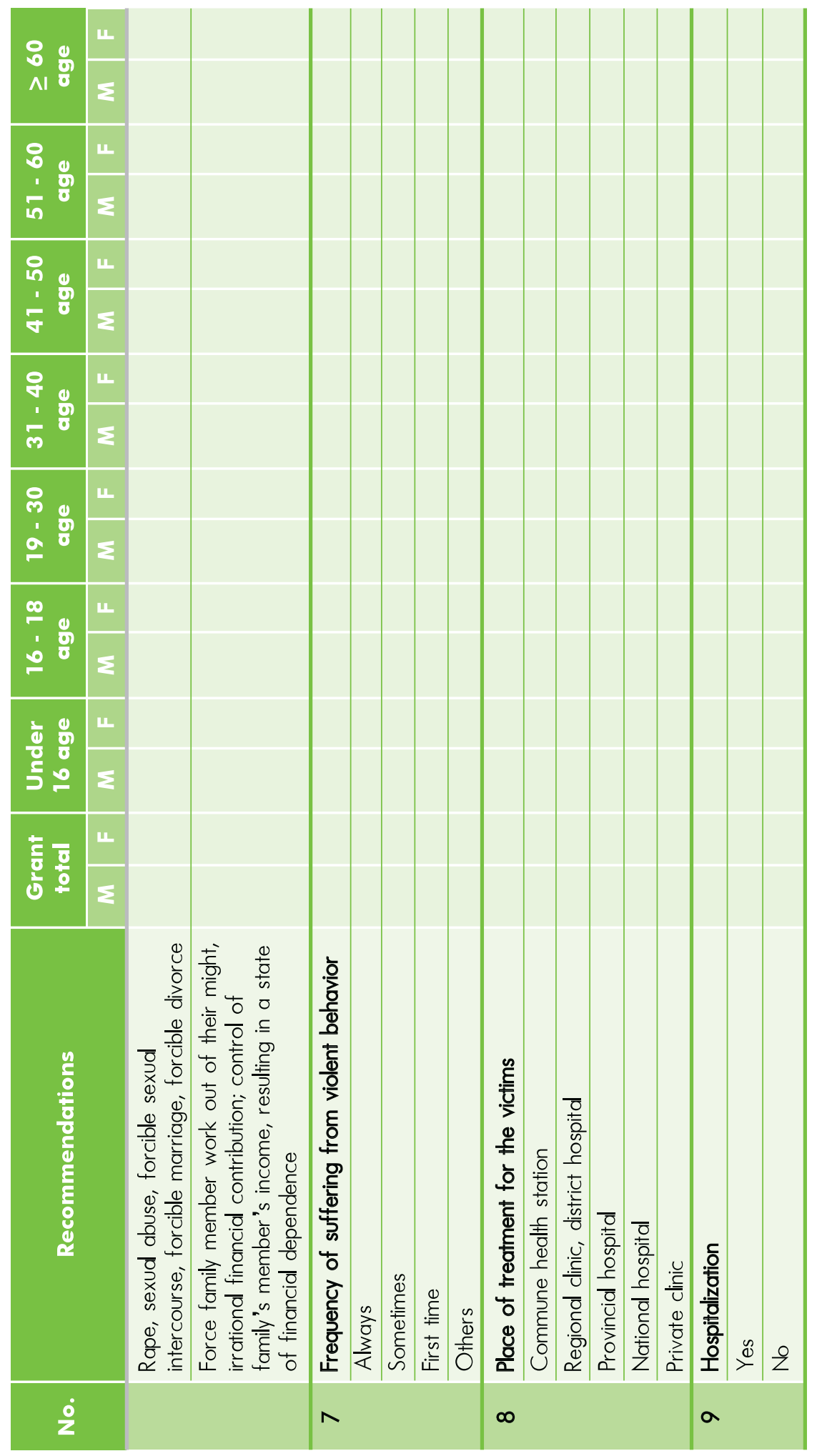




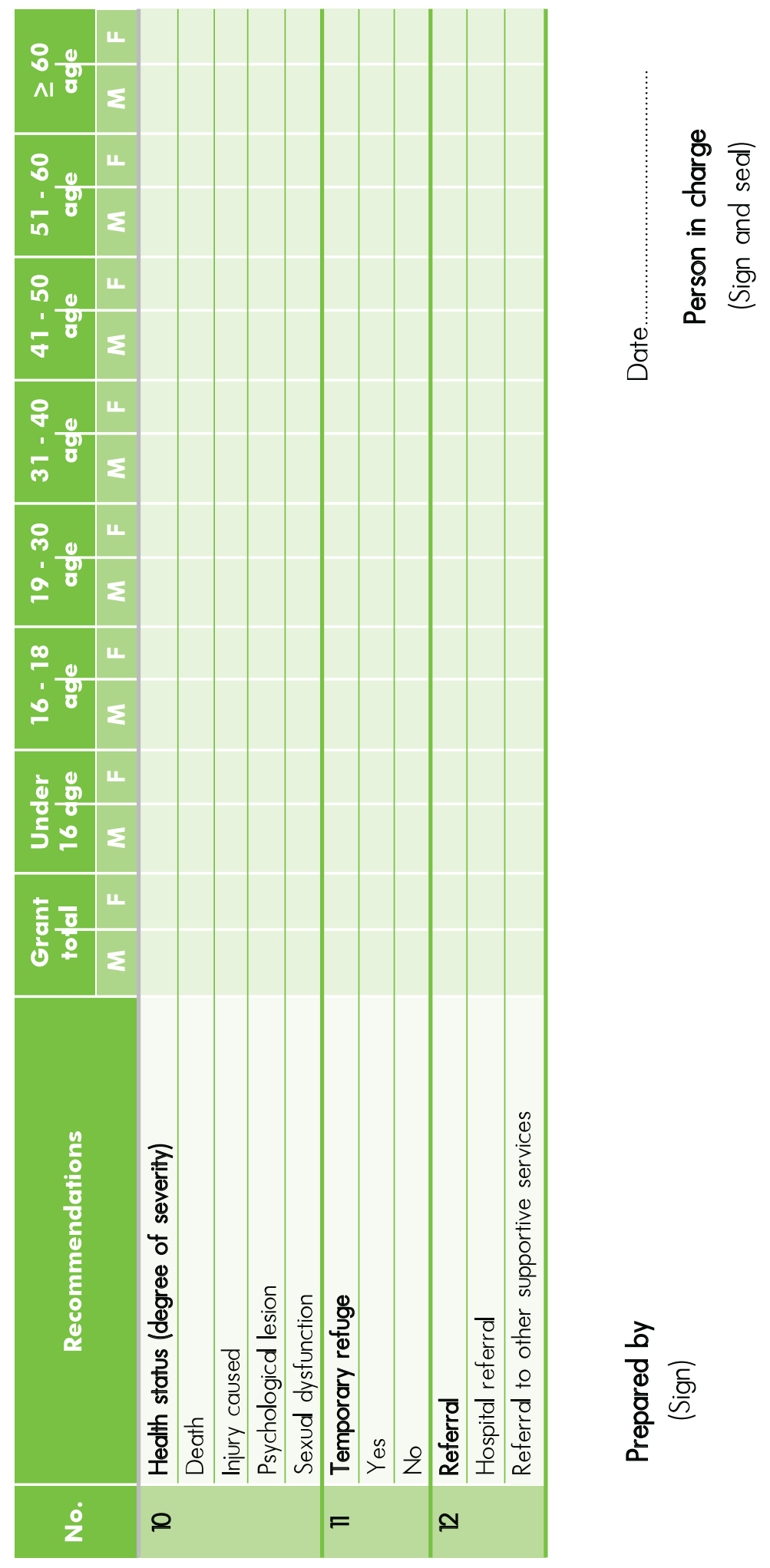




\section{LAW ON GENDER EQUALITY, PASSED 29/11/2006 BY VIET NAM NATIONAL ASSEMBLY}

THE NATIONAL ASSEMBLY

No: $73 / 2006 / Q H 11$
SOCIALIST REPUBLIC OF VIET NAM

Independence - Freedom - Happiness

Ha Noi , Day 29 month 11 year 2006

\section{LAW ON GENDER EQUALITY}

Pursuant to the 1992 Constitution of the Socialist Republic of Viet Nam, which was amended and supplemented under Resolution No. 51/2001/ QH10 of December 25, 2001, of the Xth National Assembly, the 10th session;

This Law provides for gender equality.

\section{Chapter I}

\section{GENERAL PROVISIONS}

\section{Article 1. Scope of application}

This Law provides principles of gender equality in all aspects of social and family life, measures to guarantee gender equality, and responsibilities of agencies, organizations, families and individuals in exercising gender equality.

\section{Article 2. Subjects of regulation}

1. Vietnamese state agencies, political organizations, sociopolitical organizations, socio-political professional organizations, social organizations, socio-professional organizations, economic organizations, non-business units, units of people's armed forces, families and citizens (hereinafter collectively referred to as agencies, organizations, families and individuals).

2. Foreign agencies and organizations and international organizations operating in Vietnamese territory, and foreigners residing in Viet Nam.

\section{Article 3. Application of treaties on gender equality}

When a treaty to which the Socialist Republic of Viet Nam is a contracting party contains provisions other than those of this Law, the provisions of that treaty shall be applied. 


\section{Article 4. Gender equality goals}

The goals of gender equality are to eliminate gender-based discrimination, create equal opportunities for men and women in socio-economic development and human resource development, strive to reach genuine equity between men and women, establish and strengthen cooperative and supportive relations between men and women in all aspects of social and family life.

\section{Article 5. Interpretation of terms}

\section{In this Law, the terms below are construed as follows:}

1. Gender refers to the characteristics, positions and roles of men and women in all social relationships.

2. Sex refers to biological characteristics of men and women.

3. Gender equality means that men and women have equal positions and roles, are offered conditions and opportunities to bring into play their capabilities for the development of the community and families, and to equally benefit from this development.

4. Gender prejudice is unfair and negative perceptions, attitudes and assessments of the characteristics, positions, roles and capabilities of men or women.

5. Gender discrimination is the restriction, exclusion, non-recognition or disregard of the roles and positions of men and women, causing inequality between men and women in various aspects of social and family life.

6. Measure for promoting gender equality is a measure set forth by a competent state agency to guarantee genuine gender equality in cases where a big difference exists between and women in terms of position, role, conditions and opportunities to bring into play capabilities and enjoy benefits of development and the application of the same regulations to men and women fails to reduce this difference. A measure for promoting gender equality will be implemented within a given period and end when the gender equality goals are achieved.

7. Integration of gender equality in the process of formulating legal documents is a measure to achieve the gender equality goals by identifying gender issues, forecasting the impacts of legal documents on gender, responsibilities and resources for dealing with gender issues in the social relations governed by these legal documents. 
8. Gender equality activities are activities carried out by agencies, organizations, families and individuals to achieve the gender equality goals.

9. Gender development index (GDI) is general data reflecting the real situation of gender equality, which are computed on the basis of average life expectancy, educational level and per capita income of men and women.

\section{Article 6. Basic principles of gender equality}

1. Men and women are equal in all aspects of social and family life.

2. Men and women are not discriminated in terms of gender.

3. The application of measures for promoting gender equality is not regarded as gender-based discrimination.

4. Policies on motherhood protection and support are not regarded as gender-based discrimination.

5. Gender equality issues are ensured to be integrated in the process of law formulation and enforcement.

6. Exercising gender equality is the duty of agencies, organizations, families and individuals.

\section{Article 7. State policies on gender equality}

1. To ensure gender equality in all fields of politics, economy, culture, society and family; to support and create conditions for men and women to bring into play their abilities and provide them with equal opportunities to participate in the process of development and benefit from development.

2. To protect and support mothers during pregnancy, delivery and raising of their babies; to create conditions for men and women to share housework.

3. To apply appropriate measures to abolish backward customs and habits that impede the achievement of the gender equality goals.

4. To encourage agencies, organizations, families and individuals to participate in promoting gender equality.

5. To support gender equality activities in deep-lying, remote and ethnic minority areas and areas with extremely difficult socio-economic conditions; to support necessary conditions for increasing the gender development index in sectors, fields and localities with a gender development index lower than the national average level. 


\section{Article 8. Contents of state management of gender equality}

1. Formulating and implementing national strategies, policies and goals on gender equality.

2. Promulgating and implementing legal documents on gender equality.

3. Promulgating and implementing measures for promoting gender equality.

4. Propagating and disseminating policies and laws on gender equality.

5. Building, training and retraining cadres who carry out gender equality activities.

6. Inspecting and examining the implementation of the law on gender equality; dealing with gender-related complaints and denunciations, and handling violations of the law on gender equality.

7. Making statistics, supplying information and making reports on gender equality.

8. Conducting international cooperation on gender equality.

\section{Article 9. State management agencies in charge of gender equality}

1. The Government shall perform the unified state management of gender equality.

2. A ministry or ministeriallevel agency shall be assigned by the Government to take prime responsibility before the Government for performing the state management of gender equality.

3. Ministries and ministerial-level agencies shall, within the limits of their respective tasks and powers, coordinate with the state management agency in charge of gender equality defined in Clause 2 of this Article in performing the state management of gender equality.

4. People's Committees at all levels shall perform the state management of gender equality as decentralized by the Government in their respective localities.

\section{Article 10. Forbidden acts}

1. Obstructing men and women in exercising gender equality.

2. Gender discrimination in all forms.

3. Violence for gender reasons.

4. Other acts forbidden by law. 


\section{Chapter II \\ GENDER EQUALITY IN ALL FIELDS OF SOCIAL \\ AND FAMILY LIFE}

\section{Article 11. Gender equality in politics}

1. Men and women are equal in taking part in the management of the State and in social activities.

2. Men and women are equal in taking part in formulating and implementing village codes or community conventions or rules and regulations of agencies or organizations.

3. Men and women are equal in self-nominating as candidates or nominating candidates to the National Assembly and People's Councils; in self-nominating as candidates and nominating candidates to leading bodies of political, socio-political, socio-political professional, social or socio-professional organizations.

4. Men and women are equal in professional qualifications and age when they are promoted or appointed to the same managerial or leading posts in agencies or organizations.

5. Measures for promoting gender equality in politics include:

a/ To ensure a proper proportion of female National Assembly and People's Council deputies in accordance with the national gender equality goals;

b/ To ensure a proper proportion of women appointed to hold titles in state agencies in accordance with the national gender equality goals.

\section{Article 12. Gender equality in economy}

1. Men and women are equal in setting up enterprises, carrying out production and business activities, and administering business, in accessing information, capital, market and labor sources.

2. Measures for promoting gender equality in economy include:

a/ To give tax and financial incentives to enterprises employing large numbers of female laborers in accordance with law;

b/ To provide credit support, agricultural, forestry or fishery extension to female laborers in rural areas in accordance with law. 


\section{Article 13. Gender equality in labor}

1. Men and women are equal in criteria and age when they are recruited, and are equally treated at workplaces in terms of jobs, pay, reward, social insurance, labor conditions and other working conditions.

2. Men and women are equal in criteria and age when they are promoted or appointed to hold titles in sectors and professions that have title criteria.

3. Measures for promoting gender equality in labor include:

a/ To set the proportions of men and women to be recruited;

b/ To provide training and retraining to raise female laborers' capacity;

c/ Labor users shall create labor hygiene and safety conditions for female laborers working in heavy and dangerous sectors and occupations or in contact with toxic substances.

\section{Article 14. Gender equality in education and training}

1. Men and women are equal in schooling, training and retraining age.

2. Men and women are equal in choosing professions or occupations for learning and training.

3. Men and women are equal in accessing and benefiting from education and professional training and retraining policies.

4. Female cadres, state employees and servants who bring along under36-month children when attending training or retraining courses shall be provided with supports under Government regulations.

5. Measures for promoting gender equality in education and training:

a/ To set the proportions of men and women participating in learning and training;

b/ To support female laborers in rural areas in their vocational training in accordance with law.

\section{Article 15. Gender equality in science and technology}

1. Men and women are equal in accessing and applying science and technology.

2. Men and women are equal in attending training courses on science and technology, dissemination of findings of scientific and technological researches, and innovations and patents. 
Article 16. Gender equality in culture, information, physical training and sports

1. Men and women are equal in participating in cultural, information, physical training and sports activities.

2. Men and women are equal in benefiting from culture, and accessing and using sources of information.

\section{Article 17. Gender equality in healthcare}

1. Men and women are equal in participating in activities of education and communication on healthcare, reproductive health and use of healthcare services.

2. Men and women are equal in choosing and deciding on the use of contraceptive measures, measures to ensure safe sex, and prevent and control HIV/AIDS and sexually transmitted diseases.

3. Poor women residing in deep-lying and remote areas and ethnic minority women, excluding those participating in compulsory social insurance, when giving births in accordance with the population policy, shall be provided with support according to Government regulations.

\section{Article 18. Gender equality in families}

1. Wife and husband are equal in civil relations and other relations related to marriage and family.

2. Wife and husband have equal rights and duties in owning common property, and are equal in using their common income and deciding on family resources.

3. Wife and husband are equal in discussing and deciding to choose and use appropriate family planning measures; and use their leaves to take care of their sick children in accordance with law.

4. Sons and daughters are equally taken care of, educated and provided with opportunities by their families to learn, work, play, entertain themselves and develop.

5. Female and male family members have the duty to share housework. 


\section{Chapter III}

\section{MEASURES FOR GUARANTEEING GENDER EQUALITY}

\section{Article 19. Measures for promoting gender equality}

1. Measures for guaranteeing gender equality include:

a/ To prescribe the proportions of men and women who participate and benefit or ensure appropriate proportions of women who participate and benefit;

b/ To train and retrain to raise the qualifications of women or men;

c/ To support in order to create conditions and opportunities for women or men;

d/ To prescribe specific standards and conditions for women or men;

e/ To prescribe the right of women to be selected when women and men have similar conditions and criteria;

$\mathrm{f}$ / To prescribe the prioritization of women when women and men have similar conditions and criteria;

g/ Measures for promoting gender equality specified in Clause 5 of Article 11, Clause 2 of Article 12, Clause 3 of Article 13, and Clause 5 of Article 14, of this Law.

2. The National Assembly, the National Assembly Standing Committee and the Government have competence to determine the implementation of measures for promoting gender equality and to decide to end such implementation when the gender equality goals are achieved.

Article 20. Guarantee of basic principles of gender equality in the improvement of the legal system

1. The formulation, amendment and supplementation of legal documents must guarantee the basic principles of gender equality.

2. The basic principles of gender equality constitute an important ground for reviewing, amending and supplementing legal documents.

Article 21. Integration of the issue of gender equality in the process of formulating legal documents

1. Integration of gender equality issues in the process of formulating legal documents covers:

a/ Identifying gender issues and measures in the domain regulated by legal documents; 

b/ Forecasting the impact of legal documents on men and women when promulgated;
c/ Defining responsibilities and resources for dealing with gender issues within the scope of regulation of legal documents.

2 Drafting agencies are responsible for integrating gender issues and preparing reports on integration of gender issues in the process of formulating legal documents under Clause 1 of this Article and annexes of information and data on gender related to draft legal documents.

3. Agencies that evaluate draft legal documents are responsible for coordinating with the state management agency in charge of gender equality in appraising the integration of gender equality issues in the process of formulating legal documents. Such appraisal covers:
a/ Identifying gender issues in the draft legal document;
b/ Ensuring the basic principles of gender equality in the draft legal document;
c/ Feasibility of the solution to gender issues set forth in the draft legal document;
d/ Integration of gender equality issues in the process of formulating the draft legal document under the provisions of Clause 1 of this Article.

4. The Government shall stipulate the integration of gender equality issues in the process of formulating legal documents.

\section{Article 22. Verification of integration of gender equality issues}

1. The National Assembly's Committee in charge of gender issues shall join the Ethnic Minority Council and other National Assembly Committees in verifying the integration of gender equality issues in draft laws, ordinances and resolutions before they are submitted to the National Assembly or its Standing Committee for consideration and adoption.

2. The verification of the integration of gender equality issues covers:

a/ Identifying gender issues in the draft legal document;

b/ Guarantee of the basic principles of gender equality in the draft legal document;

c/ Observance of procedures and process of appraisal of the integration of gender equality issues in the process of formulating the draft legal document;

d/ Feasibility of the draft legal document to guarantee gender equality. 
Article 23. Information, education and communication on gender and gender equality

1. Information, education and communication on gender and gender equality is an important measure to raise the awareness of gender and gender equality.

2. Information, education and communication on gender and gender equality shall be incorporated into the education programs in schools and activities of agencies, organizations and communities.

3. Information, education and communication on gender and gender equality shall be conducted through learning programs, publications, radio and television programs and other forms.

\section{Article 24. Financial sources for gender equality activities}

1. Financial sources for gender equality activities include:

a/ State budget;

b/ Voluntary contributions from organizations and individuals;

c/ Other lawful funding sources.

2. The management and use of financial sources for gender equality activities must be for proper purposes, efficient and lawful.

\section{Chapter IV}

\section{RESPONSIBILITIES OF AGENCIES, ORGANIZATIONS, FAMILIES AND INDIVIDUALS IN REALIZING AND GUARANTEEING GENDER EQUALITY}

\section{Article 25. Responsibilities of the Government}

1. To promulgate national gender equality strategies, policies and goals; annually to report to the National Assembly on the implementation of the national gender equality goals.

2. To submit to the National Assembly and its Standing Committee for promulgation or promulgate according to its competence legal documents on gender equality.

3. To direct and organize the integration of gender equality issues in the process of formulating legal documents according to its competence.

4. To organize the implementation of the law on gender equality; to direct and organize the inspection and examination of the implementation of the law on gender equality. 
5. To officially publicize national information on gender equality; to prescribe and direct the application of indicators for gender classification in state statistical data and information.

6. To coordinate with the Viet Nam Fatherland Front Central Committee and the Central Viet Nam Women's Union and direct concerned agencies in propagating, disseminating and educating about the gender equality law and raising the people's awareness of gender equality.

\section{Article 26. Responsibilities of the state management agency in charge of gender equality}

1. To formulate and submit to the Government for promulgation national gender equality strategies, policies and goals.

2. To formulate and submit to the Government for promulgation or promulgate and guide according to their respective competence legal documents on gender equality.

3. To participate in evaluating the integration of gender equality issues in the process of formulating legal documents.

4. To review and report to the Government on the implementation of the national gender equality goals.

5. To assume the prime responsibility for, and coordinate with ministries and ministerial-level agencies in, performing the state management of gender equality.

6. To examine, inspect and handle violations of the law on gender equality, and settling complaints and denunciations related to gender equality.

\section{Article 27. Responsibilities of ministries and ministerial-level agencies}

Within the limits of their respective tasks and powers, ministries and ministerial-level agencies have the following responsibilities:

1. To review legal documents in force in order to amend, supplement, annul or newly promulgate according to their competence or submit to competent agencies for them to amend, supplement, annul or newly promulgate legal documents to guarantee gender equality in the domains under their respective management.

2. To study and propose competent state agencies to promulgate measures for promoting gender equality.

3. To coordinate with the state management agency in charge of gender equality in assessing the practical situation of gender equality in the 
domains under their respective management; to inspect, examine, handle violations of law, and settle complaints and denunciations related to gender equality.

\section{Article 28. Responsibilities of People's Committees at all levels}

1. To make plans for implementation of the national gender equality goals in localities.

2. To submit to the People's Councils for promulgation or promulgate legal documents on gender equality according to their competence.

3. To organize the implementation of the law on gender equality in localities.

4. To inspect, examine, handle violations of the law on gender equality, and settle complaints and denunciations related to gender equality.

5. To organize and direct the communication and education on gender and the law on gender equality among local people.

\section{Article 29. Responsibilities of the Vietnam Fatherland Front and member organizations}

1. To participate in formulating policies and laws and in the state management of gender equality in accordance with law.

2. To ensure gender equality in their organization.

3. To participate in overseeing the implementation of the law on gender equality.

4. To advocate and mobilize the people and their members in exercising gender equality.

\section{Article 30. Responsibilities of the Vietnam Women's Union}

1. To implement the provisions of Article 29 of this Law.

2. To conduct activities assisting women, contributing to achieving the gender equality goals.

3. To coordinate with concerned agencies and organizations in training and nominating qualified women as candidates to the National Assembly and People's Councils; qualified women to managerial and leading posts in agencies in the political system.

4. To perform the functions of representing, protecting legitimate rights and interests of women and female children in accordance with law.

5. To conduct social debate on policies and laws on gender equality. 
Article 31. Responsibilities of state agencies, political organizations and socio-political organizations in exercising gender equality in their agencies and organizations

1. In their organizational and personnel work, state agencies, political organizations and socio-political organizations have the following responsibilities:

a/ To ensure equality among male and female cadres and state employees and servants and laborers in employment, training, promotion, appointment and enjoyment of welfare;

b/ To ensure the principles of gender equality in assessing cadres, state employees and servants and laborers.

2. In their operation, state agencies, political organizations and sociopolitical organizations have the following responsibilities:

a/ To identify the real situation of gender equality, formulate, and ensure the achievement of, gender equality goals in their agencies and organizations, and make annual reports thereon;

b/ To ensure the participation of male and female cadres, state employees and servants and workers in the formulation and implementation of laws, programs, plans and projects on economic, cultural and social development, unless otherwise provided for by law;

c/ To educate cadres, state employees and servants and workers in gender and the law on gender equality;

d/ To set forth measures to encourage their cadres, state employees and servants and workers in exercising gender equality in their

To create conditions for developing social welfare establishments and supporting services in order to reduce the housework burden.

\section{Article 32. Responsibilities of other agencies and organizations in exercising gender equality in their agencies and organizations}

1. In their organizational and personnel work, agencies and organizations not specified in Article 31 of this Law have the following responsibilities:

a/ To ensure equality between men and women in their participation and benefit enjoyment;

b/ To report on or supply in time information on gender equality in their agencies or organizations or relating to their operation;

c/ To propose or participate in formulating policies and laws on gender equality relating to their operation.

2. Depending on their abilities and conditions, agencies and organizations 
shall take the initiative or coordinate their participation in the following gender equality advocacy activities:

a/ To conduct communication of knowledge about gender and the law on gender equality among their members and laborers;

b/ To assign cadres to take charge of gender equality;

c/ To conduct research and apply research findings to enhance gender equality;

d/ To provide funds for gender equality activities;

e/ To organize suitable systems of nurseries to enable male and female laborers to harmoniously combine productive labor and housework;

f/ To provide support for female laborers who bring along their under 36-month children while attending training or retraining courses.

g/ To create conditions for male laborers to take fully paid leaves when their wives give birth.

The State encourages the implementation of activities specified in this Clause.

\section{Article 33. Responsibilities of families}

1. To create conditions for family members to raise their awareness and knowledge about and participate in activities related to gender equality.

2. To educate their members to share and divide housework among themselves in an appropriate manner.

3. o take care of reproductive health and create conditions for women to practice safe motherhood.

4. To equally treat and create equal opportunities for sons and daughters in their study, labor and participation in other activities.

\section{Article 34. Responsibilities of citizens}

Male and female citizens have the following responsibilities:

1. To study in order to improve their knowledge and awareness about gender and gender equality;

2. To adopt and guide other persons to adopt proper behaviors related to gender equality;

3. To criticize and prevent acts of gender discrimination;

4. To oversee the exercise and guarantee of gender equality by the communities, agencies, organizations and citizens. 


\section{Chapter V}

INSPECTION, OVERSIGHT AND HANDLING OF VIOLATIONS RELATED TO GENDER EQUALITY

\section{Article 35. Inspection of implementation of the law on gender equality}

1. The state management agency in charge of gender equality shall perform the function of gender equality inspection.

2. Tasks and powers of gender equality inspection include:

a/ Inspecting the implementation of the law on gender equality;

b/ Inspecting the implementation of the national target program on gender equality and measures to guarantee gender equality;

c/ Settling complaints and denunciations related to gender equality in accordance with this Law and the law on complaints and denunciations;

d/ Handling violations of the law on gender equality in accordance with the law on handling of administrative violations;

e/ Proposing measures to ensure implementation of the law on gender equality; proposing amendments and supplements to policies and law on gender equality;

f/ Performing other tasks and powers in accordance with law.

Article 36. Oversight of implementation of the law on gender equality

1. The National Assembly, its Standing Committee, Ethnic Minority Council and Committees, delegates of National Assembly deputies, and individual National Assembly deputies shall, within the scope of their respective tasks and powers, oversee the implementation of the law on gender equality.

2. People's Councils and individual People's Council deputies shall, within the scope of their respective tasks and powers, oversee the implementation of the law on gender equality in their localities.

\section{Article 37. Complaints and settlement of complaints about acts} of violation of the law on gender equality

1. Agencies, organizations and individuals have the right to complain decisions and acts of other agencies, organizations and individuals when they have grounds for believing that these decisions and acts 
are in violation of the law on gender equality or an infringement upon their legitimate rights and interests.

2. Complaints related to gender equality shall be settled in accordance with the law on complaints and denunciations.

Article 38. Denunciations and settlement of denunciations against acts of violation of the law on gender equality

1. Individuals have the right to denounce acts of violation of the law on gender equality.

2. Denunciations against acts of violation of the law on gender equality shall be lodged and settled in accordance with the law on complaints and denunciations.

Article 39. Principles of handling of acts of violation of the law on gender equality

All acts of violation of the law on gender equality shall be detected and stopped in time. They shall be handled in a prompt, just and thorough manner in accordance with law.

Article 40. Acts of violation of the law on gender equality in politics, economy, labor, education and training, science and technology, culture, information, physical training and sports, and health

1. Acts of violation of the law on gender equality in politics include:

a/ Obstructing on the grounds of gender prejudice men or women in self-nominating as candidates or nominating candidates to the National Assembly or People's Councils, leading bodies of political, socio-political, socio-political professional, social or socioprofessional organizations;

b/ Failing to appoint, or obstructing the appointment of, men or women to hold managerial or leading posts or professional titles on the grounds of gender prejudice;

c/ Imposing and implementing village codes or community conventions or regulations or rules of agencies or organizations that contain gender-based discrimination provisions.

2. Acts of violation of the law on gender equality in economy include:

a/ Obstructing men or women in setting up enterprises or conducting business activities on the grounds of gender prejudice;

b/ Running commercial advertisements that place at disadvantage enterprise owners or traders of one certain sex. 
3. Acts of violation of the law on gender equality in labor include:

a/ Applying different conditions in the recruitment of male and female laborers to the same job though they have the same qualifications and abilities, unless in the case of application of measures for promoting gender equality;

b/ Refusing to recruit, or recruit limited numbers of, laborers or dismiss laborers in the gender-based grounds or for their pregnancy, delivery or raising of small children;

c/ Assigning jobs based on gender discrimination resulting in different incomes or paying different wages to male and female laborers having the same qualifications and capability;

d/ Failing to implement the provisions of labor law exclusively applicable to female laborers.

4. Acts of violation of the law on gender equality in education and training include:

a/ Prescribing different training and enrolment ages between men and women;

b/ Advising or coercing other persons to drop out of school for gender reasons;

c/ Refusing to recruit qualified persons to training or retraining courses or for their pregnancy, delivery or raising of small children;

d/ Providing career-oriented education, compling and disseminating textbooks containing gender discrimination knowledge.

5 Acts of violation of the law on gender equality in science and technology include:

a/ Obstructing men and women in participating in scientific and technological activities;

b/ Refusing to admit persons of one certain gender to scientific and technological training courses.

6. Acts of violations of the law on gender equality in culture, information, physical training and sports include:

a/ Obstructing men and women in composing or criticizing cultural and art works, performing and participating in cultural activities on the grounds of gender prejudice;

b/ Composing, circulating, authorizing the publication of works under any genre or form to encourage, propagate gender inequality and gender prejudice; 
c/ Spreading ideas, conducting by oneself or inciting other people to conduct backward practices and customs of gender discrimination nature under all forms.

7. Acts of violation of the law on gender equality in the field of health include:

a/ Impeding, inciting or forcing other people not to participate in the activities of health education for gender prejudice reasons;

b/ Choosing gender of unborn babies under all forms or inciting and forcing other people to have an abortion because of the unborn baby's gender.

\section{Article 41. Acts of violation of the law on gender equality in the} family

1. Impeding members in the family who have all qualifications as provided by law from participating in the determination of assets under common ownership of a family for gender reasons.

2. Not allowing or impeding members in the family from contributing their opinions to the use of common assets of the family, conducting income-generating activities or satisfying other needs of the family for gender prejudice reasons.

3. Unequally treating members in the family for gender reasons.

4. Constraining the schooling of members in the family or forcing members in the family to drop out of school for gender reasons.

5. Imposing the performance of family work and the taking of contraceptive measures as though these are the responsibilities of members of one certain gender.

\section{Article 42. Forms of sanction against violations of the law on gender equality}

1. Those who commit acts of violation of the law on gender equality shall, depending on the nature and severity of their violations, be disciplined, administratively handled or examined for penal liability.

2. Agencies, organizations or individuals that commit acts of violation of the law on gender equality and cause damage shall pay compensations therefore in accordance with law. 


\section{Chapter VI \\ IMPLEMENTATION PROVISIONS}

Article 43. Implementation effect

This Law takes effect on July 1, 2007.

Article 44. Implementation guidance

The Government shall detail and guide the implementation of this Law.

This Law was passed on November 29, 2006, by the Xth National Assembly of the Socialist Republic of Viet Nam at its 10th session. 


\section{LAW ON MARRIAGE AND FAMILY, PASSED 9/6/2000 BY VIET NAM NATIONAL ASSEMBLY}

THE NATIONAL ASSEMBLY

No: 22/2000/QH10
SOCIALIST REPUBLIC OF VIET NAM

Independence - Freedom - Happiness

Ha Noi , Day 09 month 06 year 2000

THE MARRIAGE AND FAMILY LAW

(No. 22/2000/QH10 of June 9, 2000)

\section{PREAMBLE}

Families constitute cells of the society, cradles where men are brought up, and an important environment for personality formation and education, contributing to the construction and defense of the Fatherland. Good families make good society, good society makes better families.

In order to enhance the role of families in the social life, preserve and promote the good traditions, customs and practices of the Vietnamese people, abolish backward customs and practices regarding marriage and family;

In order to raise the responsibilities of citizens, the State and the society in the building and consolidation of the Vietnamese marriage and family regime;

To inherit and develop the Vietnamese marriage and family legislation;

Pursuant to the 1992 Constitution of the Socialist Republic of Viet Nam;

This Law provides for the marriage and family regime.

\section{Chapter I}

\section{GENERAL PROVISIONS}

Article 1. Missions and scope of application of the Marriage and Family Law

The Marriage and Family Law has the missions to contribute to building, perfecting and protecting the progressive marriage and family regime, formulate legal standards for the conducts of family members; protect the legitimate rights and interests of family members; inherit and promote the fine ethical traditions of the Vietnamese families in order to build prosperous, equal, progressive, happy and lasting families. 
The Marriage and Family Law provides for the marriage and family regime, responsibilities of citizens, the State and society in the building and consolidation of the Vietnamese marriage and family regime.

\section{Article 2. Basic principles of the marriage and family regime}

1. Voluntary, progressive and monogamous marriage in which husband and wife are equal.

2. Marriage between Vietnamese citizens of different nationalities and/ or different religions, between religious and non-religious people, and between Vietnamese citizens and foreigners is respected and protected by law.

3. Husband and wife are obliged to implement the population and family planning policy.

4. Parents are obliged to bring up their children into citizens useful for the society; children are obliged to respect, care for and support their parents; grandchildren are obliged to respect, care for and support their grandparents; family members are obliged look after, care for and help one another.

5. The State and society shall not accept discrimination among children, between sons and daughters, between biological and adopted children, between in-wedlock and out-of-wedlock children.

6. The State, society and families have the duty to protect women and children, and help mothers to fulfill their lofty motherhood functions.

\section{Article 3. The State's and society's responsibilities for marriage and family}

1. The State adopts policies and measures to create conditions for male and female citizens to establish voluntary and progressive marriage and for families to fulfill their functions; intensify the dissemination and popularization of the marriage and family legislation; mobilize people to abolish backward customs and practices related to marriage and family, promote fine traditions, customs and practices embodying the identity of each nationality; build up progressive marriage and family relations.

2. Agencies and organizations have the duty to educate and mobilize their officials, employees and members as well as every citizen to build cultural families; provide counseling on marriage and family; reconcile family discord in time, protect the legitimate rights and interests of the family members. 
3. Schools shall coordinate with families in educating, disseminating and popularizing the marriage and family legislation among the young generations.

\section{Article 4. Protection of the marriage and family regime}

1. Marriage and family relations conforming to this Law are respected and protected by law.

2. Under-age marriage, forcing marriage, hindering voluntary and progressive marriage, feigned marriage, deceiving other persons into marriage or divorce; forcing divorce, feigned divorce, and property demand for wedding are all forbidden.

A married person is forbidden to marry or live with another person as husband or wife and an unmarried person is forbidden to marry or live with a married person as husband or wife.

III-treatment and persecution against grandparents, parents, spouses, children, grandchildren, siblings or other family members are forbidden.

3. All acts of violating the marriage and family legislation must be handled promptly, strictly and in accordance with law.

Agencies, organizations and individuals have the right to request the Court or other competent bodies to take measures to promptly stop and severely handle those who commit acts of violating the marriage and family legislation.

\section{Article 5. Application of the provisions of the Civil Code}

The Civil Code's provisions related to the marriage and family relations shall be applicable to the marriage and family relations in cases where the marriage and family legislation has no relevant provisions.

\section{Article 6. Application of marriage and family-related customs and practices}

In marriage and family relations, the customs and practices embodying the identity of each nationality and not running counter to the principles laid down in this Law are respected and promoted.

Article 7. Application of the marriage and family legislation to the marriage and family relations involving foreign elements

1. The provisions of the marriage and family legislation of the Socialist Republic of Viet Nam shall be applicable to the marriage and family relations involving foreign elements, except otherwise provided for by this Law. 
2. Where an international agreement which the Socialist Republic of Viet Nam has signed or acceded to contains provisions different from this Law's provisions, the provisions of such international agreement shall apply.

\section{Article 8. Interpretation of terms}

In this Law the following terms are construed as follows:

1. The marriage and family regime means the entire law provisions on marriage, divorce, obligations and rights between wives and husbands, parents and children, and among other family members, support, determination of parents, biological children, adopted children and guardians, marriage and family relations involving foreign elements and other matters related to marriage and family;

2. Getting married is an act whereby a man and a woman establish the husband and wife relation according to the law provisions regarding conditions for getting married and marriage registration;

3. Illegal marriage means the establishment of husband and wife relation by a man and a woman who have registered their marriage but breach the marriage conditions prescribed by law;

4. Underage marriage means getting married when one or both marriage partners have not reached the marriage age prescribed by law.

5. Forcing marriage is an act of forcing other persons to get married against their will;

6. Marriage means the relationship between husband and wife after getting married;

7. Marriage period means the duration of time when the husband and wife relationship exists, counting from the date of marriage registration untill the date of marriage termination;

8. Divorce means the termination of the husband and wife relationship, which is recognized or decided by the Court at the request of either spouse or both.

9. Forcing divorce is an act of forcing other persons to divorce against their will;

10. Family means a group of persons closely bound together by marriage, blood ties or rearing relations, thus giving rise to obligations and rights among these persons according to the provisions of this Law; 
11. Support means an act whereby a person has the obligation to contribute money or other kinds of property to meet the essential needs of another person not cohabiting but having marriage, blood or rearing relations with him/her in cases where the latter is a minor or an adult who has no working capacity and no property to support himself/herself, or who meets with economic difficulties, as prescribed by this Law;

12. People of the same direct blood line are parents with respect to their children; grandparents with respect to their grandchildren;

13. Relatives within three generations means people born of the same stock: parents constituting the first generation; siblings of the same parents, of the same father but different mothers, of the same mother but different fathers constituting the second generation; children of uncles and aunts constituting the third generation;

14. Marriage and family relations involving foreign elements are marriage and family relations between:

a/ Vietnamese citizens and foreigners;

b/ Foreigners permanently residing in Viet Nam;

c/ Vietnamese citizens but the basic for establishing, changing or terminating such relations are governed by the law of a foreign country or the property related to such relations located abroad.

\section{Chapter II}

\section{GETTING MARRIED}

\section{Article 9. Conditions for getting married}

A man and a woman wishing to marry each other must satisfy the following conditions:

1. The man has reached the age of twenty or over, the woman has reached the age of eighteen or over;

2. The marriage is voluntarily decided by the man and the woman; neither partner is allowed to force or deceive the other; nobody is allowed to force or obstruct their marriage;

3. The marriage does not fall into one of the circumstances where marriage is forbidden as prescribed in Article 10 of this Law. 


\section{Article 10. Circumstances where marriage is forbidden}

Marriage is forbidden in the following circumstances:

1. Married people;

2. People who have lost their civil act capacity;

3. Between people of the same direct blood line; between relatives within three generations;

4. Between adoptive parents and adopted children; between former adoptive parents and former adopted children; between fathers-inlaw and daughters-in-law, mothers-in-law and sons-in-law, stepfathers and stepchildren, stepmothers and stepchildren;

5. Between people of the same sex.

\section{Article 11. Marriage registration}

1. Marriage must be registered with the competent State bodies (hereinafter called marriage registration offices) according to the proceedings prescribed in Article 14 of this Law.

Any marriage proceedings at variance with the provisions in Article 14 of this Law shall not be legally valid.

Man and woman who fail to register their marriage but live together as husband and wife shall not be recognized by law as husband and wife.

Divorced husband and wife wishing to remarry each other must also register their remarriage.

2. The Government shall stipulate the marriage registration in remote and deep-lying areas.

\section{Article 12. Competence to register marriage}

The People's Committees of communes, wards or townships where either of the marriage partners resides are the marriage registration offices.

The overseas Vietnamese diplomatic missions or consulates are the offices registering marriage between Vietnamese citizens living abroad.

\section{Article 13. Handling of marriage registration}

1. After receiving complete and valid documents according to the civil status legislation, the marriage registration offices check the marriage registration dossiers; if deeming that both the male and female partners to the marriage are eligible for marriage, the marriage registration offices shall organize the marriage registration. 
2. Where either or both marriage partners fail to fully meet the marriage conditions, the marriage registration office shall decline to register and clearly explain in writing the reasons therefor; if the people whose application for marriage registration is rejected disagree, they may lodge their complaints according to the provisions of law.

\section{Article 14. Organization of marriage registration}

Marriage registration must be organized in the presence of both male and female partners. A representative of the marriage registration office first asks the two partners about their wish for voluntary marriage, if they agree to marry each other, the representative of the marriage registration office shall hand the marriage certificate to them.

\section{Article 15. People entitled to request the annulment of illegal marriages}

1. The partner who is forced or deceived into marriage has the right, as prescribed by the civil procedure legislation, to request by himself/ herself the Court or propose the Procuracy to request the Court to annul the illegal marriage due to violation of the provisions in Clause 2, Article 9 of this Law.

2. The Procuracy has the right, as prescribed by the civil procedure legislation, to request the Court to annul illegal marriages due to violation of the provisions in Clause 1, Article 9 and Article 10 of this Law.

3. The following individuals, agencies and organizations have the right, as prescribed by the civil procedure legislation, to request by themselves the Court or propose the Procuracy to request the Court to annul illegal marriages due to violation of the provisions in Clause 1, Article 9 and Article 10 of this Law:

a/ Spouses, parents or children of the marriage partners;

b/ The child protection and care committees;

c/ The women's unions.

4. Other individuals, agencies and organizations have the right to propose the Procuracy to consider and request the Court to annul illegal marriages.

\section{Article 16. Annulment of illegal marriages}

At the request of individuals, agencies or organizations prescribed in Article 15 of this Law, the Court shall consider and decide the annulment of illegal marriages and send copies of its decisions to the offices that have made the marriage 
registration. Basing themselves on the Court's decisions, the marriage registration offices shall erase the marriage registration in the Marriage Register.

Article 17. Legal consequences of the annulment of illegal marriages

1. When an illegal marriage is annulled, the male and female partners must stop their relation as husband and wife.

2. Their children's interests shall be dealt with as for cases where their parents are divorced.

3. Their property shall be dealt with on the principle that his/her personal property shall still belong to him/her; their common property shall be divided as agreed upon by the two partners; if they fail to reach an agreement thereon, they may request the Court to settle it, taking into account each partner's contributions and giving priority to protecting the legitimate interests of women and children.

\section{Chapter III \\ RELATIONSHIP BETWEEN HUSBAND AND WIFE}

\section{Article 18. Husband and wife attachment}

Husband and wife are faithful to, love, respect, care for and help, each other, together build a prosperous, equal, progressive, happy and lasting family.

\section{Article 19. Equality in obligations and rights between husband and wife}

Husband and wife are equal to each other, having equal obligations and rights in all aspects of their family.

\section{Article 20. Selection of the domicile of husband and wife}

The domicile of husband and wife is selected by themselves without being bound by customs, practices and/or administrative boundaries.

Article 21. Respect for honor, dignity and prestige of husband and wife

1. Husband and wife respect each other and preserve each other's honor, dignity and prestige.

2. Husband and wife are strictly forbidden to commit acts of ill-treating, persecuting or hurting the honor, dignity or prestige of each other. 
Article 22. Respect for the right to freedom of religion and belief of husband and wife

Husband and wife respect each other's right to freedom of belief and religion; must not compel or impede each other to adhere or not adhere to any religion.

Article 23. Helping and creating conditions for each other to develop in all aspects

Husband and wife discuss together, help and create conditions for each other to select professions, study and raise their educational level, professional qualifications and skills; take part in political, economic, cultural and social activities according to each partner's aspiration and ability.

\section{Article 24. Mutual representation between husband and wife}

1. Husband and wife may authorize each other to establish, perform or terminate transactions which, as prescribed by law, must be agreed upon by both husband and wife; such authorization must be made in writing.

2. Husband and wife may represent each other when either of them loses his/her civil act capacity while the other is eligible to act as guardian or when either of them is limited in his/her civil act capacity while the other is designated by the Court to act as a representative at law for his/her partner.

Article 25. Joint liability of husband and wife for transactions conducted by either of them

Husband or wife must take joint liability for lawful civil transactions conducted by either of them to satisfy their family's daily-life essential needs.

\section{Article 26. Marriage relations when a partner returns after being declared dead}

When the Court issues a decision abrogating a declaration that a person was dead as provided for in Article 93 of the Civil Code and his/her spouse has not yet married another person, their marriage relation will be automatically restored; where his/her spouse has married another person, the marriage relation established later shall be legally valid.

\section{Article 27. Common property of husband and wife}

1. Common property of husband and wife includes property created by husband and wife, incomes generated from labor, production and business activities and other lawful incomes of husband and wife during 
the marriage period; property jointly inherited or given to both, and other property agreed upon by husband and wife as common property.

The land use right obtained by husband and wife after their marriage is their common property. The land use right obtained before the marriage or personally inherited by husband or wife shall be common property only if so agreed upon by husband and wife.

Common property of husband and wife falls under common ownership by integration.

2. Where a property under the common ownership of husband and wife is required by law to be registered for ownership, the names of both husband and wife must be inscribed in the ownership certificate thereof.

3. Where there is no evidence proving that a property being in dispute between husband and wife is his/her personal property, such property is common property.

\section{Article 28. Possession, use and disposition of common property}

1. Husband and wife have equal obligations and rights in the possession, use and disposition of their common property.

2. Common property of husband and wife is used only to ensure the family's needs and perform their common obligations.

3. The establishment, performance or termination of civil transactions related to common property which is of big value or the family's sole means of livelihood, the use of common property for business investment must be discussed and agreed upon by husband and wife, except where such common property has been divided for his/her own business investment under Clause 1, Article 29 of this Law.

\section{Article 29. Division of common property during the marriage period}

1. When marriage still exists, if husband and wife make separate business investments, perform separate civil obligations or there are other plausible reasons, husband and wife may agree to divide their common property; the division of common property must be recorded in writing; if they fail to reach an agreement thereon, they may request the Court to settle it.

2. Division of common property of husband and wife in order to shirk the performance of property obligations shall not be recognized by law. 
Article 30. Consequences of the division of common property of husband and wife

Where common property of husband and wife is divided, yields or profits arising from the divided property shall belong to the ownership of each person; the undivided property portion remains under the common ownership of husband and wife.

\section{Article 31. Husband and wife's right to inherit each others property}

1. Husband and wife have the right to inherit each other's property according to the provisions of the inheritance legislation.

2. When the wife or husband dies or is declared dead by the Court, the living partner shall manage their common property, except for cases where another person is designated in the testament to manage the heritage or the heirs agree to designate another person to manage the heritage.

3. Where there is a request to divide the heritage but the division of heritage shall seriously affect the life of the living spouse and the family, the living spouse may request the Court to determine the heritage portions to be enjoyed by the heirs but delay the heritage division for a certain period of time; past the time limit determined by the Court or if the living partner has married another person, the other heirs may request the Court to permit the division of the heritage.

\section{Article 32. Personal property of husband and wife}

1. Husband and wife have the right to own personal property.

Personal property of husband and wife includes property owned by each person before their marriage; property inherited and/or given separately during the marriage period; property separately divided to husband or wife under Clause 1, Article 29 and Article 30 of this Law; personal belongings and jewelry.

2. Husband and wife may consolidate or not consolidate their personal property into the common property.

\section{Article 33. Possession, use and disposition of personal property}

1. Husband and wife have the right to possess, use and dispose their personal property, except for cases prescribed in Clause 5 of this Article.

2. Husband and wife manage by themselves their personal property; where either spouse is not able to manage by himself or herself 
his/her personal property and does not authorize another person to manage, the other partner may manage such property.

3. Each partner's own property obligations are performed with his/her personal property.

4. Personal property of husband and wife are also used to meet their family's essential needs if their common property is not enough.

5. Where either spouse's personal property has been put to common use and the profits or yields from such personal property constitute the family's sole means of livelihood, the disposition of such personal property must be agreed upon by both husband and wife.

\section{Chapter IV}

\section{RELATIONSHIP BETWEEN PARENTS AND CHILDREN}

\section{Article 34. Obligations and rights of parents}

1. Parents have the obligations and rights to love, look after, rear, care for, and protect the legitimate rights and interests of, their children; respect their children's opinions; attend to the study and education of their children so as to ensure their healthy development in all physical, intellectual and moral aspects to become upstanding children of the family and useful citizens of the society.

2. Parents must not discriminatorily treat, ill-treat or persecute their children, or hurt their honor; must not abuse the power of their minor children to work must not incite or compel their children to act against law and social morality.

\section{Article 35. Obligations and rights of children}

Children have the duty to love, respect, show gratitude and piousness to, their parents, pay heed to the good advices of their parents, and preserve the good traditions and prestige of their family.

Children have the obligations and rights to care for and support their parents.

Children are strictly forbidden to ill-treat, persecute or hurt the honor, of their parents.

\section{Article 36. Obligations and rights to care for and support}

1. Parents have the obligations and rights to jointly care for and raise their minor children or adult children who are disabled, have lost 
their civil act capacity, have no working capacity and no property to support themselves.

2. Children have the obligations and rights to care for and support their parents, especially when their parents fall sick, become senile or disabled; where a family has several children, the children must together care for and support their parents.

\section{Article 37. Obligations and rights to educate children}

1. Parents have the obligations and rights to educate their children, attend to and create conditions for their study.

Parents create conditions for their children to live in a happy and harmonious family environment, set good examples for their children in every aspect, work closely with the school and social organizations in educating their children.

2. Parents guide their children to select professions; respect their children's rights to select professions and participate in social activities.

3. When facing difficulties which cannot be solved by themselves, parents may request concerned agencies and organizations to assist in educating their children.

\section{Article 38. Obligations and rights of or stepfathers, stepmothers} and stepchildren

1. Stepfathers or stepmothers have the obligations and rights to look after, rear, care for, and educate cohabiting stepchildren according to the provisions in Articles 34, 36 and 37 of this Law.

2. Stepchildren have the obligations and rights to care for and support cohabiting stepfathers or stepmothers according to the provisions in Articles 35 and 36 of this Law.

3. Stepfathers, stepmothers and stepchildren must not ill-treat, persecute or hurt the honor of, one another.

\section{Article 39. Representation for children}

Parents are representatives at law of their minor children or adult children who have lost their civil act capacity, except for cases where the children have other persons as their guardians or representatives at law.

\section{Article 40. Making compensation for damage caused by children}

Parents must pay compensation for damage caused by their minor children or adult children who have lost their civil act capacity, as provided for in Article 611 of the Civil Code. 
Article 41. Restrictions on fathers and/or mothers' rights toward their minor children

When fathers and/or mothers are sentenced for one of the crimes of deliberately infringing upon the health, dignity or honor of their children or commit acts of seriously breaching their obligations to look after, care for, rear and educate their children; dissipate property of their children; lead a debauched life; incite or force their children to act against law or social morality, the Court may, on the case-by-case basis, make decisions by itself or at the request of the individuals, agencies or organizations prescribed in Article 42 of this Law, to disallow such parents to look after, care for and educate their children or manage the personal property of their children or act as their children's representatives at law for a time limit of between one and five years. The Court may also consider shortening this time limit.

Article 42. People entitled to request the Court to restrict fathers' and/or mothers' rights toward their minor children

1. Fathers, mothers or relatives of minor children have the right, as prescribed by the civil procedure legislation, to request the Court by themselves or propose the Procuracy to request the Court to restrict certain rights of fathers and/or mothers toward their minor children.

2. The Procuracy has the right, as prescribed by the civil procedure legislation, to request the Court to restrict certain rights of fathers and/or mothers toward their minor children.

3. The following agencies and organizations have the right, as prescribed by the civil procedure legislation, to request the Court by themselves or propose the Procuracy to request the Court to restrict certain rights of fathers and/or mothers toward their minor children:
a/ The child protection and care committees;
b/ The women's unions.

4. Other individuals, agencies and organizations have the right to propose the Procuracy to consider and request the Court to restrict certain rights of fathers and/or mothers toward their minor children.

\section{Article 43. Legal consequences of the restrictions on the fathers' and/or mothers' rights toward their minor children}

1. Where either parent has his/her certain rights toward his/her minor children restricted by the Court, the other parent exercises her/his right to look after, rear, care for and educate the children, manage the children's personal property and acts as their representative at law. 
2. Where both parents have their rights toward their minor children restricted by the Court, a guardian shall be assigned to look after, care for and educate the children and manage the children's personal property according to the provisions of the Civil Code and this Law.

3. Fathers and/or mothers who have their rights toward their minor children restricted by the Court still have to perform the obligations to rear their children.

\section{Article 44. Children's right to have personal property}

1. Children have the right to have personal property. A child's personal property includes property inherited or given solely to him/her, incomes from his/her labor, yields and profits arising from his/her personal property and other lawful incomes.

2. Children aged from full fifteen years or older and still living with their parents are obliged to take care of their family's life; and contribute their incomes, if any, to meeting their family's essential needs.

\section{Article 45. Management of children's personal property}

1. Children aged from full fifteen years or older may manage by themselves or ask their parents to manage their personal property.

2. Personal property of children who are under fifteen years old or have lost their civil act capacity shall be managed by their parents. Parents may authorize other persons to manage their children's personal property.

3. Parents shall not manage their children's personal property if the persons giving or bequeathing under testament such property to their children have designated other persons to manage such property or in other cases prescribed by law.

\section{Article 46. Disposition of minor children's personal property}

1. Parents who manage their under-fifteen children's personal property have the right to dispose of such property in the interests of their children, taking into account the desire of the children if they are aged full nine years or older.

2. Children aged between full fifteen and under eighteen years shall have the right to dispose of their personal property; if the property is of big value or if used for business activities, the disposal thereof must be agreed upon by their parents. 


\section{Chapter V}

\section{RELATIONS BETWEEN PATERNAL GRANDPARENTS, MATERNAL GRANDPARENTS AND GRANDCHILDREN; AMONG SIBLINGS AND FAMILY MEMBERS}

\section{Article 47. Obligations and rights of paternal and maternal grandparents toward their grandchildren}

1. Paternal and maternal grandparents have the obligations and rights to look after, care for and educate their grandchildren, lead an exemplary life and set good examples for their grandchildren. Where the grandchildren are minor or adult but are disabled, have lost their civil act capacity, have no working capacity and no property to support themselves while having no one to support them as prescribed in Article 48 of this Law, their paternal and maternal grandparents shall be obliged to rear them.

2. Grandchildren have the duty to respect, care for and support their paternal and maternal grandparents.

\section{Article 48. Obligations and rights of siblings}

Siblings have the duty to love, care for and help one another; have the obligations and rights to help, protect as well as support one another in cases where they no longer have parents or their parents have no conditions to look after, rear, care for and educate their children.

\section{Article 49. Relations among family members}

1. Cohabiting family members are all obliged to care for and help one another, together care for their family life, contribute labor, money and other property to maintain their common life in proportion to their actual incomes and capabilities.

Family members are entitled to enjoy mutual care for and help. Their legitimate rights and interests are respected and protected by law.

2. The State encourages and creates conditions for different generations in families to care for and help one another in order to preserve and promote the good traditions of the Vietnamese families. 


\section{Chapter VI}

\section{SUPPORT}

\section{Article 50. The supporting obligation}

1. The supporting obligation is effected between fathers, mothers and children, among siblings, between grandparents and grandchildren, between husband and wife according to the provisions of this Law.

The supporting obligation must be neither substituted by another obligation nor transferred to other persons.

2. Where a person with the supporting obligation shirks the performance of such obligation, he/she shall be forced to perform his/her supporting obligation prescribed in this Law.

\section{Article 51. One person supports several persons}

Where a person supports several persons, the supporting person and the supported persons shall agree mutually upon the mode and extent of support appropriate to the actual income and capability of the supporting person and the essential needs of the supported persons; if they fail to reach an agreement thereon, they may request the Court to settle it.

\section{Article 52. Several persons jointly support one or several persons}

Where several persons share the same obligation to support one or several persons, they shall agree mutually upon the mode and level of support appropriate to the actual income and capability of each supporting person and the essential needs of the supported person(s); if they fail to reach an agreement thereon, they may request the Court to settle it.

\section{Article 53. Support level}

1. The support level shall be agreed upon by the person(s) with the supporting obligation and the person(s) enjoying the support or the latter's guardian on the basis of the actual income and capability of the person(s) with the supporting obligation and the essential needs of the person(s) enjoying the support; if they fail to reach an agreement thereon, they may request the Court to settle it.

2. Where there exist plausible reasons, the support level may change. The change of the support level shall be agreed upon by the concerned parties; if they fail to reach an agreement thereon, they may request the Court to settle it. 


\section{Article 54. Mode of performing the supporting obligation}

The support may be provided monthly, quarterly, biannually, annually or in lump sum.

The concerned parties may agree upon a change in the supporting mode or a pause of the support in cases where the person(s) with the supporting obligation falls into a strained economic circumstance, thus being unable to perform his/her supporting obligation; if they fail to reach an agreement thereon, they may request the Court to settle it.

Article 55. People entitled to request the performance of the supporting obligation

1. People enjoying the support or their guardians have the right, as prescribed by the civil procedure legislation, to request the Court by themselves or propose the Procuracy to request the Court to force the people who fail to voluntarily perform their supporting obligation to perform such obligation.

2. The Procuracy have the right, as prescribed by the civil procedure legislation, to request the Court to force the people who fail to voluntarily perform their supporting obligation to perform such obligation.

3. The following agencies and organizations have the right, as prescribed by the civil procedures legislation, to request the Court by themselves or to propose the Procuracy to request the Court to force the people who fail to voluntarily perform their supporting obligation to perform such obligation:

a/ The child protection and care committees;

b/ The women's unions.

4. Other individuals, agencies and organizations have the right to propose the Procuracy to consider and request the Court to force the people who fail to voluntarily perform their supporting obligation to perform such obligation

\section{Article 56. Fathers', mothers' obligations to support their} children when they are divorced

When divorced, the fathers of mothers who do not directly raise their minor children or adult children who are disabled, have lost their civil act capacity or have no working capacity and no property to support themselves, have the obligation to support the children. 
The level of support for children shall be agreed upon by the fathers and mothers, if they fail to reach an agreement thereon, they may request the Court to settle it.

\section{Article 57. Children's obligation to support their parents}

Adult children who no longer live with their parents are obliged to support their parents who have no working capacity and no property to support themselves.

\section{Article 58. Obligation of mutual support among siblings}

1. In cases where their parents are no longer alive or have no working capacity and no property to support their children, adult elder brothers and/or sisters who no longer live with their younger brothers and/ or sisters are obliged to support their minor brothers or sisters who have no property to support themselves or adult younger brothers and/or sisters who have no working capacity and no property to support themselves.

2. Adult younger sisters and/or brothers who no longer live with their elder sisters and/or brothers are obliged to support their elder sisters and/or brothers who have no working capacity and no property to support themselves.

\section{Article 59. The supporting obligation between grandparents and grandchildren}

1. Grandparents who do not live with their grandchildren are obliged to support their grandchildren if the latter are minor or grown up but have no working capacity, no property to support themselves and have no one to support as prescribed in Article 58 of this Law.

2. Grandchildren who do not live with their grandparents are obliged to support their grandparents if the latter have no working capacity, no property to support themselves and have no one else to support as prescribed by this Law.

\section{Article 60. The supporting obligation between husband and wife when divorced}

When divorced, if the party facing economic difficulties requests support with plausible reasons, the other party is obliged to support according to his/her capability. 


\section{Article 61. Termination of the supporting obligation}

The supporting obligation terminates in the following circumstances:

1. The supported people have attained their adulthood and have the working capacity;

2. The supported people have incomes or property to support themselves;

3. The supported people are adopted;

4. The supporting people directly rear the supported people;

5. The supporting people or supported people die;

6. The supported people have remarried other people after divorce;

7. Other cases prescribed by law.

Article 62. Encouragement of organizations and individuals' financial support

The State and society encourage organizations and individuals to provide support in cash or other property to families and individuals in extremely difficult and needy circumstances.

\section{Chapter VII}

\section{DETERMINATION OF FATHERS, MOTHERS, CHILDREN}

\section{Article 63. Determination of fathers, mothers}

1. Children born or conceived by the wife during the marriage period are common children of the husband and wife.

Children born before the marriage registration date and recognized by their parents are also common children of the husband and wife.

2. In cases where the fathers and mothers decline to recognize children, they must produce evidence which must be determined by the Court.

The determination of fathers and/or mothers for children born by means of scientific methods shall be stipulated by the Government.

\section{Article 64. Determination of children}

A person who is not recognized as father or mother of another person may request the Court to determine that person is his/her child.

A person who is recognized as father or mother of another person may request the Court to determine such person is not his/her child. 
Article 65. The right to recognize fathers, mothers

1. Children have the right to claim their fathers and/or mothers, even when the fathers and/or mothers have died.

2. Grown-up children may claim their fathers without the consent of their mothers; may claim their mothers without the consent of their fathers.

Article 66. People entitled to request the determination of fathers and/or mothers for minor children or adult children who have lost their civil act capacity or determination of children for fathers and/or mothers who have lost their civil act capacity

1. Mothers, fathers or guardians have the right, as prescribed by the civil procedure legislation, to request the Court by themselves or propose the Procuracy to request the Court to determine fathers and/or mothers for minor children or adult children who have lost their civil act capacity or determine children for fathers and/or mothers who have lost their civil act capacity.

2. The Procuracy have the right, as prescribed by the civil procedure legislation, to request the Court to determine fathers and/or mothers for minor children or adult children who have lost their civil act capacity or determine children for fathers and/or mothers who have lost their civil act capacity.

3. The following agencies and organizations have the right, as prescribed by the civil procedure legislation, to request the Court by themselves or propose the Procuracy to request the Court to determine fathers and/or mothers for minor children or adult children who have lost their civil act capacity or determine children for fathers and/or mothers who have lost their civil act capacity:

a/ The children protection and care committees;

b/ The women's unions.

4. Other individuals, agencies and organizations have the right, as prescribed by the civil procedure legislation, to request by themselves the Court or propose the Procuracy to request the Court to determine parents for minor children or adult children who have lost their civil act capacity or determine children for fathers and/or mothers who have lost their civil act capacity. 


\section{Chapter VIII \\ ADOPTED CHILDREN}

\section{Article 67. Child adoption}

1. Child adoption means the establishment of the parent-child relationship between the adopter and adoptee, ensuring that the adoptee will be looked after, reared, cared for and brought up in conformity with the social morality.

A person may adopt one or several persons as his/her adopted children.

The adopter and the adoptee have the rights and obligations of parents and children as prescribed by this Law.

2. The State and society encourage the adoption of orphaned, abandoned or disabled children.

3. It is strictly forbidden to abuse the child adoption to exploit the labor power, sexually assault or traffick in children or for other self-seeking purposes.

\section{Article 68. Adoptees}

1. Adoptees must be aged fifteen years or younger.

Those aged over fifteen years may be adopted if they are war invalids, disabled people or people who have lost their civil act capacity or if they are adopted by old, lonely people.

2. A person may only be adopted by one person or two persons being husband and wife.

\section{Article 69. Conditions for adopters}

Adopters must fully meet the following conditions:

1. Having full civil act capacity;

2. Being twenty years or more older than their adopted children;

3. Having good ethical qualities;

4. Having actual conditions to ensure the care for, support and education of their adopted children.

5. They must not be people who have certain parental rights toward minor children restricted or who have been sentenced for one of the crimes of deliberately infringing upon the life, health, dignity and honor of another person; ill-treating or persecuting their grandparents, 
parents, spouses, children, grandchildren and/or fosterers; inciting, forcing juvenile people to commit offenses or harboring juvenile offenders; trafficking in, fraudulently exchanging or abducting children; or the crimes of sexual abuse against children; committing acts of enticing and/or forcing their own children to act against law or social morality, but have not yet enjoyed criminal record remission.

\section{Article 70. Adoption of children by both the husband and wife}

In cases where both husband and wife adopt a child, they must fully meet the conditions prescribed in Article 69 of this Law.

\section{Article 71. Consent of natural parents, guardians and adoptees}

1. The adoption of minor children or adults who have lost their civil act capacity must be consented in writing by such persons' natural parents; if their natural parents have already died, lost their civil act capacity or cannot be determined, their guardians' written consents are required.

2. The adoption of children aged full nine years or older must have the consent of such children.

\section{Article 72. Child adoption registration}

Child adoption must be registered with the competent State agencies and inscribed in the Civil Status Register.

The procedures for child adoption registration and hand-over of adopted children shall comply with the provisions of the civil status legislation.

\section{Article 73. Refusal to register child adoption}

Where one party or all parties involved fail to fully meet the conditions for adopting children or being adopted, the child adoption registration offices shall refuse to register and clearly explain the reasons therefore in writing; if natural parents, guardians or adopters disagree, they may lodge complaints according to the law provisions.

\section{Article 74. Rights and obligations between adoptive parents and adopted children}

Adoptive parents and adopted children have the parents' and children's rights and obligations prescribed in this Law, as from the time the child adoption is registered.

Children of fallen heroes, war invalids or people with meritorious services to the revolution, who are adopted by other people, shall continue to 
enioy all benefits of the children of fallen heroes, war invalids or people with meritorious services to the revolution.

\section{Article 75. Change of family name, given name; determination of} nationalities of adopted children

1. At the request of the adoptive parents, the competent State agencies shall decide the change of the family names and/or given names of their adopted children.

The change of the family names and/or given names of adopted children aged from nine years or older must have their consents.

The change of the family names and/or given names of adopted children shall comply with the provisions of the civil status legislation.

2. The determination of adopted children's nationalities shall comply with the provisions in Article 30 of the Civil Code.

\section{Article 76 Termination of child adoption}

At the request of the persons defined in Article 77 of this Law, the Court may decide to terminate the adoption in the following circumstances:

1. Adoptive parents and the adopted children who have attained adulthood voluntarily terminate the adoptive relationship;

2. The adopted children are sentenced for one of the crimes of infringing upon the life, health, dignity and honor of their adoptive fathers and/or mothers; ill-treating, persecuting their adoptive fathers and/or mothers or committing acts of dissipating their adoptive fathers' and/or mothers' property;

3. The adoptive parents have committed the acts specified in Clause 3, Article 67 or Clause 5, Article 69 of this Law.

\section{Article 77. Persons entitled to request the Court to terminate child adoption}

1. The adopted children who have attained adulthood, their natural parents or guardians, their adoptive fathers and/or mothers have the right, as prescribed by the civil procedure legislation, to request the Court by themselves or propose the Procuracy to request the Court to decide to terminate the child adoption in the cases specified in Article 76 of this Law.

2. The Procuracy has the right, as prescribed by the civil procedure legislation, to request the Court to decide to terminate the child 
adoption in the cases specified at Points 2 and 3, Article 76 of this Law.

3. The following agencies and organizations have the right, as prescribed the civil procedure legislation, to request the Court by themselves or propose the Procuracy to request the Court to decide to terminate the child adoption in the cases specified at Points 2 and 3, Article 76 of this Law:

a/ The child protection and care committees;

b/ The women's unions.

4. Other individuals, agencies and organizations have the right to propose the Procuracy to consider and request the Court to decide to terminate the child adoption in the cases specified at Points 2 and 3, Article 76 of this Law:

\section{Article 78. Legal consequences of the termination of child adoption}

1. When the child adoption is terminated by decision of the Court, the rights and obligations between adoptive parents and adopted children shall also terminate; if the adopted children are minors or adults who are disabled, have lost their civil act capacity, have no working capacity and no property to support themselves, the Court shall issue decisions to assign such persons to their natural parents or other individuals or organizations for care and support.

2. Where adopted children have personal property they are entitled to receive back such property; if adopted children contributed labor and efforts to the common property of their adoptive parents' families, they are entitled to receive part of such common property according the agreement between the adopted children and their adoptive parents; if they fail to reach an agreement thereon, they may request the Court to settle it.

3. Where the child adoption terminates, at the request of the former adopted children or their natural parents, the competent State agencies shall decide on the former adopted children's reclaiming their family names, and/or names given by their natural parents. 


\title{
Chapter IX \\ GUARDIANSHIP BETWEEN FAMILY MEMBERS
}

\begin{abstract}
Article 79. Application of the guardianship legislation to family relations

Where a family member needs guardianship, the guardianship shall be in compliance with the guardianship provisions of the Civil Code and this Law.
\end{abstract}

\section{Article 80. Guardianship of children by parents}

Where both parents act as guardians of their adult children who have lost their civil act capacity, they have to together exercise the guardian's rights and perform the guardian's obligations. The fathers and mothers shall agree upon acting as representatives at law for their children in civil transactions in the interests of their children.

\section{Article 81. Appointment of guardians by parents for their children}

Where the parents are still alive but have no conditions to personally look after, rear, care for and educate their minor children and/or adult children who have lost their civil act capacity, they may appoint guardians for their children; the parents and the guardians shall agree upon the performance of part or whole of the guardianship by the guardians.

\section{Article 82. Guardianship by stepchildren for their stepfathers or stepmothers}

Where stepfathers or stepmothers have no guardians as prescribed in Article 72 of the Civil Code, stepchildren who are living with the stepfathers or stepmothers shall act as guardians if they are eligible for acting as guardians.

\section{Article 83. Guardianship among brothers and sisters}

1. Where a blood brother or sister needs to have a guardian, his/her brothers or sisters who have attained their adulthood and have civil act capacity shall agree upon the appointment of one of them, who is eligible, for acting as the guardian.

2. When deciding personal matters or property of a minor younger brother or sister, the elder brother or sister acting as the guardian of his/her younger brother or sister must consult his/her next of kin and the younger brother or sister, if he/she is aged full nine years or older. 
Article 84. Guardianship between paternal grandparents, maternal grandparents and grandchildren

1. Where a grandchild needs to have a guardian and his/her paternal grandparents and maternal grandparents are eligible to act as guardians, they shall agree upon the appointment of one of them to acts as the guardian.

2. A grandchild who is eligible to act as guardian must act as a guardian for his/her paternal grandparents and/or maternal grandparents if the grandparents have no children to rely on.

\section{Chapter X}

\section{DIVORCE}

Article 85. The right to request the Court to settle a divorce

1. Either spouse or both have the right to request the Court to settle their divorce.

2. Where the wife is pregnant or is nursing a under-12-month infant, the husband is not entitled to request a divorce.

\section{Article 86. Encouragement of grassroots-level reconciliation}

The State and society encourage the grassroots-level reconciliation when husband and/or wife apply for a divorce. The reconciliation shall comply with the legislation on grassroots-level reconciliation.

\section{Article 87. Processing and handling of divorce applications}

The Court processes and handles divorce applications according to the provisions of the civil procedure legislation.

Where a couple who have not registered their marriage file an application for divorce, the Court shall process and handle the case and declare nonrecognition of their spousal relation according to the provisions in Clause 1, Article 11 of this Law; any children- or property-related requests shall be dealt with according to Clauses 2 and 3, Article 17 of this Law.

\section{Article 88. Reconciliation at the Court}

After processing and handling a divorce application, the Court shall proceed with the reconciliation according to the provisions of the civil procedure legislation. 


\section{Article 89. Bases for permitting a divorce}

1. The Court considers the divorce application, if deeming that the situation is serious, the couple can no longer live together and the marriage purposes cannot be achieved, the Court shall decide to permit the divorce.

2. Where the spouse of the person who has been declared missing by the Court applies for a divorce, the Court shall permit such divorce.

\section{Article 90. Divorce by consent}

Where both the husband and wife request a divorce and the reconciliation at the Court fails, if deeming that the two parties are really willing to divorce and have agreed upon the property division, the nursing, rearing, care for and education of their children, the Court shall recognize the divorce by consent and the agreement on property and children on the basis of ensuring the legitimate interests of the wife and children; if the husband and wife fail to reach an agreement or have reached an agreement which, however, fails to ensure the legitimate interests of the wife and children, the Court shall make decisions thereon.

\section{Article 91. Divorce at the request of one party}

When either spouse requests a divorce and the reconciliation at the Court fails, the Court shall consider and decide the divorce.

Article 92. The nursing, care for, education and raising of children after the divorce

1. After their divorce, the husband and wife are still obliged to look after, care for, educate and rear their minor children or adult children who are disabled, have lost their civil act capacity, have no working capacity and no property to support themselves.

The person who does not directly rear children is obliged to provide support for the children.

2. Husband and wife agree upon who shall directly rear their children, the rights and obligations of each party toward their children after divorce; if they fail to reach an agreement thereon, the Court shall decide to assign one party to directly rear the children, on the basis of the children's interests in every aspect, if the children are aged full nine years or older, their wishes must be taken into consideration.

In principle, all children under three years of age shall be assigned to their mothers for direct rearing, unless otherwise agreed upon by the two parties. 


\section{Article 93. Change of the person directly raising children after divorce}

In the interests of children, at the request of one or both parties, the Court may decide to change the person directly raising the children.

The change of the person directly raising the children after divorce shall be carned out in cases where such person fails to ensure the children's interests in all aspects, with the wishes of children aged full nine years or older taken into consideration.

\section{Article 94. The right to visit children after divorce}

After divorce, the person who does not directly rear children has the right to visit the children; nobody is allowed to impede such person to exercise this right.

Where the person who does not directly raise the children abuses his/ her visits to impede or badly affect the nursing, care for, education and rearing of the children, the person directly raising the children may request the Court to restrict such person's right to visit children.

\section{Article 95. Principles of division of property upon divorce}

1. Upon a divorce the division of property shall be agreed upon by the concerned parties; if they fail to reach an agreement thereon, they may request the Court to settle it. Personal property of one party shall belong to such party.

2. The division of common property is carried out on the following principles:

a/ The common property of husband and wife shall, in principle, be halved, with due consideration given to each party's situation, the property status, each party's contributions to the creation, preservation and development of this property. The housework done in the family by the husband and/or wife is regarded as income-generating labor;

b/ The legitimate rights and interests of wife, minor children or adult children who are disabled, have lost their civil act capacity, have no working capacity and no property to support themselves, are protected;

c/ The legitimate interests of each party in their production, business and career activities are protected to provide them with conditions to continue their income-generating labor. 
d/ The common property of husband and wife is divided in kind or according to its value; the party who receives his/her property portion in kind which has a value bigger than the portion he/she deserves, he/she must pay the value difference to the other party.

3. The settlement of joint property obligations of the husband and wife is agreed upon by themselves; if they fail to reach an agreement thereon, they may request the Court to settle it.

\section{Article 96. Division of property in cases where a couple divorce} while living with the whole family.

1. Where a couple divorce while living with the whole family, if their property cannot be determined separately from the whole family's common property, the wife or husband shall divide part of the family's common property on the basis of the husband's and wife's contributions to the creation, preservation and development of the common property as well as the life of the whole family. The divorced couple and their family shall agree upon the portion divided from the whole family's common property; if they cannot reach agreement thereon, they may request the Court to settle it.

2. Where the couple lives with the whole family and their property can be determined as a portion of the whole family's common property, such property portion of the couple, when they divorce, shall be extracted from the common property for division.

\section{Article 97. Division of the husband's and/or wife's land use right when they divorce}

1. The land use right solely owned by one party shall still belong to such party after divorce.

2. The divorced couple's common land use right is divided as follows:

a/ For agricultural land under annual crops or aquaculture, if both parties have the need and conditions to directly use the land, the land use right shall be divided according to their agreement; if they fail to reach an agreement thereon, they may request the Court to settle it according to the provisions in Article 95 of this Law.

Where only one party has the need and conditions to directly use the land, such party may continue to use the land but must pay to the other party the portion of the land use right value the latter is entitled to; 
b/ Where husband and wife share the right to use agricultural land under annual crops or aquaculture with the whole household, when they divorce the couple's share of such land use right shall be separated for division according to the provisions at Point a of this Clause;

c/ For agricultural land under perennial trees, forestry land for forestation or residential land, the land use right is divided according to the provisions in Article 95 of this Law;

d/ The division of the right to use other categories of land shall comply with provisions of the land and civil legislation.

3. Where husband and wife live with the whole family and share no land use right with the whole household, when they divorce the interests of the party who does not have the land use right and does not continue to live with the family shall be settled according to the provisions in Article 96 of this Law.

\section{Article 98. Division of a residential house jointly owned by husband and wife}

Where a residential house jointly owned by husband and wife may be divided for use by each party, when they divorce, the house shall be divided under Article 95 of this Law; if the house is indivisible, the person who is allowed to continue using the house must pay to the other party the value he/she is entitled to.

\section{Article 99. Settlement of the interests of divorced husband or wife where the residential house is under the private ownership of one party.}

Where the residential house being under private ownership of one party has been put to common use, when the couple divorce, such residential house still belongs to its owner who, however, must pay to the other party part of the house's value, depending on the latter's contributions to maintaining, upgrading, renovating and/or repairing the house. 


\section{Chapter XI \\ MARRIAGE AND FAMILY RELATIONS INVOLVING FOREIGN ELEMENTS}

Article 100. Protection of the legitimate rights and interests of the parties to the marriage and family relations involving foreign elements

1. In the Socialist Republic of Viet Nam, the marriage and family relations involving foreign elements are respected and protected in accordance with the provisions of the Vietnamese law and international agreements which the Socialist Republic of Viet Nam has signed or acceded to.

2. In their marriage and family relations with Vietnamese citizens, foreigners in Viet Nam enjoy the same rights and obligations like Vietnamese citizens, except otherwise provided for by the Vietnamese law.

3. The Socialist Republic of Viet Nam State protects the legitimate rights and interests of Vietnamese citizens abroad in their marriage and family relations in accordance with the Vietnamese law, the host country's law and international laws and practices.

4. The provisions in this Chapter shall also apply to the marriage and family relations between Vietnamese citizens where one or both parties reside abroad.

Article 101. Application of foreign laws to the marriage and family relations involving foreign elements

Where this Law and other legal documents of Viet Nam prescribe or the international agreements which the Socialist Republic of Viet Nam has signed or acceded to invoke, the invoked foreign law shall apply, if such application does not contravene the principles laid down in this Law.

Where a foreign law refers back to the Vietnamese law, Viet Nam's marriage and family legislation shall apply.

Article 102. Competence to settle matters related to the marriage and family relations involving foreign elements

1. The People's Committees of the provinces and centrally-run cities carry out the marriage registration, child adoption and guardianship involving foreign elements in accordance with the provisions of this Law and other Vietnamese law provisions. 
The marriage registration, child adoption and guardianship between Vietnamese citizens residing in border areas and citizens of neighboring countries living in the areas bordering on Viet Nam shall be stipulated by the Government.

2. The Vietnamese overseas diplomatic missions and consulates effect the marriage registration and settle matters related to child adoption and guardianship involving foreign elements in accordance with the provisions of this Law and other Vietnamese relevant law provisions and international agreements which the Socialist Republic of Viet Nam has signed or acceded to, if such registration or settlement does not contravene the host country's law; have the responsibility to protect the legitimate rights and interests of Vietnamese citizens in the marriage and family relations involving foreign elements.

3. The People's Courts of the provinces and centrally-run cities annul illegal marriages, settle divorce cases, disputes over the rights and obligations of husband and wife, parents and children, recognition of fathers, mothers or or children, child adoption and guardianship, which involve foreign elements, consider the recognition or nonrecognition of marriage and family-related judgments and decisions of the Court or other competent bodies of foreign countries in accordance with the provisions of this Law and other Vietnamese law provisions.

The People's Courts of rural districts, urban districts, provincial towns or cities where Vietnamese citizens reside annul illegal marriages, settle divorce cases, disputes over the rights and obligations of husband and wife, parents and children, recognition of parents, children, child adoption and guardianship between Vietnamese citizens residing in the border areas with citizens of neighboring countries living in the areas bordering on Viet Nam according to the provisions of this Law and other Vietnamese law provisions.

\section{Article 103. Marriage involving foreign elements}

1. For marriages between Vietnamese citizens and foreigners, each party must abide by his/her country's legislation on the marriage conditions; if their marriage is effected at a Vietnamese competent State agency, the foreigner must also abide by the provisions of this Law on the marriage conditions.

The marriages between foreigners in Viet Nam before the Vietnamese competent agencies must comply with the provisions of this Law on the marriage conditions. 
2. It is strictly forbidden to take advantage of the marriages involving foreign elements to traffick in, sexually abuse against women or for other self-seeking purposes.

\section{Article 104. Divorce involving foreign elements}

1. Divorce between a Vietnamese citizen and a foreigner or between two foreigners permanently residing in Viet Nam is settled according to the provisions of this Law.

2. Where a partner being a Vietnamese citizen does not reside in Viet Nam at the time of requesting the divorce, the divorce shall be settled according to the law of the country where husband and wife permanently co-reside; if they do not have a permanent co-residence place, the Vietnamese law shall apply.

3. The settlement of a divorced couple's property being an immovable in a foreign country shall comply with the legislation of the country where such immovable is located.

4. Divorce judgments or decisions of foreign Courts or other foreign competent bodies shall be recognized in Viet Nam according to the provisions of the Vietnamese law.

\section{Article 105. Child adoption involving foreign elements}

1. Foreigners applying to adopt Vietnamese children or foreign children permanently residing in Viet Nam must abide by the provisions of this Law and of the law of the country where such foreigners are citizens regarding the conditions for child adoption.

Adoption of foreign children by Vietnamese citizens, which have been already registered at foreign competent bodies shall be recognized in Viet Nam.

It is strictly forbidden to take advantage of child adoption to exploit the labor power of, sexually abuse against or traffick in, children, or for other self-seeking purposes.

2. Where a child adoption involving foreign elements is made in Viet $\mathrm{Nam}$, the rights and obligations of the adoptive parents and the adopted children and the termination of the adoption shall comply with the provisions of this Law.

Where a child adoption is made between Vietnamese citizens and foreigners in foreign countries, the rights and obligations of the adoptive parents and the adopted children and the termination of adoption shall comply with the law provisions of the country of residence of the adopted children. 
Article 106. Guardianship in the marriage and family relations involving foreign elements

1. Guardianship in the marriage and family relations involving foreign elements made in Viet Nam, guardianship already registered at overseas Vietnamese diplomatic missions or consulates must comply with the provisions of this Law and other Vietnamese law provisions.

2. Where the guardianship in the marriage and family relations between Vietnamese citizens and foreigners is effected in foreign countries, the rights and obligations of the guardian and ward shall comply with the law of the country of residence of the guardian.

\section{Chapter XII \\ HANDLING OF VIOLATIONS}

\section{Article 107. Handling of law violations of marriage and family relations}

Those who breach the provisions on marriage conditions; obstruct the lawful marriages, forge papers for marriage registration or child adoption registration; ill-treat, persecute or hurt the honor and dignity of their grandfathers, grandmothers, fathers, mothers, spouses, children and other family members; abuse adoption to make illegal profits; fail to perform the supporting or guardianship obligations; or commit other acts of violating the marriage and family legislation, shall, depending on the nature and seriousness of their violations, be administratively sanctioned or examined for penal liability; if causing any damage, they must pay compensation therefore.

\section{Article 108. Handling law violations by people with positions and powers}

Those who abuse their positions and powers to register marriages, child adoptions, determination of parents or children in contravention of law; violate regulations on competence or procedures for marriage registration and child adoption registration; fail to settle the requests to protect the legitimate rights and interests of family members or commit other acts of abusing their positions and powers to breach the marriage and family legislation, shall, depending on the nature and seriousness of their violations, be disciplined or examined for penal liability, if causing any damage, they must pay compensation therefore. 


\section{Chapter XIII \\ IMPLEMENTATION PROVISIONS}

\section{Article 109.- Implementation effect}

This Law comes into force from January 1st, 2001.

This Law replaces the 1986 Marriage and Family Law.

The December 3, 1993 Ordinance on Marriage and Family between Vietnamese Citizens and Foreigners ceases to be effective from January 1st, 2001.

\section{Article 110.- Implementation guidance}

The Government, the Supreme People's Court and the Supreme People's Procuracy shall, within their respective tasks and powers, guide the implementation of this Law.

This Law was adopted by the Socialist Republic of Viet Nam's Xth National Assembly at its 7th session on June 9, 2000.

\section{National Assembly Chairman}

NONG DUC MANH 




\section{(P Population Council}

\section{Population Council Viet Nam}

41 Le Hong Phong, Ba Dinh $\mathrm{Ha}$ Noi, Viet Nam

$$
\text { Tel: +(84-4) } 3734 \text { 5821/2/3/4/5/6 }
$$

Fax: +(84-4) 37545827

Website: www.popcouncil.org 